\title{
WestVirginiaUniversity
}

THE RESEARCH REPOSITORY @ WVU

Graduate Theses, Dissertations, and Problem Reports

2018

\section{Real-time Energy Visualization Solutions for Light Commercial Businesses.}

Nathaniel Smith

Follow this and additional works at: https://researchrepository.wvu.edu/etd

\section{Recommended Citation}

Smith, Nathaniel, "Real-time Energy Visualization Solutions for Light Commercial Businesses." (2018). Graduate Theses, Dissertations, and Problem Reports. 8185.

https://researchrepository.wvu.edu/etd/8185

This Thesis is protected by copyright and/or related rights. It has been brought to you by the The Research Repository @ WVU with permission from the rights-holder(s). You are free to use this Thesis in any way that is permitted by the copyright and related rights legislation that applies to your use. For other uses you must obtain permission from the rights-holder(s) directly, unless additional rights are indicated by a Creative Commons license in the record and/ or on the work itself. This Thesis has been accepted for inclusion in WVU Graduate Theses, Dissertations, and Problem Reports collection by an authorized administrator of The Research Repository @ WVU. For more information, please contact researchrepository@mail.wvu.edu. 


\title{
Real-time Energy Visualization Solutions for Light Commercial Businesses
}

\author{
Nathaniel Smith \\ Thesis submitted to the Benjamin M. Statler College of \\ Engineering and Mineral Resources at \\ West Virginia University in partial fulfillment \\ of the requirement for the degree of
}

Master of Science
in
Industrial Engineering

Ashish D. Nimbarte, Ph.D., Chair

Bhaskaran Gopalakrishnan, Ph.D.

Thorsten Wuest, Ph.D.

Department of Industrial and Management Systems Engineering

Morgantown, West Virginia

2018

Keywords: energy visualization, energy management, energy monitoring, light commercial businesses, PLC, IoT

Copyright 2018 Nathaniel Smith 


\section{ABSTRACT \\ Real-time Energy Visualization Solutions for Light Commercial Businesses}

\section{Nathaniel Smith}

In recent years, several real-time Energy Visualization (EV) systems have emerged in the market with specific applications for large industrial and commercial facilities and residential buildings. However, light commercial businesses have been neglected with only a few attempts for EV solutions. The purpose of this study was to develop and test a system that could provide a cost effective and flexible EV solution for light commercial businesses. The system consisted of monitoring hardware and three energy visualization dashboards. Testing and validation of the system was conducted using a focused group of participants consisting of energy managers, engineers, and other typical dashboard users through analytical (usability test) and subjective (NASA TLX) methods. The EV dashboard designed using visuals such as gauges, alternating light meters, and color changes, etc. received higher engaging and lower analytical ratings compared to the dashboard designed using visuals such as simple charts, lines, etc. The engaging dashboard received the highest "interesting and trustworthy" ratings, the lowest mental workload, and the quickest time to answer energy questions. It is expected that the system developed in this study would assist the facilities in making energy efficiency decisions instantaneously instead of waiting for a monthly utility bill. Finally, in order to guide business owners with design, development and installation of a custom-made real-time EV system, an Energy Dashboard Installation Guide program was developed. Based on the unique operational requirements of a business, this program produces a wiring diagram, list of hardware, and an approximate system cost. 


\section{ACKNOWLEDGEMENTS}

I would like to thank my committee chair and advisor, Dr. Ashish Nimbarte, for all the assistance, support, and guidance throughout my research endeavors and graduate school. I would also like to thank Dr. Bhaskaran Gopalakrishnan for teaching and expanding my horizons in the energy engineering field. I would also like to thank Dr. Thorsten Wuest for his mentorship and teachings surrounding Product Service Systems (PSS).

I would like to thank my parents, Randy and Donna, for their endless love, support, and encouragement throughout my academic career. I would also like to thank my sister and best friend, Kayla, for her love, sense of humor, and reassurance. 


\section{Table of Contents}

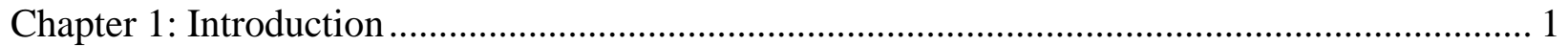

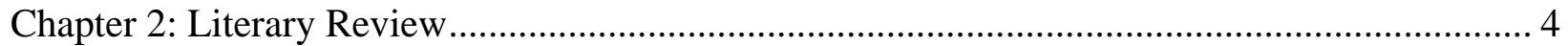

2.1 Data Visualization Background .................................................................................... 4

2.2 Data Visualization Effects on Users............................................................................. 7

2.3 Energy Data Visualization Techniques ........................................................................... 9

2.3.1 Dashboard Visualization Technique Overview............................................................ 9

2.3.2 Dashboard Visualization Detailed Techniques.............................................................. 12

2.4 Current Energy Visualization Systems on Market ............................................................ 17

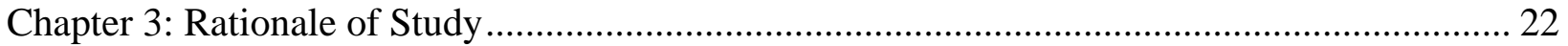

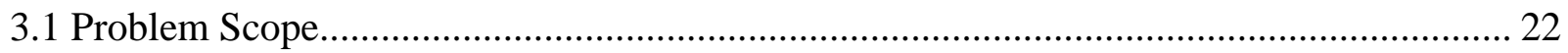

3.2 Research Question and Objectives .................................................................................. 24

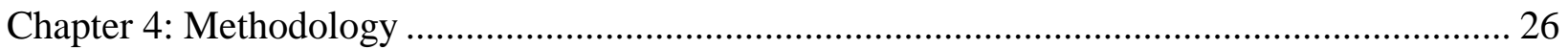

4.1 System Development................................................................................................. 26

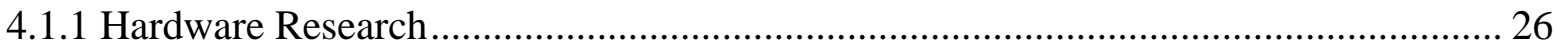

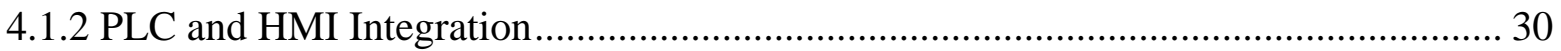

4.2 System and Dashboard Validation ................................................................................... 31

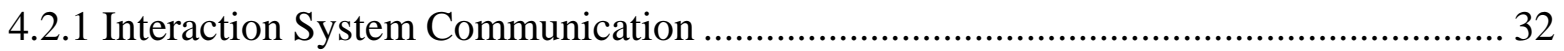

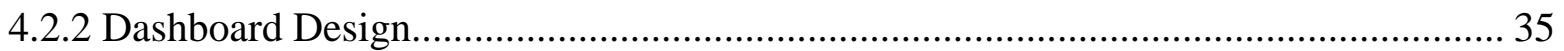

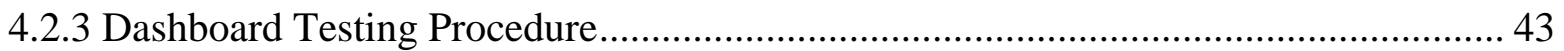

4.3 Energy Dashboard Installation Guide ...................................................................... 50

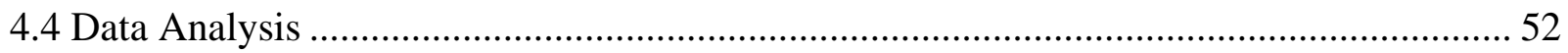

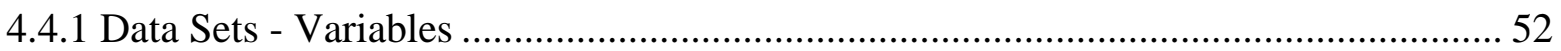

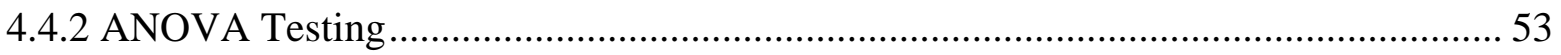

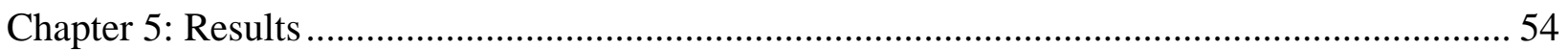

5.1 Participant Demographics ......................................................................................... 54

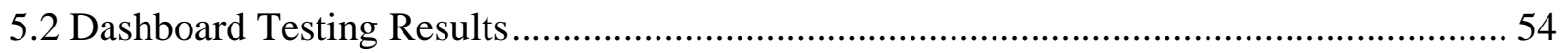

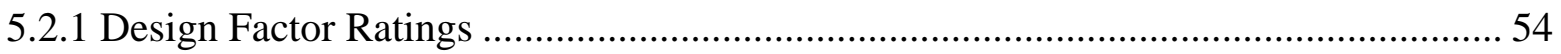

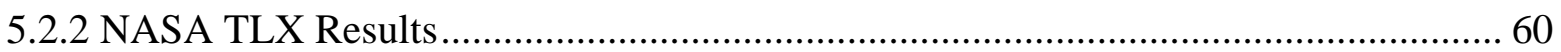

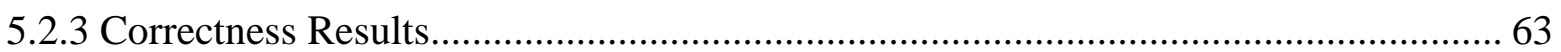

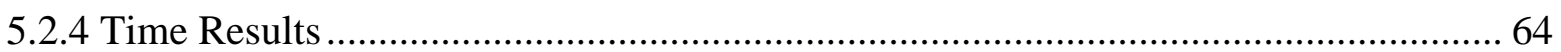

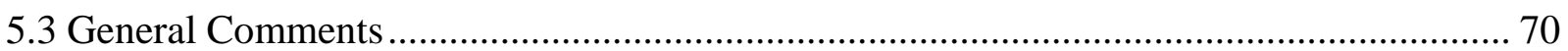

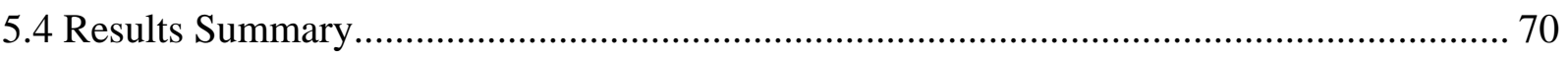

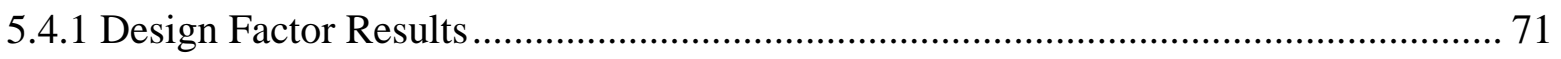




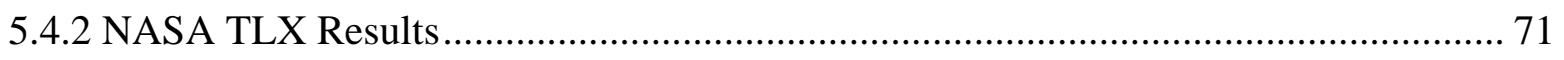

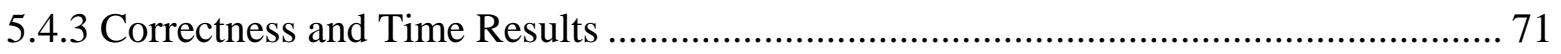

5.5 Energy Dashboard Installation Guide Program Results.................................................... 72

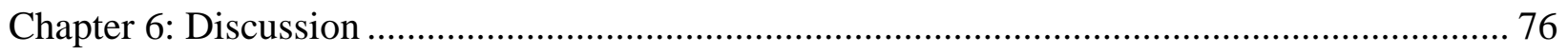

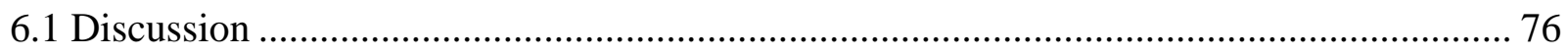

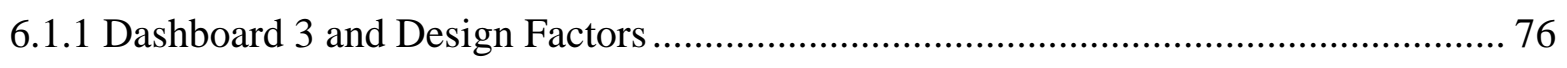

6.1.2 Overall Dashboard Findings.................................................................................... 78

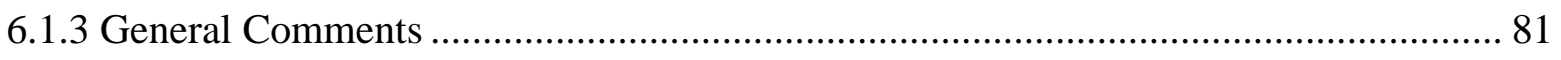

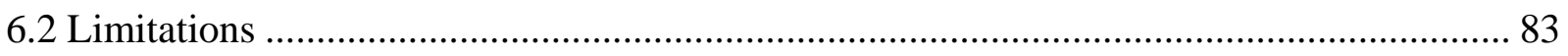

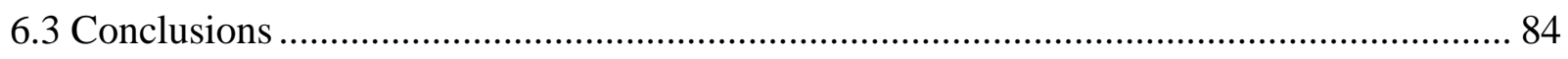

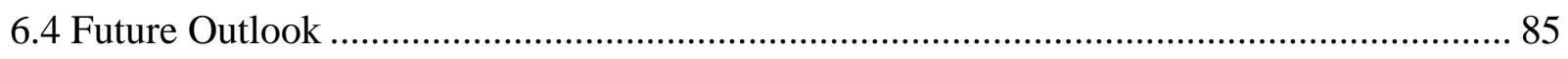

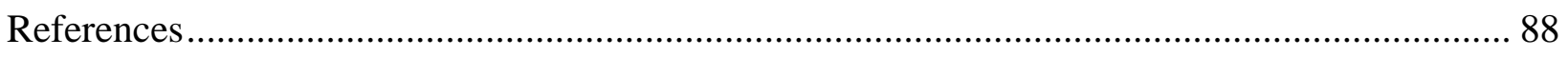

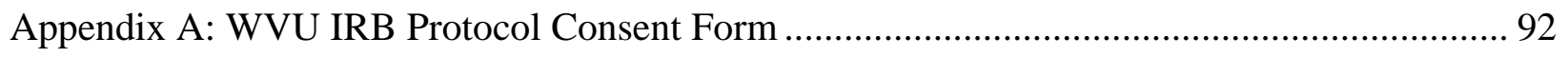

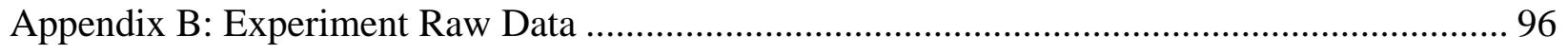

Appendix B-1: Experimental Correctness and Time Data........................................................ 97

Appendix B-2: NASA TLX Output Data............................................................................. 107

Appendix C: Design Factor ANOVA Testing ................................................................... 116

Appendix C-1: Analytical Ratings - Normal Distribution........................................................ 117

Appendix C-2: Analytical Ratings - Normality of Residuals and Equality of Variances ...... 118

Appendix C-3: Analytical Ratings - ANOVA Testing.......................................................... 119

Appendix C-4: Analytical Ratings - Pairwise Comparisons .................................................. 120

Appendix C-5: Engaging Ratings - Normal Distribution .................................................... 121

Appendix C-6: Engaging Ratings - Normality of Residuals and Equality of Variances ....... 122

Appendix C-7: Engaging Ratings - ANOVA Testing .......................................................... 123

Appendix C-8: Engaging Ratings - Pairwise Comparisons.................................................... 124

Appendix C-9: Interesting Rating - Distribution Fit and Box-Cox Transformation ............... 125

Appendix C-10: Interesting Ratings - Normality of Residuals and Equality of Variances.... 126

Appendix C-11: Interesting Ratings - ANOVA Testing ...................................................... 127

Appendix C-12: Interesting Ratings - Pairwise Comparisons ................................................ 128

Appendix C-13: Trustworthy Ratings - Distribution Fitting and Box-Cox............................. 129

Appendix C-14: Trustworthy Ratings - Normality of Residuals and Equality of Variances. 130

Appendix C-15: Trustworthy Ratings - ANOVA Testing........................................................ 131

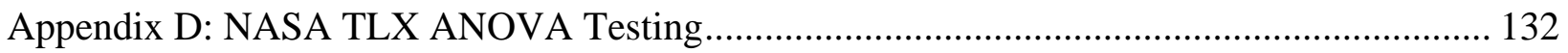

Appendix D-1: NASA TLX Scores - Distribution Check......................................................... 133 
Appendix D-2: Overall NASA TLX Scores - Normality of Residuals and Equality of Variance Check 134

Appendix D-3: Overall NASA TLX Score - ANOVA Testing... 135

Appendix D-4: Temporal Demand - Distribution Fitting. 136

Appendix D-5: Temporal Demand - Normality of Residuals and Equality of Variance Check 137

Appendix D-6: Temporal Demand - ANOVA Testing 138

Appendix D-7: Performance - Distribution Fitting and Box-Cox Transformation. 139

Appendix D-8: Performance - Normality of Residuals and Equality of Variances 140

Appendix D-9: Performance - ANOVA Testing. 141 Appendix E: Time ANOVA Testing 142

Appendix E-1: Group 1 - Distribution Check and Box-Cox Transformation. 143

Appendix E-2: Group 1 - Check for Normality of Residuals and Equality of Variances....... 144

Appendix E-3: Group 1 - Full Factorial ANOVA............................................................. 145

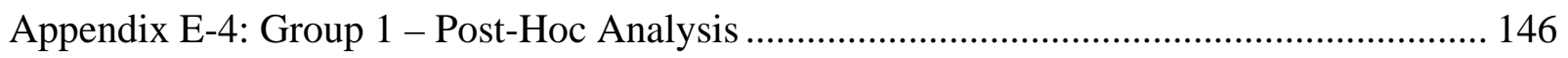

Appendix E-5: Group 2 - Distribution Check and Box-Cox Transformation ........................ 147

Appendix E-6: Group 2 - Normality of Residual and Equality of Variances Check .............. 148

Appendix E-7: Group 2 - ANOVA Testing and Comparing Means....................................... 149

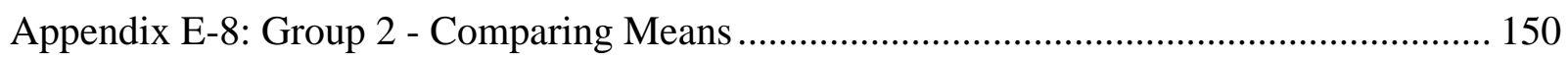

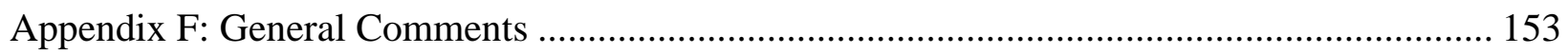




\section{Table of Figures}

Figure 2.1: Analytical Features (Salmon et al., 2016) ......................................................... 6

Figure 2.2: Engagement Features (Salmon et al., 2016)........................................................ 7

Figure 2.3: Preattentive Visual Perception Attributes (Knaflic, 2015)...................................... 8

Figure 2.4: Bar Chart vs. Map for Data Visualization (Salmon et al., 2016) ............................ 10

Figure 2.5: Texas University’s Energy Dashboard for Multiple Buildings (iDashboards, 2017) 11

Figure 2.6: Overview Dashboard of Entire Building (Johnson Controls, 2013) ........................ 11

Figure 2.7: Celequest Dashboard Utilizing Tables and Graphs Simultaneously (Few, 2006) ..... 12

Figure 2.8: Load Duration Curve for a Facility for One Year (Energy Efficiency \& Demand

Management \& AEE Northern Ohio Chapter, 2014) .............................................. 13

Figure 2.9: Stacked Bar Chart for Several Meters for Electrical Demand (Energy Efficiency \&

Demand Management \& AEE Northern Ohio Chapter, 2014) ................................ 14

Figure 2.10: Double Y-Axis Chart to Compare Electrical Demand and Degree Days (Energy

Efficiency \& Demand Management \& AEE Northern Ohio Chapter, 2014) ........... 14

Figure 2.11: Thermal Images for Hot Water Boiler, Radiator, and Water Faucet (Giacomin \&

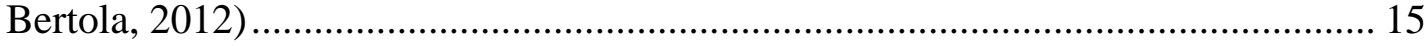

Figure 2.12: Geographic Heat Map (Irwin et al., 2017) .......................................................... 16

Figure 2.13: Word Cloud Example for Aviation (Irwin et al., 2017) ....................................... 16

Figure 4.1: Block Diagram for the Proposed EV System ..................................................... 30

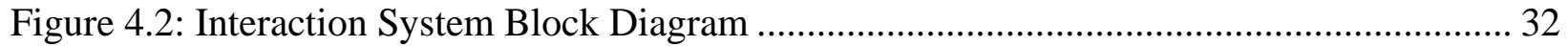

Figure 4.3: Dashboard 1 for Simulated Testing for Participants ........................................... 40

Figure 4.4: Dashboard 2 for Simulated Testing for Participants ............................................ 40

Figure 4.5: Dashboard 3 for Simulated Testing for Participants .............................................. 41

Figure 4.6: Electric Monthly Usages and Demand from Dashboard 1................................... 42

Figure 4.7: Natural Gas Monthly Usages from Dashboard 1 .............................................. 42

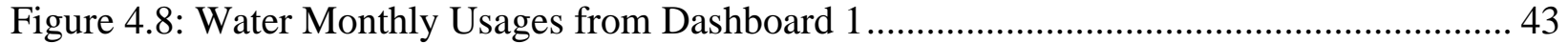

Figure 4.9: Dashboard Testing Procedure Flow Diagram ..................................................... 43

Figure 4.10: Phase 1 - Dashboard 3 Interaction for Participants ............................................. 45

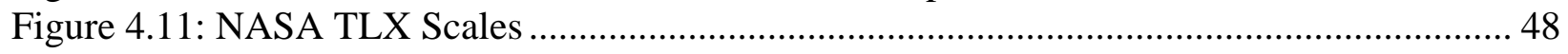

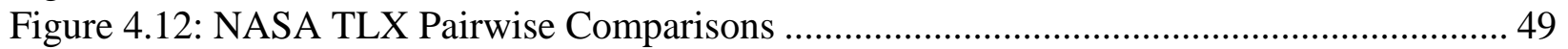

Figure 4.13: Energy Dashboard Installation Guide Program.............................................. 51

Figure 5.1: Average Analytical vs. Engaging Ratings for Each Dashboard.............................. 55

Figure 5.2: Average Interesting and Trustworthy Ratings. Error bars represent 95\% confidence

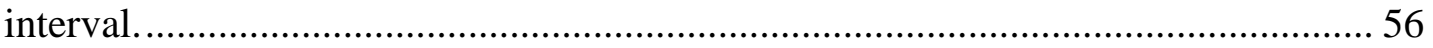

Figure 5.3: Interval Plot of Analytical Ratings vs. Dashboards ........................................... 57

Figure 5.4: Interval Plot of Engaging Ratings vs. Dashboards................................................ 58

Figure 5.5: Interval Plot of Interesting Ratings vs. Dashboards ............................................ 59

Figure 5.6: Interval Plot of Trustworthy Ratings vs. Dashboards .......................................... 60

Figure 5.7: Average NASA TLX Scores for Each Dashboard. Error bars represent 95\%

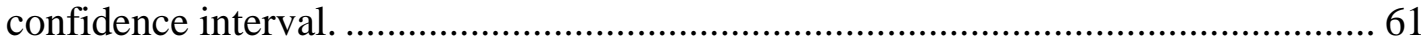

Figure 5.8: Average NASA TLX Weights. Error bars represent 95\% confidence interval.......... 62

Figure 5.9: Natural Gas Monthly Usages - Dashboard 2 ..................................................... 64

Figure 5.10: Average Time to Answer All Questions Per Dashboard. Error bars represent 95\%

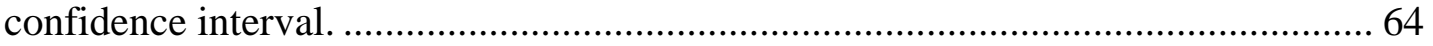

Figure 5.11: Interval Plot for Button-Click Time vs Questions............................................. 66

Figure 5.12: Interval Plot for Button-Click Time vs Dashboards*FirstDash ............................ 67 
Figure 5.13: Interval Plot for On-Screen Times vs Dashboards*Questions .............................. 69

Figure 5.14: Interval Plot for On-Screen Times vs Dashboards*FirstDash ............................. 69

Figure 5.15: Energy Dashboard Installation Guide Program - Electrical Equipment Selection.. 73

Figure 5.16: Energy Dashboard Installation Guide - General Questions Asked ....................... 74

Figure 5.17: Energy Dashboard Installation Guide Program - Equipment List and Costing....... 74

Figure 5.18: Energy Dashboard Installation Guide Program - Custom Wiring Diagram............ 75 


\section{Table of Tables}

Table 2.1: Comparison Table of Different Platforms' Capabilities ......................................... 21

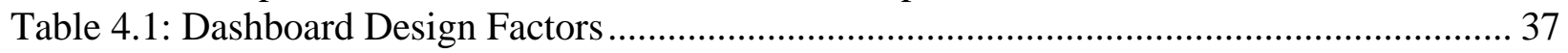

Table 4.2: NASA TLX Rating Scale and Description (Cao et al., 2009) .................................. 47

Table 5.1: Participant Demographics................................................................................ 54

Table 5.2: Mean (SD) of Design Factor Ratings for Dashboards............................................. 56

Table 5.3: Mean (SD) of NASA TLX Values for Dashboards............................................... 60

Table 5.4: Button-Click Time and the Effects of Dashboards, Questions, and FirstDash ........... 65

Table 5.5: On-Screen Time and the Effects of Dashboards, Questions, and FirstDash .............. 68 


\section{Chapter 1: Introduction}

Energy consciousness is a growing concern in society and within the industry. Facilities utilize electricity, natural gas, and other forms of energy to produce products and perform various processes. In 2015, residential energy consumption totaled to 20,558 TBtu (Trillion Btu) while both commercial and industrial energy consumption totaled to 49,403 TBtu ("Energy Consumption by Sector,” 2016). This enormous amount of energy consumed across all sectors places a strain on both nonrenewable and renewable resources. In 2015, only 601 TBtu in the residential sector and 2,539 TBtu in the industrial and commercial sectors were from renewable resources (U.S. Energy Information Administration, 2016). The demand for energy will only continue to increase with a rising population and increasing energy consumption. The U.S. and the world cannot afford to allow an energy crisis to arise in the upcoming years.

Apart from energy, the economy of the U.S. has had many peaks and pitfalls during its history. Today, the economy is continuing to gradually improve from a large economical loss in 2008 (The Economist, 2013). Many companies have had to cut jobs, lower production, and even shut facilities down across the nation. Every major manufacturing and industrial facility is continually facing financial decisions and striving to provide innovations that allow them to succeed in this competitive market.

To combat the increasing demand for energy, many initiatives have been promoted, but a few have gained traction within the past decade - energy visualization, management and control systems. Energy Management Systems (EMS) is defined as a system which employs microprocessors, control panels, equipment, monitors, and other devices that are configured into a network with multiple locations for visualization of data and control (Panke, 2001). An EMS operates by controlling the energy usage through commands. Energy visualization (EV) is a 
system that allow users to visualize their energy usage in real time. An EV system can only visualize the energy usage. If combined, then the EV and EMS systems can visualize and control, respectively, energy in real time. Instead of waiting for a monthly utility bill, facilities can measure the energy usage of their equipment individually in real-time to monitor signals of any anomalies, electrical usage peaks, analytics, etc. This provides further context for facilities to better manage their overall energy usages and monitor their equipment closely. Overall, human behavior is important for achieving energy efficiency as a good energy control/management system is not sufficient if it is failing to make a connection with the user. Thus, EV systems can aid with bridging this gap.

EV systems when coupled with EMS or control systems, can possess capabilities to monitor and display specific metrics from various pieces of equipment that include but are not limited to: operating temperatures, pressures, flows, current, etc. A totalizer can be incorporated to track the total amount of energy being consumed in a certain time period. Additionally, an integrated historian can also be incorporated to allow review of previously recorded data. Such systems can truly serve as a valuable tool for achieving energy efficiency as the users could track and perhaps reduce their energy consumption.

Across residential, commercial, and industrial sectors, hardware and monitoring software can acquire "Big Data" and consolidate it for review or control. Various visualizations are utilized in the software to allow the users to interact and understand the data in a graphical and visual manner. Currently, a significant number of energy monitoring and control systems are available on the market for residential, large commercial, and industrial applications.

A "small business" is defined as a company that is staffed by 500 or less employees by the U.S. Department of Agriculture (U.S. Department of Agriculture, n.d.). However, this is a 
broad range of businesses. Many would consider a commercial business that had over 100 employees would be classified as a large commercial business. Furthermore, a commercial business is identified as a business that is an energy-consuming business that consists of serviceproviding facilities and equipment of businesses (U.S. Energy Information Administration, n.d.a). An industrial business is defined as a business that consists of all facilities and equipment used for producing, processing, and assembling goods; manufacturing is heavily involved in the industrial sector (U.S. Energy Information Administration, n.d.-b). For this research, a light commercial business is defined as a commercial business that staffs less than 100 employees.

The light commercial industry has been asked to adapt a different sector's EMS and/or EV solution for their use. However, this is unacceptable as the light commercial sector has its own requirements and operates completely differently than the other sectors. The overall objective of the research is to develop and evaluate a new EV system for the light commercial sector that is low cost and flexible for the different types of businesses. Research also focused on different techniques of data and energy visualization, impact of data visualization on user, and the current EV systems on the market. 


\section{Chapter 2: Literary Review}

\section{$\underline{\text { 2.1 Data Visualization Background }}$}

Data visualization is typically used to help users understand the data through viewing it from different viewpoints (Mizuno, Mori, Taniguchi, \& Tsuji, 1997). Data visualization has two main aspects: the content of the data and the graphical representation of the data. First, the content and type of data is important. Data visualization is not simply showing data, it is essentially storytelling. A comparison of exploratory vs. explanatory analysis will assist in this explanation. Knaflic explains that exploratory analysis is simply showing all of the possible data gathered (Knaflic, 2015). Many people do this to show the robustness of the analysis and that a lot of work has been completed. However, she argues that it is better to use explanatory analysis to tell a story with the data. Explaining who, what, and how, along with an overall objective and message will allow for a user to better develop a data visualization set. When considering visualizing energy data, the data must be important and have worth to the business or company functions. Without importance, necessity, or function, the data is worthless to a user. Useless or faulty data is worse than having no data. The data must be meaningful to the user and encourage the user to make an action. This is a crucial, and often overlooked, step in designing visualizations.

Second, the graphical representation of the data is of high importance. Though the content of the data is essential, if a user cannot interpret or draw conclusions from the data effectively and efficiently, the visualization is of no use either. A new term in recent years that has been trending is “dashboard.” Dashboards are a visual display showing the most important information used to achieve an objective; while they are arranged on a single screen and can be viewed and monitored at a glance (Few, 2006). The definition of dashboard is as follows: a 
dashboard is a single screen showing multiple visuals using several energy data points to display information in an efficient manner. From a macroscopic view, these dashboards should provide data visualizations for the user using a combination of graphics and text to provide a clear message to the viewer. Furthermore, these visualizations should immediately identify whether the company or process is performing well or not. Key performance indicators (KPIs) or other metrics should be agreed upon within the company or business and provided within these dashboards or data visualizations. In general, the visuals on a dashboard will be dependent on the type of data being displayed and the function of the data within the business.

Furthermore, a growing trend is that analytics are being implemented along with the visualizations. Automatic fault detection, diagnostics, and data interpretation software serve as great analytical tools for users (Capehart, 2005). Abnormal patterns and alert systems allow for preventive maintenance to be performed before a major shutdown or other issues occur (Guity \& Rabinowitz, 2013). Additionally, in analytics, benchmarking with benchmark databases and tools serve as a great standard for companies to strive. Benchmarking data from databases can be integrated into the analytical process within data visualization using toolkits such as from Seventhwave (Gunasingh, Marsicek, \& Vigliotta, n.d.).

Not only are there visual representations of data, but also filtering, drilling into further levels of detail, and dynamic graphing (Few, 2007). The ability to manipulate data visually and in real-time has been a huge improvement over static graphs and visuals. Dashboards may offer multiple graphs that are all dynamic in nature so that when a selection of data is made, all the graphs and charts can change based on the selection made. This probes for further analytical investigation into the data and will allow for new insights to surface. Further animations 
representing change throughout time and correlations have been utilized in recent years and will continue to grow.

To assist in the explanation, two main distinctive categories of features have been identified as analytical and engagement features (Salmon, Morejohn, Office, \& Davis, 2016). Analytical features provide vision into energy management such as multivariable analysis, trend detection, and alert capabilities as seen in Figure 2.1. Engagement features offer aesthetically pleasing visuals to serve as quick and easy viewing for users as shown in Figure 2.2. Both main feature categories can be utilized when building a dashboard to offer a balance between analytics and aesthetics.

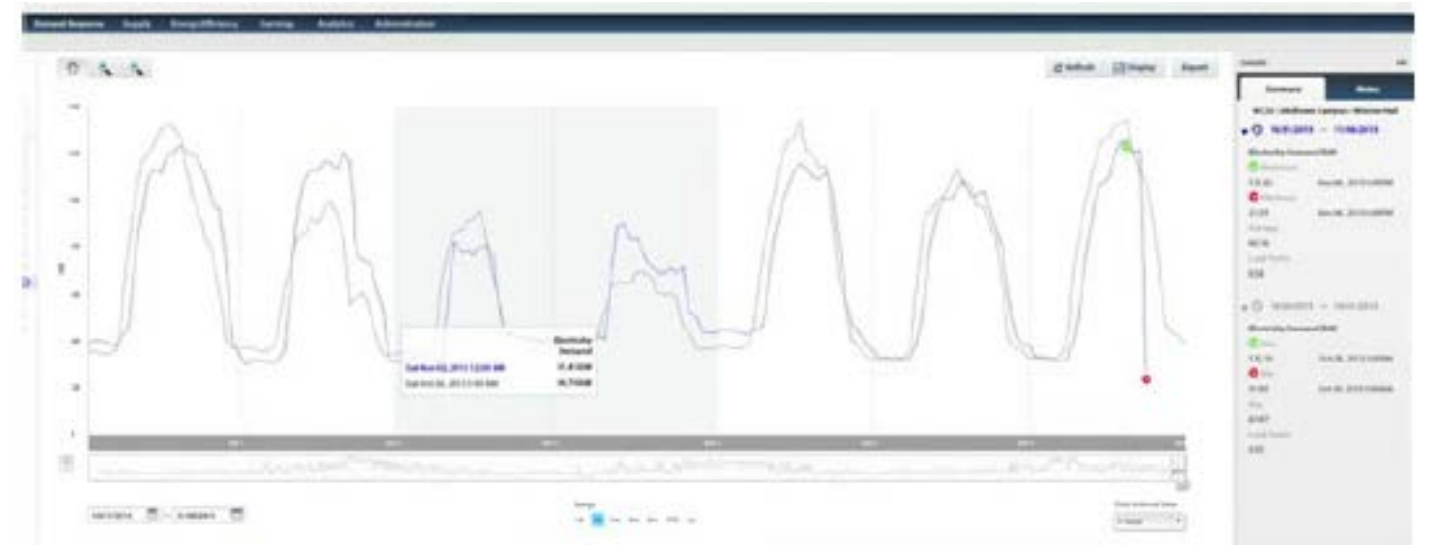

Figure 2.1: Analytical Features (Salmon et al., 2016) 


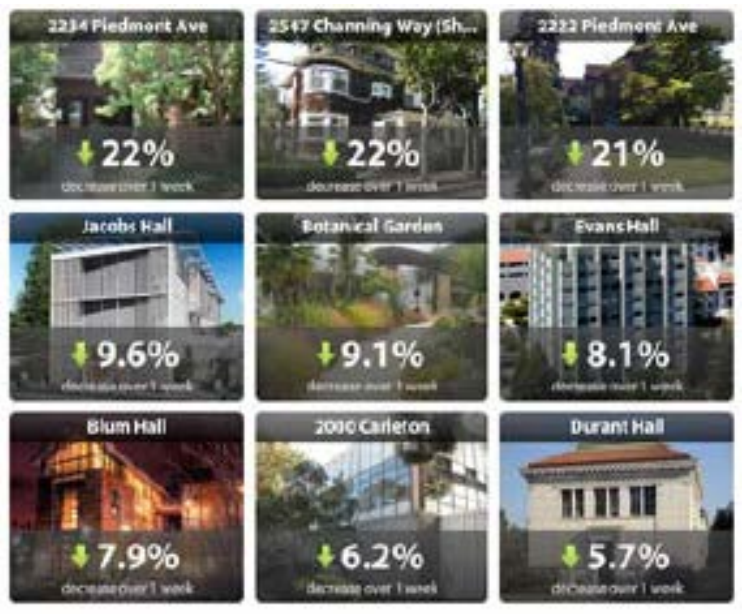

Figure 2.2: Engagement Features (Salmon et al., 2016)

\subsection{Data Visualization Effects on Users}

Overall, little academic research has been completed on the effects of different energy dashboards and visualizations and their effect on the user. Visual perception is obviously the most important attribute when designing a dashboard. The user will use his/her working memory when viewing different data visualizations. As this type of memory is temporary and limited in nature, the design should adhere to these principles. For example, utilizing “preattentive attributes” as shown in Figure 2.3 allow for a user to quickly identify differences in data and capture a user’s attention (Knaflic, 2015). 


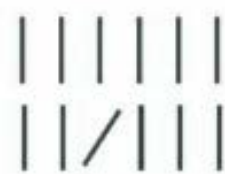

Orientation
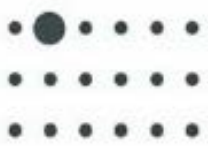

Size
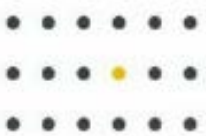

Hue

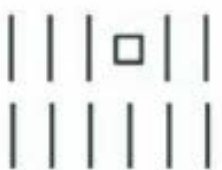

Shape
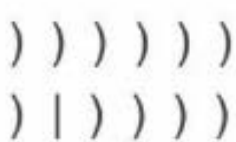

Curvature
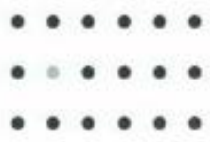

Intensity

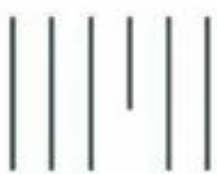

Line length
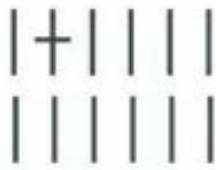

Added marks

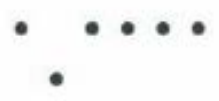

Spatial position

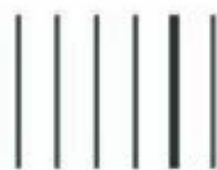

Line width

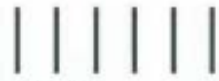

$1 \||| \mid$

Enclosure

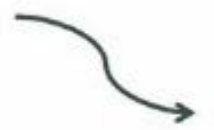

Motion

Figure 2.3: Preattentive Visual Perception Attributes (Knaflic, 2015)

Regarding dashboards, contrasts in color, text size, form and orientation of visuals, position, and motion are other preattentive attributes that can be utilized to comply with a user's visual perception (Few, 2013). These preattentive attributes allow for the mind to easily distinguish differences in data without large cognitive processing of the mind. By simply viewing Figure 2.3, a user is easily able to pick out the differences in each scenario with little mental processing. Thus, the working memory is not placed under a large load and can be utilized for more detailed visuals in the dashboard.

There are overarching goals that are prevalent in designing a comprehensive dashboard. The aesthetics of the visuals, clarity of the data, and the efficiency of interpretation of the amount of data presented at once is crucial to the designing of a dashboard. These factors give a foundation for the development of a dashboard and will allow for a visually appealing and highly informative dashboard to be presented to the user. 


\section{$\underline{\text { 2.3 Energy Data Visualization Techniques }}$}

\subsubsection{Dashboard Visualization Technique Overview}

Energy data visualization is a relatively new topic within recent years. Specifically, energy dashboards provide data visualizations in the form of graphics and text to display the data in an intuitive manner. Energy dashboards have allowed for quick visualizations of energy trends, the ability to spot any anomalies in energy usage, and excessive loads (Lehrer, Vasudev, \& Webster, 2010). Collectively, a well-designed dashboard should deliver the necessary information that is well organized, condensed to one screen, specific and customized to the user viewing the data, and displayed in the clearest and concise way possible (Few, 2013).

In a case study, 277 participants were asked which visual in Figure 2.4 was seen as more interesting and trustworthy for building energy usage (Salmon et al., 2016). The map was identified as the most interesting and significantly more trustworthy than the bar chart. Enhancing the map to a bubble graph circling each building again proved to be more interesting, but slightly less accurate. This example shows that graphical interfaces such as the map is a great tool to promote interest as well as trustworthiness. However, this should be used in the correct manner to sustain accuracy. In large commercial applications, companies such as QA Graphics offer similar energy dashboard solutions using maps (QAGraphics, n.d.). 

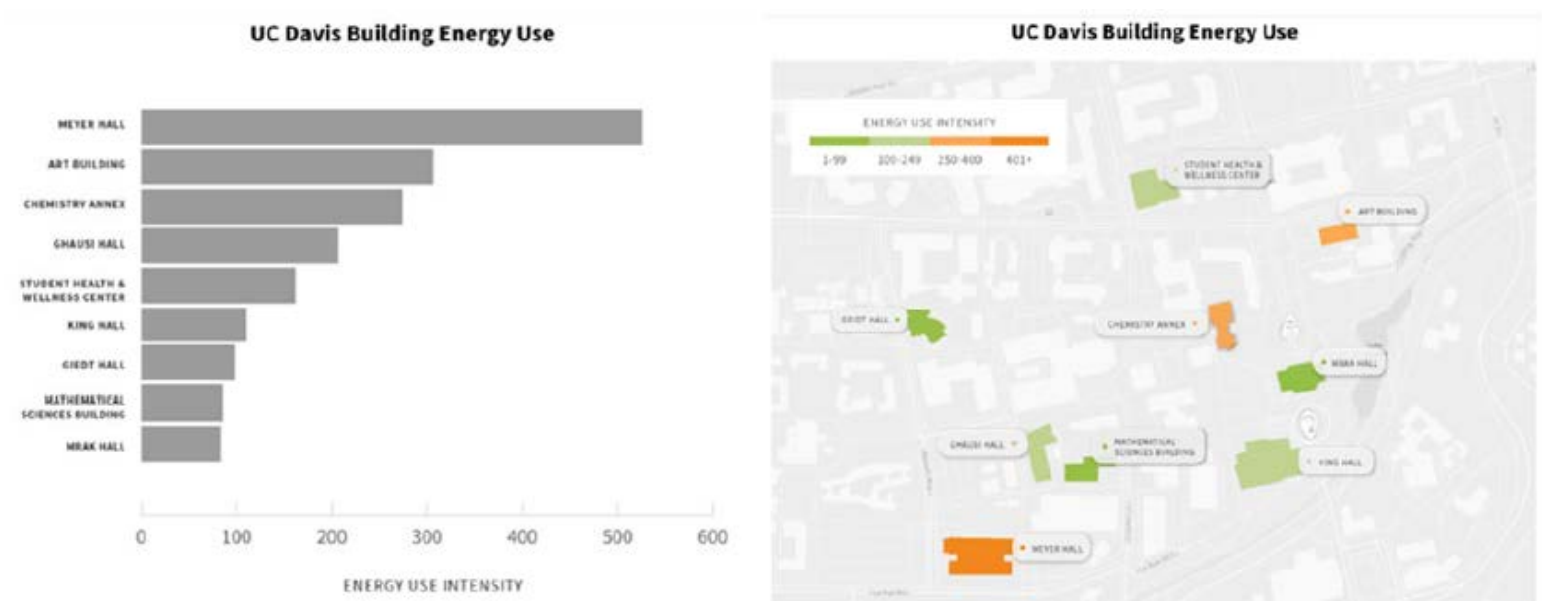

Figure 2.4: Bar Chart vs. Map for Data Visualization (Salmon et al., 2016)

Data visualization expert, Cole Nussbaumer Knaflic, explains that there are twelve main different types of visuals used for data visualization purposes used across hundreds of different visuals and industries (Knaflic, 2015). These include: simple text, scatterplot, vertical bar, horizontal bar, table, line graph, stacked vertical bar, stacked horizontal bar, heatmap, slopegraph, waterfall, and square area. Each of these visuals are not difficult to utilize but must be used in the correct manner. To accompany Knaflic’s recommendations for data visualization, dashboard expert, Stephen Few, recommends specific visuals exclusively for dashboards. These include variations of line and bar graphs, gauges, spatial/geographic maps, box plots, and tree maps.

Many dashboards utilize these visualizations to display data and show KPIs and metrics as shown in Figure 2.5. Overviews showing performance over an entire facility can be utilized as seen in Figure 2.6. Additionally, both graphical visuals can be used in conjunction with textbased tables to give the graphics further detail as seen in Figure 2.7 as an example. 


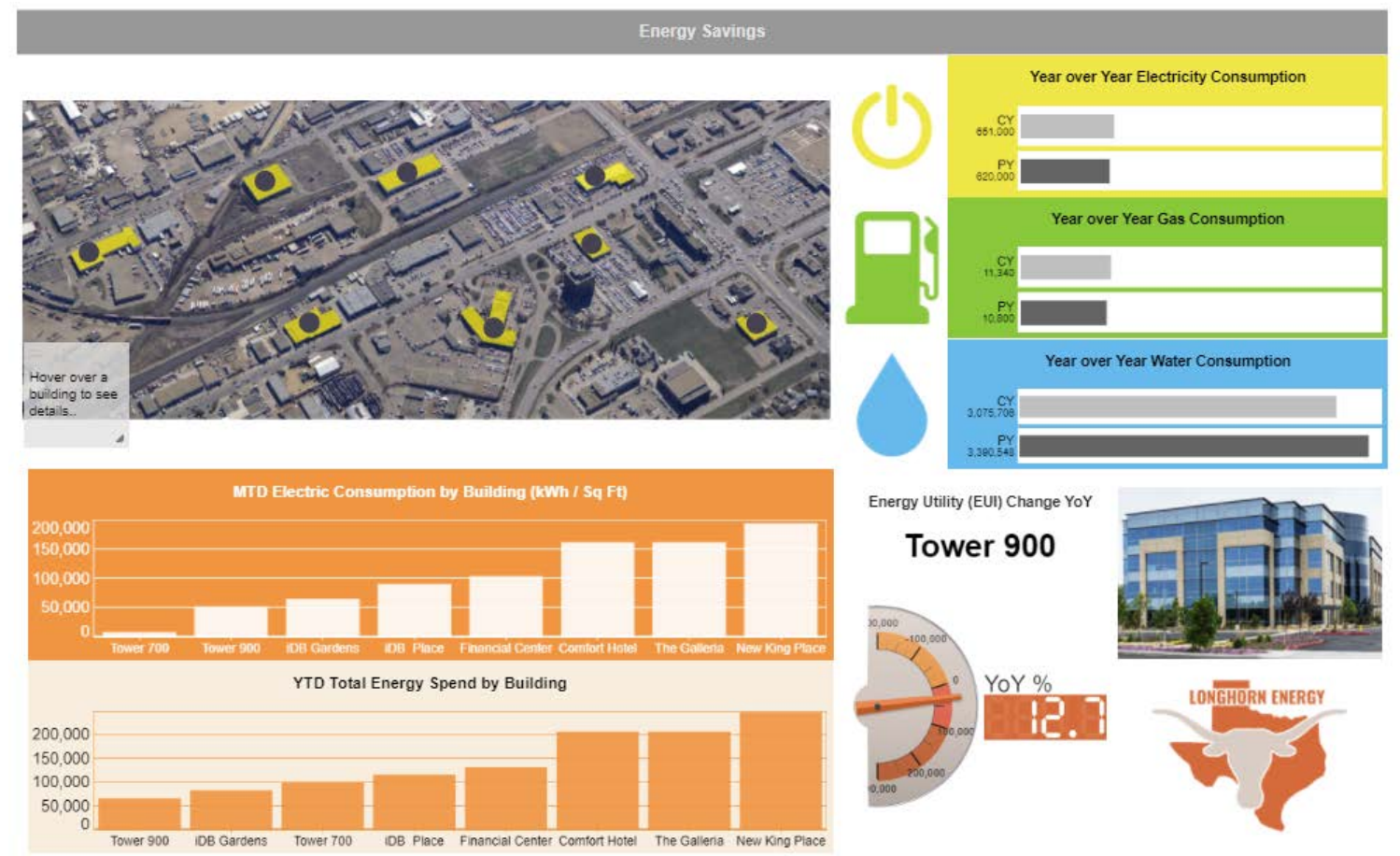

Figure 2.5: Texas University’s Energy Dashboard for Multiple Buildings (iDashboards, 2017)

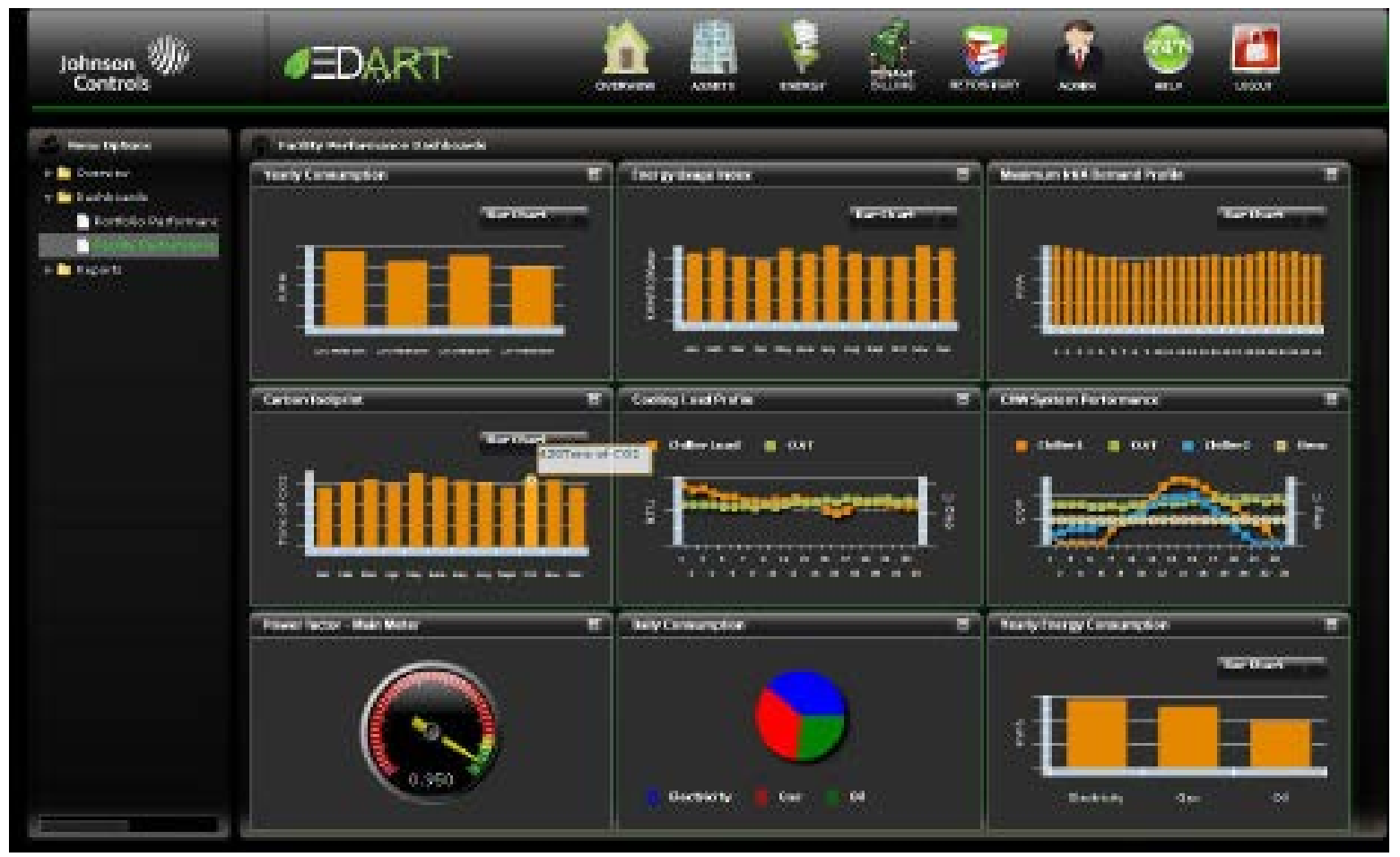

Figure 2.6: Overview Dashboard of Entire Building (Johnson Controls, 2013) 


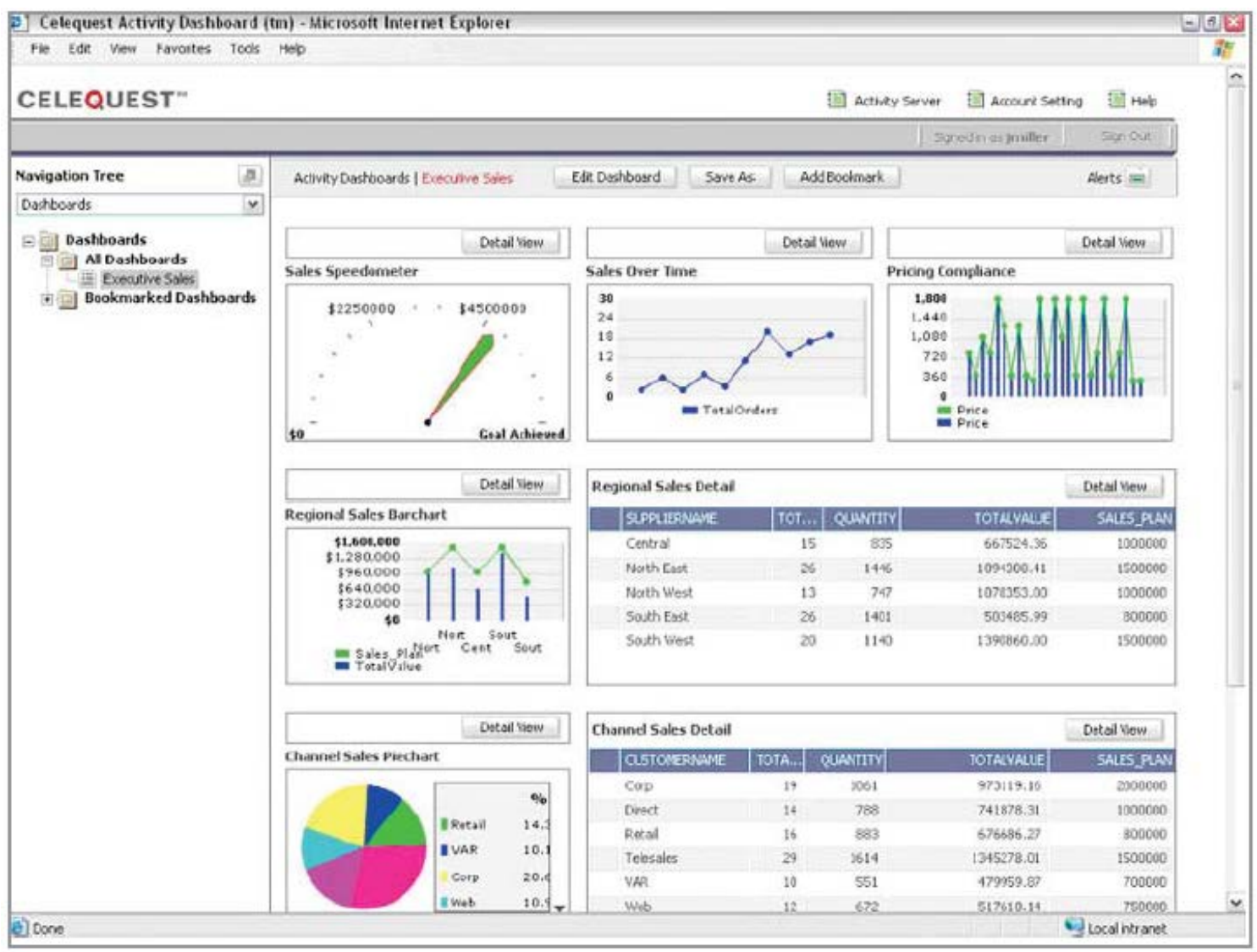

Figure 2.7: Celequest Dashboard Utilizing Tables and Graphs Simultaneously (Few, 2006)

\subsubsection{Dashboard Visualization Detailed Techniques}

While simple bar graphs, line graphs, and tables can be used to display data in a traditional manner, these can be manipulated to give additional perspectives into the data. Further visualizations include load duration curves (Figure 2.8), stacked meter consolidation bar charts (Figure 2.9), and energy usage profiles (Figure 2.10) (Energy Efficiency \& Demand Management \& AEE Northern Ohio Chapter, 2014). Each of these graphs provide more data than just the amount of energy consumption over time. The line graph shown in Figure 2.8 shows the base load and the percent of time that the facility was under a certain electrical demand. This line graph explains if a certain load was simply a peak for the year, or if the load was typical of 
that facility. For Figure 2.9, the stacked bar chart gives a detailed explanation as to the electrical demand for two different meters over time. As opposed to simply one totalized graph or two separate meter graphs, the stacked bar chart offers a comparison between the two meters for the same time frame. These charts are used for comparison among the different categories (meter 1 and 2) over time. The categories serve as a breakdown of the total and serve as comparison of those categories (Kirk, 2012). For Figure 2.10, combining a bar chart with a smoothed line graph offers additional explanation for demand given the plotted degree days. All three of these visuals have been enhanced to provide additional details to be concluded from one visual. Utilizing visuals such as these are more intuitive than simple graphs, save space on a dashboard, and allow for more details from one visual.

(A) A one year load duration curve is plotted, with load on the $y$-axis

(B) The $x$-axis indicates the percent time that the load was at or greater than the $y$-value

(C) The base load is never less than $\sim 48 \mathrm{~kW}$ and the maximum load is about $140 \mathrm{~kW}$

(D) The peak demand above $120 \mathrm{~kW}$ is only $2-3 \%$ of the time throughout the year

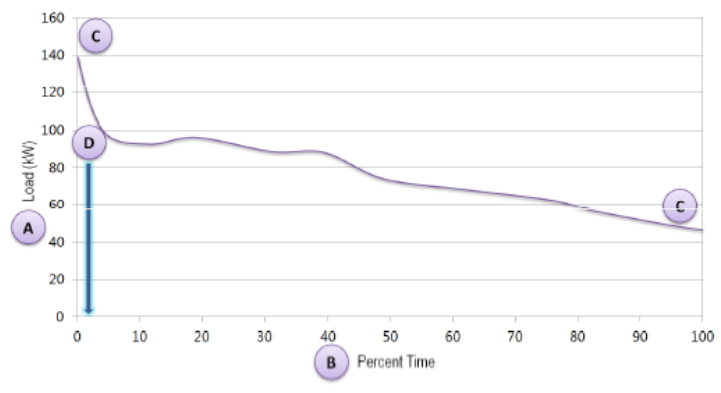

Figure 2.8: Load Duration Curve for a Facility for One Year (Energy Efficiency \& Demand Management \& AEE Northern Ohio Chapter, 2014) 


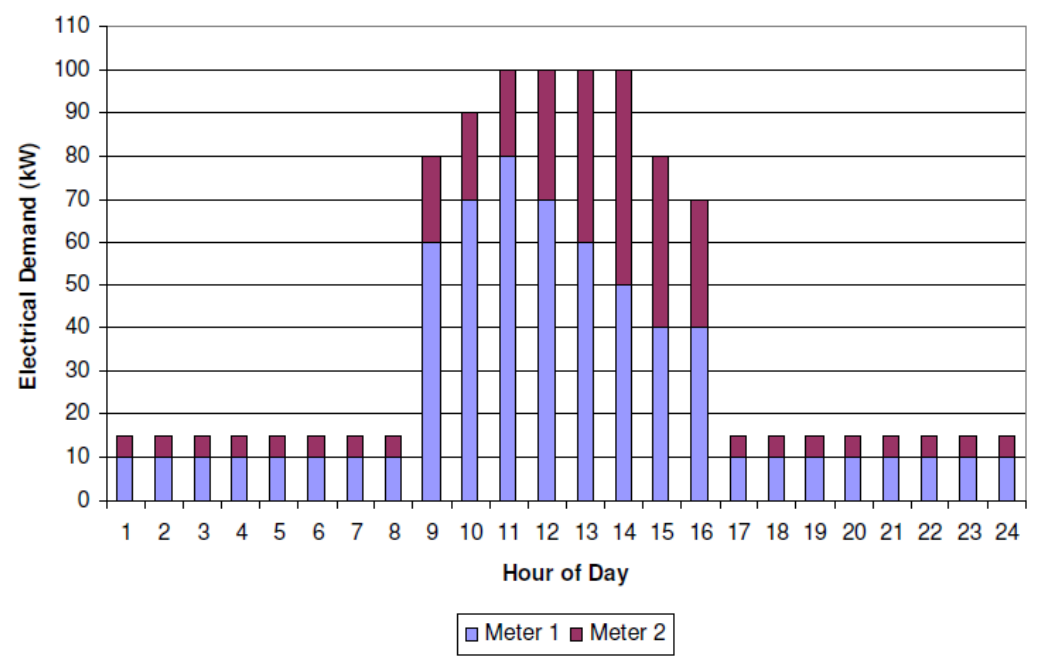

Figure 2.9: Stacked Bar Chart for Several Meters for Electrical Demand (Energy Efficiency \& Demand Management \& AEE Northern Ohio Chapter, 2014)

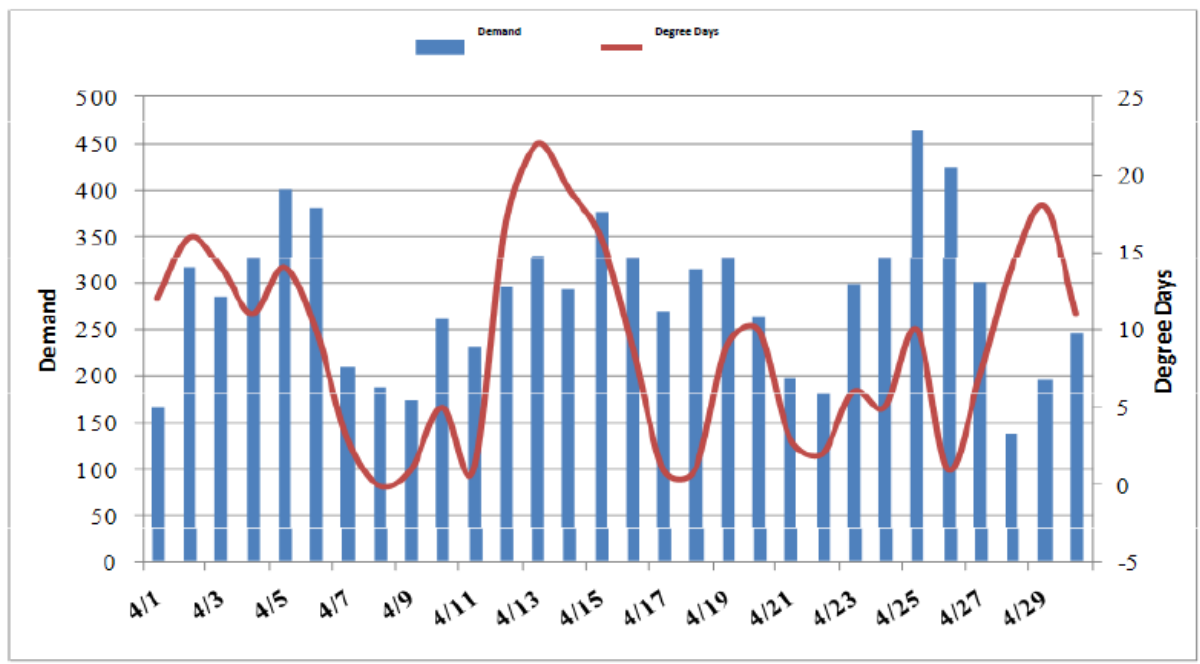

Figure 2.10: Double Y-Axis Chart to Compare Electrical Demand and Degree Days (Energy Efficiency \& Demand Management \& AEE Northern Ohio Chapter, 2014)

While these dashboards do typically provide quantitative measures for energy consumption data (billing systems, energy usages, etc.), one interesting viewpoint was that of Giacomin who investigated sensory and perceptual qualitative representations of pieces of equipment and appliances in regards to energy visualization (Giacomin \& Bertola, 2012). When conducting the experiment, participants viewed pieces of energy-intensive equipment in their homes as thermal images in color, but also in gray-scale. The research team found that the 
infrared blue-red thermal images showed higher levels of emotional activation as seen in Figure 2.11.
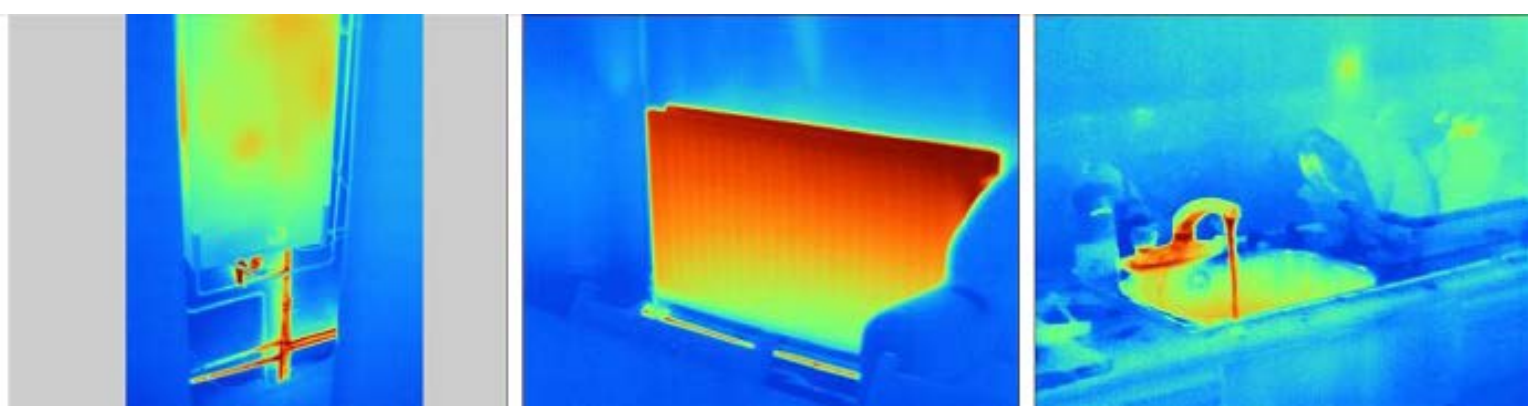

Figure 2.11: Thermal Images for Hot Water Boiler, Radiator, and Water Faucet (Giacomin \& Bertola, 2012)

Another research team confirmed that thermal images left a lasting impression on the users and they considered being more energy conservative (Pahl, Goodhew, Boomsma, \& Sheppard, 2016). Thus, this research confirms the fact that color provides high importance in energy visualization techniques.

Data visualizations are utilized for other industries that may not be trivial. Other data visualizations was that of geographic plotting systems acting as a heat map and a word cloud as seen in Figure 2.12 and Figure 2.13, respectively (Irwin, Robinson, \& Belt, 2017). The heat map was used to identify where certain airplanes were and the congestion associated with them. The word cloud was an example of how often certain words were used in text. The larger words were used more often whereas the smaller words were used less frequently. 


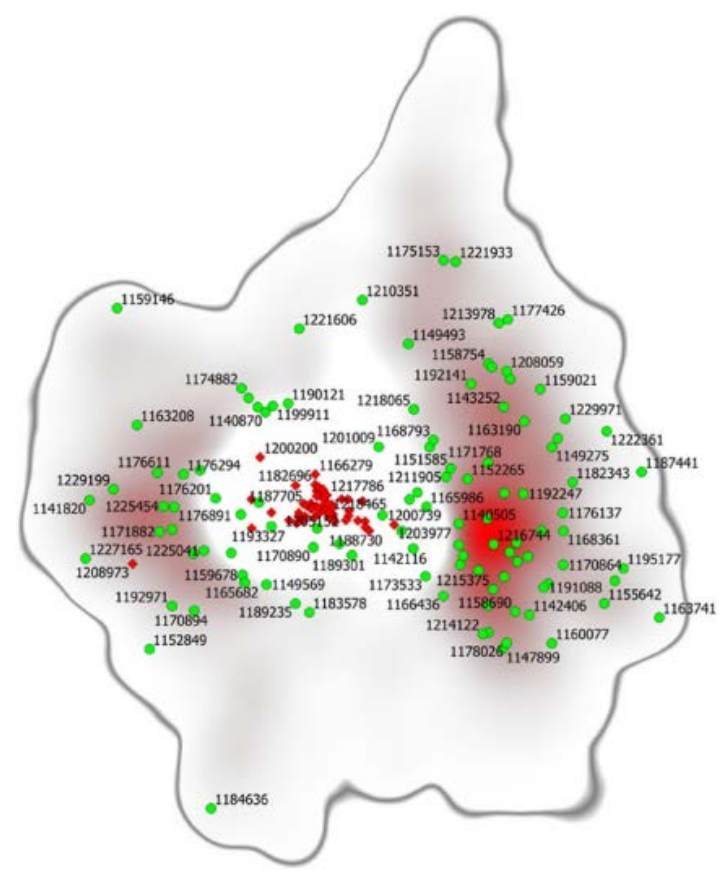

Figure 2.12: Geographic Heat Map (Irwin et al., 2017)

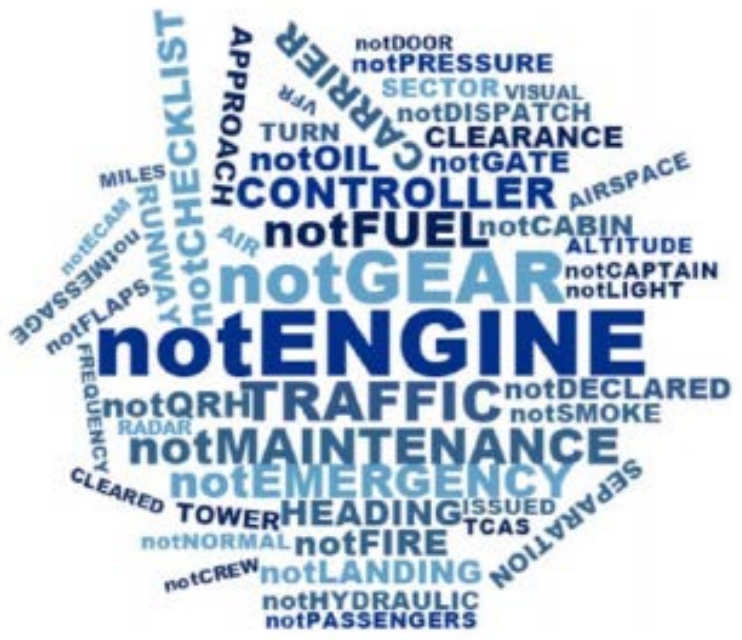

Figure 2.13: Word Cloud Example for Aviation (Irwin et al., 2017)

There are hundreds, if not, thousands of different data visualization techniques and opportunities to be utilized for visualizing data. However, the visuals must match the data and its overall function. One visual technique may be better in some applications while another is better in another application. Depending on the facility, it is important to first decide on the KPIs that 
are necessary and what data is required to be measured. From there, the visuals can be selected based on the best way to represent that data in a graphical and intuitive manner.

\subsection{Current Energy Visualization Systems on Market}

In the public spotlight, companies such as Sense, Neurio, and CURB have introduced simple and easy residential home energy monitoring solutions. These products monitor the main electrical lines in one's home and their technology can detect, based on changes in current, how much electricity different appliances are consuming. Each appliance and major electrical device has “clues," or an electrical current signature profile, that it produces so that the company’s technology can detect as to which appliance is which (Phillips, 2016). The data points are sent to a cloud-database through Wi-Fi and can be viewed on primarily a smartphone application or a desktop application. The Internet of Things (IoT) has provided a great insight into connecting many devices together. Capturing data through the use of sensors and analyzing this data can be crucial to the success of many companies (Smith \& Wuest, 2017). The management of data collected from electronic sensors are essential to the success of energy efficiency (Perles et al., 2017). IoT is a major concept that is beginning to not only shape residential homes, but it also has industrial applications as well.

In the commercial sector, there are EV systems currently offered on the market. First, the U.S. Department of Energy (DOE) does offer the Energy Looking Glass Dashboard for large hotels and resorts (U.S. Department of Energy, 2012). With this tool, a user must enter data daily into the generic template. The system allows for inputs from electric, gas, steam, and water meters. By utilizing cooling degree days (CDD) and heating degree days (HDD), the program calculates the overall energy usage of the building while providing some minor data analytics. ASHRAE also provides algorithms, formulas, and other calculation programs to assist in the 
basic calculations of building energy usage (Strohm, 2014). Other building management systems (BMS) such as Metasys, Automated Logic, and other systems provide insight into a facility's building (Lehrer et al., 2010). However, much of what is missing is the capability to drill-down to further detail, visualizing more data points, and tools to use data analysis.

Within the industrial sector, facilities have utilized "Supervisory Control And Data Acquisition” (SCADA) systems and other industrial energy monitoring/control systems. By connecting large HVAC systems, compressed air systems, and even lighting to a SCADA system, facilities have been able to monitor and control their energy usage in recent years. Companies such as Siemens, Honeywell, and other large corporations provide large expensive installations for these companies that are interested in monitoring and controlling their energy usage in their plant or facility. These HVAC or compressed air systems are all connected to a main programmable logic controller (PLC) that receives the data, makes a decision based on the data, and then sends a signal to either make changes to the system or relays this data to a monitoring system for a user to view.

From the research, four main tiers have been established based on the different capabilities necessary. These tiers are categorized based on three viewing options:

- Local - Access the data only through the human machine interface (HMI) by viewing it physically at the HMI. Can only view from the HMI at the PLC

- Remote - View the local display at the HMI from another location through virtual network computing (VNC). "Remotely view the local display"

- Cloud - View the data from a cloud-based database through the internet. Global viewing from anywhere in the world

Generally, with these tiers, price follows the capabilities where price is ascending from least expensive to most expensive. Tier 1 only offers local viewing while tiers 2, 3, and 4 offer the 
potential for remote viewing. However, only tiers 3 and 4 offer cloud viewing. The tiers are defined as follows:

1. Local Touchscreen with Basic PLC - Utilizing a simple PLC (such as Velocio or Click) or I/O (input/output) module, an HMI or touchscreen can be attached for local display of data that the PLC or I/O module receives. This tier has access to data locally at the basic PLC (limited inputs and outputs) with limited visualizations and data analytics.

2. HMI Intranet Remote Access via VNC - Through VNC, highly capable HMIs (such as Allen Bradley PanelView or Maple Systems HMIs) at the PLC can communicate with a remote computer on the same intranet network and display the local HMI through a program interface. This tier offers more inputs and outputs, more visual options and metrics, and can view data remotely from computer while on the main network using VNC.

3. Open Database-driven System - Utilizing Visual Basic .NET, data can be pushed from the highly capable PLC to the database where hundreds of preset visualizations are available for manipulation. As an open programming system, this tier offers data analytics, many visualizing options, and is capable for cloud access.

4. Integrated SCADA System - Systems such as Wonderware and FactoryTalk offer the full fleet of data visualizations and data analytics. This tier is the most expensive with hundreds of preset visualizations, cloud capable, an integrated historian, trend and analytic capabilities, and alerts via e-mail and SMS.

Based on the different tiers, a company may select an option based on their budget and facility needs. In addition, the facility must decide whether they will only need local viewing and little data analytics, or will they prefer remote access from anywhere and endless data analytic options.

Combining both the residential, commercial, and industrial sectors along with the different tiers of energy data visualization, a comparison must be made. As there is overlap between these sectors, Table 2.1 assists in providing context. Each platform is compared based on the following factors: 
- Viewing capabilities - Local (L) and/or Remote (R) viewing capabilities

- Cloud capabilities - Whether the platform supports a cloud database

- Cost - \$, \$, \$\$ for least expensive to most expensive, respectively

- Visualization Richness - The degree of quality of the data visualizations and abundancy of potential visuals on a scale of $1-5$ ranging from least rich to most rich, respectively

- Customizable - What range of manipulation and customizing can the platform perform on a scale of $1-5$ ranging from least customizable to most customizable, respectively

- Enable Analytics - Whether the platform allows for the potential for data analytics and program intelligence to be integrate 
Table 2.1: Comparison Table of Different Platforms' Capabilities

\begin{tabular}{|c|c|c|c|c|c|c|c|c|}
\hline \multicolumn{2}{|c|}{ Sector } & Platform & $\begin{array}{c}\text { Viewing } \\
\text { Capabilities }\end{array}$ & $\begin{array}{c}\text { Cloud } \\
\text { Capabilities }\end{array}$ & Cost & $\begin{array}{l}\text { Visualization } \\
\text { Richness }\end{array}$ & Customizable & $\begin{array}{c}\text { Enable } \\
\text { Analytics }\end{array}$ \\
\hline \multirow{3}{*}{\multicolumn{2}{|c|}{ Residential }} & Sense & \multicolumn{2}{|c|}{ Remote/Cloud } & $\$$ & 3 & 1 & $\mathrm{X}$ \\
\hline & & Neurio & \multicolumn{2}{|c|}{ Remote/Cloud } & $\$$ & 2 & 1 & $\mathrm{X}$ \\
\hline & & CURB & \multicolumn{2}{|c|}{ Remote/Cloud } & $\$$ & 3 & 1 & $X$ \\
\hline \multirow{4}{*}{ Commercial } & & $\begin{array}{l}\text { Local Touchscreen with Basic } \\
\text { PLC }\end{array}$ & $\mathrm{L}$ & $\mathrm{X}$ & $\$$ & 1 & 2 & $\mathrm{X}$ \\
\hline & \multirow{3}{*}{ Industrial } & $\begin{array}{l}\text { HMI Intranet Remote Access via } \\
\text { VNC }\end{array}$ & $\mathrm{L} / \mathrm{R}$ & $\mathrm{X}$ & $\$ \$$ & 2 & 3 & $X$ \\
\hline & & Open Database-driven System & $\mathrm{L} / \mathrm{R}$ & $\checkmark$ & $\$ \$$ & 4 & 5 & $\checkmark$ \\
\hline & & Integrated SCADA System & $\mathrm{L} / \mathrm{R}$ & $\checkmark$ & $\$ \$ \$$ & 5 & 4 & $\checkmark$ \\
\hline
\end{tabular}




\section{Chapter 3: Rationale of Study}

\subsection{Problem Scope}

In recent years, both the residential and large industrial sectors are benefited with EMS and EV solutions that provide them with capabilities to monitor and control their energy usage in real-time. Within the light commercial sector, solutions for EMS and EV are limited: a low-cost option consists of general and simple building energy calculators based on the manual entry of data by the users; expensive BMS available for a large installation and ongoing annual costs. Small commercial buildings (less than 50,000 square feet) make up 90\% of the total number of buildings in the United States (Barnes \& Parrish, 2016). Yet, there are limited options for this sector.

Interestingly, there are papers identifying that small commercial buildings are a niche that has not been met in EV realm. There are multiple sources that confirm that little research has been completed on this topic (Lehrer, Kaam, \& Vasudev, 2014; Lock, Shyan, \& Hartman, 2016). Some opportunities are considered such as downsizing larger EV systems typically used for large commercial or industrial applications, smart thermostats that can control lighting or other loads, and upsizing residential systems (Ehrlich, 2015). One project by the Lawrence Berkeley National Laboratory and Architecture 2030 partnered to develop the Small Commercial Toolkit which offered a program that included HVAC, lighting, plug load, and whole building calculators (Barnes \& Parrish, 2016). Barnes identifies the obvious barriers of the small commercial sector with limited budgets, lack of time for focusing on energy efficiency, and other factors.

For small commercial buildings, there is a technology gap where this industry is not currently being serviced in the EV realm. EV and EMS systems are currently available for largescale facilities utilizing IoT and connecting many pieces of energy-intensive equipment to the 
network as well as continuous monitoring. These IoT networks are also integrated into the main intranet network of the facility - potentially causing protection and safety concerns. Shrinking this scope to the residential market, companies like Sense, Neurio, and CURB provide simple “plug-and-play” energy monitoring devices for refrigerators, dryers, and small HVAC systems to be connected to the computer and apps on a smartphone.

Each of these technologies satisfy the industrial, large commercial, and residential markets. However, the small to light commercial industry is forgotten. Residential EV systems cannot withstand the many pieces of equipment that a commercial facility has, or the amount of energy used. On the larger spectrum, large-scale facility EV systems are overkill for the light commercial industry - both economically and in complexity. The large commercial systems that are offered are still complex and require significant upfront engineering project cost. Not only do the large commercial systems offer a high upfront cost (over \$20,000), but there are also high ongoing costs (over \$16,000 annually) (Granderson \& Lin, 2016).

Thus, the market is begging for a light commercial EV system option to be introduced. A system for this sector must be:

- Economic for the small business

- Easy to install and source necessary data devices

- Flexible for a variety of equipment and future installations

- Provide a safe, non-intrusive solution for EV

- Automatic updating of data without interference

Furthermore, little to no research has been completed, from an ergonomic and human factors perspective, for energy visualization systems. The various visuals, the human-to-machine 
interfacing, the best ergonomic design layouts for energy dashboards, etc. have yet to be researched. These are just a few topics of the EV domain that have yet to have extensive research.

\subsection{Research Question and Objectives}

While the residential sector has EV systems that offer low-cost options, the customizations, viewing capabilities, and analytics are lacking. On the other extreme, Integrated SCADA systems provide all the visuals, customizations, and data analytics, but is quite expensive for light commercial businesses. Based on the different options in Table 2.1, the Open Database-driven System provides the best solution for a reasonable priced system that is highly capable of energy visualization for light commercial businesses.

Our research question was: Does the proposed Open Database-driven energy visualization system provide a reasonable avenue for data capturing and visualization in the light commercial sector? The following objectives were set forth to address the research

\section{question:}

Objective 1 - System Design and Development: A system was designed and developed by adhering to the criteria of the Open Database-driven system. This involved tedious research of the capabilities of different components. The components were required to perform necessary duties to capture data from the various energy sources and transmit them to the I/O module or PLC. Communication from the devices, to the I/O module or PLC, and to the computer were essential to the success of the system.

Objective 2 - Dashboard Testing and Validation: Once the system was developed, the dashboards were evaluated by a focused group of participants consisting of energy managers and engineers, and other typical dashboard users through analytical and subjective testing. 
Objective 3 - Energy Dashboard Installation Guide Program: Finally, for the businesses that may be interested in implementing a system similar to the one developed in this study, a computer program was developed. This program, based on the operational characteristics of a business, develops a custom wiring diagram. It also creates an installation checklist that includes a list of energy monitoring equipment and approximate system costs. 


\section{Chapter 4: Methodology}

The system was developed with a mindset that the required hardware was readily available to purchase on the market and provided a low cost and flexible option for small business owners. The system was built to be a simple "plug-and-play" system with built-in visuals for the PLC software. This chapter is divided into four main sections. A section on system development (objective 1) discusses how the system operates and communication of different hardware within the system as well as dashboard development. In the next section, system and dashboard validation is discussed where the system simulated energy consumption; 25 participants were used to evaluate three different dashboards (objective 2). The next section on the Energy Dashboard Installation Guide Program (objective 3) focuses on the development and use of the program to guide business owners through the installation of their own energy dashboard for their specific business. The final section contains the process used for data analysis.

\subsection{System Development}

\subsubsection{Hardware Research}

To provide an appropriate EV system application for light commercial businesses, thorough research was first conducted to determine the best technology and application. Since one of the objectives of the research was to build a low-cost EV system and keep the system open to several different pieces of equipment, economics and flexibility were given high priority. An essential product design phase roadmap centered around the customer was proposed in the early 2000’s (Wickens, Lee, Liu, \& Becker, 2004). By first utilizing a front-end analysis approach, the major features of the current systems were recorded and identified, as seen in 
Table 2.1, to be used in the proposed system. The features that are common among the different EV systems were included in the design of the proposed EV system.

When researching how to build the system, it was first determined as to which energy sources to capture. Three main energy sources for light commercial businesses included electric, natural gas, and water ${ }^{1}$. From these sources, components were required to obtain the data and relay this information to a central computer. Adhering to low cost and flexibility priority, exhaustive research was completed to identify which components were capable to capture data from the three different energy sources. Capabilities of meters and different hardware were researched and identified while designing the proposed system.

It was identified that current transducers (CTs) were great devices for obtaining current readings from electrical equipment. These included freezers, chillers, HVAC systems, hot water electrical heaters, etc. These clamp-on devices could be placed on the main electrical lines of one phase of the equipment power wiring and wired back to the PLC. For lighting, one or several occupancy sensors could be installed in separate rooms to determine the energy usage of the lighting. The occupancy sensor could be connected to a digital input in the PLC. Once the sensor detects that the lights are operating, the PLC could record the data. To translate light usage into energy consumption, a small lighting assessment must be completed to obtain the number of lights, type of bulbs, and wattages.

After evaluation of natural gas, it was determined that it was best measured using a natural gas flow meter that indicated instantaneous flow or total volume of gas. However, natural

\footnotetext{
${ }^{1}$ Water, in principle, is a utility in the sense that it is generally easy to gain access. However, water can be used as a medium to carry/move energy. Electric and natural gas can be characterized as utilities as well in some contexts. However, throughout the paper, electric, natural gas, and water are labeled as "energy sources” though they can also be labeled as utilities in other contexts.
} 
gas flow meters are intrusive (must be inserted into the main line) and expensive. Furthermore, most light commercial companies do not own their own natural gas flow meters, but utility companies do have their own flow meters. If this was not an option, for example, a gas furnace could be measured using two thermocouple wires and an airflow sensor. By inserting the airflow sensor into the airstream of the furnace, this will allow for recording of the air flow of the furnace. Next, the thermocouple wires can measure the ambient temperature and the output temperature, respectively. The overall energy usage of the furnace can be determined using the thermodynamic equation as seen in Figure 4.1.

For water usage, there were several options available to obtain the data for energy usage. First, one must determine whether there is currently a water meter installed on the main water line. Typically, water meters produce a “pulse train” that is representative of flow rate through the meter. Additionally, manufacturers rate water meters based on a certain "k-factor" that is defined as the number of pulses that the meter outputs per unit of volume. In most cases, this is pulses per gallon. The time between pulses (in milliseconds) can be used to calculate the instantaneous flow rate. The total number of pulses can be used to calculate the total volume of water in gallons.

If there is already an installed water meter, the water meter may have a pulse counter output on the meter. Many water meters offer a pulse counter output so that it can be connected to the PLC for measurement of the pulses to determine water flow. If this is the case, a pulse counter can be wired from the water meter straight into the digital input on the PLC. If there is no pulse counter output on the currently installed water meter, but there is an analog dial, then installing a simple photoeye in front of the analog dial can be used. Both the pulse counter and 
the photoeye will be able to count the number of pulses or rotations, respectively, that occurred. Thus, the water flow can be calculated within the PLC.

If there is no installed water meter, then a clamp-on water meter can be utilized. In this case, the clamp-on water meter can be placed on the main water line or on a gas hot water heater. The clamp-on water meter will display and output the rate of water that is flowing through the pipe. Next, one must determine the change in temperature to determine the overall flow. Two thermocouple wires will need to be wired on the main ambient water line and one after the piece of equipment. One wire will record the ambient water temperature and one wire will record the hotter water temperature after the piece of equipment (hot water heater). Finally, the overall flow of the water can be estimated to determine the amount of water being used in the facility.

An installation diagram was developed for the proposed EV system to show all possible options as shown in Figure 4.1. Utilizing a PLC, CTs, pulse counters, photoeyes, and other equipment, a user may gain insight into how the energy is being utilized in the light commercial facility. 


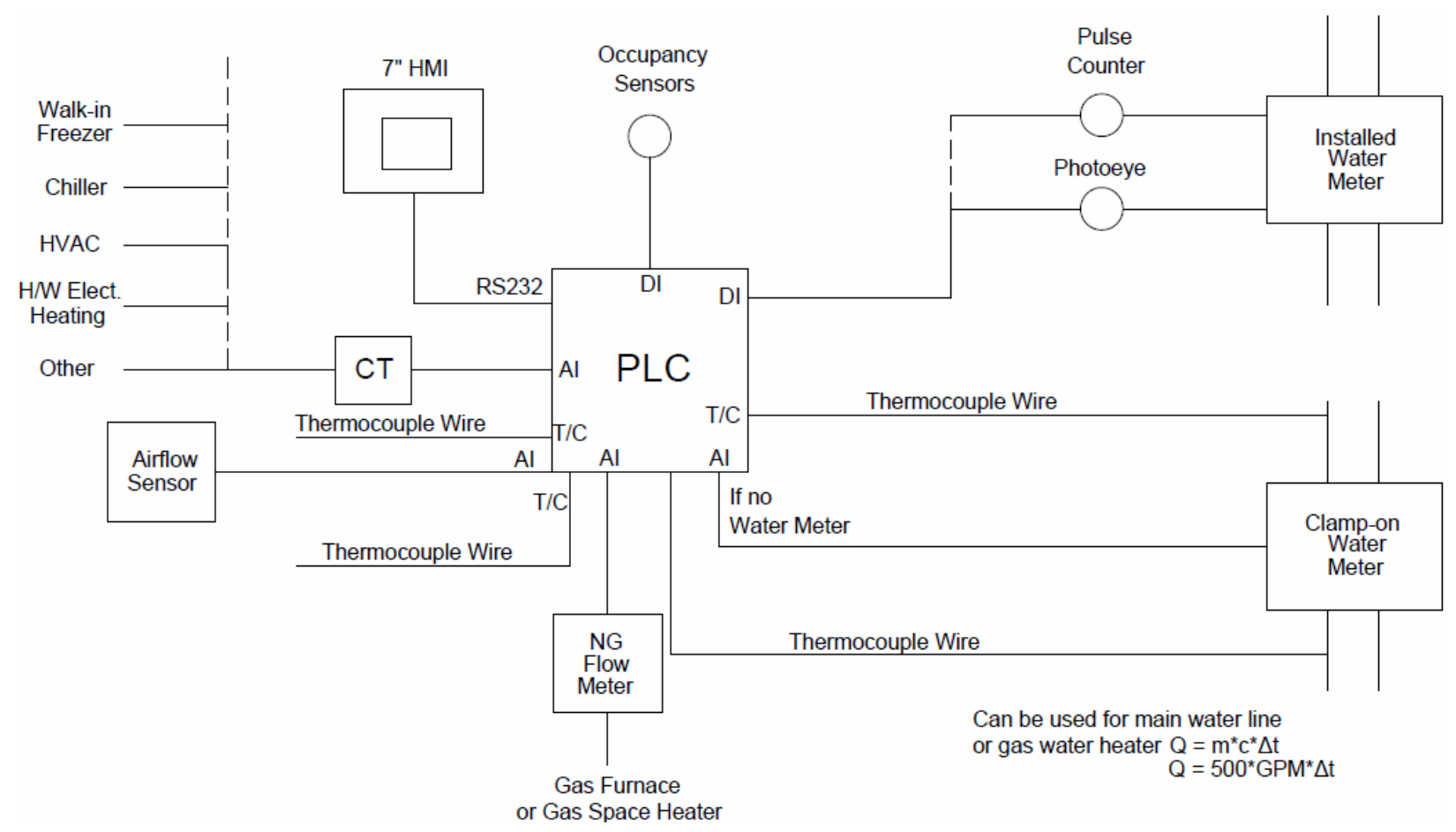

Figure 4.1: Block Diagram for the Proposed EV System

This block diagram explains the different capabilities that the proposed EV system offers.

Regarding a field installation, the specific wiring diagram would be dependent upon the equipment that the facility owns. Depending on the equipment and the utility metering (water and natural gas) capabilities, the diagram will alter based on the different options presented previously.

\subsubsection{PLC and HMI Integration}

Each component had to connect to a single device that was capable of inputting and outputting multiple data points - both analog and digital signals - depending on the energy source. Thus, a PLC or I/O module was decided to be used for obtaining the data and relaying the data to a main computer or HMI for visualization.

A PLC acts as the "brains" of the operation of the EV system, so a PLC had to be determined. A PLC must be able to collectively analyze and continuously monitor several 
different inputs into the system. The PLC could capture many different types of data, which made the system an open system. These inputs included analog, digital, and thermocouple inputs (AI, DI, T/C, respectively). Analog inputs allow various values to be recorded. These include electrical current, flow, etc. Digital inputs are considered on/off values and are binary. This includes occupancy sensors or a photoeye that detect whether there is movement or not. Thermocouple inputs are special types of inputs in that they are for direct connection to thermocouple wire to measure the temperature of the object that the wire is physically attached.

The Velocio Ace 7096v5 PLC was chosen as the main PLC due to its capabilities of 6 digital inputs, 12 digital outputs, 4 analog inputs, 2 analog outputs, 4 thermocouple inputs, and 2 RS232 outputs. The PLC would allow many different pieces of equipment to be connected to the PLC and offer space for future potential equipment to be installed. A common output of the PLC is RS232. Regarding Figure 4.1, a small 7” HMI was installed to display the energy data collected as an output from the PLC to the HMI using the RS232 output. The HMI was touchscreen allowing the user to view energy usage of certain pieces of equipment, view the data over a defined period of time, and view the data in real time. The HMI served as a local display for the user and provided a direct display of the energy usage from the PLC to the HMI for human interaction.

\subsection{System and Dashboard Validation}

To validate the proposed system, an experiment was conducted to test the capabilities of the system and dashboard. The System Communication section provides insight as to how the components and devices communicated with one another for the experiment. The Dashboard Design section explains how the dashboards were developed based on the literary review. 
Finally, the Dashboard Testing Procedure section explains how the experiment was conducted in various phases using usability and subjective testing methods.

\subsubsection{Interaction System Communication}

\subsubsection{System Communication Overview}

Since the system proposed using electric, natural gas, and water energy sources, certain components were required to simulate the actions of a real-time business. The components used in the system were CTs (electric), natural gas flow meters (natural gas), occupancy sensors (electric), and water meters (water). To simulate each of these, further research into how each of these components operate was necessary. For example, since the CTs and natural gas flow meters provide either $4-20 \mathrm{~mA}$ signals or $0-10 \mathrm{~V}$, then a signal generator could be used for each. Similarly, a running switch served as simulation for an occupancy sensor, a pulse generator for a water meter. Thermocouple wires could have been used to simulate temperature, but this was not completed in the experiment. The interaction system can be seen in Figure 4.2.

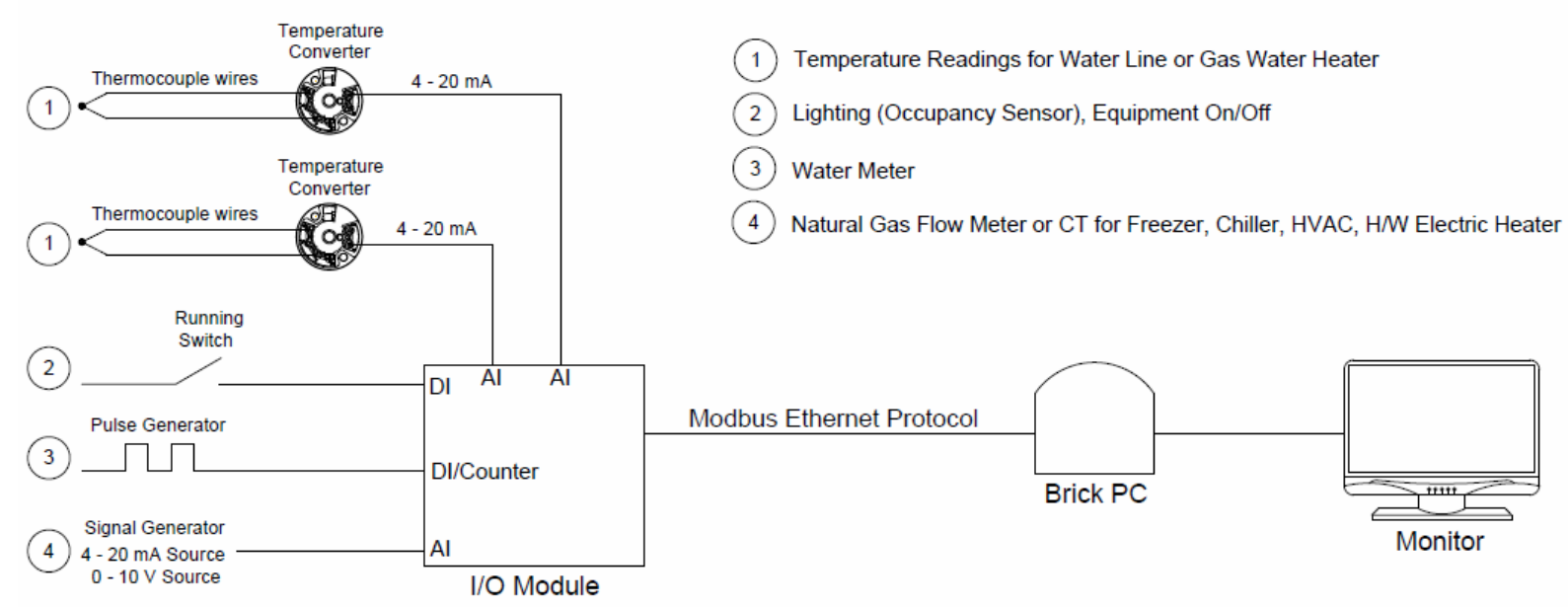

Figure 4.2: Interaction System Block Diagram

With this setup, the I/O module received many inputs (both analog and digital) and allowed for multiple outputs. A pulse generator simulated a water meter by outputting several 
pulses per second using a counter. Two 4-20 mA signal generators served as sources for a CT and natural gas flow meter using an analog input. The signal generator simulated the current obtained from a CT. Electrical equipment was kept generic to represent current from a large freezer, chiller, HVAC system, or hot water electric heater. Similarly, another signal generator was used to simulate the current from a natural gas flow meter providing gas for a gas furnace. Both devices had dials that contained a potentiometer (to vary the resistance) that allowed for manual adjustment to simulate the changes in pulse or signal.

A running switch was used to simulate a binary Boolean effect. The switch could communicate to the I/O module to signal as to whether a piece of equipment was on/off, whether there was occupancy in a room, or other on/off uses. In the system, the running switch was used to identify whether there was occupancy in a room. Each device and input were modeled to simulate a piece of equipment that would be in a light commercial facility.

After sourcing the components to communicate with the I/O module, the I/O module had to communicate with the brick computer. After research of communication options between I/O modules and PLCs to computers, it was identified that Modbus Ethernet Protocol was a great selection. Using software and an ethernet cord, communication occurred between the two devices. From the PC, a monitor was connected to view the visualizations and developed dashboard. Specific software allowed for the data to be recorded into a database for further visualizations. Customization of the data and visualizations were completed using the VB .Net programming language within the database as well as the free software, Advanced HMI (“AdvancedHMI,” 2018). 


\subsubsection{Interaction System Setup}

In the simulated system, a running switch was used to simulate the operation of the lighting. The system recorded the 1's and 0's (on/off) as this measurement was Boolean. Additionally, it recorded the amount of time that the lights were operating. Combining both measurements, the overall electrical energy usage for the lights were determined.

For natural gas, most companies have a main natural gas meter. These meters display the total amount of gas flow, usually in MCF (thousands of cubic feet of natural gas) and operate using a $4-20 \mathrm{~mA}$ signal. All natural gas meters have a certain operating flow rate range that they operate. By setting an operating meter range proportionally to the $4-20 \mathrm{~mA}$ analog signal, this assigned specific current signals to appropriate gas flow values via the signal generator dial. For example, suppose a meter has a range from 0 MBTU/hr (thousands of British Thermal Units per hour) to $100 \mathrm{MBTU} / \mathrm{hr}$ and the signal generator produces $4-20 \mathrm{~mA}$ signal. If the meter reads $50 \mathrm{MBTU} / \mathrm{hr}$, then this would correspond to a 12-mA signal. The signals can then be generated according to example meter readings. For the natural gas values, the simulated natural gas meter was calibrated to have a range from 0 to $100 \mathrm{MBTU} / \mathrm{hr}$.

Regarding water meters, these meters produce a pulse train representative of water flow rate as discussed earlier. As a meter will be calibrated to a certain k-factor (number of pulses per gallon), this assisted in calculating an instantaneous flow rate and total water volume. The time between pulses were used for calculating instantaneous flow rate while the total number of pulses were used to calculate the total water volume. The following equation gave the instantaneous flow rate in gallons per minute (GPM):

$$
F R=\frac{1}{k} * \frac{1}{T_{B}} * \frac{1000 \mathrm{~ms}}{\mathrm{sec}} * \frac{60 \mathrm{sec}}{\min }
$$


Where,

$$
\begin{array}{ll}
\mathrm{FR} & =\text { Instantaneous flow rate (gallons/min) } \\
\mathrm{k} & =\text { K-factor (pulses per gallon) } \\
\mathrm{T}_{\mathrm{B}} & =\text { Time between pulses (milliseconds/pulse) }
\end{array}
$$

The total water volume in gallons were calculated by using the following equation:

$$
T V=\frac{1}{k} * N
$$

Where,

$$
\begin{array}{ll}
\mathrm{TV} & =\text { Total volume (gallons) } \\
\mathrm{k} & =\text { K-factor (pulses per gallon) } \\
\mathrm{N} & =\text { Number of pulses }
\end{array}
$$

Both equations were used to calculate the instantaneous flow rate and the total water volume. The pulse generator was adjusted to 3 gallons/min to produce representative pulses during the simulation.

\subsubsection{Dashboard Design}

\subsubsection{Dashboard KPI Measurements}

The dashboards were designed in such a way that they provided real-time visualizations of energy used by the following energy sources in some way:

- Major electrical consumption equipment (Current transducer)

- Lighting (Occupancy sensor)

- HVAC (Natural gas meter)

- Water (Water meter)

Dashboards typically contain different KPIs for measuring and gauging the performance of a facility. In the proposed dashboards for a light commercial business, the following KPIs were utilized to some degree: 
- Totalized usages with breakdown percentages of different energy sources

- Alternating lights indicating on/off or pulsating

- Maximum and minimum ranges

These KPI measurements satisfy most of light commercial businesses as equipment is limited in nature. Furthermore, light commercial businesses will typically not have past energy data other than utility bills. Thus, it can be difficult to obtain benchmarking data from past energy usages as well as the correct ranges certain energy sources should be within. After introduction of an EV system over some time, the system can be upgraded for benchmarking and comparison of data from previous points in time.

\subsubsection{Design Factors}

From the literary review, many concepts and design factors that define a successful energy dashboard were identified (Table 4.1). Each factor was fairly based on an opinion, but there are distinctions. A dashboard was generally comprised of some combination of analytical and engaging rated on a $0-100 \%$ scale (e.g. $60 \%$ analytical, $40 \%$ engaging).

Conversely, two other factors were on a separate scale that measures human feelings. These features were termed as interesting and trustworthy. These ratings were subjective and measured how interesting or peculiar a dashboard is compared to a dull dashboard. Additionally, trustworthiness ratings provided insight into how the user trusted the data that was presented. These factors were rated on a scale of 1 to 10 . 
The following factors were defined for use of rating the dashboards:

- Analytical - use of detailed diagnostic visuals (e.g. detailed bar charts, enhanced line charts, etc.)

- Engaging - visually pleasing visuals or graphics (use of preattentive attributes e.g. gauges, stoplights, etc.)

- Interesting - measure of curiosity or attention to the user to desire to obtain further details

- Trustworthy - measure of the user's confidence in the data and believes in the accuracy of the data

Table 4.1: Dashboard Design Factors

\begin{tabular}{|c|c|c|}
\hline Type & Factor & $\begin{array}{c}\text { Rating } \\
\text { Scale }\end{array}$ \\
\hline \multirow{2}{*}{ Combination } & Analytical & $0-100 \%$ \\
\cline { 2 - 3 } & Engagement & $0-100 \%$ \\
\hline \multirow{2}{*}{ Individual } & Interesting & $0-10$ \\
\cline { 2 - 3 } & Trustworthy & $0-10$ \\
\hline
\end{tabular}

\subsubsection{Dashboard Visualization Methods}

As discussed in the Energy Data Visualization Techniques section, there were several graphs, tables, and visuals that were at one’s disposal for energy dashboard design. Experts in the data visualization field agree that the ability to present information are not instinctive, but rather require that certain principles be learned (Few, 2013; Kirk, 2012; Knaflic, 2015). For the purposes of the experiment, certain visualizations were better than others for visualizing light commercial energy data.

Simple bar charts, line graphs, and tables were used in the dashboards. These visuals provided primitive data from the signal generators without much altering. This allowed for a simple view of the data to understand the real time energy usage. Enhanced charts and graphs such as the stacked bar charts were also integrated. These enhanced visuals provided more 
context and were more analytical than the simple graphing techniques. Additionally, gauges, pie charts, and easy-to-read visuals that utilize preattentive attributes were also used to display energy data efficiently. As a generally accepted data visualization principle, preattentive attributes should be used for quick visualizing without extra load on the working memory (Knaflic, 2015).

\subsubsection{Dashboard Development}

Utilizing these techniques, three main categorical dashboards were developed to capture and visualize all the energy data. These three dashboards were based on the features learned from the literary review including: preattentive attributes, the correct data visual tools, enhanced graphs/charts, dynamic display and other characteristics. Adhering to the concept of clarity and efficiency of interpretation, the dashboards were developed specifically for the light commercial industry.

The three proposed dashboards are seen in Figure 4.3, Figure 4.4, and Figure 4.5, respectively. The dashboards were classified ranging from highly analytical to highly engaging. Design factors played a significant role in the dashboard development process. From the literary review and examining similar energy dashboards, each dashboard was rated using the design factors. The simple and enhanced line charts, bar graphs, and tables were considered analytical visuals as they provided analytical insight with details. As for the preattentive design factors including gauges, pie charts, alternating lights, etc., these were considered engaging attributes as they were more aesthetically pleasing and offered an overview of the energy situation rather than providing great details than the analytical visuals provided.

Dashboard 1 (Figure 4.3) offered a simplistic view with line charts and bar graphs from the pulses/switch readings. These graphs simply plotted the current, natural gas flow, and pulses 
from the energy sources, respectively. A table displayed the totalized energy usage values along with a categorical percentage of each energy source. Historical data could be viewed by clicking on the respective buttons for previous months' data. This dashboard layout shows simple graphs and tables and are typically used with a simple HMI or visualization software. From the literary review, the dashboard is rated as $80 \%$ analytical and $20 \%$ engaging.

Dashboard 2 (Figure 4.4) offered simple tables and line charts, but also included engaging visuals including a light indicator for lighting and a pie chart breakout for the totalized energy usages. The graphs and values provided context for electric, natural gas, and water energy usages, respectively. The pie chart gives context for the percentages of energy usage. In addition, the lighting is viewed using a stoplight to provide easy viewing with preattentive attributes to indicate if lights are on or off. This type of dashboard is easy to comprehend, but also allows for depth of analysis with historical data via the respective monthly data buttons. This is typically used in the "HMI Intranet Remote Access via VNC" and "Open Database-driven System" as discussed in Table 2.1. From the literary review, the dashboard is rated as $60 \%$ analytical and $40 \%$ engaging.

Dashboard 3 (Figure 4.5) presented the data in a more engaging manner with gauges, alternating stoplights, lights, and a pie chart. The gauges showed instantaneous percentage load values while the alternating lights displayed whether lights were on or if water was running. Energy usage values were presented along with a pie chart that shows the percentages of energy usage from the different sources. This type of dashboard is typically completed using complex, higher end cloud-based visualization software. From the literary review, the dashboard is rated as $20 \%$ analytical and $80 \%$ engaging. 


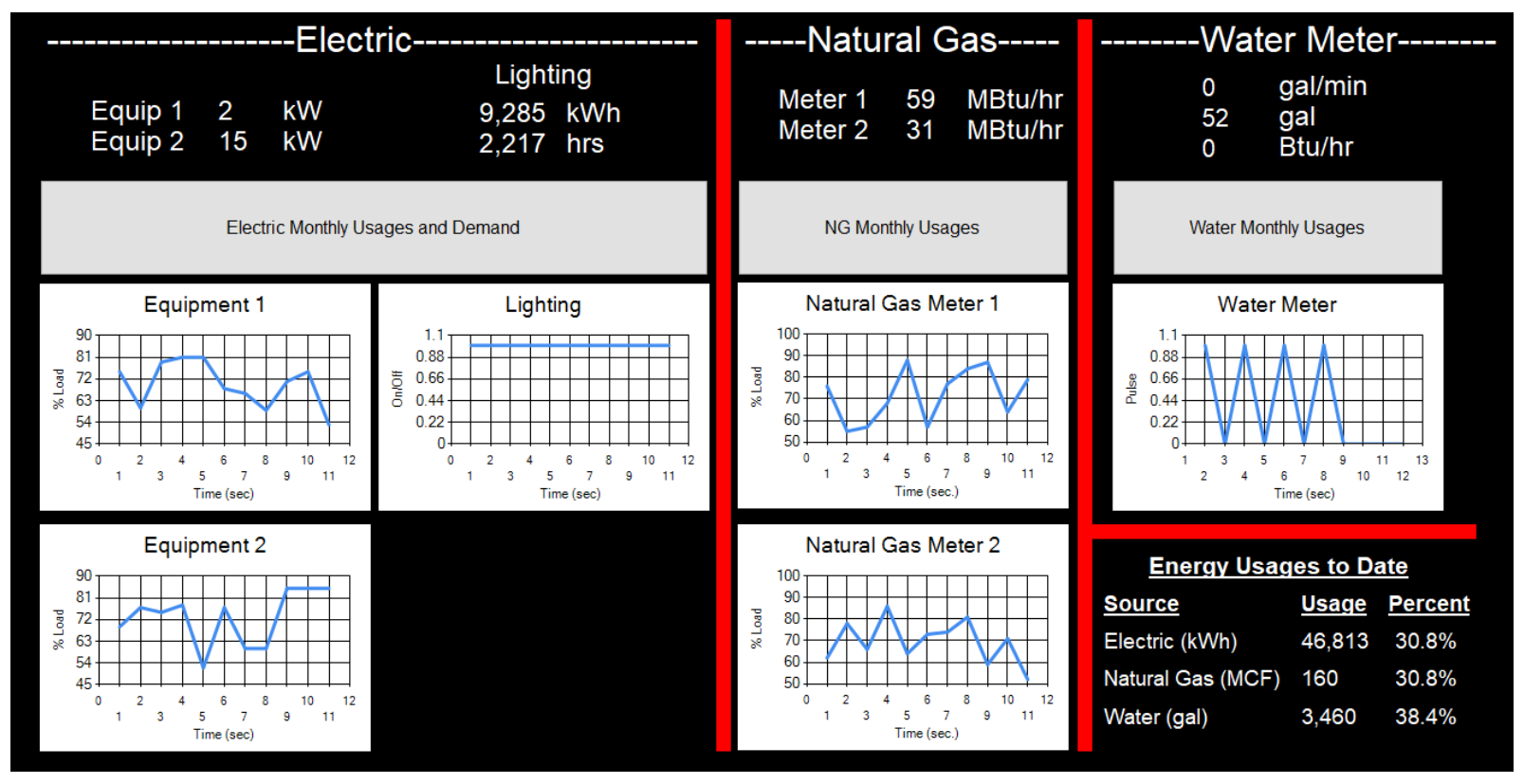

Figure 4.3: Dashboard 1 for Simulated Testing for Participants

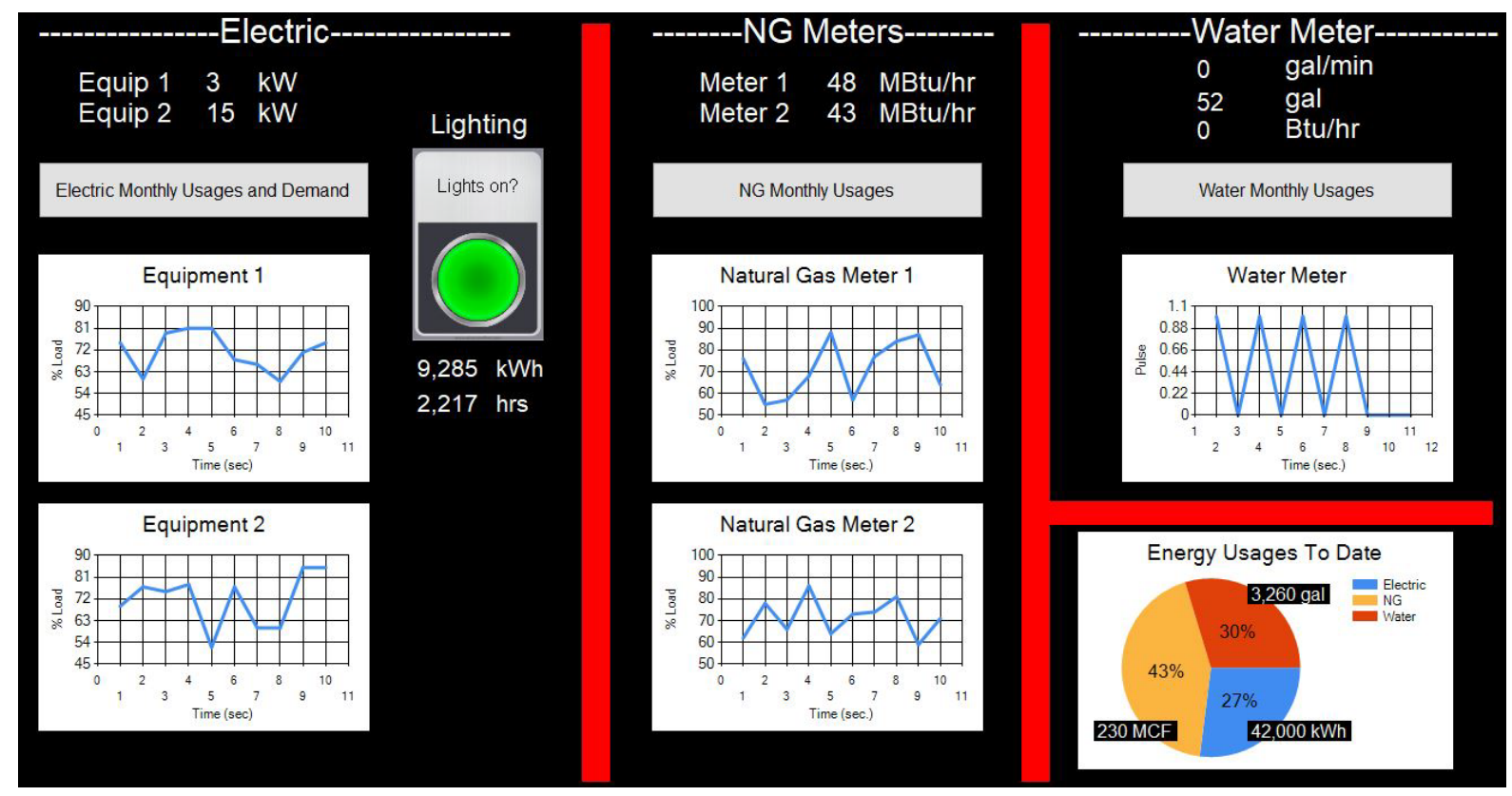

Figure 4.4: Dashboard 2 for Simulated Testing for Participants 


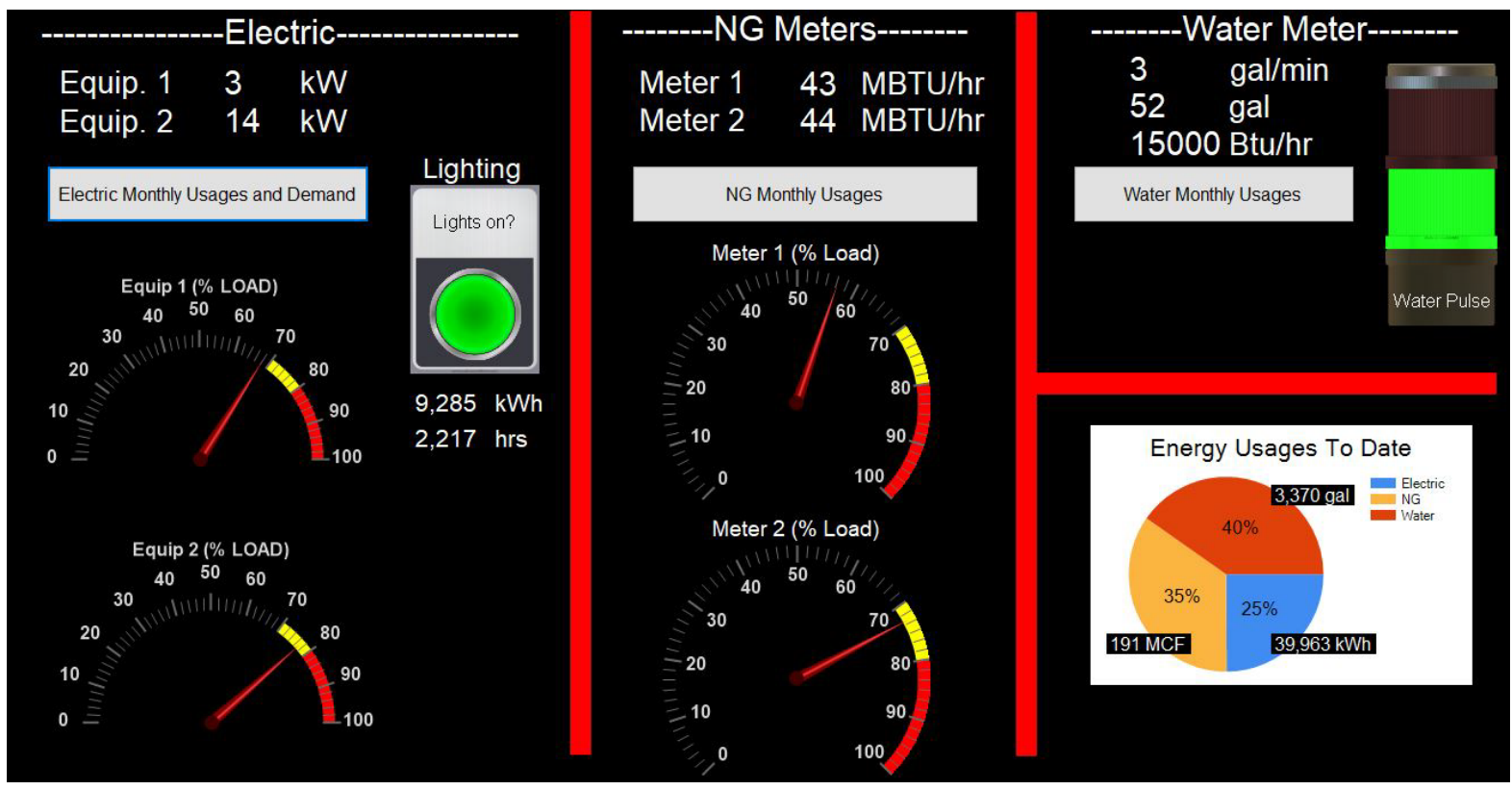

Figure 4.5: Dashboard 3 for Simulated Testing for Participants

In addition, each dashboard seen above included three individual buttons for historical data. These included the electrical monthly usage and demand (Figure 4.6), natural gas monthly usages (Figure 4.7), and water monthly usages (Figure 4.8), respectively. To obtain monthly data, a user would click the specific button to read a graph displaying the monthly usages for the chosen energy source. After clicking a button, the respective monthly data would appear in a pop-up window. 

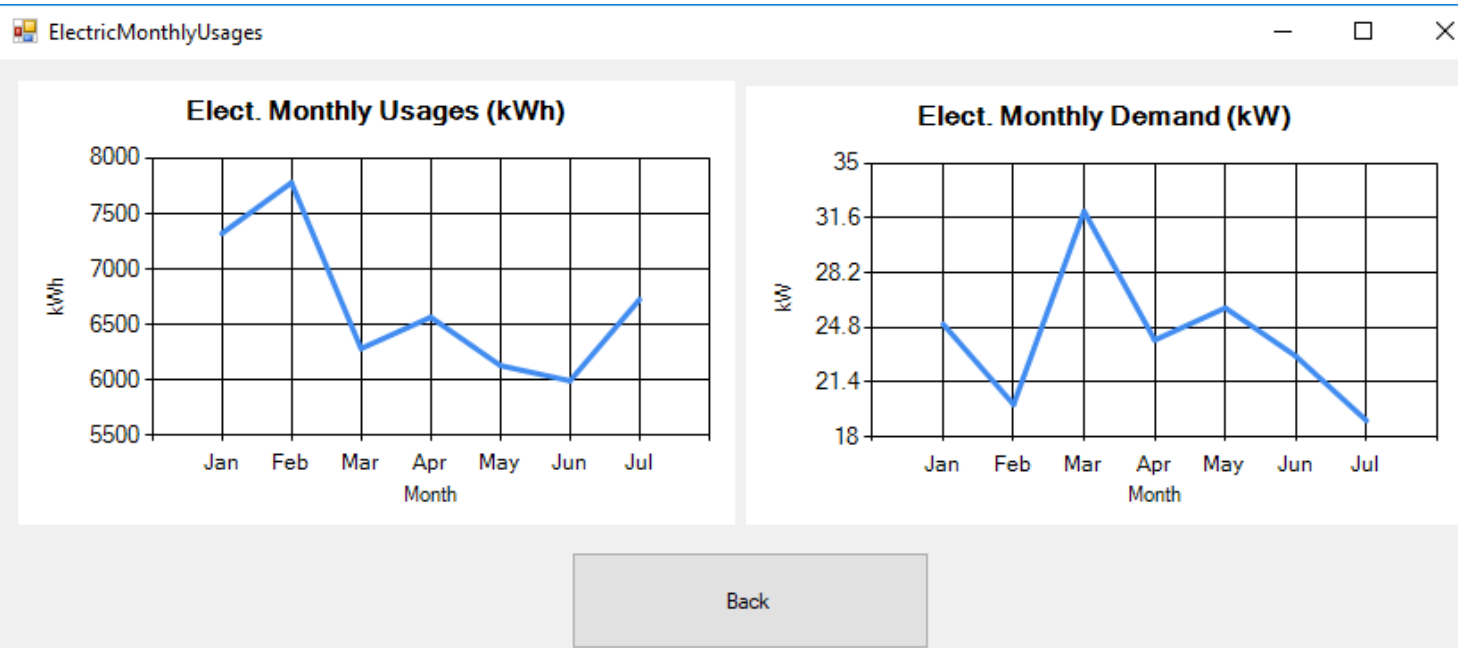

Figure 4.6: Electric Monthly Usages and Demand from Dashboard 1

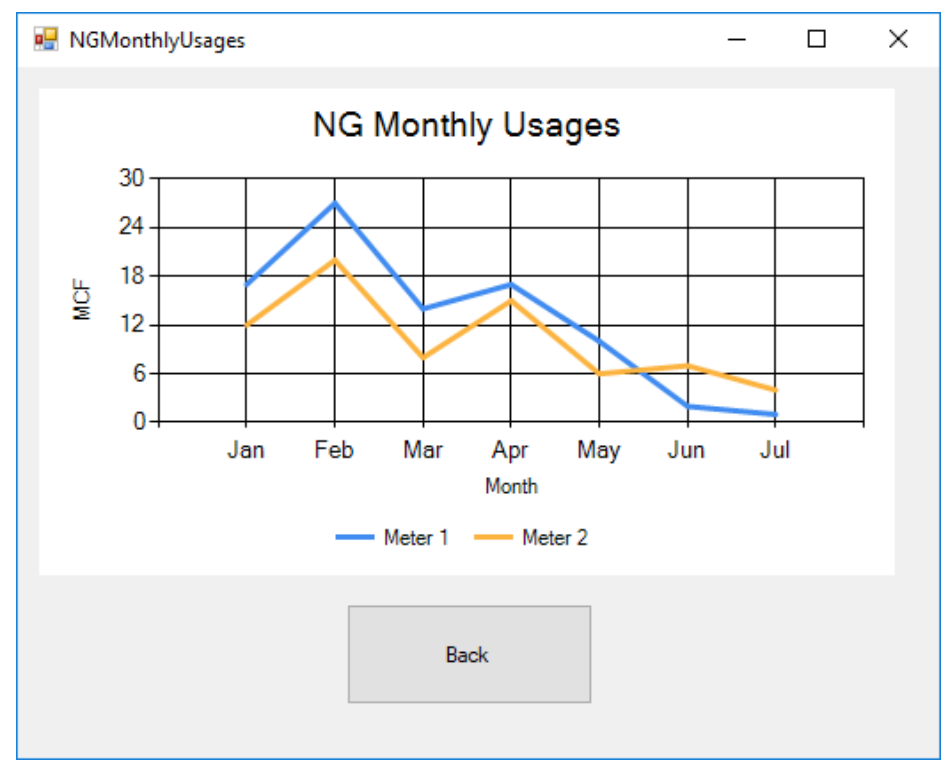

Figure 4.7: Natural Gas Monthly Usages from Dashboard 1 


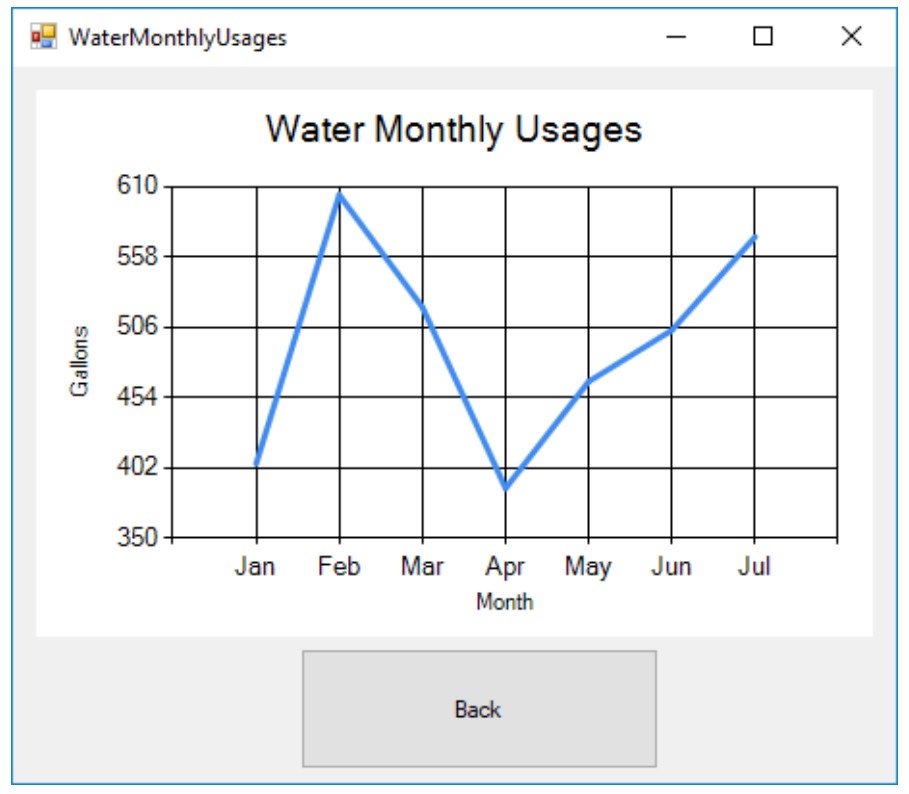

Figure 4.8: Water Monthly Usages from Dashboard 1

\subsubsection{Dashboard Testing Procedure}

The Dashboard Testing Procedure overview can be seen in the flow diagram in Figure 4.9. Regarding Figure 4.9, the three phases in blue were repeated for each of the three dashboards, per participant. A total of 25 participants were recruited for the testing.

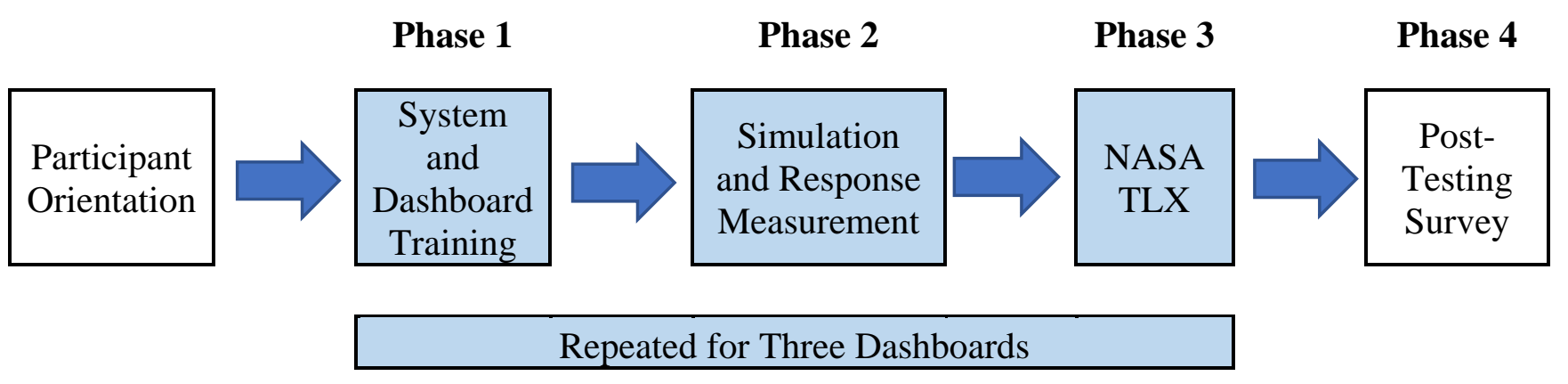

Figure 4.9: Dashboard Testing Procedure Flow Diagram 


\subsubsection{Participant Orientation}

First, a script was read to the participants (Adapted from (Brown, 2002; Flowers, n.d.)):

- To greet the participants

- To explain the overall purpose of the study

- To explain system functionality and different dashboards that were being evaluated

- To ensure that the participants understood that they would be voice recorded for analysis in the experiment

- To encourage the participants to think aloud so the researcher could understand their thought process

After reading the script, the participants were asked to read and sign a consent form approved by the WVU Institutional Review Board (IRB) as seen in Appendix A.

\subsubsection{Phase 1: System and Dashboard Training}

For the first phase of the experiment, the participants had five minutes per dashboard to view, interact, and simulate the data to mimic as if a business were operating in real-time. Each major energy source column was shown to the participant to help with identification. Using the knobs and switches, the participants viewed how the dashboard changed as they simulated the data, the KPIs involved with the dashboard, and the different visuals that each dashboard offered. The participants were guided by the instructor as to how to turn each knob and how this affected the visuals on the dashboards. The data shown on the dashboard was only representative of the adjustments that the users inputted to the signal generators and occupancy lighting switch. This initial dashboard only contained one piece of electrical equipment, one natural gas meter, and one water meter. Other data was purged for this initial dashboard to ensure that the user 
understood how the system worked and operated without being distracted from other visuals.

Dashboard 3 is seen as an example in Figure 4.10:

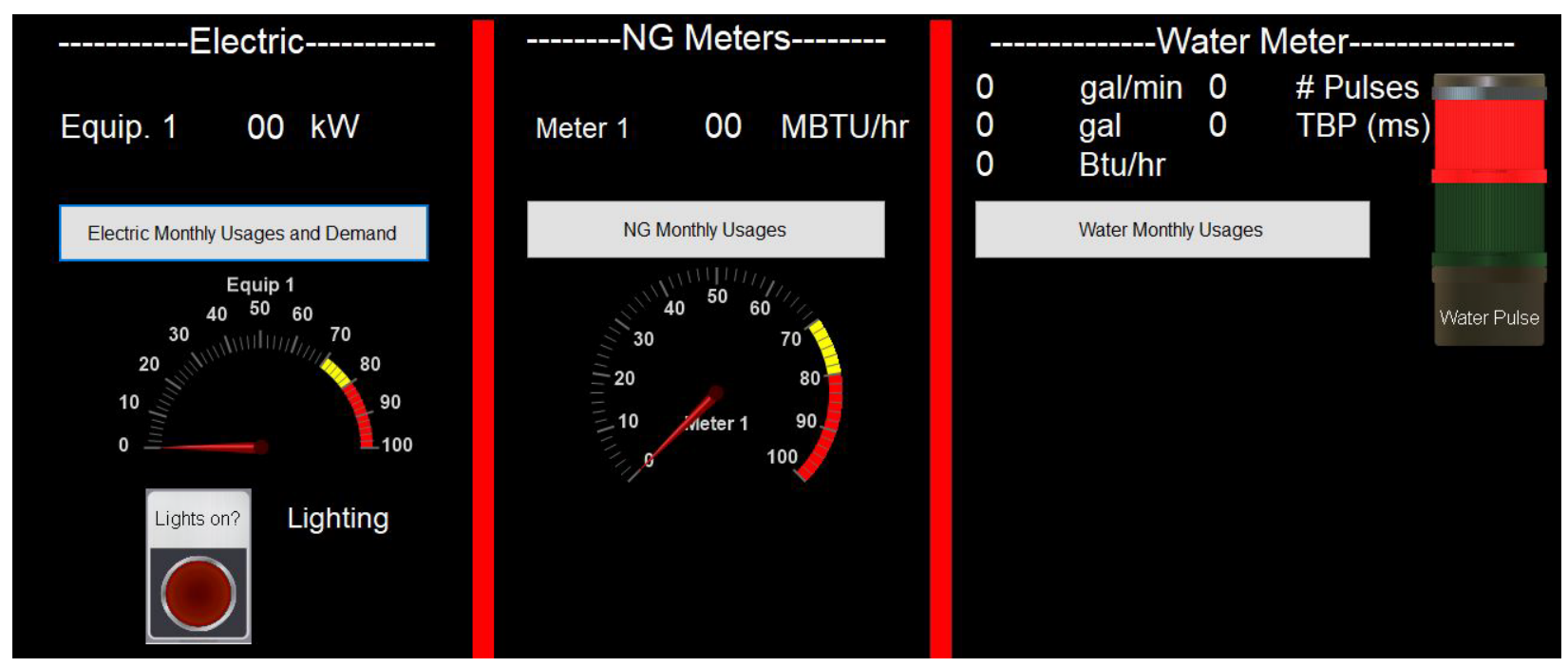

Figure 4.10: Phase 1 - Dashboard 3 Interaction for Participants

\subsubsection{Phase 2: Simulation and Response Measurement}

Next, analytical testing was completed on the dashboards. To measure the analytical capability of the dashboards, an "exploratory test” was conducted to examine the system during its early design phase (Flowers, n.d.; Jókai, 2009). Such type of testing is used when there are unidentified problem areas. Participants were placed in an office environment where energy data would typically be analyzed and reviewed.

During this phase, the dashboards displayed energy consumption of 2 pieces of electrical equipment, 2 natural gas meters, and 1 water meter using simulated data. A series of questions were asked, and their response were voice recorded via a recording device:

1. What percentage of the total energy usage is water?

2. Identify the total electrical usage (kWh) for the month of April. 
3. Are the lights currently on or off?

4. How much natural gas has been consumed to date?

5. What is the current energy content of water $(\mathrm{Btu} / \mathrm{hr})$ ?

6. Which month had the greatest electrical peak demand $(\mathrm{kW})$ ?

7. Which natural gas meter had more consumption in June?

8. Please continually read values of Meter 2 in \% Load until I say stop. Ready?

9. What is the current flow of water in gallons per minute (GPM)?

10. Is water currently running?

11. Identify which month has the largest peak in water usage.

12. What is the energy content of natural gas (MBTU/hr) of meter 1 currently?

13. What is the electric usage $(\mathrm{kW})$ of Equipment 2 currently?

14. Please continually read values of Equipment 1 in \% Load until I say stop. Ready?

The order in which the dashboards were presented, and the questions asked were randomized. The participants were asked to answer the questions as fast as they could, creating a time pressure. Participant responses were timed, and each response was marked as correct or incorrect. No interference or assistance was provided to the participant. If the participant was found having trouble determining an answer or reaches an impasse, then assistance was provided (Brown, 2002; Flowers, n.d.).

\subsubsection{Phase 3: NASA TLX}

Subjective testing followed the analytical testing. The NASA Task Load Index (TLX) was used to measure subjective mental workloads including six different dimensions: mental, 
physical, and temporal demand, performance, effort, and frustration levels as seen in Table 4.2

(Cao, Chintamani, Pandya, \& Ellis, 2009).

Table 4.2: NASA TLX Rating Scale and Description (Cao et al., 2009)

NASA-TLX Rating Scale Descriptions

\begin{tabular}{|c|c|c|}
\hline Title & Endpoints & Description \\
\hline Mental Demand & Low/High & $\begin{array}{l}\text { How much mental and perceptual activity was required (e.g., thinking, deciding, } \\
\text { calculating, remembering, looking, searching, etc.)? Was the task easy or demanding, } \\
\text { simple or complex, exacting or forgiving? }\end{array}$ \\
\hline Physical Demand & Low/High & $\begin{array}{l}\text { How much physical activity was required (e.g., pushing, pulling, turning, controlling, } \\
\text { activating, etc.)? Was the task easy or demanding, slow or brisk, slack or strenuous, } \\
\text { restful or laborious? }\end{array}$ \\
\hline Temporal Demand & Low/High & $\begin{array}{l}\text { How much time pressure did you feel due to the rate or pace at which the tasks or task } \\
\text { elements occurred? Was the pace slow and leisurely or rapid and frantic? }\end{array}$ \\
\hline Performance & Good/Poor & $\begin{array}{l}\text { How successful do you think you were in accomplishing the goals of the task set by } \\
\text { the experimenter (or yourself)? How satisfied were you with your performance in ac- } \\
\text { complishing these goals? }\end{array}$ \\
\hline Effort & Low/High & $\begin{array}{l}\text { How hard did you have to work (mentally and physically) to accomplish your level of } \\
\text { performance? }\end{array}$ \\
\hline Frustration Level & Low/High & $\begin{array}{l}\text { How insecure, discouraged, irritated, stressed, and annoyed or secure, gratified, con- } \\
\text { tent, relaxed, and complacent did you feel during the task? }\end{array}$ \\
\hline
\end{tabular}

A computer-based computer program of NASA TLX was used for the experiment as seen in Figure 4.11. This method of testing was used due to its high degree of validity across various tasks (Sugarindra, Suryoputro, \& Permana, 2017). 


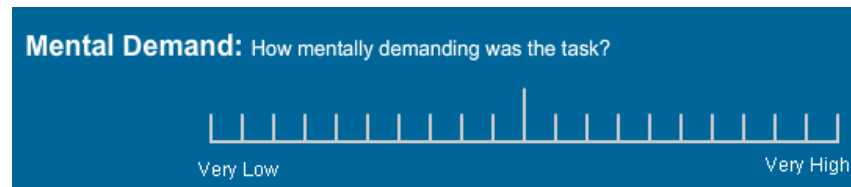

Physical Demand: How physically demanding was the task?

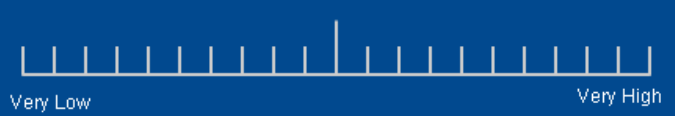

Temporal Demand: How hurried or rushed was the pace of the task?

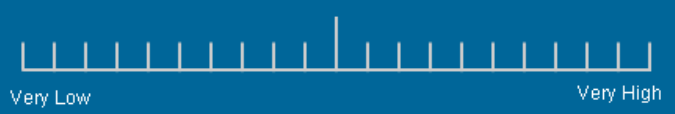

Performance: How successful were you in accomplishing what you were asked to do?

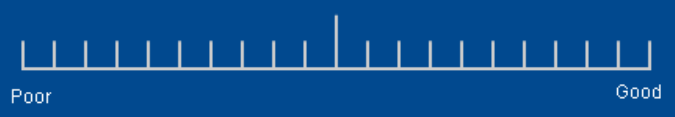

Effort: How hard did you have to work to accomplish your level of performance?
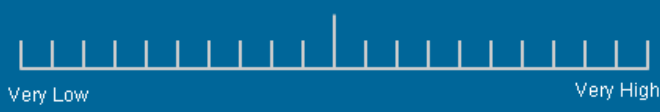

Frustration: How insecure, discouraged, irritated, stressed, and annoyed were you?

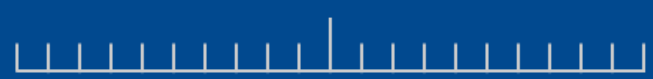

\section{INSTRUCTIONS:}

Please rate all six workload measures on the left by clicking a point on the scale that best represents your experience with the task you just completed.

Consider each scale individually and select your responses carefully. Mouse over the scale definitions for additional information.

Your ratings will play an important role in the evaluation being conducted. Your active participation is essential to the success of this experiment, and is greatly appreciated.

Click the Submit button when you have completed all six ratings.

Please note that the Performance scale goes from Poor on the left to Good on the right.

\section{Figure 4.11: NASA TLX Scales}

Each participant was asked to rate each dimension on a 0 to 100 scale (least to most

demanding). After the participants assigned a rating to each dimension, weights were determined based on a pairwise comparison between the different dimensions. Fifteen combinations of pairs were presented to the participant to choose based on the more prevalent workload as seen in Figure 4.12. A final weighted score using both the ratings and weights was calculated for an overall workload score. 


\section{Mental Demand}

How much mental and perceptual activity was

required (e.g. thinking, deciding, calculating,

remembering, looking, searching, etc.)? Was the

task easy or demanding, simple or complex,

exacting or forgiving?

\section{Physical Demand}

How much physical activity was required (e.g.

pushing, pulling, turning, controlling, activating.

etc.)? Was the task easy or demanding, slow or

brisk, slack or strenuous, restful or laborious?

Temporal Demand

How much time pressure did you feel due to the

rate or pace at which the tasks or task elements

occurred? Was the pace slow and leisurely or

rapid and frantic?

Effort

How hard did you have to work (mentally and

physically) to accomplish your level of

performance?

Of the two workload measures below, which one contributed the most to the task you just completed?

\section{Frustration}

or

\section{Mental Demand}

Performance

How successful do you think you were in

accomplishing the goals of the task set by the

experimenter (or yourself)? How satisfied were

you with your performance in accomplishing

these goals?

Frustration Level

How insecure, discouraged, irritated, stressed

and annoyed versus secure, gratified, content,

relaxed and complacent did you feel during the

task?

Figure 4.12: NASA TLX Pairwise Comparisons

\subsubsection{Phase 4: Post-Testing Survey}

Finally, a survey of questions was given to the participants to evaluate the dashboard

visuals, potential for different dashboards to be used in a light commercial business, and other

pertinent questions. These are listed below:

1. Which dashboard visuals (graph, gauges, etc.) provided the best information, in your opinion?

2. How realistic is the dashboard to be used in a light commercial business?

3. What is your preference between the Engaging Visuals (gauges, lights, alternating light water meter, etc.) versus the Analytical visuals (bar charts, line graphs, etc.) Pick one example or a combination of both.

4. What did you enjoy about the energy visualization experience? 
5. What would you add/change to the dashboard designs?

6. Rank each dashboard. On a $0-100 \%$ scale, how analytical or engaging is the dashboard? (e.g. $60 \%$ analytical, $40 \%$ engaging). On a $0-10$ scale, rank each dashboard by how interesting and trustworthy each were ( 0 is least, 10 is most)

a. Dashboard 1

i. Analytical

ii. Engaging

iii. Interesting

iv. Trustworthy

b. Dashboard 2

i. Analytical

ii. Engaging

iii. Interesting

iv. Trustworthy

c. Dashboard 3

i. Analytical

ii. Engaging

iii. Interesting

iv. Trustworthy

\subsection{Energy Dashboard Installation Guide}

A program was developed to guide light commercial business owners through a step-bystep process to assist in the purchasing and installation of energy monitoring equipment - given their operations and energy usage. The initial program screen can be seen in Figure 4.13. The program is available for download at:

https://drive.google.com/file/d/1dFURrpuNvDxOpFG3hGMtSWtZPbPtAc44 


\section{Energy Dashboard Installation Guide}

1

Begin - Energy Data
2

General Questions
3

Figure 4.13: Energy Dashboard Installation Guide Program

First, the user is asked multiple questions regarding their current equipment usage. These include questions regarding major electrical equipment, natural gas meters, and water meters. Per the hardware installation options were explained in section 4.1.1 Hardware Research, this program ensures that the right installation choice will be made for the specific business. Furthermore, the program asks general questions to determine the capabilities of the proposed I/O module, an additional HMI or monitor, and if a dedicated brick PC is necessary.

Based on the user's inputs, this computer-based program delivers a detailed list of energy monitoring equipment and their costing. A custom detailed wiring diagram for installation of the equipment is also constructed. This wiring diagram allows for a general overview of how the current equipment and proposed equipment will be installed for use in the energy dashboard.

Once a business owner has received the proposed equipment list and wiring diagram, they are able to easily develop their own low-cost energy dashboard to be used in their business. With the assistance of free energy dashboard software, such as AdvancedHMI, the business will 
be able to monitor and visualize their energy data for their light commercial business

(“AdvancedHMI,” 2018).

\subsection{Data Analysis}

Data analysis was performed using descriptive statistics and General Linear Analysis of Variance (ANVOA). Nine different data sets were evaluated in this study.

\subsubsection{Data Sets - Variables}

\subsubsection{Design Factors}

The effect of Dashboard design options on the Analytical, Engaging, Interesting, and Trustworthy ratings was tested using one-way ANOVA. The independent variables, Dashboards, was treated at 3 fixed levels. The dependent variables were the Analytical, Engaging, Interesting, and Trustworthy ratings. The analytical vs engaging ratings and interesting and trustworthy ratings were also evaluated using descriptive and qualitative data analysis techniques.

\subsubsection{NASA TLX}

The effect of Dashboard design options on the NASA TLX scores and weights was tested using one-way ANOVA. The independent variable, Dashboards, was treated at 3 fixed levels. The dependent variables were the NASA TLX Overall Scores, Temporal Demand Weights, and Performance Weights. The participants were treated as the random variable.

\subsubsection{Button-Click Time}

The time data was split into two groups: Button-Click Times and On-Screen Times. Button-Click Times were recorded when a participant was asked a question related to the use of buttons on the dashboards. This group of questions required longer response times than the On- 
Screen Times. In the ANOVA analysis, three independent variables were considered:

Dashboards (treated at 3 levels), Questions (treated at 4 levels), and FirstDash (treated at 3 levels). The FirstDash variable was defined as if a dashboard was their first dashboard during testing (i.e. did the participant take longer answering questions on their first dashboard than the last dashboard).

\subsubsection{On-Screen Time}

On-Screen Times were recorded when a participant was asked a question regarding using the main screen of the dashboards (no button clicks). This group of questions had quicker response times than the Button-Click Times. In the ANOVA analysis, three independent variables were considered: Dashboard (treated at 3 levels), Questions (treated at 8 levels), and FirstDash (treated at 3 levels).

\subsubsection{ANOVA Testing}

Prior to applying ANOVA, the data set was tested for the assumptions of normality and equality of variances. Appropriate data transformations were applied to meet these assumptions. For the dependent variables that showed significant statistical effect of the independent variables, a post-hoc analysis was completed through using a Student t's pairwise comparison and 95\% confidence interval plots. The statistical analysis was performed using JMP and Minitab (JMP, 2018; Minitab, 2018). 


\section{Chapter 5: Results}

\section{$\underline{5.1}$ Participant Demographics}

Twenty-five participants participated in the dashboard testing experiment. The demographics of the participants can be seen in Table 5.1 including number of males and females, mean and standard deviation of age, and if the participants' academic background.

Table 5.1: Participant Demographics

\begin{tabular}{|c|c|c|c|c|}
\hline \multirow{2}{*}{ Gender } & \multirow{2}{*}{ Count } & \multirow{2}{*}{ Age - Mean (SD) } & \multicolumn{2}{|c|}{ Background } \\
\cline { 4 - 5 } & & $24(1.57)$ & 13 & 5 \\
\hline Male & 18 & $25(7.53)$ & 4 & 3 \\
\hline Female & 7 & - & $\mathbf{1 7}$ & $\mathbf{8}$ \\
\hline Total & $\mathbf{2 5}$ & & Engr. & Not Engr. \\
\hline
\end{tabular}

\subsection{Dashboard Testing Results}

The raw experimental data including time, correctness, and NASA TLX scores are included in Appendix B.

\subsubsection{Design Factor Ratings}

\subsubsection{Descriptive Statistics}

Regarding the analytical and engaging ratings from each experiment, the distributions are seen in Figure 5.1. Dashboard 1 was rated as the most analytical at 83\% while Dashboard 3 was rated the most engaging at $73 \%$. 


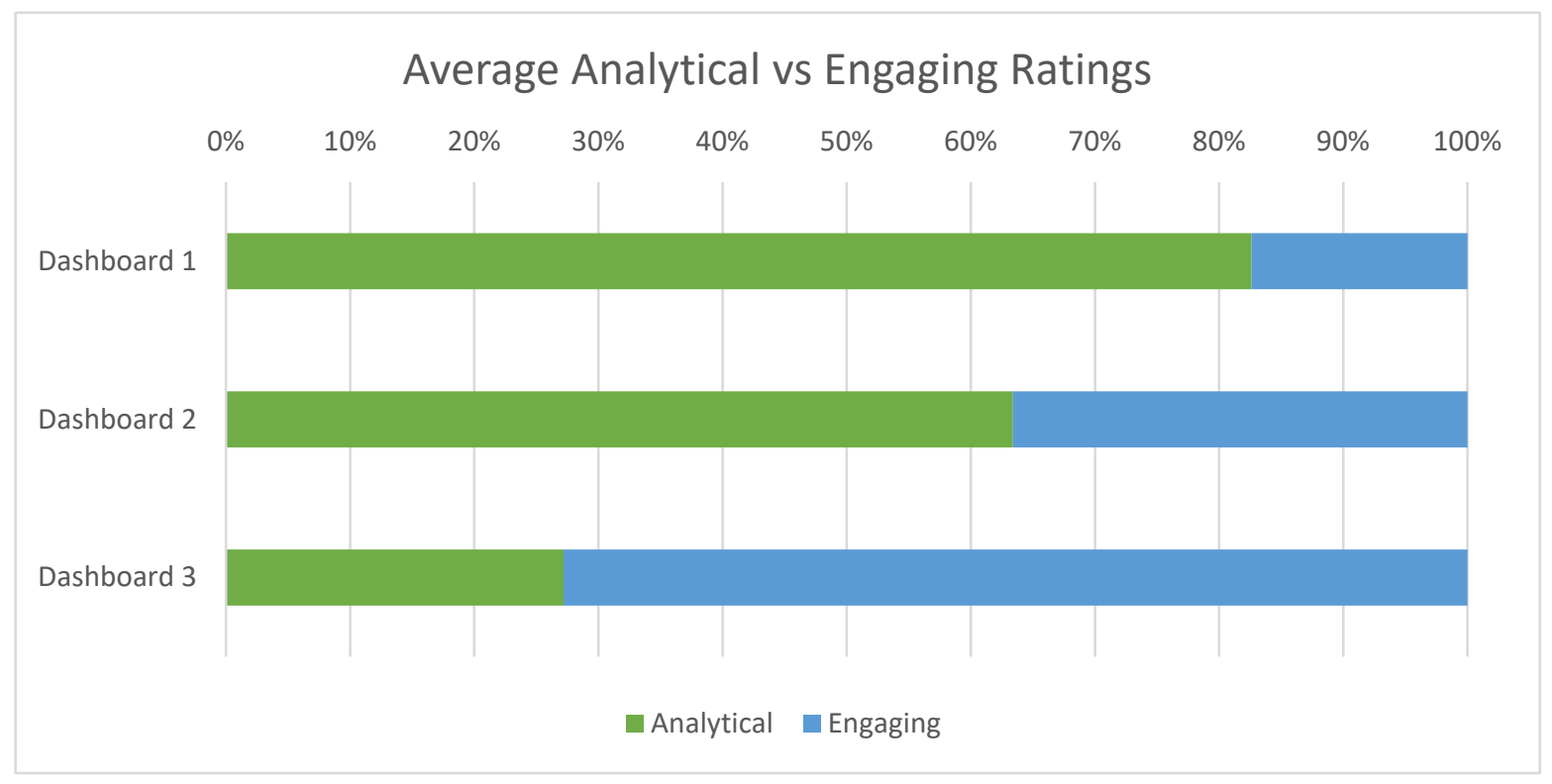

Figure 5.1: Average Analytical vs. Engaging Ratings for Each Dashboard

The participants rated the dashboards on a scale from 0 - 10 (with 10 being the highest) regarding interesting and trustworthy. Dashboard 3 was rated the highest for interesting rating of 8.4 and trustworthy rating of 8.1. Dashboard 1 was rated the lowest for interesting rating of 5.4 and trustworthy rating of 6.6. The interesting rating for Dashboard 3 was $55.6 \%$ higher than Dashboard 1. The trustworthy rating for Dashboard 3 was $21.7 \%$ higher than Dashboard 1 . The average interesting and trustworthy ratings are shown in Figure 5.2. 


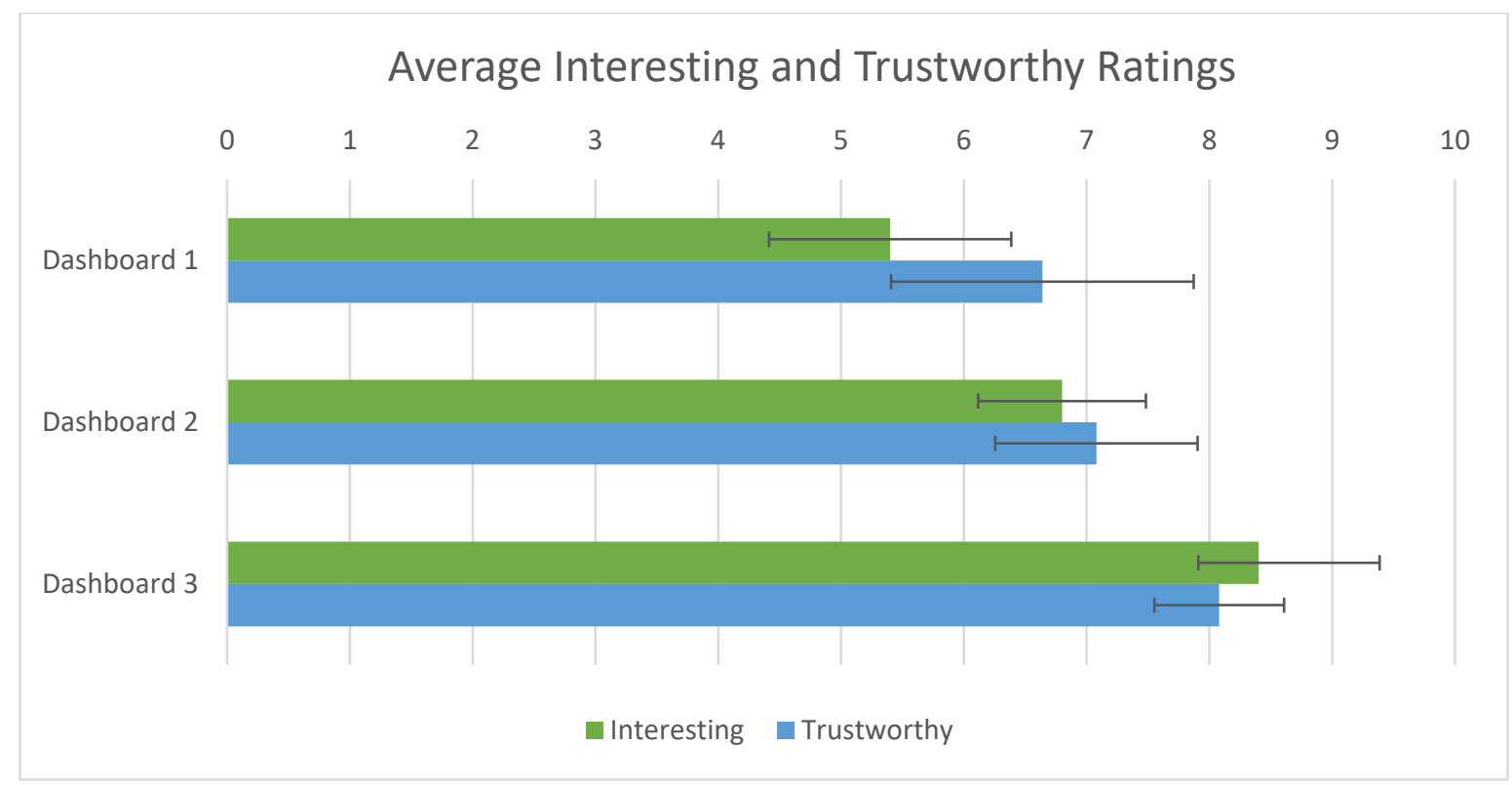

Figure 5.2: Average Interesting and Trustworthy Ratings. Error bars represent $95 \%$ confidence interval.

\subsubsection{ANOVA Statistics}

Statistical ANOVA testing was completed for the design factors including Analytical, Engaging, Interesting, and Trustworthy. The independent variable, "Dashboards” was tested at 3 levels to determine if they had a significant effect on each of the dependent variables as seen in Table 5.2.

Table 5.2: Mean (SD) of Design Factor Ratings for Dashboards

\begin{tabular}{|l|c|c|c|c|}
\hline & Dashboard 1 & Dashboard 2 & Dashboard 3 & P-Value \\
\hline Analytical & $82.6(20.42)$ & $63.4(11.25)$ & $27.2(17.02)$ & 0.0001 \\
\hline Engaging & $17.4(20.42)$ & $36.6(11.25)$ & $72.8(17.02)$ & 0.0001 \\
\hline Interesting & $5.4(2.47)$ & $6.8(1.71)$ & $8.4(1.22)$ & 0.0001 \\
\hline Trustworthy & $6.64(3.08)$ & $7.08(2.06)$ & $8.1(1.32)$ & 0.1553 \\
\hline
\end{tabular}

One-way ANOVAs were completed for each of the dependent variables vs. Dashboards. The Analytical ratings followed a normal distribution (Appendix C-1). In addition, normality of residuals and equality of variances tests were completed and confirmed (Appendix C-2). The 
independent variable, "Dashboards” was significant with a p-value <0.001 (Appendix C-3). Using Student t's pairwise comparisons, each dashboard was significantly different from one another (Appendix C-4). Furthermore, the interval plot in Figure 5.3 shows that the means are significantly different for each dashboard regarding Analytical ratings. From Dashboard 1 to Dashboard 3, the analytical ratings decline.

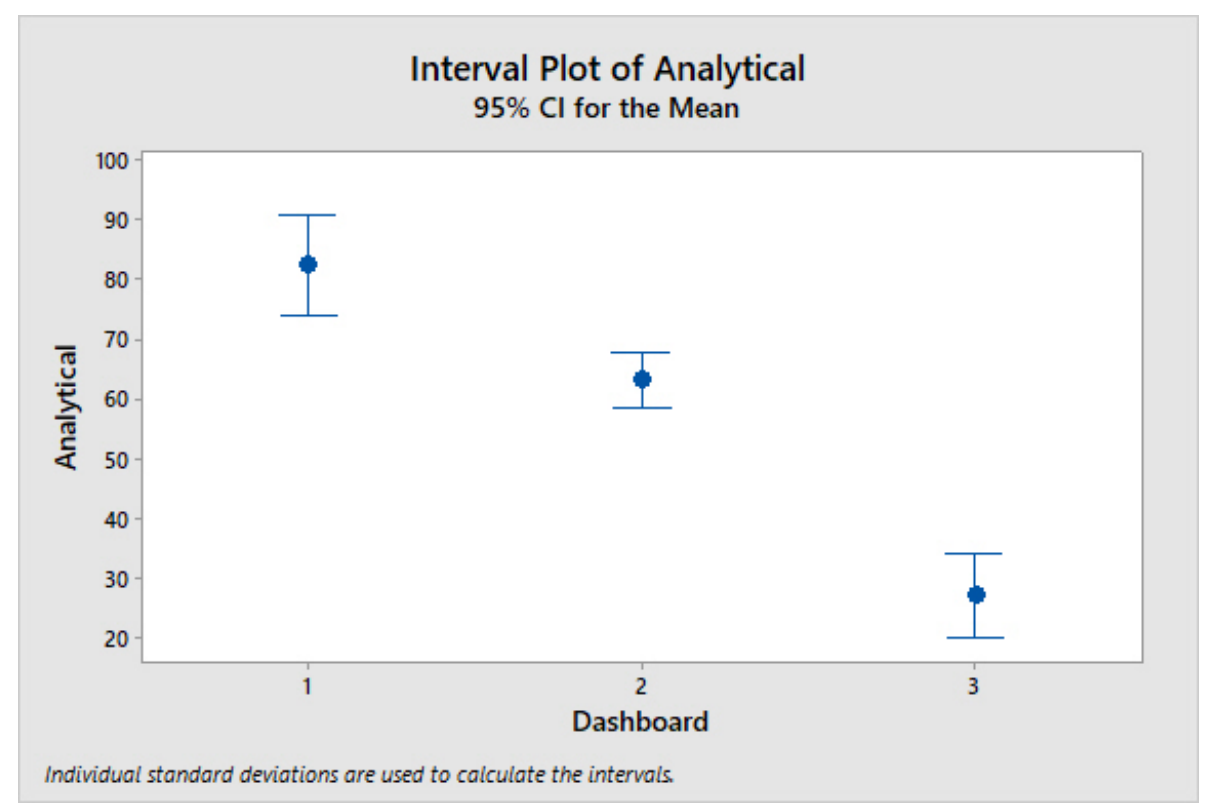

Figure 5.3: Interval Plot of Analytical Ratings vs. Dashboards

The Engaging ratings followed a normal distribution (Appendix C-5). In addition, normality of residuals and equality of variances tests were completed and confirmed (Appendix C-6). The independent variable, “Dashboards” was significant with a p-value $<0.001$ (Appendix C-7). Using Student t's pairwise comparisons, each dashboard was significantly different from one another (Appendix C-8). Furthermore, the interval plot in Figure 5.4 shows that the means are significantly different for each dashboard regarding Engaging ratings. From Dashboard 1 to Dashboard 3, the engaging ratings increase. 


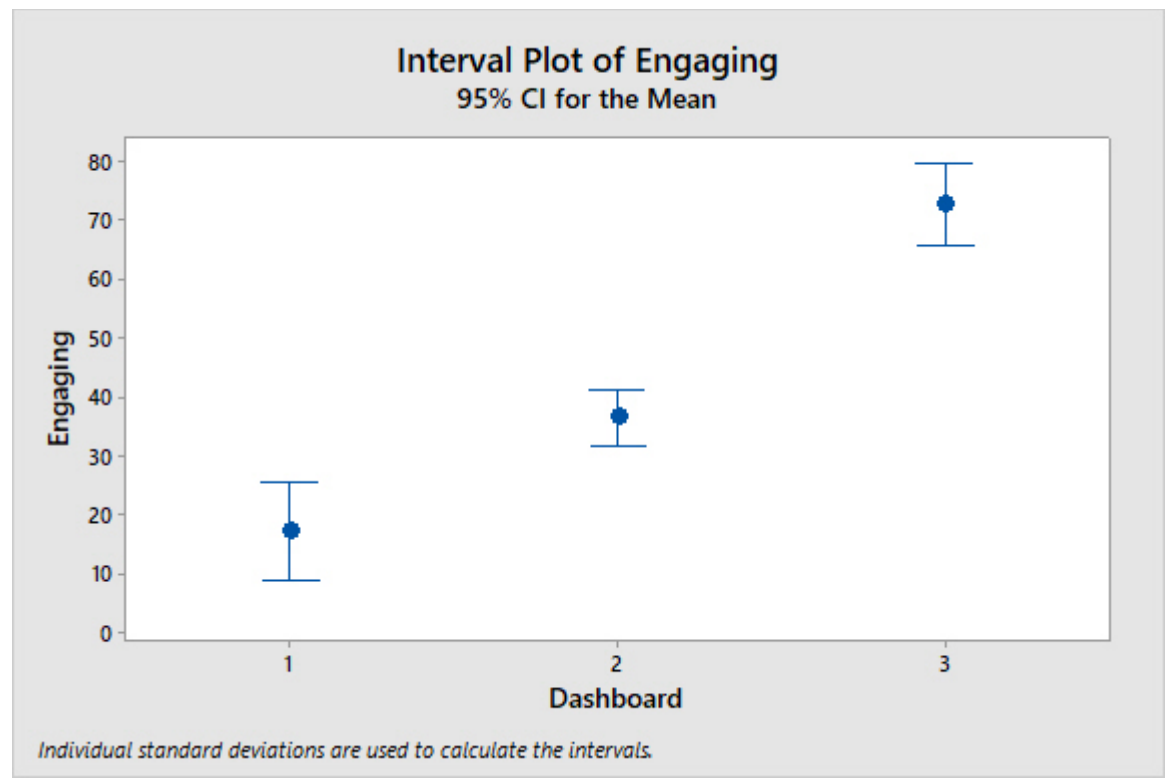

Figure 5.4: Interval Plot of Engaging Ratings vs. Dashboards

The Interesting rating data was used to determine as to which distribution fit best, but none of the distributions was good fit (Appendix C-9). In order to combat this, the Box-Cox method was used. It was determined that the best $\lambda=1.561$ and the data was transformed using the following formula: $y=$ Interesting $^{(1.561)}$ (Appendix C-9). Once transformed, the check for the normality of the residuals and the equality of variances was completed and confirmed (Appendix C-10). The effect of independent variable, "Dashboards” on the transformed Interesting ratings was found to be significant (p-value of $<0.001$ ) (Appendix C-11). Using Student t's pairwise comparisons, it was determined that each dashboard is significantly different from one another (Appendix C-12). Furthermore, the interval plot in Figure 5.5 shows that the means are significantly different for each dashboard regarding Interesting ratings. From Dashboard 1 to Dashboard 3, the interesting ratings increase. 


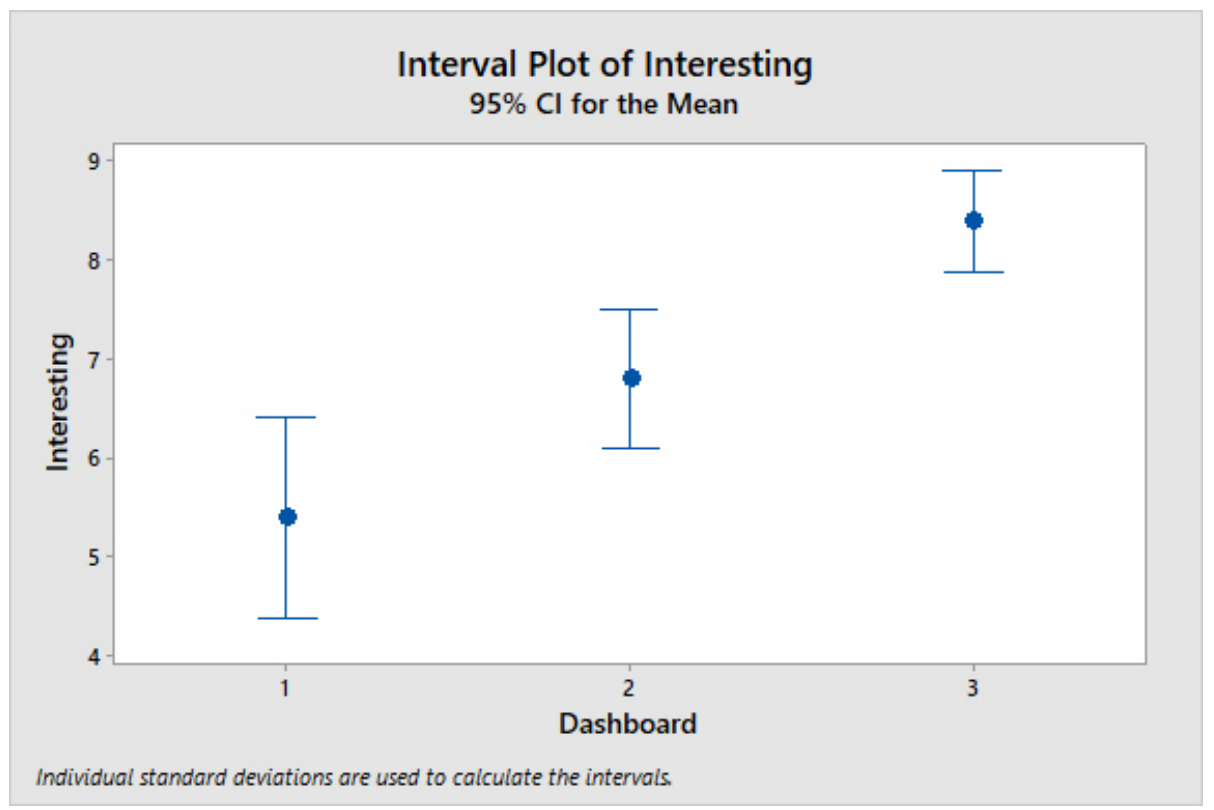

Figure 5.5: Interval Plot of Interesting Ratings vs. Dashboards

The Trustworthy rating data was used to determine as to which distribution fit best, but none of the distributions was good fit (Appendix C-13). In order to combat this, the Box-Cox method was used. It was determined that the best $\lambda=1.759$ and the data was transformed using the following formula: $y=$ Trustworthy ${ }^{(1.759)}$ (Appendix C-13). Once transformed, the check for the normality of the residuals and the equality of variances was completed and confirmed (Appendix C-14). The effect of independent variable, "Dashboards” on the transformed Trustworthy ratings was found to be insignificant (p-value of 0.1553) (Appendix C-15). Furthermore, the interval plot in Figure 5.6 shows that the means are not significantly different for each dashboard regarding Interesting ratings. From Dashboard 1 to Dashboard 3, the trustworthy ratings generally increase, but with major overlap in the $95 \%$ confidence intervals. 


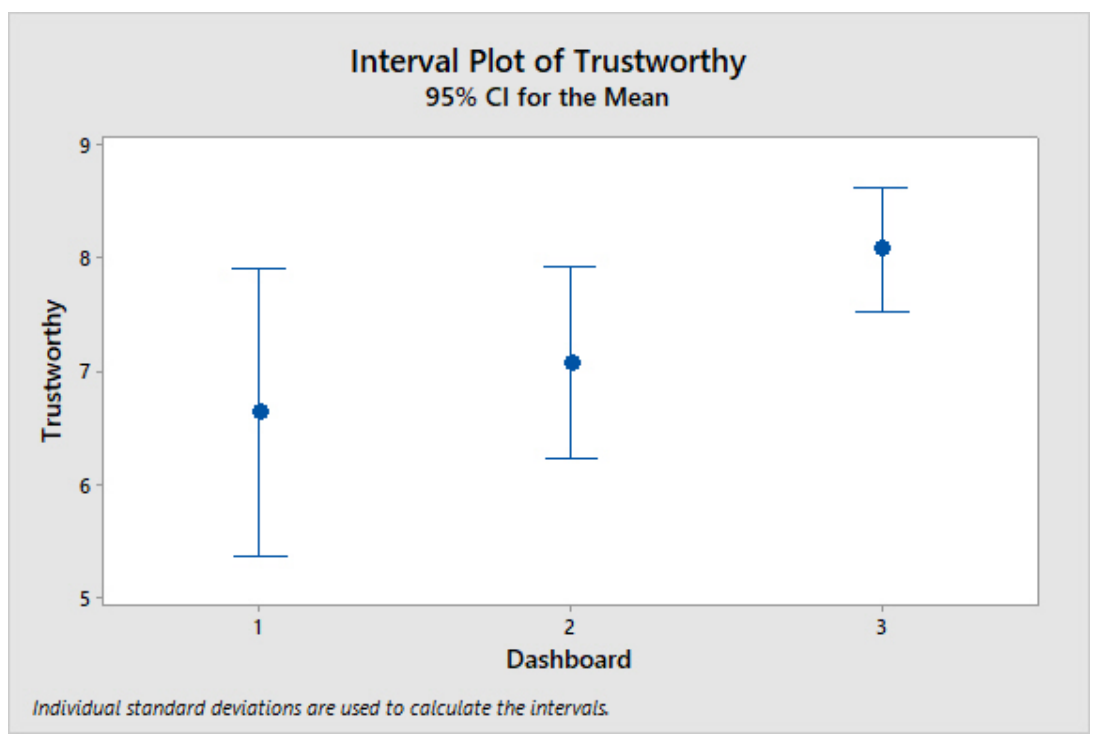

Figure 5.6: Interval Plot of Trustworthy Ratings vs. Dashboards

\subsubsection{NASA TLX Results}

The independent variable, "Dashboards," was tested at 3 levels to determine if it had a significant effect on the dependent variables listed in Table 5.3.

Table 5.3: Mean (SD) of NASA TLX Values for Dashboards

\begin{tabular}{|l|c|c|c|c|}
\hline & Dashboard 1 & Dashboard 2 & Dashboard 3 & P-Value \\
\hline NASA TLX Overall Scores & $39.07(18.19)$ & $32.99(17.01)$ & $27.86(17.63)$ & 0.0665 \\
\hline Temporal Demand Weights & $12.44(8.37)$ & $10.26(7.51)$ & $9.67(8.83)$ & 0.2988 \\
\hline Performance Weights & $4.62(3.72)$ & $4.59(3.27)$ & $3.82(2.42)$ & 0.7691 \\
\hline
\end{tabular}

\subsubsection{NASA TLX Overall Scores}

Figure 5.7 represents the average overall NASA TLX mental workload scores.

Dashboard 3 had the lowest average score of 26.7 while Dashboard 1 had the highest score of 39.1. Dashboard 1's overall NASA TLX score is 46.1\% higher than Dashboard 3's score. 


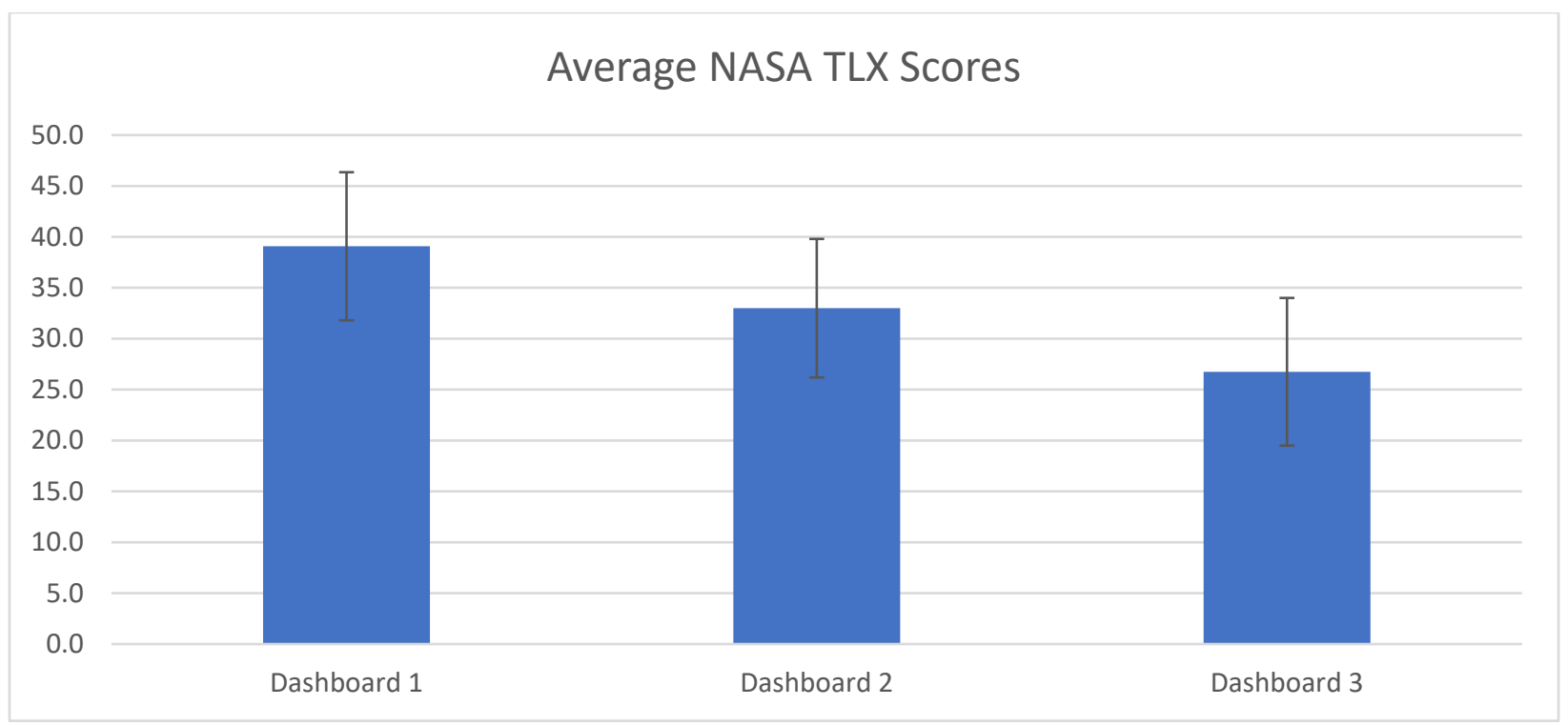

Figure 5.7: Average NASA TLX Scores for Each Dashboard. Error bars represent 95\% confidence interval.

Statistical ANOVA testing was completed for the NASA TLX Overall Scores based on the independent variable “Dashboards.” First, the data was analyzed to determine which distribution closely fit the data. The SHASH (sinh-arcsinh) distribution, which is a form of transformation based on the normal distribution, demonstrated a good fit (Appendix D-1) and therefore, was used to transform the data (JMP, 2018; Jones \& Pewsey, 2009). Next, the normality of the residuals was checked. As the residuals followed a normal distribution and the values fit inside the Normal Quantile Plot, it was determined that the residuals do follow the normal distribution (Appendix D-2). The equality of variance was also checked to be true (Appendix D-2).

Then, an ANOVA was completed with the independent variable, "Dashboards”, along with the SHASH transformed y-values. With “Dashboards” receiving a p-value of 0.0665, it was found that the dashboards were not significant regarding the overall NASA TLX Scores. 


\subsubsection{NASA TLX Mental Workload Scores}

Based on the NASA TLX workload weights, Performance and Temporal Demand dimensions were found to be the most demanding dimensions independent of the dashboard used (Figure 5.8). Dashboard 1's Performance and Temporal Demand dimensions were both weighted at 12.4 while Dashboard 3’s Performance and Temporal Demand dimensions were both weighted at 9.3. Dashboard 1's average workload dimensional weights were $34 \%$ higher than that of Dashboard 3's weights. Dashboard 2's Temporal Demand and Performance dimensions were both weighted at 10.3 .

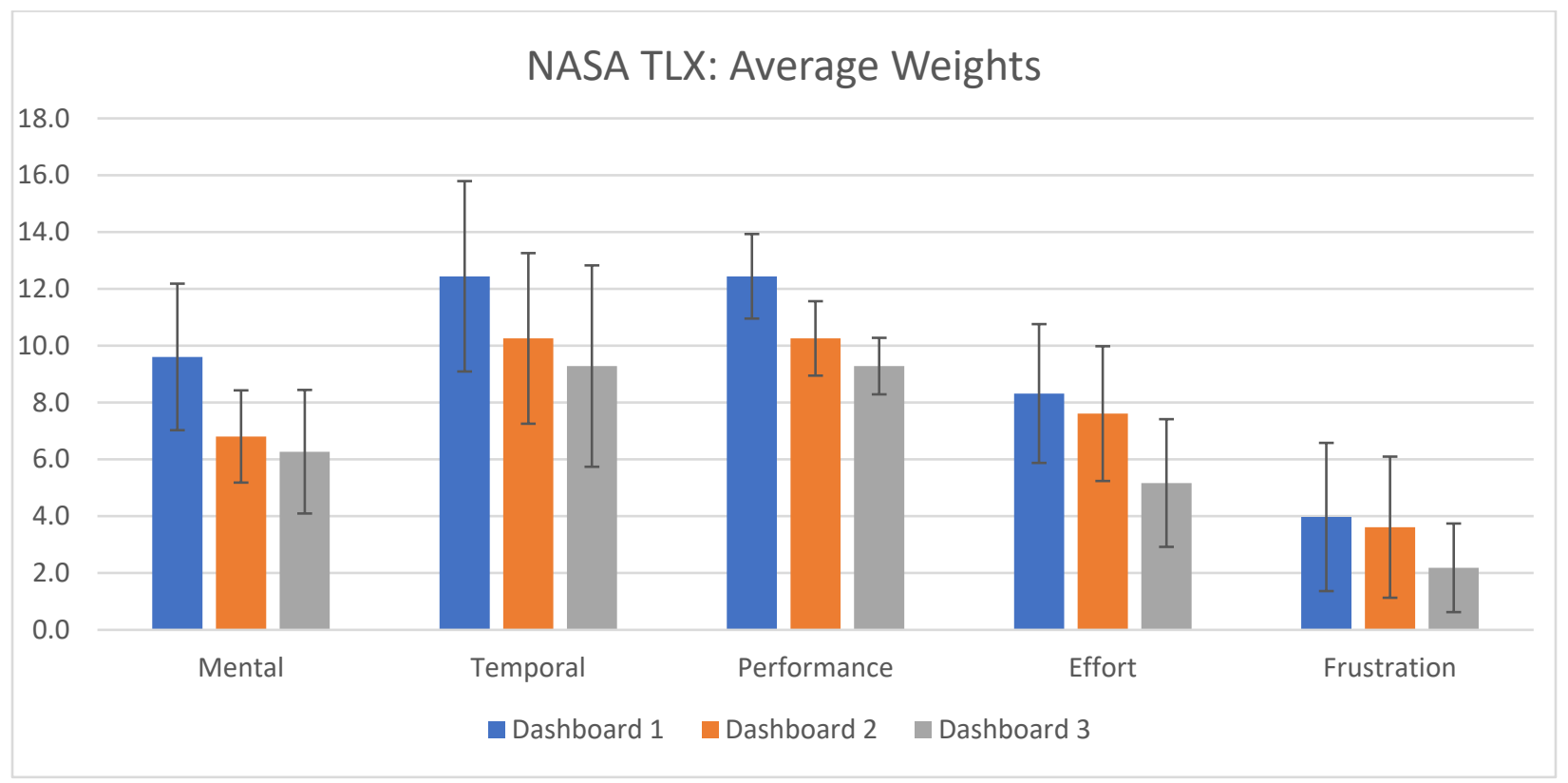

Figure 5.8: Average NASA TLX Weights. Error bars represent $95 \%$ confidence interval.

Since Temporal Demand and Performance received the highest weights, these variables were further analyzed using ANOVA. The Temporal Demand data was transformed using the SHASH distributions similar to the overall NASA TLX Scores (Appendix D-4). After transforming the data, the normality of the residuals and the equality of variances test were performed, and the assumptions were found to be true (Appendix D-5). The effect of the 
independent variable, "Dashboards" on the transformed Temporal Demand weight y-values was found to be insignificant (p-value of 0.2988) (Appendix D-6).

Similar analysis was performed for the Performance weights. Unfortunately, none of the distributions fit as well for the Performance y-values (Appendix D-7). In order to combat this, the Box-Cox method was used. It was determined that the best $\lambda=0.471$ and the data was transformed using the following formula: $y=$ Performance ${ }^{(0.471)}$ (Appendix D-7).

Once transformed, the check for the normality of the residuals and the equality of variances was completed and confirmed (Appendix D-8). The effect of independent variable, "Dashboards" on the transformed Performance weight y-values was found to be insignificant (pvalue of 0.7691) (Appendix D-9).

\subsubsection{Correctness Results}

Correct and incorrect answers were marked for each question that was asked to the participants. Most participants answered all questions correctly with some exceptions. There were no major identifiers for questions that were repeatedly given the wrong answer - except one. Regarding correctness, 8/25 people gave incorrect answers for Question 7 on Dashboard 2. This question asked, “Which natural gas meter had more consumption in February?” As seen in Figure 5.9 for the February column, Meter 1 was the correct answer, but some participants felt that due to the orange bars (Meter 2) being on top of the blue bars, Meter 2 had more consumption. Thus, they chose Meter 2, but this was incorrect. 


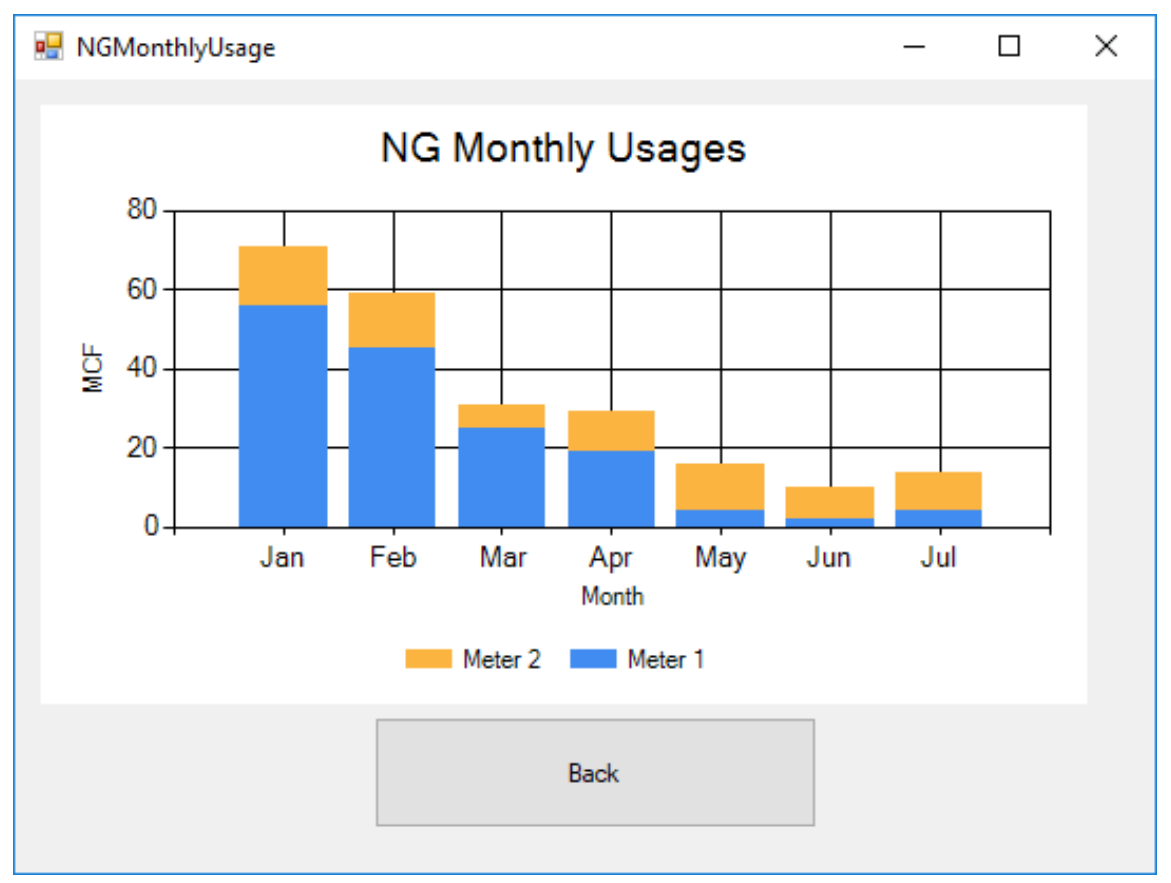

Figure 5.9: Natural Gas Monthly Usages - Dashboard 2

\subsubsection{Time Results}

The participants were timed from the time the question was finished being asked to the time that they gave an answer. All times were recorded as seen in Appendix B-1. The average time to answer all questions is seen in Figure 5.10.

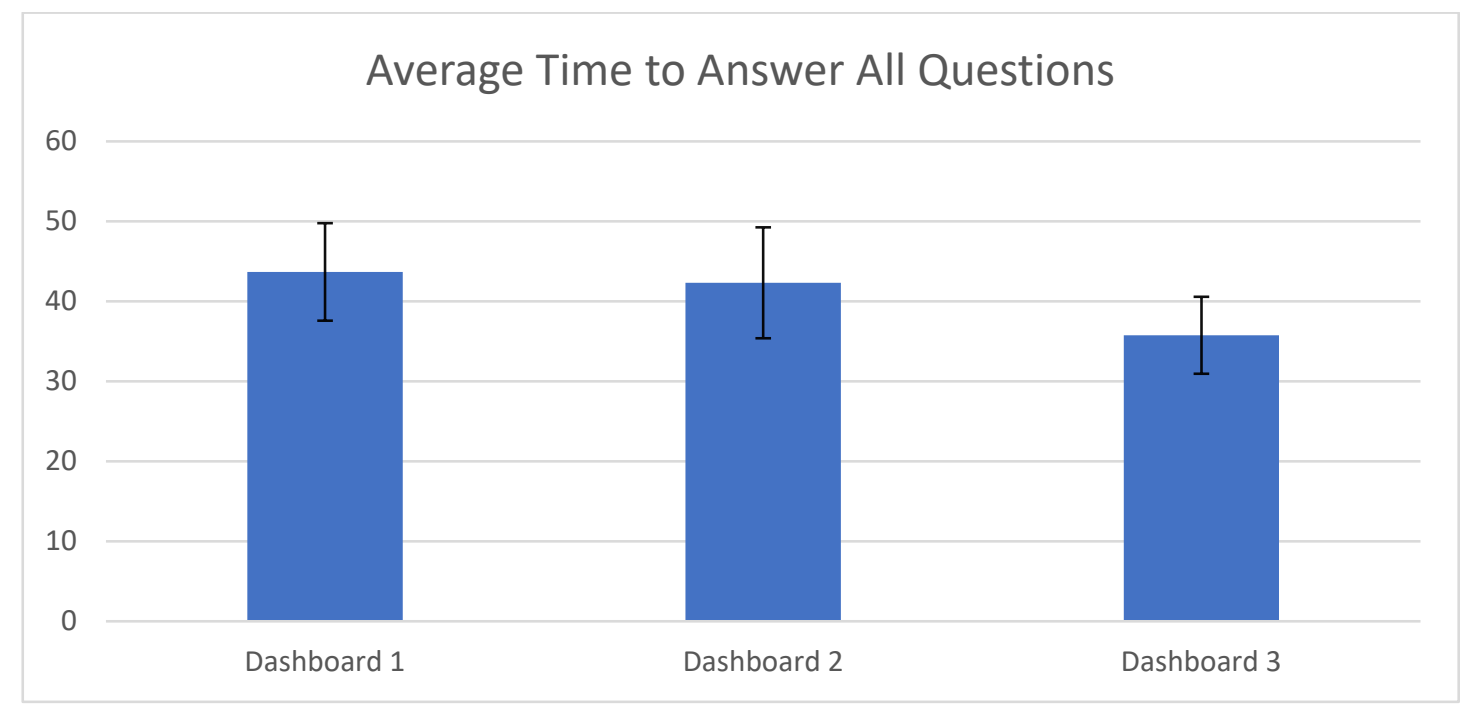

Figure 5.10: Average Time to Answer All Questions Per Dashboard. Error bars represent 95\% confidence interval. 


\subsubsection{Time Results for Button Clicking Questions}

The Button-Click Time data was used to determine which distribution fit to the data best. However, even the "best" distribution did not fit the data well (Appendix E-1). The Box-Cox method had to be utilized again for the best transformation to the normal distribution. The BoxCox method gave a $\lambda$ value of -0.133 (Appendix E-1). Further analysis allowed for the Time response variable for transformation to the following: $y=1 / \operatorname{Time}^{(-0.133)}$ (Appendix E-1) (Montgomery, 2013). After transforming the data, normality of the residuals and equality of variances tests were completed and confirmed (Appendix E-2).

The variables Question, FirstDash, and Dashboards*FirstDash (interaction) were significant with p-values of $<0.001$ (Appendix E-3). Regarding the main effect, the significance can be seen in Table 5.4 with Questions and FirstDash both being statistically significant.

Table 5.4: Button-Click Time and the Effects of Dashboards, Questions, and FirstDash

\begin{tabular}{|c|c|c|}
\hline $\begin{array}{l}\text { Source } \\
\end{array}$ & Mean (SD) & P-value \\
\hline Dashboard & & \multirow{4}{*}{0.0717} \\
\hline Dashboard 1 & $4.81(2.55)$ & \\
\hline Dashboard 2 & $4.97(2.83)$ & \\
\hline Dashboard 3 & $4.27(2.12)$ & \\
\hline \multicolumn{2}{|l|}{ Questions } & \multirow{5}{*}{0.0001} \\
\hline Q2 & $6.28(2.70)$ & \\
\hline Q6 & $4.21(2.29)$ & \\
\hline Q7 & $4.98(2.29)$ & \\
\hline Q11 & $3.27(1.76)$ & \\
\hline \multicolumn{2}{|l|}{ FirstDash } & \multirow{4}{*}{0.0001} \\
\hline 1 & $4.21(2.37)$ & \\
\hline 2 & $5.36(2.64)$ & \\
\hline 3 & $4.49(2.28)$ & \\
\hline
\end{tabular}

As the independent variables Questions, FirstDash, and Dashboards*FirstDash (interaction) were significant with p-values of $<0.001$, Student t's pairwise comparisons were 
completed. However, only the main effects were compared. From the analysis, all questions were significantly different from one another (Appendix E-4). FirstDash 1 and 2 and FirstDash 2 and 3 were significantly different from one another (Appendix E-4). Furthermore, interval plots were developed for the Questions variable (Figure 5.11) and Dashboards*FirstDash interaction (Figure 5.12) to assist in explaining the differences in means. For the Dashboards*FirstDash interaction, Figure 5.12 shows the means of each time, for each dashboard, and with which dashboard the participant began answering questions.

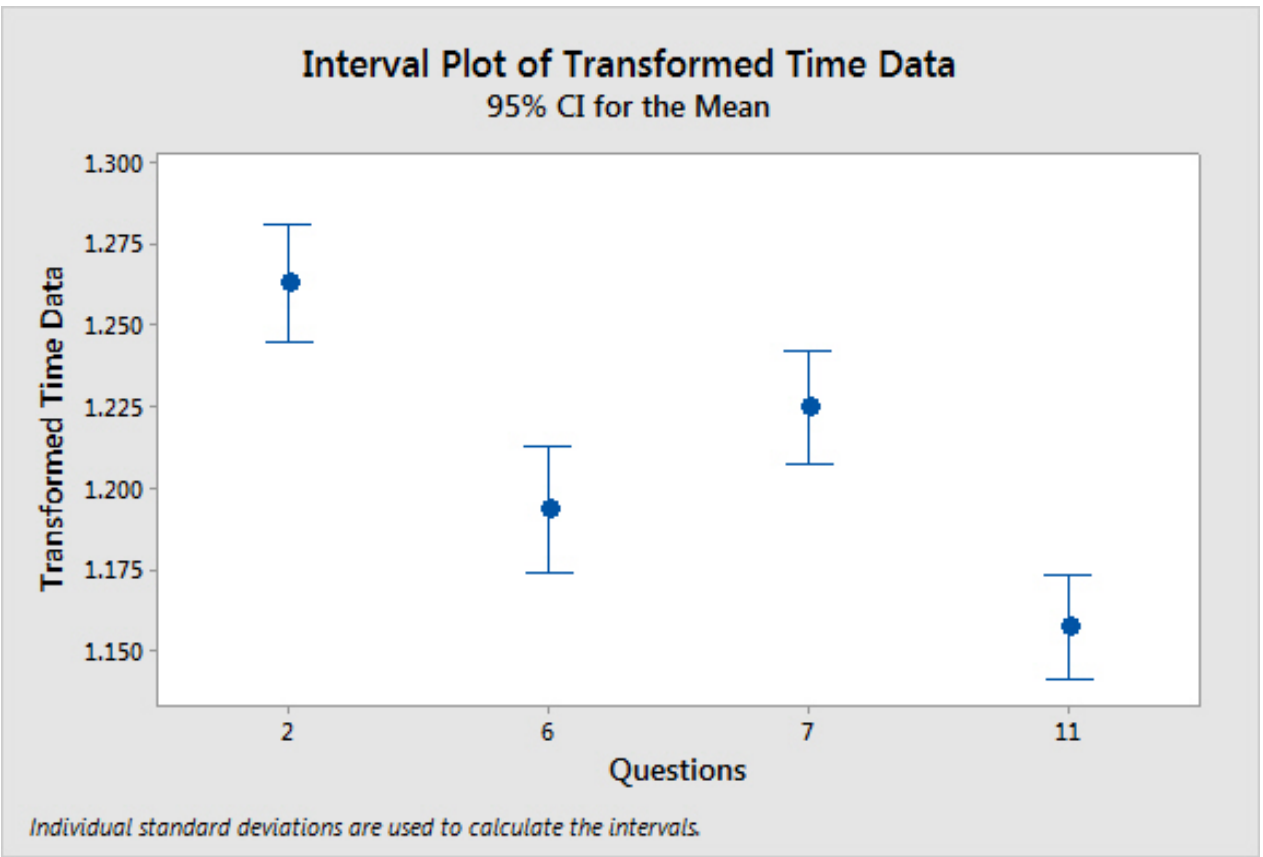

Figure 5.11: Interval Plot for Button-Click Time vs Questions 


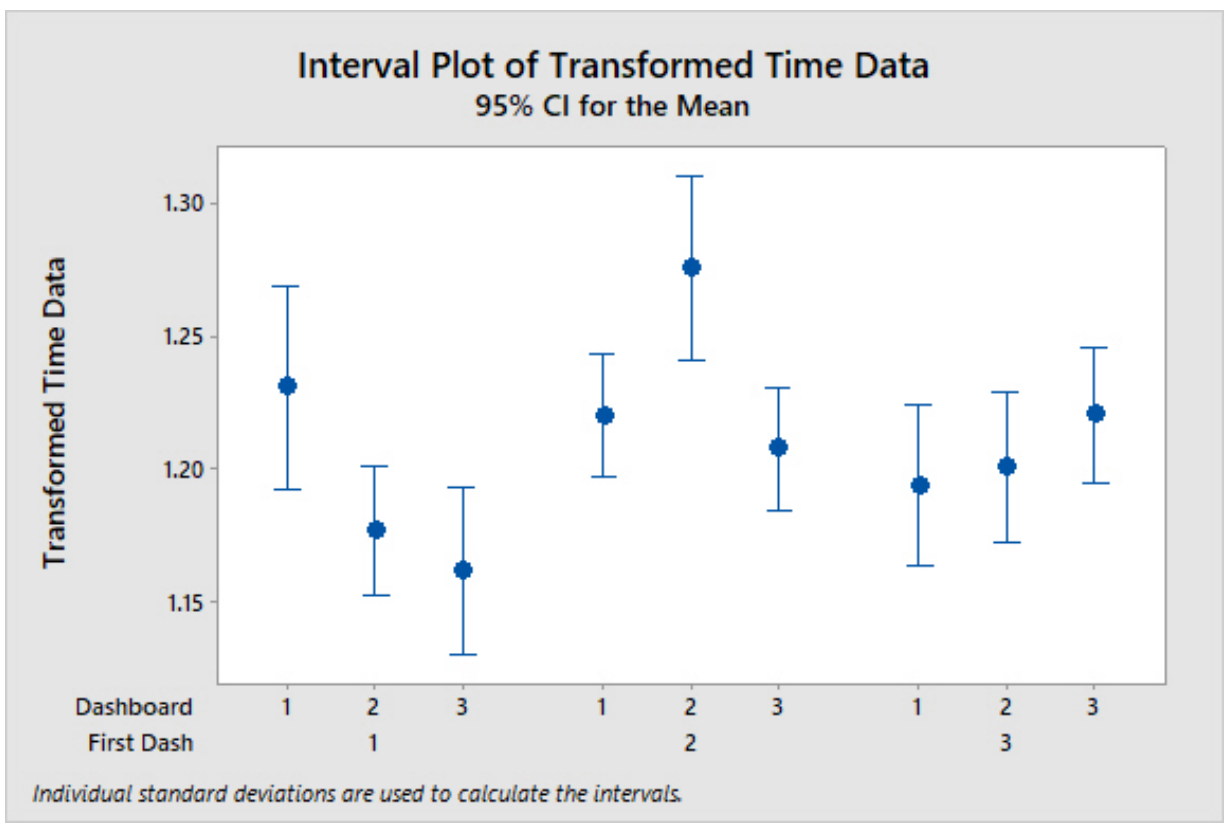

Figure 5.12: Interval Plot for Button-Click Time vs Dashboards*FirstDash

\subsubsection{Time Results for On-Screen Questions}

The On-Screen Time data was used to check for various distributions that could fit best. The Box-Cox method was finally used for the data transformation. The $\lambda$ value was determined as $\lambda=-0.836$. Further analysis allowed for the Time response variable for transformation to the following: $y=1 /$ Time $^{(-0.836)}$ (Appendix E-5). After the transformation, normality of residuals and equal variances tests were completed and confirmed (Appendix E-6).

The variables of Questions, Dashboards*Questions, Dashboards*FirstDash, and Dashboards*Questions*FirstDash were all significant with p-values of <0.001 (Appendix E-7). Furthermore, Dashboards and Questions were both significant with p-values of 0.0477 and 0.0459, respectively. Regarding the main effects, Dashboards, Questions, and FirstDash were all significant factors. However, the above interactions were all significant as well. 
Table 5.5: On-Screen Time and the Effects of Dashboards, Questions, and FirstDash

\begin{tabular}{|c|c|c|}
\hline Source & Mean (SD) & P-value \\
\hline Dashboard & & \multirow{4}{*}{0.0477} \\
\hline Dashboard 1 & $2.51(2.10)$ & \\
\hline Dashboard 2 & $2.38(2.82)$ & \\
\hline Dashboard 3 & $2.18(2.29)$ & \\
\hline \multicolumn{2}{|l|}{ Questions } & \multirow{9}{*}{0.0001} \\
\hline Q1 & $3.74(2.42)$ & \\
\hline Q3 & 1.65 (1.36) & \\
\hline Q4 & 4.97 (3.79) & \\
\hline Q5 & $2.29(2.53)$ & \\
\hline Q9 & $1.85(1.86)$ & \\
\hline Q10 & $1.48(0.83)$ & \\
\hline $\mathrm{Q} 12$ & $1.32(0.81)$ & \\
\hline Q13 & $1.61(1.12)$ & \\
\hline \multicolumn{2}{|l|}{ FirstDash } & \multirow{4}{*}{0.0459} \\
\hline 1 & $2.17(2.28)$ & \\
\hline 2 & $2.59(2.70)$ & \\
\hline 3 & $2.31(2.27)$ & \\
\hline
\end{tabular}

Furthermore, by comparing the means completing Student t’s pairwise comparisons, Dashboard 1 and Dashboard 3 were significantly different (Appendix E-8). For questions, several questions were different from one another as seen in Appendix E-8. Finally, FirstDash 1 was significantly different from FirstDash 2 (Appendix E-8).

Furthermore, the two significant interactions of Dashboards*Questions and Dashboards*FirstDash were further analyzed using interval plots as seen in Figure 5.13 and Figure 5.14, respectively. The three-factor interaction was not considered feasible for the interval plots. In Figure 5.13 for each question, a mean time is given for each dashboard for comparison. In Figure 5.14 for each starting dashboard, a mean time is given for each dashboard for comparison. 


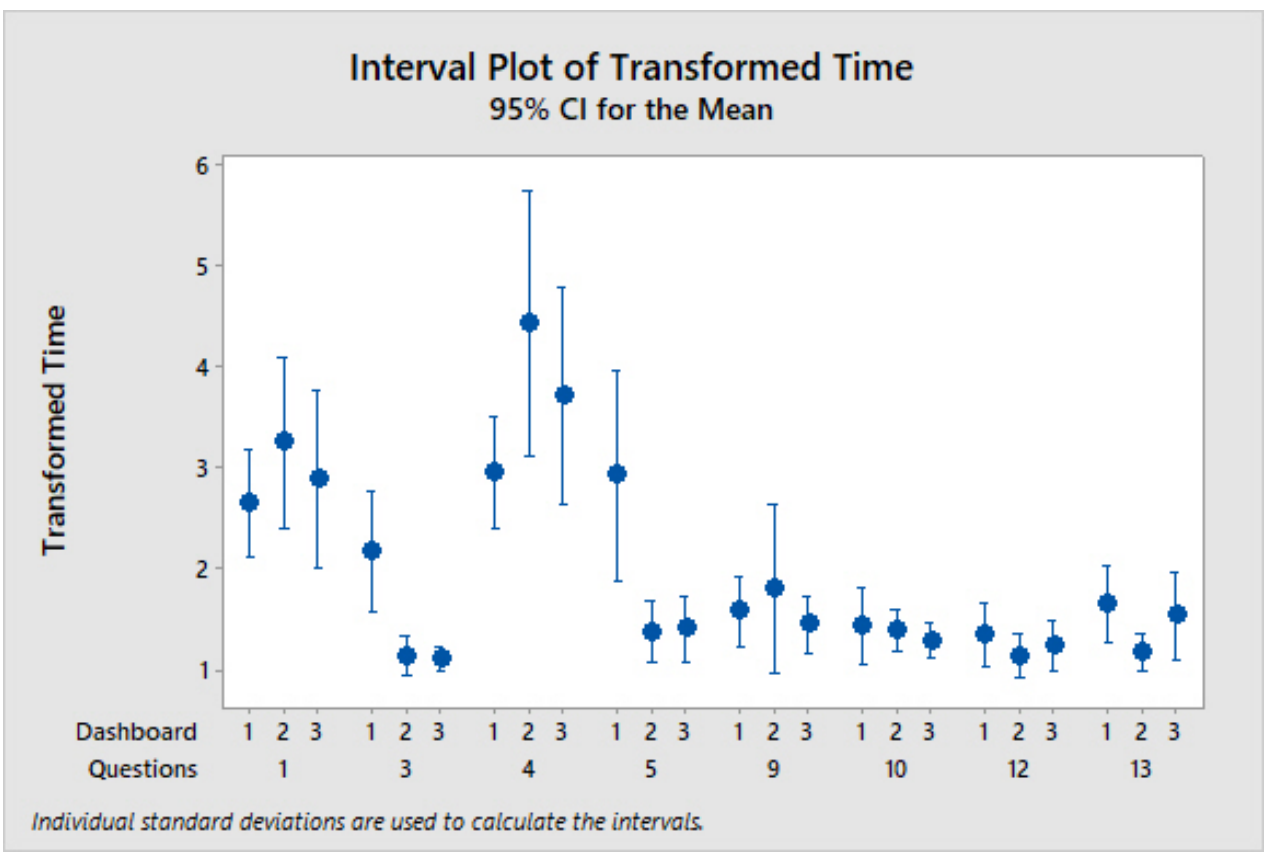

Figure 5.13: Interval Plot for On-Screen Times vs Dashboards*Questions

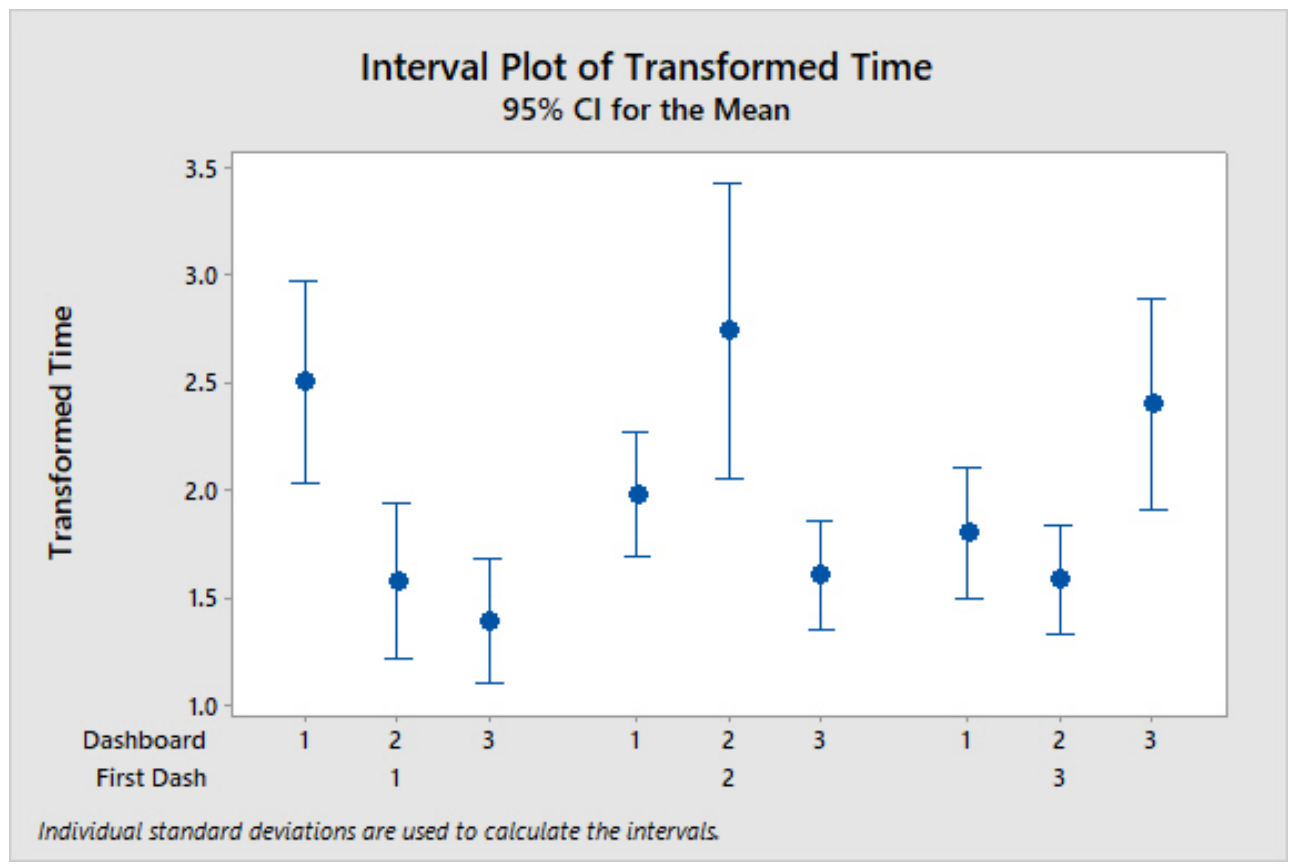

Figure 5.14: Interval Plot for On-Screen Times vs Dashboards*FirstDash 


\subsection{General Comments}

During the final survey, various questions were asked (as seen in the Dashboard Testing Procedure section), and comments were captured from the 25 participants (Appendix E). The open discussion structure of the questions allowed for the participants to answer freely and give criticisms based on their experience. From the comments, the participants were asked to choose the "best” dashboard for light commercial businesses:

- $16 / 25=64 \%$ of participants said that Dashboard 3 was the best

- $4 / 25=16 \%$ participants said that Dashboard 2 was the best

- $1 / 25=4 \%$ of the participants said that Dashboard 1 was the best

- $4 / 25=16 \%$ of the participants said that a combination of Dashboards was the best option

General critiques and comments were summarized into the following:

- Create color differentiation between energy sources

- Use a bigger monitor or display of images

- Speed of data changing (polling rate) was too fast

- Ensure that increments in charts are in 5 s or 10 s to make it easier

- All 25 participants could see the dashboard concept being utilized for a light commercial business.

\section{$\underline{5.4 \text { Results Summary }}$}

To summarize the results presented in the previous sections, the main findings are presented in the following sections. 


\subsubsection{Design Factor Results}

- Dashboard 1 was rated the most analytical with an average rating of $83 \%$ analytical and $17 \%$ engaging

- Dashboard 3 was rated the most engaging with an average rating of $73 \%$ and $27 \%$ analytical.

- Dashboard 3 was rated as the highest in both Interesting and Trustworthy categories.

- Dashboard 1 was rated as the least in both categories.

- Through statistical analysis, Dashboards had a significant effect on Analytical, Engaging, and Interesting ratings, but not Trustworthy ratings.

- All dashboards were significantly different from one another

\subsubsection{NASA TLX Results}

- Dashboard 3 had the lowest average overall NASA TLX score of 26.7 while Dashboard 1 had the highest average overall NASA TLX score of 39.1.

- Through statistical analysis, Dashboards did not have a significant effect on the overall NASA TLX Overall Scores and individual factor weights.

\subsubsection{Correctness and Time Results}

\subsubsection{Correctness Results}

- $8 / 25=32 \%$ of participants answered Question 7 on Dashboard 2 incorrectly by viewing a stacked bar chart. 


\subsubsection{Time Results}

- For the button-clicking questions, Questions, FirstDash, and Dashboard*FirstDash were all significant on the time to answer the questions.

- For the button-clicking questions, all questions were significantly different from one another. FirstDash 1 was significantly different from 2. FirstDash 2 was significantly different from 3.

- For the main screen questions, Dashboards, Questions, Dashboards*Questions, FirstDash, Dashboards*FirstDash, and Dashboards*Questions*FirstDash were all significant on the time to answer the questions.

- For the main screen questions, Dashboard 1 was significantly different than Dashboard 3 regarding time to answer the questions. Various questions were different from one another. FirstDash 1 was significantly different from 2.

\subsection{Energy Dashboard Installation Guide Program Results}

The Energy Dashboard Installation Guide Program is used to guide light commercial business owners through a series of questions to allow the program to determine the best energy monitoring and visualization system for their facility. A hypothetical scenario was developed involving a retail location to showcase the performance of this program.

It was assumed that the retail location had a natural gas meter through the utility company (not their own), but the owner did not know if the meter had 4-20mA outputs. There was a water meter installed on the main water line for the business, but it had an analog dial showing the water consumption. Further, it was assumed that the retail location had the following energy consuming equipment: 


\section{Electric}

- Electrical HVAC

- Hot Water Electrical Heating

- 3 Major Areas of Light

\section{Natural Gas}

- Natural Gas Furnace

\section{Water}

- Analog Dial Water Meter

As a first step, the facility would use the program to input their equipment as seen in Figure 5.15.

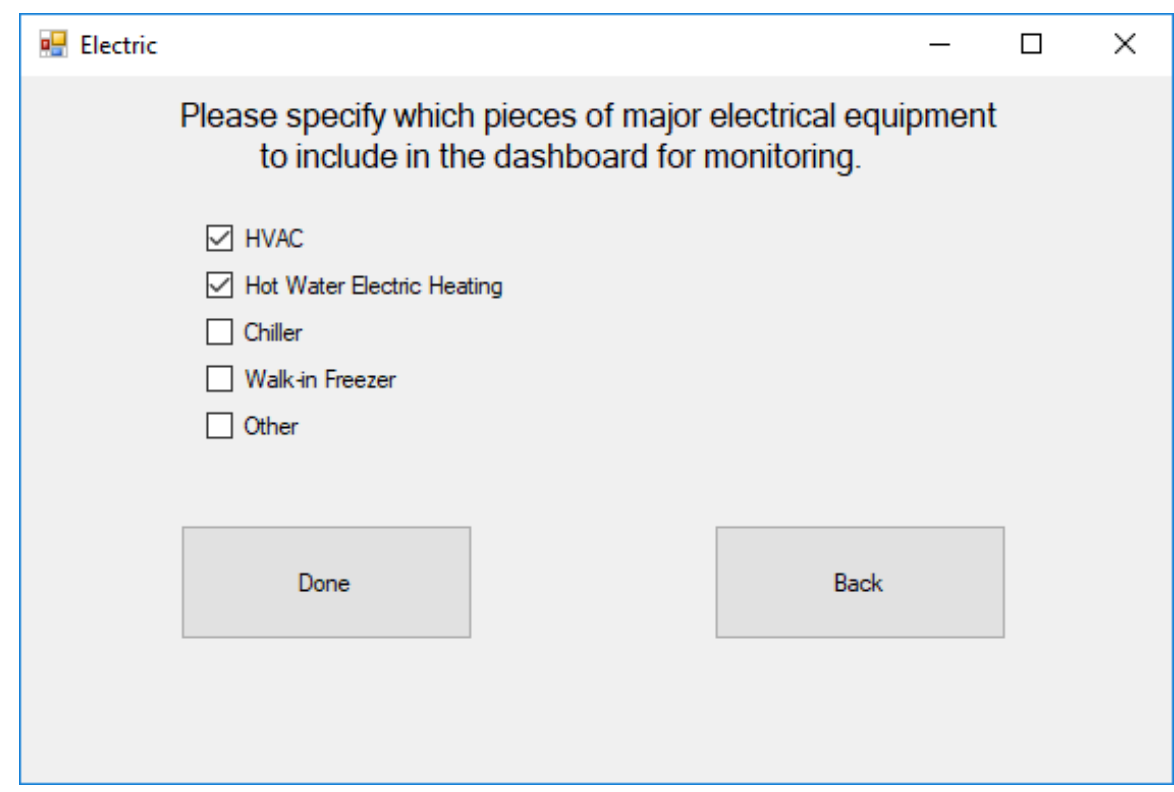

Figure 5.15: Energy Dashboard Installation Guide Program - Electrical Equipment Selection

The facility owner would then be continued to the second step of “General Questions” related to the use of current PC or purchase of a new PC. An example of the questions asked is seen in Figure 5.16. 


\section{$-\square \times$}

Will you be using your current PC or will there be a dedicated PC for the dashboard?

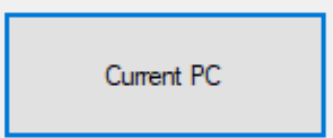

Figure 5.16: Energy Dashboard Installation Guide - General Questions Asked

After the business owner answered all necessary questions, the program output provides an equipment list, costing, and a wiring diagram as seen in Figure 5.17 and Figure 5.18.

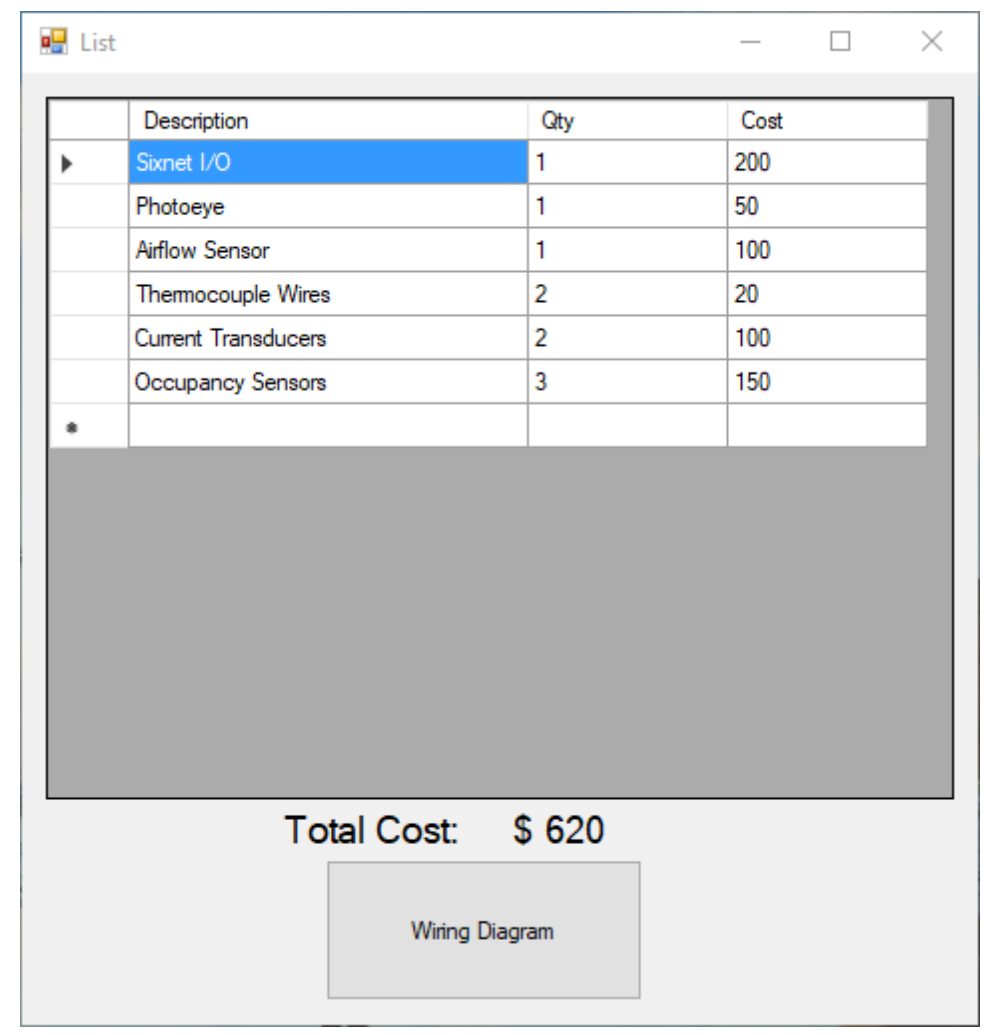

Figure 5.17: Energy Dashboard Installation Guide Program - Equipment List and Costing 


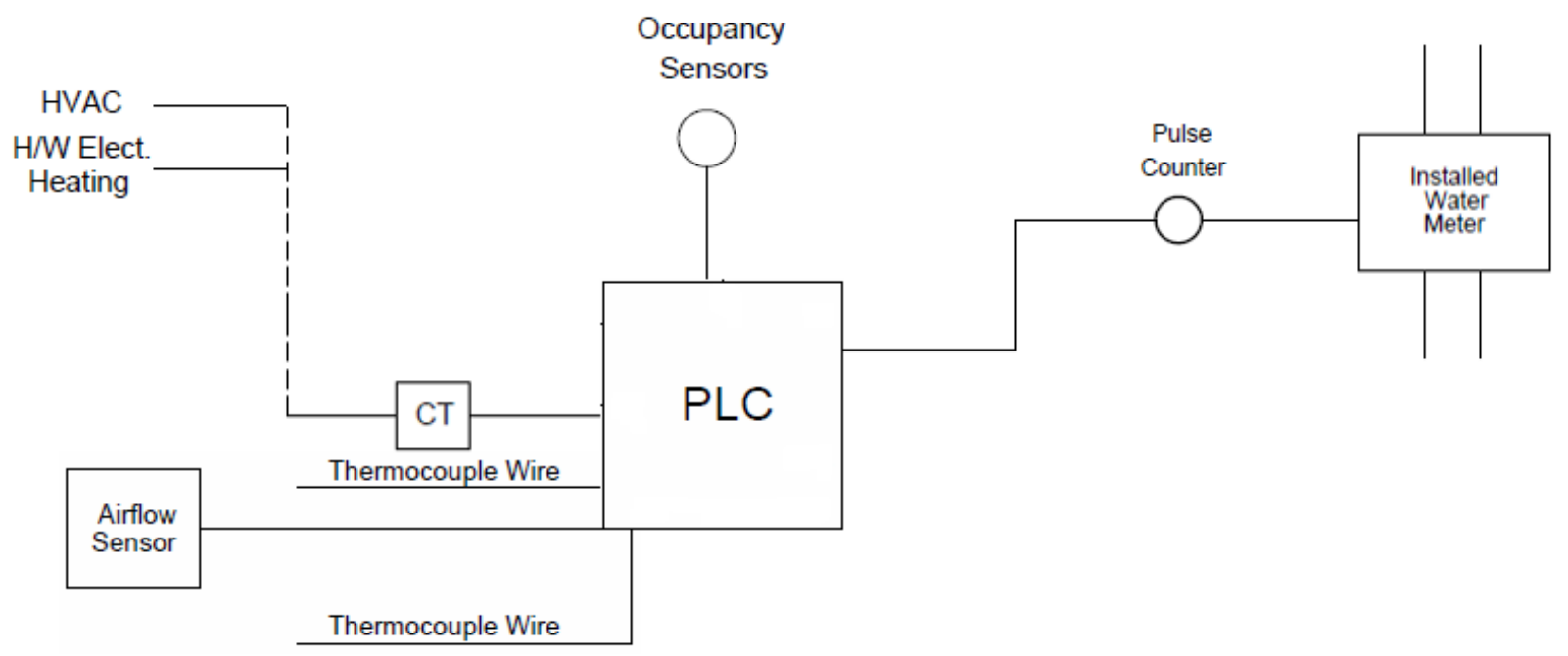

Figure 5.18: Energy Dashboard Installation Guide Program - Custom Wiring Diagram

The Sixnet I/O module was chosen for the facility since the business owner wanted the option to expand to additional equipment. The Sixnet I/O had many inputs and outputs as opposed to a less expensive I/O module. A photoeye was used for the water meter to capture the movement on the analog dial. The airflow sensor and thermocouple wires were used for the natural gas furnace since the natural gas meter cannot be accessed. Current transducers were used for the electrical HVAC system and Hot Water Electrical Heating. Finally, the three major areas of lighting were captured using the occupancy sensors. 


\section{Chapter 6: Discussion}

\section{$\underline{\text { 6.1 Discussion }}$}

The purpose of this study was to determine if the proposed Open Database-driven energy visualization system provided a reasonable avenue for data capturing and visualization in the light commercial sector. Through conducting analytical usability testing and subjective testing with NASA TLX, many findings have been determined. Regarding energy dashboard design, mental workloads, and usability of the energy dashboards, all were explored with this research.

\subsubsection{Dashboard 3 and Design Factors}

Dashboard 3 was rated as the most interesting and trustworthy. Dashboard 3 was also rated as the highest engaging dashboard. With the use of engaging visuals such as the gauges, alternating light meters, and flashing colors, the interesting ratings were the highest in comparison to the simple bar charts and tables. This agrees with Salmon’s research regarding interesting and trustworthy ratings for an energy dashboard (Salmon et al., 2016).

Expanding upon the research, analytical, engaging, interesting, and trustworthy ratings were introduced with this study. Comparing Figure 5.4, Figure 5.5, and Figure 5.6, as the dashboards became more engaging, generally, the interesting and trustworthy ratings also increased. With Dashboard 3 as the highest engaging dashboard, this dashboard also received the highest interesting and trustworthy ratings. When new engaging visuals were introduced (away from simple bar charts and tables), these created a sense of interesting and probe for further investigation. However, with some participants, this created a lack of trustworthiness. This lack of trustworthiness could be a reason as to why the dashboards were not found to be significant on the trustworthy ratings. Some participants felt that they were not able to trust the data because of the newer visuals. Perhaps this was due to the participant being unfamiliar with the visuals since 
many people are conditioned to reading bar charts and tables. Ultimately, if the engaging visuals are utilized in a manner that enhances the ability of the user to read data quickly and efficiently (preattentive attributes) and becomes trustworthy, then such visuals will be more powerful for energy dashboards than the traditional visuals of bar charts and tables.

Furthermore, Dashboard 3 was the favorite among the participants. With the analytical and subjective testing, Dashboard 3 also produced the quickest answering times and the least mental workload. Since Dashboard 3 was designed to have the most engaging visuals, this again agrees with Salmon's research (Salmon et al., 2016). Dashboard 3 also adhered to the concept of preattentive attributes with flashing lights, changes in color and size, and easy readings. This agrees with Knaflic's and Few's research regarding how preattentive attributes can be quite successful in reducing one's mental workload and overall time of perception (Few, 2013; Knaflic, 2015). In addition, the flashing light meters and color changes also allowed for immediate identification of change. Agreeing with Leher’s research, energy dashboards can be used to spot trends, anomalies, and changes in data (Lehrer et al., 2010).

Statistically, Dashboard 1 and 3 were proven to be significantly different from each other regarding the time to answer questions. As the designs of Dashboard 1 and 3 were quite different regarding analytical vs engaging characteristics, this provides additional support for the claim that engaging and preattentive attributes can be heavily beneficial when designing an energy dashboard.

Thus, Dashboard 3 provided an all-in-one collective screen that displayed a lot of informative and valuable data in one location. The use of engaging visuals (Salmon et al., 2016), explanatory analysis (Knaflic, 2015), and overall dashboard concepts (Few, 2013) allowed for 
this Dashboard to be the most efficient and effective in providing a better energy dashboard visualization experience for the participants.

\subsubsection{Overall Dashboard Findings}

\subsubsection{Enhanced Visuals}

Enhanced visuals such as load duration curve, stacked bar charts, and double y-axes charts were found to be highly successful in research (Energy Efficiency \& Demand Management \& AEE Northern Ohio Chapter, 2014; Kirk, 2012). However, 32\% of participants incorrectly answered a question regarding the stacked bar chart for natural gas usage. It was determined that participants had trouble understanding the totality of the overall usage instead of breaking down the overall bar in sections as shown in Figure 5.9. As this was one example of the many possible enhanced visuals, one cannot state that all visuals, including the stacked bar chart, should not be used. Instead, proper understanding and training of the visual may be required when using the visual in energy dashboards. As these enhanced visuals may not be immediately intuitive, training may be required for participants to fully understand how to read the visuals. Other enhanced visuals could have been tested within the dashboards to determine if they required extra training as well.

\subsubsection{Effect of Dashboards on NASA TLX Scores}

Regarding NASA TLX scores, the dashboards did not have a statistically significant effect. Though statistically the dashboards did not have an effect, it was interesting to note that the average NASA TLX Overall Scores, Temporal Demand Weights, and Performance Weights all generally declined as the dashboards became more and more engaging.

NASA TLX may have not been the best tool to be used for the study to measure mental workloads. NASA TLX prompts the user to input ratings (0-100) for each of the six workload 
dimensions and select the more prevalent dimension in 15 pairwise comparisons. This process can become time consuming if being repeated with the same participant. During the study, it was found that participants had carefully selected the options in NASA TLX for the first dashboard. However, when the final dashboard was tested, the participants quickly selected the options. It seemed that the NASA TLX procedure was redundant for the participants. It was noted that the pairwise comparisons were not generally necessary due to the dashboard testing process was relatively the same for each dashboard. The only true varying values were that of the six workload dimension ratings. NASA TLX could have presented too many options to the user or was too time consuming and redundant. It is also possible that the dashboards did not provide enough of a mental workload to show significance.

Moreover, the dashboards and included visuals may have influenced their mental workload. As working memory is heavily used when viewing an energy dashboard, this research supports that claim (Few, 2013; Knaflic, 2015). Using preattentive attributes and engaging visuals will assist in relieving the mental workloads from the participants when an energy dashboard is viewed.

\subsubsection{Learning Curves}

The variable, FirstDash and interaction of Dashboards*FirstDash, were both found to have a high significance in the time to answer the questions in the experiment. FirstDash was used to determine if there was a learning curve involved during the experiment. As time progressed and the participants continued using each dashboard consecutively, they began to learn where information was located, how to read visuals quickly, and ultimately answer the questions quickly. As the participants were only able to view the partial dashboards for five minutes each, this created difficulty for the participant as they were not able to fully examine the 
dashboard before being questioned. As this was done purposely to determine how quickly a dashboard could be learned, this created interesting findings.

For the Button-Click Times in Figure 5.12 and On-Screen Times in Figure 5.14, the means were higher in each FirstDash category for the dashboards that the participants began with. For example, regarding Figure 5.12, participants that began with Dashboard 1 had longer response times with Dashboard 1 than the other dashboards. Thus, a learning curve was involved as the participants improved their response times in the consecutive dashboards. This is true for each of the FirstDash categories. Furthermore, in both Time groups, participants that began with Dashboard 2 had a longer or "steeper" learning curve due to the means of the entire FirstDash 2 category being higher than the other FirstDash categories.

For Button-Click Times in Table 5.4 and On-Screen Times in Table 5.5, the participants who began with Dashboard 1 (FirstDash 1) had lower average answering times than the participants who started with Dashboard 2 or 3. Though the average is lower for FirstDash 1, Figure 5.12 and Figure 5.14 provide additional context to show that the dashboard is not only a main factor, but also with which dashboard the participant began testing. After the participant's initial dashboard, the times significantly improved for each consecutive dashboard.

These findings may have been due to the participants being conditioned to read line charts, bar graphs, and other typical analytical visuals for most of their time in education and post-education careers. The engaging visuals may have not been as trivial, initially. As Dashboard 2 consisted of both analytical and engaging visuals, this may have been an obstacle for participants, initially. After completing the initial dashboard testing, participants improved significantly in the consecutive dashboards to follow. Further training and practice with the engaging visuals may have showed a faster improvement in the time of answering questions. 
This research has showed that though a dashboard can be quickly learned, training is recommended on the dashboard to learn its full capabilities and to be able to locate all information quickly.

\subsubsection{Questions and Dashboards}

Statistical analysis had showed that both the questions asked, and the interaction between the questions and dashboards were significant on the time to answer the questions. In Figure 5.11, for Button-Click Times, the average time to answer was sporadic for each of the questions as the means were at different value ranges. In Figure 5.13 for On-Screen Times, additional context was given to compare each dashboard for a specific question. Dashboard 3 generally had the tightest intervals per question and had the lowest mean for $50 \%$ of the questions for OnScreen Times.

As time is of the essence, dashboards should be able to have clear and concise visuals, obtain information quickly and easily, and answer any combination of questions that may arise for a facility. The dashboards should be able to immediately provide the answer to general and typical questions that a facility may have on a day-to-day basis. However, it should also provide the means to answer questions requiring more in-depth analyses whether in its own platform or with other analysis tools. Combining both quick information readings with in-depth analyses delivers a powerful dashboard that can light commercial business owners can use to manage their energy usages.

\subsubsection{General Comments}

Overall general comments were captured using a final survey at the end of each experiment. Based on section 5.2 General Comments, different findings were determined. All participants could realistically see the EV dashboard concept being utilized for a light 
commercial business. As this energy visualization concept is relatively low-cost $(<\$ 1,000)$ and is easily able to be implemented, the study shows that the proposed Open Database-driven energy visualization system provided a reasonable avenue for data capturing and visualization in the light commercial sector.

As the dashboards were on a black background with white fonts, participants had asked that there would be a color differentiation between the different energy sources to assist in distinguishing the different energy sources. This corresponds to the preattentive attribute of color that Knaflic and Few identified as crucial to energy dashboards (Few, 2013; Knaflic, 2015). Participants also asked that the visuals and display monitor would be larger. However, the laptop was a traditional 16" screen that would be typically used by light commercial business owners. To ensure that the dashboards included all necessary data and visuals, all visuals had to be of the same size. Some of these detailed visuals may have required enlarging.

It was noted that the speed of the data being changed (also known as polling rate) was too fast at 1.5 seconds. Participants had asked that the speed would be longer to allow for further analysis and processing. However, this polling rate was selected to create a sense of time pressure and quick changing visuals for the participants to generate a mental workload. Another comment was to ensure that the line charts were all in 5 s and/or 10 s increments to ensure that the data was easy to read. The electric line charts on Dashboards 1 and 2 were purposely formatted to have odd increments to generate a mental workload. By incorporating both measures, the NASA TLX scores could be better differentiated between one another as opposed to having little differences between the dashboards. 


\section{$\underline{6.2 \text { Limitations }}$}

There were limitations involved with the experiments. First, the learning curve from dashboard to dashboard was significant as seen in the previous section. Due to this, times were longer for the first dashboard the participants had utilized and the times were shorter by their final dashboard. This presented some outliers and skewness in the data. These outliers were removed, and that data was later transformed to conform to a normal distribution. Some of the outliers could have been avoided if the participant had been previously trained on the dashboard. However, this would sacrifice the understanding of how quickly a dashboard could be learned under a time constraint.

With further training and explanations during the first phase of the initial dashboard, the results may have improved and provided a stronger model. Ensuring that the participants fully understood every aspect of the dashboard would have guaranteed that there were no misconceptions about the information or location of the data. Again, however, this would sacrifice the understanding of how quickly a participant could learn a dashboard under a time constraint.

Further limitations include small distractions and noises. As the experiments took place in the same room, in a controlled office environment, there were small noises and distractions from adjoining rooms that could have influence on the results. As light commercial business owners will typically not be viewing the energy dashboards in a completely silent setting, this limitation may not be as significant.

Regarding the general comments, differentiation between energy sources could have promoted for faster recognition of information location on the dashboard which would have 
affected the overall time to answer questions. Furthermore, larger visuals or a larger display monitor could have allowed for easier recognition and a faster response time from the participants. As for the polling rate and line chart increments, these were purposely designed to generate a mental workload on the participants. For odd line chart increments, this was only used on the electric line charts, but not on the natural gas line charts. Questions were asked on both line charts for both dashboards. However, this still could have influenced the participants to believe that Dashboard 1 or 2 was more difficult than 3 due to the odd increments as this could affect their NASA TLX score.

\subsection{Conclusions}

Throughout this research and study, many new developments and findings have emerged. First, a framework for an energy monitoring system for light commercial businesses was developed. There was no previous research or blueprints explaining how to obtain various data points from energy consuming equipment within the light commercial sector. This was completed thorough research of existing technologies and current products on the market for various sectors. Integrating this data with newly-designed real-time energy dashboards provided a new low-cost and feasible option for light commercial business owners. Dashboard testing and validation was performed utilizing analytical and subjective testing methods to test the usability and mental workload of the dashboards through using participants such as energy engineers and managers, and other typical dashboard users. A program was also developed and published to guide business owners through purchasing of specific energy monitoring equipment for their facility that included an equipment list, costing, and a wiring diagram - specific to their facility.

From an ergonomics perspective, no research has been completed on the usability or mental workloads associated with energy dashboards and energy visualization (EV) systems. 
Testing three levels of a combination of analytical and engaging dashboards through analytical usability testing and subjective testing with NASA TLX provided a foundation for future testing on applicable energy dashboards.

It was concluded that the overall design of energy dashboards is crucial to the success of business owners managing their energy usage. Moreover, training and understanding of the energy dashboards allow for questions that a business owner may have to be answered efficiently and accurately. Ensuring that energy dashboards are easy to view, minimize working memory, provide valuable and informative information, and provide means for in-depth analysis will ultimately assist light commercial business owners in their energy managing endeavors.

From this research, light commercial business owners are now able to build and develop their own EV systems and dashboards to monitor their energy usages. The proposed systems proposed provide light commercial business owners with a flexible, safe, economic, and easy-toinstall energy dashboard system. Furthermore, the research exposes a niche that was not studied before. Now, further research and studies can be completed to assist the light commercial sector to help small businesses manage their energy usages; which was not available before due to other restrictions.

\subsection{Future Outlook}

As energy consciousness and energy usages are both increasing, more research must be completed on energy visualization systems. Energy visualization is improving and becoming more accessible from the industrial plants to even residential homes. One cannot manage the energy that one does not measure. Thus, energy visualization is essential to managing energy 
consumption in any sector. Continual research efforts should be completed to develop new technologies, new dashboard systems, and new energy solutions.

As an overall endeavor to promote energy efficiency, incentives and rebates could be introduced in the energy dashboards. Electrical companies provide rebates to light commercial businesses based on energy usage reduction or other metrics. Inclusion of incentives and rebate information in the energy dashboards would benefit society with energy consciousness and efficiency.

Another concept would be that of a "point system" or "achievement system.” Such systems would allow users to gain "points" or "achievements" for completing certain energy saving activities. Users would then be able to directly apply these points as rebates or other incentives with utility companies or other partnered entities. Thus, the dashboard users are incentivized to use the energy dashboards for their facility as it is a great initiative to both the user and the utility companies involved.

Regarding further enhancements to the dashboards, including internal intelligence to combat "error propagation” would be a great addition. Error propagation consists of equipment giving false or skewed data that contains errors that is then translated to the final calculated value on the dashboard. To avoid this, internal intelligence could be incorporated into the dashboards that validates the data continuously as it is recorded. For example, the data could be crosschecked against a historical average, between maximum and minimum ranges, or other metrics. If the dashboard detected that there were errors in the data, then an error message or alert could be issued directly to the user via the dashboard or via e-mail or SMS text message. 
Regarding light commercial businesses, they have typically been ignored as simply small businesses with little energy consumption. However, due to their large presence in our economy with small commercial buildings consisting of over $90 \%$ of all buildings in the United States, these small businesses actually consume a large portion of the United States' energy (Barnes \& Parrish, 2016). Thus, more accessible energy monitoring solutions for the light commercial sector needs to be developed. With further research, the energy usages by small businesses can be significantly decreased and have an enormous impact on the United States' energy consumption. As an energy saving endeavor, small businesses can now take new roles in reducing the world's energy consumption. 


\section{References}

AdvancedHMI. (2018). Retrieved April 13, 2018, from https://www.advancedhmi.com/

Barnes, E., \& Parrish, K. (2016). Small buildings, big impacts: The role of small commercial building energy efficiency case studies in 2030 Districts. Sustainable Cities and Society, 27, 210-221. https://doi.org/10.1016/j.scs.2016.05.015

Brown, C. (2002). Usability Testing in Internet Time. Performance Improvement, 41(10), 40-46.

Cao, A., Chintamani, K. K., Pandya, A. K., \& Ellis, R. D. (2009). NASA TLX: Software for assessing subjective mental workload. Behavior Research Methods, 41(1), 113-117. https://doi.org/10.3758/BRM.41.1.113

Capehart, B. (2005). Web Based Energy Information And Control Systems. Case Studies and Applications. The Fairmont Press. Lilburn, GA.

Ehrlich, P. (2015, May). Building Automation For Small Commercial Buildings. Engineered Systems, 22.

Energy Consumption by Sector. (2016). Retrieved February 5, 2017, from https://www.eia.gov/totalenergy/data/monthly/pdf/sec2_3.pdf

Energy Efficiency \& Demand Management, I., \& AEE Northern Ohio Chapter. (2014). Advanced Excel for Energy Efficiency Professionals [Powerpoint Slides] Retreived January 25, 2018, from http://www.aeeohio.com/ADVANCED\%20EXCEL\%20FOR\%20Energy \%20Engineers_AEE_CLE_11142014.pdf

Few, S. (2006). Clarifying the vision. In Information Dashboard Design The Effective Visual Communication of Data (p. 223). Sebastopol, CA: O’Reilly Media, Inc.

Few, S. (2007). Data Visualization: Past, Present, and Future. IBM Cognos Innovation Center for Performance Management, 3-11. Retrieved January 12, 2018 from http://perceptualedge.com/articles/Whitepapers/Data_Visualization.pdf

Few, S. (2013). Information Dashboard Design: Displaying Data for At-A-Glance Monitoring. Burlingame: Analytics Press.

Flowers, J. (2005, June). Usability Testing in Technology Education. The Technology Teacher, 64(8). Retreived from http://citeseerx.ist.psu.edu/viewdoc/download?doi=10.1.1.464.6538 \&rep=rep1\&type=pdf

Giacomin, J., \& Bertola, D. (2012). Human emotional response to energy visualisations. International Journal of Industrial Ergonomics, 42(6), 542-552. https://doi.org/10.1016/j.ergon.2012.07.006

Granderson, J., \& Lin, G. (2016). Building energy information systems: synthesis of costs, savings, and best-practice uses. Energy Efficiency, 9(6), 1369-1384.

https://doi.org/10.1007/s12053-016-9428-9

Guity, A., \& Rabinowitz, J. (2013, September). Energy Efficiency’s Next Frontier. 
Enviornmental Design and Construction Magazine, 16(9). Retreived from http://www.mazzetti.com/wp-content/uploads/2016/10/EDC_Reprint_0913_ EnergyEfficiencyNextFrontier_v1.pdf

Gunasingh, S., Marsicek, G., \& Vigliotta, D. (n.d.). Seventhwave Offers Free Energy Analysis Tools. Retrieved January 25, 2018, from http://www.hpbmagazine.org/SeventhwaveOffers-Free-Energy-Analysis-Tools/

iDashboards. (2017). Energy \& Utility - Longhorn Energy. Retrieved January 24, 2018, from https://www.idashboards.com/dashboard-examples/energy-utility-dashboard-longhornenergy/

Irwin, W. J., Robinson, S. D., \& Belt, S. M. (2017). Visualization of Large-Scale Narrative Data Describing Human Error. Human Factors, 59(4), 520-534. https://doi.org/10.1177/0018720817709374

JMP. (2018). Continuous Fit Distributions. Retrieved April 5, 2018, from https://www.jmp.com/support/help/14/continuous-fit-distributions.shtml

Johnson Controls. (2013). Energy Dashboards and Report Tool (EDART) [Brochure]. Retrieved January 25, 2018 from http://www.bex-asia.com/_novadocuments/12614

Jókai, E. (2009). Usability testing methods on e-learning environment. Periodica Polytechnica, Social and Management Sciences, 17(2), 79-87. https://doi.org/10.3311/pp.so.2009-2.04

Jones, M. C., \& Pewsey, A. (2009). Sinh-arcsinh distributions. Biometrika, 96(4), 761-780. https://doi.org/10.1093/biomet/asp053

Kirk, A. (2012). Data Visualization: A Successful Design Process. Birmingham: Pakt Publishing.

Knaflic, C. N. (2015). Storytelling with Data: A Data Visualization Guide for Business Professionals. Hoboken: John Wiley \& Sons.

Lehrer, D., Kaam, S., \& Vasudev, J. (2014). A Usability Study of a Social Media Prototype for Building Energy Feedback and Operations [Powerpoint slides]. Retreived January 12, 2018 from https://www.cbe.berkeley.edu/research/pdf_files/Lehrer-2014-slides-social-mediaenergy.pdf

Lehrer, D., Vasudev, J., \& Webster, T. (2010). Visualizing Building Information. Center for the Built Environment [Powerpoint slides]. Retreived January 12, 2018 from https://www.cbe.berkeley.edu/research/pdf_files/Lehrer2010-slides-visualizing-info.pdf

Lock, L. E., Shyan, T. E., \& Hartman, T. (2016). Improving Commercial Building Energy Performance. ASHRAE Journal, 40-45.

Minitab. (2018). Minitab 18. Retrieved from http://www.minitab.com/en-us/products/minitab/

Mizuno, H., Mori, Y., Taniguchi, Y., \& Tsuji, H. (1997). Data queries using data visualization techniques. 1997 IEEE International Conference on Systems, Man, and Cybernetics. Computational Cybernetics and Simulation, 3, 2392-2396.

https://doi.org/10.1109/ICSMC.1997.635285 
Montgomery, D. C. (2013). Selecting a Transformation: The Box-Cox Method. In Design and Analysis of Experiments (pp. 643-652). Hoboken: John Wiley \& Sons Ltd.

Pahl, S., Goodhew, J., Boomsma, C., \& Sheppard, S. R. J. (2016). The role of energy visualization in addressing energy use: Insights from the eViz project. Frontiers in Psychology, 7(February), 1-4. https://doi.org/10.3389/fpsyg.2016.00092

Panke, R. A. (2001). Energy Management Systems and Direct Digital Control. Lilburn, GA: Fairmont Press.

Perles, A., Pérez-Marín, E., Mercado, R., Segrelles, J. D., Blanquer, I., Zarzo, M., \& GarciaDiego, F. J. (2017). An energy-efficient internet of things (IoT) architecture for preventive conservation of cultural heritage. Future Generation Computer Systems, 81. https://doi.org/10.1016/j.future.2017.06.030

Phillips, M. (2016). How Does Sense Detect My Devices?. Sense. Retrieved January 11, 2018 from https://blog.sense.com/articles/how-does-sense-detect-my-devices/

QAGraphics. (2018). Energy Dashboards. Retreived January 25, 2018 from https://www.qagraphics.com/energy-dashboards/

Salmon, K., Morejohn, J., Office, E. C., \& Davis, U. C. (2016). The Iterative Design of a University Energy Dashboard, 1-12.

Smith, N., \& Wuest, T. (2017). Identifying Key Aspects of Success for Product Service Systems. In Advances in Production Management Systems. The Path to Intelligent, Collaborative and Sustainable Manufacturing : IFIP WG 5.7 International Conference, APMS 2017, Hamburg, Germany, September 3-7, 2017, Proceedings, Part I (pp. 231-238). Springer International Publishing.

Strohm, P. (2014, September). Commercial Energy Management. Emerging Markets, 24. Retreived January 12, 2018.

Sugarindra, M., Suryoputro, M. R., \& Permana, A. I. (2017). Mental workload measurement in operator control room using NASA-TLX. IOP Conference Series: Materials Science and Engineering, 277(1), 1-7. https://doi.org/10.1088/1757-899X/277/1/012022

The Economist. (2013). The origins of the financial crisis: Crash Course. The Economist. Retrieved January 12, 2018 from https://www.economist.com/news/schoolsbrief/21584534effects-financial-crisis-are-still-being-felt-five-years-article

U.S. Department of Agriculture. (n.d.). Small Business. U.S. Department of Agriculture. Retrieved April 15, 2018 from https://nifa.usda.gov/topic/small-business

U.S. Department of Energy. (2012). Energy Looking Glass. Better Buildings Initiative. Retrieved January 12, 2018 from https://betterbuildingsinitiative.energy.gov/implementationmodels/energy-looking-glass-dashboard

U.S. Energy Information Administration. (2016). Renewable and Alternative Fuels. Retrieved January 25, 2018 from https://www.eia.gov/renewable/data.php\#summary 
U.S. Energy Information Administration. (n.d.-a). Commercial Sector. U.S. Energy Information Administration. Retrieved April 15, 2018 from https://www.eia.gov/tools/glossary/ index.php

U.S. Energy Information Administration. (n.d.-b). Industrial Sector. U.S. Energy Information Administration. Retrieved April 15, 2018 from https://www.eia.gov/tools/glossary/ index.php

Wickens, C. D., Lee, J., Liu, Y., \& Becker, S. G. (2004). Design and Evaluation Methods. An Introduction to Human Factors Engineering. New York: Pearson. 


\section{Appendix A: WVU IRB Protocol Consent Form}




\section{WestVirginiaUniversitys}

Human Research Protocol

Only Minimal Risk Consent Form

Without HIPAA

\section{Only Minimal Risk Consent Information Form (without HIPAA)}

Principal Investigator

Department

Protocol Number

Study Title

Co-Investigator(s)

Sponsor (if any)
Dr. Ashish Nimbarte

Industrial and Management Systems Engineering

1802986228

Usability Study and Subjective Testing on Computer-Based Energy Dashboards

Nathaniel Smith

N/A

\section{Contact Persons}

In the event you experience any side effects or injury related to this research, you should contact Dr. Ashish Nimbarte at (304) 293-9473. If you have any questions, concerns, or complaints about this research, you can contact Nathaniel Smith at (304) 550-3658.

For information regarding your rights as a research subject, to discuss problems, concerns, or suggestions related to the research, to obtain information or offer input about the research, contact the Office of Research Integrity and Compliance at (304) 293-7073.

In addition if you would like to discuss problems, concerns, have suggestions related to research, or would like to offer input about the research, contact the Office of Research Integrity and Compliance at 304-293-7073.

\section{Introduction}

You, , have been asked to participate in this research study, which has been explained to you by Nathaniel Smith. This study is being conducted by Nathaniel Smith in the Department of Industrial and Management Systems Engineering at West Virginia University.

\section{Purpose(s) of the Study}

The purpose of the study is to analyze the usability (ease of use) of three energy dashboards. By analyzing the timed responses of certain questions, further developments can be made to further enhance the energy dashboards to be more user-friendly. In addition, subjective testing will be used to determine the mental workloads on the participants as to how much strain was placed on the user's mind when viewing these computer-based dashboards.

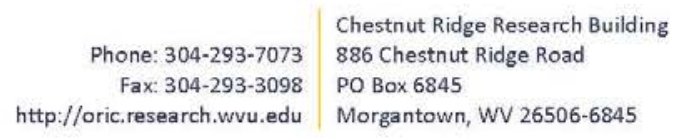

$$
\text { Page } \mid 1
$$

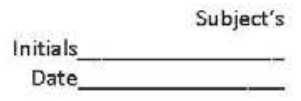




\title{
W- WestVirginiaUniversity:
}

\author{
Human Research Protocol \\ Only Minimal Risk Consent Form \\ Without HIPAA
}

\section{Description of Procedures}

Before the experiment begins, the experiment will be explained in full to you. You will be asked to sign this consent form. The entire experiment should take about 45 minutes to one hour. You will have the opportunity to see the questionnaire before signing this consent form.

For the Usability Study, you will be asked to view, simulate, and manipulate the dashboard and system to understand how the dashboard operates for 10 minutes. At the end of this time interval, you will be asked to answer a series of questions under which you will be timed. The timing begins once the question has been finished being asked. The participant will respond with an answer as quickly as possible and the response and time will be voice recorded. This will be continued for 10 questions. This process will repeat for the other two dashboards.

For the Subjective Testing, the participant will be asked to complete a computer-based version of NASA TLX where the program will ask them a series of questions regarding their mental workloads. The participants will rate six different types of mental workloads. They will then complete a pairwise comparison of the different mental workloads as to the more prevalent workload.

Finally, a general discussion of experience and thoughts will be completed as well as a small survey.

\section{Discomforts}

There are no known or expected risks from participating in this study.

\section{Alternatives}

You do not have to participate in this study as it is completely voluntary.

\section{Benefits}

You may not receive any direct benefit from this study. The knowledge gained from this study may eventually benefit others. Participating in this study will not be counted as extra credit and will have no effect on your grade(s) or your standing at WVU.

\section{Financial Considerations}

You will not receive any compensation for participation in the study and will not incur any costs related to the study.

\section{Confidentiality}

Any information about you that is obtained as a result of your participation in this research will be kept as confidential as legally possible. Your research records and test results, just like hospital records, may be subpoenaed by court order or may be inspected by the study sponsor or federal regulatory authorities (including the FDA if applicable) without your additional consent.

Audiotapes or videotapes will be kept locked up and will be destroyed as soon as possible after the research is finished.

\begin{tabular}{r|lr} 
& Chestnut Ridge Research Building & P a g e I 2 \\
Phone: 304-293-7073 & 886 Chestnut Ridge Road & Subject's \\
Fax: 304-293-3098 & PO Box 6845 & Initials__ \\
http://oric. research.wvu.edu & Morgantown, WV 26506-6845 &
\end{tabular}


In any publications that result from this research, neither your name nor any information from which you might be identified will be published without your consent.

\section{Voluntary Participation}

Participation in this study is voluntary. You are free to withdraw your consent to participate in this study at any time.

Refusal to participate or withdrawal will not affect [your class standing or grades, as appropriate] and will involve no penalty to you. Refusal to participate or withdrawal will not affect your future care, or [your employee status, as appropriate] at West Virginia University.

In the event new information becomes available that may affect your willingness to participate in this study, this information will be given to you so that you can make an informed decision about whether or not to continue your participation.

You have been given the opportunity to ask questions about the research, and you have received answers concerning areas you did not understand.

Upon signing this form, you will receive a copy.

I willingly consent to participate in this research.

\section{Signatures}

Signature of Subject

$\begin{array}{lll}\text { Printed Name } & \text { Date Time }\end{array}$

The participant has had the opportunity to have questions addressed. The participant willingly agrees to be in the study.

Signature of Investigator or Co-Investigator

\begin{tabular}{lll}
\hline Printed Name & Date & Time
\end{tabular}

\begin{tabular}{r|l} 
& Chestnut Ridge Research Building \\
Phone: 304-293-7073 & $\mathbf{8 8 6 \text { Chestnut Ridge Road }}$ \\
Fax: 304-293-3098 & PO Box 6845 \\
http://oric.research.wvu.edu & Morgantown, WV 26506-6845
\end{tabular}

Phone: 304-293-7073

http://oric. research.wvu.edu
$P a g e \mid 3$

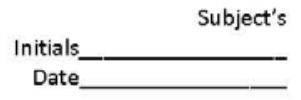


Appendix B: Experiment Raw Data 


\section{Appendix B-1: Experimental Correctness and Time Data}

Dashboard 1

\begin{tabular}{|c|c|c|c|c|c|c|c|c|c|c|c|c|c|c|c|c|}
\hline \multirow[b]{2}{*}{ Question } & \multicolumn{2}{|c|}{ Participant 1} & \multicolumn{2}{|c|}{ Participant 2} & \multicolumn{2}{|c|}{ Participant 3} & \multicolumn{2}{|c|}{ Participant 4} & \multicolumn{2}{|c|}{ Participant 5} & \multicolumn{2}{|c|}{ Participant 6} & \multicolumn{2}{|c|}{ Participant 7} & \multicolumn{2}{|c|}{ Participant 8} \\
\hline & Time & Correct? & Time & Correct? & Time & Correct? & Time & Correct? & Time & Correct? & Time & Correct? & Time & Correct? & Time & Correct? \\
\hline 1 & 4 & $\mathrm{Y}$ & 5 & $\mathrm{Y}$ & 3 & $\mathrm{Y}$ & 5 & $\mathrm{Y}$ & 5 & $\mathrm{Y}$ & 5 & $\mathrm{Y}$ & 1 & $\mathrm{Y}$ & 4 & $\mathrm{Y}$ \\
\hline 2 & 12 & $Y$ & 13 & $Y$ & 6 & $Y$ & 6 & $Y$ & 6 & $Y$ & 12 & $Y$ & 3 & $Y$ & 7 & $Y$ \\
\hline 3 & 5 & $Y$ & 3 & $Y$ & 7 & $\mathrm{~N}$ & 1 & $Y$ & 6 & $Y$ & 6 & $Y$ & 1 & $Y$ & 2 & $Y$ \\
\hline 4 & 5 & $Y$ & 3 & $Y$ & 5 & $\mathrm{~N}$ & 1 & $Y$ & 4 & $Y$ & 9 & $\mathrm{Y}$ & 1 & $\mathrm{Y}$ & 6 & $Y$ \\
\hline 5 & 9 & Y & 12 & $Y$ & 2 & Y & 2 & $Y$ & 1 & Y & 2 & $Y$ & 1 & Y & 16 & $Y$ \\
\hline 6 & 9 & $\mathrm{Y}$ & 5 & $Y$ & 4 & $Y$ & 5 & $Y$ & 6 & $Y$ & 4 & $Y$ & 2 & $Y$ & 5 & $\mathrm{~N}$ \\
\hline 7 & 5 & $Y$ & 5 & $Y$ & 5 & $Y$ & 5 & $Y$ & 10 & $Y$ & 2 & $Y$ & 2 & $Y$ & 8 & $Y$ \\
\hline 8 & - & $Y$ & - & $Y$ & - & $Y$ & - & $Y$ & - & $Y$ & - & $Y$ & - & $Y$ & - & $Y$ \\
\hline 9 & 4 & $Y$ & 3 & $Y$ & 2 & $Y$ & 1 & $Y$ & 5 & $Y$ & 1 & $Y$ & 1 & $Y$ & 3 & $Y$ \\
\hline 10 & 1 & $Y$ & 5 & $Y$ & 5 & $Y$ & 2 & $Y$ & 2 & $Y$ & 3 & $Y$ & 1 & $Y$ & 1 & $Y$ \\
\hline 11 & 3 & $Y$ & 4 & $Y$ & 3 & $Y$ & 3 & $Y$ & 3 & $Y$ & 2 & $Y$ & 2 & $Y$ & 3 & $Y$ \\
\hline 12 & 1 & $Y$ & 1 & $Y$ & 2 & $Y$ & 1 & $Y$ & 1 & $Y$ & 1 & $Y$ & 1 & $Y$ & 1 & $Y$ \\
\hline 13 & 3 & $Y$ & 2 & $Y$ & 3 & $Y$ & 2 & $Y$ & 1 & $Y$ & 1 & $Y$ & 1 & $Y$ & 3 & $Y$ \\
\hline 14 & - & $Y$ & - & $Y$ & - & $Y$ & - & $Y$ & - & $Y$ & - & $Y$ & - & $Y$ & - & $Y$ \\
\hline
\end{tabular}




\begin{tabular}{|c|c|c|c|c|c|c|c|c|c|c|c|c|c|c|c|c|}
\hline & \multicolumn{2}{|c|}{ Participant 9 } & \multicolumn{2}{c|}{ Participant 10 } & \multicolumn{2}{c|}{ Participant 11 } & \multicolumn{2}{c|}{ Participant 12 } & \multicolumn{2}{c|}{ Participant 13 } & \multicolumn{2}{c|}{ Participant 14 } & \multicolumn{2}{c|}{ Participant 15 } & \multicolumn{2}{c|}{ Participant 16 } \\
\hline Question & Time & Correct? & Time & Correct? & Time & Correct? & Time & Correct? & Time & Correct? & Time & Correct? & Time & Correct? & Time & Correct? \\
\hline 1 & 5 & $\mathrm{Y}$ & 4 & $\mathrm{Y}$ & 4 & $\mathrm{Y}$ & 1 & $\mathrm{Y}$ & 6 & $\mathrm{Y}$ & 2 & $\mathrm{Y}$ & 3 & $\mathrm{Y}$ & 2 & $\mathrm{Y}$ \\
\hline 2 & 9 & $\mathrm{Y}$ & 7 & $\mathrm{Y}$ & 6 & $\mathrm{Y}$ & 4 & $\mathrm{Y}$ & 11 & $\mathrm{Y}$ & 12 & $\mathrm{Y}$ & 6 & $\mathrm{Y}$ & 5 & $\mathrm{Y}$ \\
\hline 3 & 3 & $\mathrm{Y}$ & 3 & $\mathrm{Y}$ & 5 & $\mathrm{Y}$ & 1 & $\mathrm{Y}$ & 1 & $\mathrm{Y}$ & 3 & $\mathrm{Y}$ & 2 & $\mathrm{Y}$ & 1 & $\mathrm{Y}$ \\
\hline 4 & 4 & $\mathrm{Y}$ & 3 & $\mathrm{Y}$ & 5 & $\mathrm{Y}$ & 3 & $\mathrm{Y}$ & 4 & $\mathrm{Y}$ & 20 & $\mathrm{Y}$ & 5 & $\mathrm{Y}$ & 4 & $\mathrm{Y}$ \\
\hline 5 & 3 & $\mathrm{Y}$ & 5 & $\mathrm{Y}$ & 4 & $\mathrm{Y}$ & 1 & $\mathrm{Y}$ & 5 & $\mathrm{Y}$ & 3 & $\mathrm{Y}$ & 2 & $\mathrm{Y}$ & 2 & $\mathrm{Y}$ \\
\hline 6 & 3 & $\mathrm{Y}$ & 4 & $\mathrm{Y}$ & 4 & $\mathrm{~N}$ & 2 & $\mathrm{Y}$ & 6 & $\mathrm{Y}$ & 4 & $\mathrm{Y}$ & 7 & $\mathrm{Y}$ & 3 & $\mathrm{Y}$ \\
\hline 7 & 7 & $\mathrm{Y}$ & 7 & $\mathrm{Y}$ & 7 & $\mathrm{Y}$ & 6 & $\mathrm{Y}$ & 5 & $\mathrm{Y}$ & 3 & $\mathrm{Y}$ & 4 & $\mathrm{Y}$ & 4 & $\mathrm{Y}$ \\
\hline 8 & - & $\mathrm{Y}$ & - & $\mathrm{Y}$ & - & $\mathrm{Y}$ & - & $\mathrm{Y}$ & - & $\mathrm{Y}$ & - & $\mathrm{Y}$ & - & $\mathrm{Y}$ & - & $\mathrm{Y}$ \\
\hline 9 & 1 & $\mathrm{Y}$ & 3 & $\mathrm{Y}$ & 2 & $\mathrm{Y}$ & 1 & $\mathrm{Y}$ & 2 & $\mathrm{Y}$ & 3 & $\mathrm{Y}$ & 1 & $\mathrm{Y}$ & 1 & $\mathrm{Y}$ \\
\hline 10 & 1 & $\mathrm{Y}$ & 1 & $\mathrm{Y}$ & 1 & $\mathrm{Y}$ & 1 & $\mathrm{Y}$ & 1 & $\mathrm{Y}$ & 2 & $\mathrm{Y}$ & 1 & $\mathrm{Y}$ & 1 & $\mathrm{Y}$ \\
\hline 11 & 5 & $\mathrm{Y}$ & 4 & $\mathrm{Y}$ & 6 & $\mathrm{Y}$ & 4 & $\mathrm{Y}$ & 2 & $\mathrm{Y}$ & 2 & $\mathrm{Y}$ & 3 & $\mathrm{Y}$ & 3 & $\mathrm{Y}$ \\
\hline 12 & 1 & $\mathrm{Y}$ & 1 & $\mathrm{Y}$ & 3 & $\mathrm{Y}$ & 1 & $\mathrm{Y}$ & 4 & $\mathrm{Y}$ & 1 & $\mathrm{Y}$ & 4 & $\mathrm{Y}$ & 1 & $\mathrm{Y}$ \\
\hline 13 & 2 & $\mathrm{Y}$ & 3 & $\mathrm{Y}$ & 6 & $\mathrm{Y}$ & 1 & $\mathrm{Y}$ & 2 & $\mathrm{Y}$ & 1 & $\mathrm{Y}$ & 2 & $\mathrm{Y}$ & 1 & $\mathrm{Y}$ \\
\hline 14 & - & $\mathrm{Y}$ & - & $\mathrm{Y}$ & - & $\mathrm{Y}$ & - & $\mathrm{Y}$ & - & $\mathrm{Y}$ & - & $\mathrm{Y}$ & - & $\mathrm{Y}$ & - & $\mathrm{Y}$ \\
\hline
\end{tabular}




\begin{tabular}{|c|c|c|c|c|c|c|c|c|c|c|c|c|c|c|c|c|c|c|}
\hline \multirow[b]{2}{*}{$\mathbf{Q}$} & \multicolumn{2}{|c|}{ Participant 17} & \multicolumn{2}{|c|}{ Participant 18} & \multicolumn{2}{|c|}{ Participant 19} & \multicolumn{2}{|c|}{ Participant 20} & \multicolumn{2}{|c|}{ Participant 21} & \multicolumn{2}{|c|}{ Participant 22} & \multicolumn{2}{|c|}{ Participant 23} & \multicolumn{2}{|c|}{ Participant 24} & \multicolumn{2}{|c|}{ Participant 25} \\
\hline & Time & Correct? & Time & Correct? & Time & Correct? & Time & Correct? & Time & Correct? & Time & Correct? & Time & Correct? & Time & Correct? & Time & Correct? \\
\hline 1 & 2 & $\mathrm{Y}$ & 1 & $\mathrm{Y}$ & 10 & $\mathrm{Y}$ & 6 & $\mathrm{Y}$ & 6 & $\mathrm{Y}$ & 1 & $\mathrm{Y}$ & 3 & $\mathrm{Y}$ & 3 & $\mathrm{Y}$ & 1 & $\mathrm{Y}$ \\
\hline 2 & 5 & $Y$ & 7 & $Y$ & 7 & $Y$ & 25 & $Y$ & 8 & $Y$ & 5 & $\mathrm{~N}$ & 9 & $Y$ & 6 & $Y$ & 4 & $Y$ \\
\hline 3 & 1 & $Y$ & 2 & $Y$ & 3 & $Y$ & 3 & $Y$ & 1 & $Y$ & 2 & $Y$ & 5 & $Y$ & 1 & $Y$ & 1 & $Y$ \\
\hline 4 & 4 & $Y$ & 2 & $Y$ & 10 & $Y$ & 4 & $Y$ & 4 & $Y$ & 2 & $Y$ & 3 & $Y$ & 2 & $Y$ & 4 & $Y$ \\
\hline 5 & 1 & $Y$ & 2 & $Y$ & 5 & $Y$ & 6 & $Y$ & 2 & $Y$ & 2 & $Y$ & 2 & $Y$ & 7 & $Y$ & 7 & $Y$ \\
\hline 6 & 3 & $Y$ & 3 & $Y$ & 4 & $Y$ & 6 & $Y$ & 2 & $Y$ & 3 & $Y$ & 3 & $Y$ & 3 & $Y$ & 2 & $Y$ \\
\hline 8 & - & $Y$ & - & $Y$ & - & $Y$ & - & $Y$ & - & $Y$ & - & $Y$ & - & $Y$ & - & $Y$ & - & $Y$ \\
\hline 9 & 1 & $Y$ & 2 & $Y$ & 9 & $Y$ & 4 & $Y$ & 1 & $Y$ & 1 & $Y$ & 1 & $Y$ & 1 & $Y$ & 2 & $Y$ \\
\hline 10 & 1 & $Y$ & 1 & $Y$ & 2 & $Y$ & 2 & $Y$ & 1 & $Y$ & 1 & $Y$ & 1 & $Y$ & 1 & $Y$ & 1 & $Y$ \\
\hline 11 & 2 & $Y$ & 4 & $Y$ & 7 & $Y$ & 3 & $Y$ & 4 & $Y$ & 2 & $Y$ & 3 & $Y$ & 2 & $Y$ & 1 & $Y$ \\
\hline 12 & 1 & $Y$ & 2 & $Y$ & 6 & $Y$ & 3 & $Y$ & 1 & $Y$ & 1 & $Y$ & 1 & $Y$ & 1 & $Y$ & 1 & $Y$ \\
\hline 13 & 1 & $Y$ & 1 & $Y$ & 3 & $Y$ & 6 & $Y$ & 3 & $Y$ & 1 & $Y$ & 2 & $Y$ & 1 & $Y$ & 1 & $Y$ \\
\hline 14 & - & $Y$ & - & $Y$ & - & $Y$ & - & $Y$ & - & $Y$ & - & $Y$ & - & $Y$ & - & $Y$ & - & $Y$ \\
\hline
\end{tabular}




\begin{tabular}{|c|c|c|c|c|c|c|c|c|c|c|c|c|c|c|}
\hline \multirow[b]{2}{*}{ Question } & \multicolumn{2}{|c|}{ Participant 19} & \multicolumn{2}{|c|}{ Participant 20} & \multicolumn{2}{|c|}{ Participant 21} & \multicolumn{2}{|c|}{ Participant 22} & \multicolumn{2}{|c|}{ Participant 23} & \multicolumn{2}{|c|}{ Participant 24} & \multicolumn{2}{|c|}{ Participant 25} \\
\hline & Time & Correct? & Time & Correct? & Time & Correct? & Time & Correct? & Time & Correct? & Time & Correct? & Time & Correct? \\
\hline 1 & 10 & $\mathrm{Y}$ & 6 & $\mathrm{Y}$ & 6 & $Y$ & 1 & $Y$ & 3 & $Y$ & 3 & $Y$ & 1 & $\mathrm{Y}$ \\
\hline 2 & 7 & $Y$ & 25 & $Y$ & 8 & $Y$ & 5 & $\mathrm{~N}$ & 9 & $Y$ & 6 & $Y$ & 4 & $Y$ \\
\hline 3 & 3 & $Y$ & 3 & $Y$ & 1 & $Y$ & 2 & $Y$ & 5 & $Y$ & 1 & $Y$ & 1 & $Y$ \\
\hline 4 & 10 & $Y$ & 4 & $Y$ & 4 & $Y$ & 2 & $Y$ & 3 & $Y$ & 2 & $Y$ & 4 & $Y$ \\
\hline 5 & 5 & $Y$ & 6 & $Y$ & 2 & $Y$ & 2 & $Y$ & 2 & $Y$ & 7 & $Y$ & 7 & $Y$ \\
\hline 6 & 4 & $Y$ & 6 & $Y$ & 2 & $Y$ & 3 & $Y$ & 3 & $Y$ & 3 & $Y$ & 2 & $Y$ \\
\hline 7 & 9 & $Y$ & 6 & $Y$ & 5 & $Y$ & 4 & $Y$ & 3 & $Y$ & 11 & $Y$ & 3 & $Y$ \\
\hline 8 & - & $Y$ & - & $Y$ & - & $Y$ & - & $Y$ & - & $Y$ & - & $Y$ & - & $Y$ \\
\hline 9 & 9 & $Y$ & 4 & $Y$ & 1 & $Y$ & 1 & $Y$ & 1 & $Y$ & 1 & $Y$ & 2 & $Y$ \\
\hline 10 & 2 & $Y$ & 2 & $Y$ & 1 & $Y$ & 1 & $Y$ & 1 & $Y$ & 1 & $Y$ & 1 & $Y$ \\
\hline 11 & 7 & $Y$ & 3 & $Y$ & 4 & $Y$ & 2 & $Y$ & 3 & $Y$ & 2 & $Y$ & 1 & $Y$ \\
\hline 12 & 6 & $Y$ & 3 & $Y$ & 1 & $Y$ & 1 & $Y$ & 1 & $Y$ & 1 & $Y$ & 1 & $Y$ \\
\hline 13 & 3 & $Y$ & 6 & $Y$ & 3 & $Y$ & 1 & $Y$ & 2 & $Y$ & 1 & $Y$ & 1 & $Y$ \\
\hline 14 & - & $Y$ & - & $Y$ & - & $Y$ & - & $Y$ & - & $Y$ & - & $Y$ & - & $Y$ \\
\hline
\end{tabular}


Dashboard 2

\begin{tabular}{|c|c|c|c|c|c|c|c|c|c|c|c|c|c|c|c|c|}
\hline \multirow[b]{2}{*}{ Question } & \multicolumn{2}{|c|}{ Participant 1} & \multicolumn{2}{|c|}{ Participant 2} & \multicolumn{2}{|c|}{ Participant 3} & \multicolumn{2}{|c|}{ Participant 4} & \multicolumn{2}{|c|}{ Participant 5} & \multicolumn{2}{|c|}{ Participant 6} & \multicolumn{2}{|c|}{ Participant 7} & \multicolumn{2}{|c|}{ Participant 8} \\
\hline & Time & Correct? & Time & Correct? & Time & Correct? & Time & Correct? & Time & Correct? & Time & Correct? & Time & Correct? & Time & Correct? \\
\hline 1 & 3 & $Y$ & 1 & $\mathrm{Y}$ & 1 & $\mathrm{Y}$ & 1 & $\mathrm{Y}$ & 1 & $\mathrm{Y}$ & 1 & $\mathrm{Y}$ & 1 & $\mathrm{Y}$ & 1 & $\mathrm{Y}$ \\
\hline 2 & 6 & $\mathrm{~N}$ & 1 & $Y$ & 1 & $Y$ & 1 & $Y$ & 1 & $Y$ & 1 & $\mathrm{Y}$ & 1 & $\mathrm{Y}$ & 1 & $\mathrm{Y}$ \\
\hline 3 & 7 & $Y$ & 1 & $Y$ & 2 & $Y$ & 1 & $Y$ & 1 & $Y$ & 1 & $\mathrm{Y}$ & 1 & $\mathrm{Y}$ & 1 & $\mathrm{Y}$ \\
\hline 4 & - & $Y$ & - & Y & - & $Y$ & - & $Y$ & - & $Y$ & - & $\mathrm{Y}$ & - & $\mathrm{Y}$ & - & $\mathrm{Y}$ \\
\hline 5 & 3 & $Y$ & 3 & $Y$ & 3 & $Y$ & 5 & $Y$ & 1 & $Y$ & 2 & $\mathrm{Y}$ & 2 & $\mathrm{Y}$ & 4 & $\mathrm{Y}$ \\
\hline 6 & 4 & $Y$ & 1 & $Y$ & 2 & $Y$ & 1 & $Y$ & 1 & $Y$ & 1 & $Y$ & 1 & $Y$ & 1 & $Y$ \\
\hline 7 & 5 & $Y$ & 2 & $\mathrm{Y}$ & 6 & $Y$ & 6 & $Y$ & 4 & $Y$ & 6 & $Y$ & 3 & $\mathrm{Y}$ & 5 & $\mathrm{Y}$ \\
\hline 8 & 16 & $Y$ & 12 & $Y$ & 6 & $\mathrm{~N}$ & 20 & $Y$ & 3 & $Y$ & 3 & $Y$ & 3 & $Y$ & 3 & $Y$ \\
\hline 9 & 5 & $Y$ & 3 & $Y$ & 7 & $Y$ & 8 & $Y$ & 3 & $Y$ & 4 & $Y$ & 2 & $\mathrm{Y}$ & 8 & $\mathrm{~N}$ \\
\hline 10 & 1 & $Y$ & 1 & $\mathrm{Y}$ & 1 & $Y$ & 1 & $Y$ & 1 & $Y$ & 1 & $Y$ & 1 & $\mathrm{Y}$ & 1 & $Y$ \\
\hline 11 & - & $Y$ & - & $Y$ & - & $Y$ & - & $Y$ & - & $Y$ & - & $Y$ & - & $Y$ & - & $Y$ \\
\hline 12 & 9 & $Y$ & 6 & $Y$ & 11 & $\mathrm{~N}$ & 6 & $Y$ & 4 & $Y$ & 3 & $\mathrm{Y}$ & 5 & $Y$ & 5 & $Y$ \\
\hline 13 & 4 & $Y$ & 2 & $Y$ & 1 & $Y$ & 3 & $Y$ & 2 & $Y$ & 2 & $Y$ & 1 & $Y$ & 1 & $Y$ \\
\hline 14 & 11 & $Y$ & 4 & $Y$ & 2 & $Y$ & 3 & $Y$ & 3 & $Y$ & 2 & $Y$ & 2 & $Y$ & 2 & $Y$ \\
\hline
\end{tabular}




\begin{tabular}{|c|c|c|c|c|c|c|c|c|c|c|c|c|c|c|c|c|}
\hline & \multicolumn{2}{|c|}{ Participant 9 } & \multicolumn{2}{c|}{ Participant 10 } & \multicolumn{2}{c|}{ Participant 11 } & \multicolumn{2}{c|}{ Participant 12 } & \multicolumn{2}{c|}{ Participant 13 } & \multicolumn{2}{c|}{ Participant 14 } & \multicolumn{2}{c|}{ Participant 15 } & \multicolumn{2}{c|}{ Participant 16 } \\
\hline Question & Time & Correct? & Time & Correct? & Time & Correct? & Time & Correct? & Time & Correct? & Time & Correct? & Time & Correct? & Time & Correct? \\
\hline 1 & 1 & $\mathrm{Y}$ & 3 & $\mathrm{Y}$ & 4 & $\mathrm{Y}$ & 2 & $\mathrm{Y}$ & 1 & $\mathrm{Y}$ & 1 & $\mathrm{Y}$ & 3 & $\mathrm{~N}$ & 14 & $\mathrm{Y}$ \\
\hline 2 & 1 & $\mathrm{Y}$ & 1 & $\mathrm{Y}$ & 1 & $\mathrm{Y}$ & 1 & $\mathrm{Y}$ & 1 & $\mathrm{Y}$ & 1 & $\mathrm{Y}$ & 2 & $\mathrm{Y}$ & 1 & $\mathrm{Y}$ \\
\hline 3 & 1 & $\mathrm{Y}$ & 2 & $\mathrm{Y}$ & 2 & $\mathrm{Y}$ & 1 & $\mathrm{Y}$ & 1 & $\mathrm{Y}$ & 1 & $\mathrm{Y}$ & 2 & $\mathrm{Y}$ & 2 & $\mathrm{Y}$ \\
\hline 4 & - & $\mathrm{Y}$ & - & $\mathrm{Y}$ & - & $\mathrm{Y}$ & - & $\mathrm{Y}$ & - & $\mathrm{Y}$ & - & $\mathrm{Y}$ & - & $\mathrm{Y}$ & - & $\mathrm{Y}$ \\
\hline 5 & 2 & $\mathrm{Y}$ & 15 & $\mathrm{~N}$ & 3 & $\mathrm{Y}$ & 3 & $\mathrm{Y}$ & 4 & $\mathrm{Y}$ & 2 & $\mathrm{Y}$ & 5 & $\mathrm{Y}$ & 8 & $\mathrm{Y}$ \\
\hline 6 & 1 & $\mathrm{Y}$ & 1 & $\mathrm{Y}$ & 2 & $\mathrm{Y}$ & 1 & $\mathrm{Y}$ & 1 & $\mathrm{Y}$ & 1 & $\mathrm{Y}$ & 1 & $\mathrm{Y}$ & 1 & $\mathrm{Y}$ \\
\hline 7 & 4 & $\mathrm{Y}$ & 12 & $\mathrm{Y}$ & 13 & $\mathrm{Y}$ & 4 & $\mathrm{Y}$ & 3 & $\mathrm{Y}$ & 2 & $\mathrm{Y}$ & 5 & $\mathrm{Y}$ & 10 & $\mathrm{Y}$ \\
\hline 8 & 2 & $\mathrm{Y}$ & 15 & $\mathrm{Y}$ & 7 & $\mathrm{Y}$ & 9 & $\mathrm{Y}$ & 4 & $\mathrm{Y}$ & 2 & $\mathrm{Y}$ & 16 & $\mathrm{Y}$ & 10 & $\mathrm{Y}$ \\
\hline 9 & 3 & $\mathrm{Y}$ & 8 & $\mathrm{~N}$ & 14 & $\mathrm{Y}$ & 9 & $\mathrm{Y}$ & 3 & $\mathrm{~N}$ & 2 & $\mathrm{~N}$ & 4 & $\mathrm{Y}$ & 6 & $\mathrm{Y}$ \\
\hline 10 & 1 & $\mathrm{Y}$ & 1 & $\mathrm{Y}$ & 3 & $\mathrm{Y}$ & 1 & $\mathrm{Y}$ & 1 & $\mathrm{Y}$ & 3 & $\mathrm{Y}$ & 1 & $\mathrm{Y}$ & 1 & $\mathrm{Y}$ \\
\hline 11 & - & $\mathrm{Y}$ & - & $\mathrm{Y}$ & - & $\mathrm{Y}$ & - & $\mathrm{Y}$ & - & $\mathrm{Y}$ & - & $\mathrm{Y}$ & - & $\mathrm{Y}$ & - & $\mathrm{Y}$ \\
\hline 12 & 6 & $\mathrm{~N}$ & 12 & $\mathrm{Y}$ & 9 & $\mathrm{Y}$ & 20 & $\mathrm{Y}$ & 4 & $\mathrm{Y}$ & 7 & $\mathrm{Y}$ & 10 & $\mathrm{Y}$ & 9 & $\mathrm{Y}$ \\
\hline 13 & 2 & $\mathrm{Y}$ & 1 & $\mathrm{Y}$ & 2 & $\mathrm{Y}$ & 2 & $\mathrm{Y}$ & 1 & $\mathrm{Y}$ & 1 & $\mathrm{Y}$ & 1 & $\mathrm{Y}$ & 2 & $\mathrm{Y}$ \\
\hline 14 & 3 & $\mathrm{Y}$ & 7 & $\mathrm{Y}$ & 3 & $\mathrm{Y}$ & 6 & $\mathrm{Y}$ & 2 & $\mathrm{Y}$ & 3 & $\mathrm{Y}$ & 4 & $\mathrm{Y}$ & 4 & $\mathrm{Y}$ \\
\hline
\end{tabular}




\begin{tabular}{|c|c|c|c|c|c|c|c|c|c|c|c|c|c|c|c|c|c|c|}
\hline \multirow[b]{2}{*}{$\mathbf{Q}$} & \multicolumn{2}{|c|}{ Participant 17} & \multicolumn{2}{|c|}{ Participant 18} & \multicolumn{2}{|c|}{ Participant 19} & \multicolumn{2}{|c|}{ Participant 20} & \multicolumn{2}{|c|}{ Participant 21} & \multicolumn{2}{|c|}{ Participant 22} & \multicolumn{2}{|c|}{ Participant 23} & \multicolumn{2}{|c|}{ Participant 24} & \multicolumn{2}{|c|}{ Participant 25} \\
\hline & Time & Correct? & Time & Correct? & Time & Correct? & Time & Correct? & Time & Correct? & Time & Correct? & Time & Correct? & Time & Correct? & Time & Correct? \\
\hline 1 & 1 & $\mathrm{Y}$ & 1 & $\mathrm{Y}$ & 2 & $\mathrm{Y}$ & 2 & $\mathrm{Y}$ & 1 & $\mathrm{Y}$ & 6 & $\mathrm{Y}$ & 1 & $\mathrm{Y}$ & 1 & $\mathrm{Y}$ & 1 & $\mathrm{Y}$ \\
\hline 2 & 1 & $\mathrm{Y}$ & 1 & $Y$ & 1 & $Y$ & 2 & $\mathrm{Y}$ & 1 & $\mathrm{Y}$ & 4 & $\mathrm{Y}$ & 1 & $Y$ & 1 & $\mathrm{Y}$ & 1 & $\mathrm{Y}$ \\
\hline 3 & 1 & $\mathrm{Y}$ & 4 & $Y$ & 2 & $Y$ & 1 & $Y$ & 1 & $\mathrm{Y}$ & 1 & $\mathrm{Y}$ & 1 & $Y$ & 4 & $\mathrm{Y}$ & 1 & $\mathrm{Y}$ \\
\hline 4 & - & $\mathrm{Y}$ & - & $Y$ & - & $Y$ & - & $Y$ & - & $\mathrm{Y}$ & - & $\mathrm{Y}$ & - & $Y$ & - & $\mathrm{Y}$ & - & $\mathrm{Y}$ \\
\hline 5 & 2 & $\mathrm{Y}$ & 3 & $Y$ & 7 & $\mathrm{Y}$ & 3 & $\mathrm{Y}$ & 7 & $Y$ & 7 & $\mathrm{Y}$ & 4 & $\mathrm{Y}$ & 6 & $\mathrm{Y}$ & 2 & $\mathrm{Y}$ \\
\hline 6 & 1 & $Y$ & 2 & $Y$ & 8 & $Y$ & 2 & $Y$ & 3 & $Y$ & 1 & $Y$ & 1 & $Y$ & 1 & $\mathrm{Y}$ & 1 & $Y$ \\
\hline 8 & 2 & $Y$ & 2 & $Y$ & 7 & $Y$ & 3 & $Y$ & 12 & $Y$ & 5 & $Y$ & 1 & $Y$ & 2 & $Y$ & 11 & $\mathrm{Y}$ \\
\hline 9 & 4 & $\mathrm{Y}$ & 5 & $Y$ & 10 & $\mathrm{~N}$ & 5 & $Y$ & 3 & $\mathrm{Y}$ & 4 & $\mathrm{~N}$ & 4 & $\mathrm{~N}$ & 4 & $\mathrm{Y}$ & 3 & $\mathrm{~N}$ \\
\hline 10 & 1 & $\mathrm{Y}$ & 1 & $Y$ & 2 & $\mathrm{Y}$ & 1 & $Y$ & 1 & $Y$ & 1 & $Y$ & 1 & $Y$ & 1 & $\mathrm{Y}$ & 1 & $Y$ \\
\hline 11 & - & $Y$ & - & $Y$ & - & $Y$ & - & $Y$ & - & $Y$ & - & $Y$ & - & $Y$ & - & $\mathrm{Y}$ & - & $\mathrm{Y}$ \\
\hline 12 & 5 & $\mathrm{Y}$ & 5 & $Y$ & 7 & $\mathrm{Y}$ & 7 & $Y$ & 9 & $\mathrm{Y}$ & 8 & $\mathrm{Y}$ & 5 & $\mathrm{Y}$ & 3 & $\mathrm{Y}$ & 3 & $\mathrm{Y}$ \\
\hline 13 & 2 & $\mathrm{Y}$ & 2 & $Y$ & 2 & $\mathrm{Y}$ & 3 & $\mathrm{Y}$ & 1 & $\mathrm{Y}$ & 1 & $\mathrm{Y}$ & 1 & $\mathrm{Y}$ & 1 & $\mathrm{Y}$ & 1 & $\mathrm{Y}$ \\
\hline 14 & 2 & $Y$ & 6 & $Y$ & 6 & $Y$ & 2 & $Y$ & 2 & $Y$ & 3 & $Y$ & 2 & $Y$ & 3 & $Y$ & 3 & $Y$ \\
\hline
\end{tabular}


Dashboard 3

\begin{tabular}{|c|c|c|c|c|c|c|c|c|c|c|c|c|c|c|c|c|}
\hline & \multicolumn{2}{|c|}{ Participant 1} & \multicolumn{2}{|c|}{ Participant 2} & \multicolumn{2}{|c|}{ Participant 3} & \multicolumn{2}{|c|}{ Participant 4} & \multicolumn{2}{|c|}{ Participant 5} & \multicolumn{2}{|c|}{ Participant 6} & \multicolumn{2}{|c|}{ Participant 7} & \multicolumn{2}{|c|}{ Participant 8} \\
\hline Question & Time & Correct? & Time & Correct? & Time & Correct? & Time & Correct? & Time & Correct? & Time & Correct? & Time & Correct? & Time & Correct? \\
\hline 1 & 6 & $\mathrm{Y}$ & 2 & $\mathrm{Y}$ & 1 & $\mathrm{Y}$ & 1 & $\mathrm{Y}$ & 1 & $\mathrm{Y}$ & 1 & $\mathrm{Y}$ & 1 & $\mathrm{Y}$ & 1 & $\mathrm{Y}$ \\
\hline 2 & 2 & $\mathrm{Y}$ & 1 & $\mathrm{Y}$ & 1 & $\mathrm{Y}$ & 2 & $Y$ & 1 & $Y$ & 2 & $Y$ & 2 & $\mathrm{Y}$ & 1 & $\mathrm{Y}$ \\
\hline 3 & 11 & $\mathrm{~N}$ & 3 & Y & 3 & Y & 3 & $Y$ & 3 & $Y$ & 2 & Y & 2 & Y & 2 & Y \\
\hline 4 & 8 & $\mathrm{Y}$ & 1 & $\mathrm{Y}$ & 6 & $\mathrm{Y}$ & 1 & $\mathrm{Y}$ & 1 & $Y$ & 9 & $\mathrm{~N}$ & 8 & $\mathrm{~N}$ & 1 & $\mathrm{Y}$ \\
\hline 5 & - & $Y$ & - & Y & - & Y & - & $Y$ & - & Y & - & Y & - & $Y$ & - & $\mathrm{Y}$ \\
\hline 6 & 8 & $\mathrm{Y}$ & 4 & $\mathrm{Y}$ & 7 & $\mathrm{Y}$ & 3 & $\mathrm{Y}$ & 4 & $\mathrm{~N}$ & 6 & $Y$ & 3 & $\mathrm{Y}$ & 2 & $Y$ \\
\hline 7 & 2 & $Y$ & 1 & $Y$ & 1 & $Y$ & 2 & $Y$ & 1 & $Y$ & 2 & $\mathrm{~N}$ & 1 & $Y$ & 1 & $Y$ \\
\hline 8 & 5 & $Y$ & 2 & $Y$ & 10 & $\mathrm{~N}$ & 2 & $Y$ & 2 & $Y$ & 5 & $Y$ & 3 & $Y$ & 2 & $Y$ \\
\hline 9 & 5 & $\mathrm{Y}$ & 5 & $\mathrm{Y}$ & 6 & $Y$ & 4 & $Y$ & 3 & $Y$ & 5 & $\mathrm{Y}$ & 4 & $\mathrm{Y}$ & 4 & $Y$ \\
\hline 10 & 1 & $Y$ & 1 & $Y$ & 2 & $Y$ & 1 & $Y$ & 1 & $Y$ & 1 & $Y$ & 1 & $Y$ & 1 & $Y$ \\
\hline 11 & 2 & $Y$ & 1 & $Y$ & 3 & $\mathrm{~N}$ & 2 & $Y$ & 1 & $Y$ & 1 & $\mathrm{Y}$ & 2 & $\mathrm{Y}$ & 1 & $Y$ \\
\hline 12 & 6 & $Y$ & 5 & $Y$ & 7 & $Y$ & 4 & $Y$ & 2 & $Y$ & 6 & $Y$ & 4 & $Y$ & 6 & $Y$ \\
\hline 13 & 3 & $Y$ & 1 & $\mathrm{Y}$ & 2 & $Y$ & 2 & $Y$ & 1 & $Y$ & 3 & $Y$ & 1 & $\mathrm{Y}$ & 1 & $Y$ \\
\hline 14 & - & $Y$ & - & $Y$ & - & $Y$ & - & $Y$ & - & $Y$ & - & $Y$ & - & $Y$ & - & $Y$ \\
\hline
\end{tabular}




\begin{tabular}{|c|c|c|c|c|c|c|c|c|c|c|c|c|c|c|c|c|}
\hline \multirow[b]{2}{*}{ Question } & \multicolumn{2}{|c|}{ Participant 9} & \multicolumn{2}{|c|}{ Participant 10} & \multicolumn{2}{|c|}{ Participant 11} & \multicolumn{2}{|c|}{ Participant 12} & \multicolumn{2}{|c|}{ Participant 13} & \multicolumn{2}{|c|}{ Participant 14} & \multicolumn{2}{|c|}{ Participant 15} & \multicolumn{2}{|c|}{ Participant 16} \\
\hline & Time & Correct? & Time & Correct? & Time & Correct? & Time & Correct? & Time & Correct? & Time & Correct? & Time & Correct? & Time & Correct? \\
\hline 1 & 1 & $Y$ & 1 & $Y$ & 1 & $Y$ & 1 & $Y$ & 1 & $Y$ & 1 & $Y$ & 1 & $Y$ & 1 & $\mathrm{Y}$ \\
\hline 2 & 2 & $Y$ & 1 & $Y$ & 1 & $Y$ & 2 & $Y$ & 2 & $Y$ & 1 & $Y$ & 1 & $Y$ & 1 & $\mathrm{Y}$ \\
\hline 3 & 2 & $Y$ & 3 & $Y$ & 3 & $Y$ & 5 & $Y$ & 3 & $Y$ & 2 & $Y$ & 3 & $Y$ & 3 & $Y$ \\
\hline 4 & 10 & $Y$ & 8 & $Y$ & 3 & $Y$ & 8 & $Y$ & 2 & $Y$ & 2 & $Y$ & 3 & $Y$ & 2 & $\mathrm{Y}$ \\
\hline 5 & - & $Y$ & - & $Y$ & - & $Y$ & - & $Y$ & - & $Y$ & - & $Y$ & - & $Y$ & - & $Y$ \\
\hline 6 & 2 & $Y$ & 5 & $Y$ & 5 & $Y$ & 4 & $Y$ & 2 & $Y$ & 1 & $Y$ & 3 & $Y$ & 3 & $Y$ \\
\hline 7 & 1 & $Y$ & 1 & $Y$ & 3 & $Y$ & 2 & $Y$ & 2 & $Y$ & 3 & $Y$ & 2 & $Y$ & 2 & $Y$ \\
\hline 8 & 8 & $Y$ & 4 & $Y$ & 4 & $Y$ & 15 & $\mathrm{~N}$ & 1 & $Y$ & 5 & $Y$ & 4 & $Y$ & 3 & $\mathrm{Y}$ \\
\hline 9 & 3 & $Y$ & 5 & $Y$ & 8 & $Y$ & 7 & $Y$ & 3 & $Y$ & 7 & $Y$ & 5 & $Y$ & 5 & $Y$ \\
\hline 10 & 1 & $Y$ & 1 & $Y$ & 1 & $Y$ & 1 & $Y$ & 1 & $Y$ & 1 & $Y$ & 1 & $Y$ & 1 & $Y$ \\
\hline 11 & 1 & $Y$ & 1 & $Y$ & 5 & $\mathrm{~N}$ & 6 & $Y$ & 1 & $Y$ & 1 & $Y$ & 1 & $Y$ & 1 & $Y$ \\
\hline 12 & 12 & $Y$ & 5 & $Y$ & 8 & $Y$ & 6 & $Y$ & 3 & $Y$ & 6 & $Y$ & 6 & $Y$ & 5 & $Y$ \\
\hline 13 & 1 & $Y$ & 1 & $Y$ & 2 & $Y$ & 2 & $Y$ & 1 & $Y$ & 1 & $Y$ & 1 & $Y$ & 1 & $Y$ \\
\hline 14 & - & $Y$ & - & $Y$ & - & $Y$ & - & $Y$ & - & $Y$ & - & $Y$ & - & $Y$ & - & $Y$ \\
\hline
\end{tabular}




\begin{tabular}{|c|c|c|c|c|c|c|c|c|c|c|c|c|c|c|c|c|c|c|}
\hline \multirow[b]{2}{*}{$\mathbf{Q}$} & \multicolumn{2}{|c|}{ Participant 17} & \multicolumn{2}{|c|}{ Participant 18} & \multicolumn{2}{|c|}{ Participant 19} & \multicolumn{2}{|c|}{ Participant 20} & \multicolumn{2}{|c|}{ Participant 21} & \multicolumn{2}{|c|}{ Participant 22} & \multicolumn{2}{|c|}{ Participant 23} & \multicolumn{2}{|c|}{ Participant 24} & \multicolumn{2}{|c|}{ Participant 25} \\
\hline & Time & Correct? & Time & Correct? & Time & Correct? & Time & Correct? & Time & Correct? & Time & Correct? & Time & Correct? & Time & Correct? & Time & Correct? \\
\hline 1 & 1 & $\mathrm{Y}$ & 2 & $\mathrm{Y}$ & 2 & $\mathrm{Y}$ & 1 & $\mathrm{Y}$ & 1 & $\mathrm{Y}$ & 1 & $\mathrm{Y}$ & 3 & $\mathrm{Y}$ & 4 & $\mathrm{Y}$ & 1 & $\mathrm{Y}$ \\
\hline 2 & 1 & $Y$ & 2 & $Y$ & 1 & $\mathrm{Y}$ & 1 & $\mathrm{Y}$ & 2 & $\mathrm{Y}$ & 1 & $\mathrm{Y}$ & 1 & $Y$ & 1 & $Y$ & 1 & $\mathrm{Y}$ \\
\hline 3 & 2 & $\mathrm{Y}$ & 7 & $Y$ & 3 & $Y$ & 3 & $Y$ & 4 & $\mathrm{Y}$ & 3 & $\mathrm{Y}$ & 5 & $Y$ & 13 & $\mathrm{Y}$ & 2 & $\mathrm{Y}$ \\
\hline 4 & 2 & $\mathrm{Y}$ & 5 & $Y$ & 2 & $Y$ & 12 & $Y$ & 2 & $\mathrm{Y}$ & 2 & $\mathrm{Y}$ & 3 & $Y$ & 2 & $\mathrm{Y}$ & 1 & $\mathrm{Y}$ \\
\hline 5 & - & $\mathrm{Y}$ & - & $Y$ & - & $\mathrm{Y}$ & - & $\mathrm{Y}$ & - & $Y$ & - & $\mathrm{Y}$ & - & $\mathrm{Y}$ & - & $\mathrm{Y}$ & - & $\mathrm{Y}$ \\
\hline 6 & 2 & $Y$ & 6 & $Y$ & 4 & $Y$ & 5 & $Y$ & 6 & $Y$ & 3 & $Y$ & 4 & $Y$ & 3 & $\mathrm{Y}$ & 2 & $Y$ \\
\hline 8 & 6 & $Y$ & 4 & $Y$ & 5 & $Y$ & 8 & $Y$ & 5 & $Y$ & 2 & $Y$ & 7 & $Y$ & 15 & $Y$ & 1 & $\mathrm{Y}$ \\
\hline 9 & 3 & $\mathrm{Y}$ & 6 & $Y$ & 6 & $Y$ & 5 & $\mathrm{Y}$ & 4 & $\mathrm{Y}$ & 3 & $\mathrm{Y}$ & 4 & $Y$ & 5 & $\mathrm{Y}$ & 3 & $\mathrm{Y}$ \\
\hline 10 & 1 & $\mathrm{Y}$ & 1 & $Y$ & 1 & $Y$ & 1 & $Y$ & 2 & $\mathrm{Y}$ & 1 & $Y$ & 2 & $Y$ & 1 & $\mathrm{Y}$ & 1 & $\mathrm{Y}$ \\
\hline 11 & 1 & $Y$ & 2 & $Y$ & 1 & $Y$ & 1 & $Y$ & 1 & $Y$ & 1 & $Y$ & 1 & $Y$ & 3 & $\mathrm{Y}$ & 1 & $\mathrm{Y}$ \\
\hline 12 & 6 & $\mathrm{Y}$ & 4 & $Y$ & 4 & $\mathrm{Y}$ & 4 & $Y$ & 9 & $\mathrm{Y}$ & 2 & $\mathrm{Y}$ & 4 & $\mathrm{Y}$ & 4 & $\mathrm{Y}$ & 2 & $\mathrm{Y}$ \\
\hline 13 & 1 & $\mathrm{Y}$ & 5 & $Y$ & 2 & $\mathrm{Y}$ & 2 & $\mathrm{Y}$ & 1 & $Y$ & 1 & $\mathrm{Y}$ & 3 & $\mathrm{Y}$ & 1 & $\mathrm{Y}$ & 1 & $\mathrm{Y}$ \\
\hline 14 & - & $Y$ & - & $Y$ & - & $Y$ & - & $Y$ & - & $Y$ & - & $Y$ & - & $Y$ & - & $Y$ & - & $Y$ \\
\hline
\end{tabular}




\section{Appendix B-2: NASA TLX Output Data}

\begin{tabular}{|c|c|c|c|c|c|c|c|c|}
\hline experimentalID & participantID & tlx_Score & scale_mental & scale_physical & scale_temporal & scale_perform & scale_effort & scale_frustration \\
\hline Dash2 & Part1 & 42.73 & 14 & 1 & 64 & 50 & 42 & 29 \\
\hline Dash1 & Part1 & 23.67 & 10 & 4 & 49 & 22 & 40 & 9 \\
\hline Dash3 & Part1 & 12.19 & 4 & 0 & 13 & 14 & 15 & 20 \\
\hline Dash1 & Part2 & 39.07 & 25 & 0 & 49 & 51 & 39 & 10 \\
\hline Dash2 & Part2 & 17.47 & 15 & 0 & 14 & 26 & 15 & 0 \\
\hline Dash3 & Part2 & 15.67 & 9 & 0 & 10 & 31 & 18 & 0 \\
\hline Dash3 & Part3 & 47.53 & 39 & 9 & 65 & 11 & 74 & 66 \\
\hline Dash1 & Part3 & 41.33 & 60 & 5 & 28 & 17 & 66 & 41 \\
\hline Dash2 & Part3 & 36.21 & 25 & 4 & 43 & 10 & 65 & 50 \\
\hline Dash2 & Part4 & 11.67 & 5 & 0 & 15 & 5 & 50 & 10 \\
\hline Dash3 & Part4 & 2.73 & 4 & 5 & 4 & 1 & 4 & 0 \\
\hline Dash1 & Part4 & 9.81 & 9 & 5 & 11 & 11 & 10 & 4 \\
\hline Dash1 & Part5 & 27.47 & 48 & 16 & 29 & 16 & 12 & 5 \\
\hline Dash3 & Part5 & 17.47 & 19 & 20 & 19 & 16 & 15 & 6 \\
\hline Dash2 & Part5 & 28.39 & 38 & 11 & 27 & 25 & 34 & 5 \\
\hline Dash3 & Part6 & 49.33 & 69 & 9 & 78 & 16 & 39 & 8 \\
\hline Dash1 & Part6 & 58.13 & 74 & 6 & 72 & 29 & 50 & 29 \\
\hline Dash2 & Part6 & 26.27 & 33 & 1 & 46 & 1 & 53 & 0 \\
\hline Dash3 & Part7 & 52.26 & 50 & 5 & 67 & 39 & 30 & 50 \\
\hline Dash2 & Part7 & 64.01 & 59 & 0 & 74 & 36 & 60 & 70 \\
\hline Dash1 & Part7 & 62.59 & 58 & 0 & 70 & 33 & 60 & 65 \\
\hline Dash1 & Part8 & 19.2 & 24 & 1 & 35 & 12 & 13 & 6 \\
\hline Dash2 & Part8 & 14.27 & 5 & 1 & 20 & 19 & 10 & 3 \\
\hline Dash3 & Part8 & 8.6 & 1 & 2 & 13 & 7 & 12 & 4 \\
\hline Dash1 & Part9 & 24.2 & 32 & 1 & 23 & 13 & 41 & 1 \\
\hline Dash3 & Part9 & 24.6 & 34 & 8 & 19 & 11 & 44 & 18 \\
\hline
\end{tabular}




\begin{tabular}{|c|c|c|c|c|c|c|c|c|}
\hline Dash2 & Part9 & 31.13 & 42 & 8 & 23 & 35 & 33 & 11 \\
\hline Dash2 & Part10 & 42.94 & 34 & 5 & 50 & 31 & 50 & 49 \\
\hline Dash1 & Part10 & 45.59 & 60 & 44 & 65 & 11 & 60 & 50 \\
\hline Dash2 & Part11 & 21.87 & 29 & 5 & 29 & 16 & 19 & 1 \\
\hline Dash3 & Part11 & 2.01 & 2 & 2 & 0 & 1 & 6 & 1 \\
\hline Dash1 & Part11 & 72.86 & 84 & 67 & 89 & 50 & 70 & 60 \\
\hline Dash1 & Part12 & 3.47 & 2 & 3 & 4 & 3 & 5 & 2 \\
\hline Dash1 & Part13 & 33.27 & 44 & 5 & 45 & 2 & 44 & 5 \\
\hline Dash2 & Part13 & 25.74 & 19 & 9 & 50 & 5 & 49 & 8 \\
\hline Dash3 & Part13 & 52.81 & 70 & 10 & 50 & 30 & 64 & 30 \\
\hline Dash1 & Part14 & 37.07 & 7 & 8 & 50 & 35 & 70 & 41 \\
\hline Dash1 & Part15 & 31.27 & 0 & 0 & 45 & 1 & 94 & 4 \\
\hline Dash3 & Part15 & 0 & 0 & 0 & 0 & 0 & 0 & 0 \\
\hline Dash2 & Part16 & 28.73 & 27 & 3 & 52 & 19 & 22 & 1 \\
\hline Dash3 & Part16 & 22.87 & 17 & 1 & 41 & 24 & 8 & 2 \\
\hline Dash1 & Part16 & 43.53 & 61 & 1 & 42 & 35 & 37 & 16 \\
\hline Dash3 & Part17 & 57.2 & 79 & 9 & 80 & 20 & 60 & 50 \\
\hline Dash1 & Part17 & 73.4 & 66 & 22 & 93 & 61 & 72 & 55 \\
\hline Dash2 & Part17 & 68.54 & 79 & 45 & 74 & 42 & 74 & 63 \\
\hline Dash3 & Part18 & 12.14 & 15 & 1 & 9 & 22 & 0 & 2 \\
\hline Dash2 & Part18 & 24.27 & 38 & 7 & 5 & 30 & 29 & 5 \\
\hline Dash1 & Part18 & 24.4 & 30 & 0 & 11 & 20 & 44 & 0 \\
\hline
\end{tabular}




\begin{tabular}{|c|c|c|c|c|c|c|c|c|}
\hline Dash3 & Part19 & 51.6 & 55 & 9 & 79 & 5 & 60 & 54 \\
\hline Dash1 & Part20 & 34.33 & 36 & 3 & 48 & 14 & 49 & 0 \\
\hline Dash3 & Part20 & 36 & 44 & 1 & 58 & 23 & 18 & 9 \\
\hline Dash2 & Part20 & 18.74 & 4 & 0 & 10 & 11 & 64 & 10 \\
\hline Dash2 & Part21 & 25.06 & 41 & 1 & 34 & 1 & 19 & 1 \\
\hline Dash1 & Part21 & 30.8 & 50 & 3 & 45 & 2 & 24 & 11 \\
\hline Dash3 & Part21 & 21.14 & 36 & 3 & 44 & 2 & 14 & 1 \\
\hline Dash1 & Part22 & 33.47 & 21 & 0 & 50 & 36 & 20 & 5 \\
\hline Dash3 & Part23 & 16.67 & 30 & 0 & 15 & 20 & 10 & 5 \\
\hline Dash1 & Part23 & 36.4 & 34 & 1 & 54 & 22 & 46 & 32 \\
\hline Dash2 & Part23 & 19.19 & 22 & 1 & 30 & 16 & 16 & 10 \\
\hline Dash3 & Part24 & 41.2 & 25 & 0 & 54 & 35 & 33 & 49 \\
\hline Dash2 & Part25 & 53.13 & 35 & 5 & 64 & 36 & 75 & 40 \\
\hline Dash3 & Part25 & 16 & 19 & 14 & 26 & 11 & 10 & 10 \\
\hline
\end{tabular}




\begin{tabular}{|c|c|c|c|c|c|c|c|}
\hline experimentalID & participantID & workload_mental & workload_physical & workload_temporal & workload_perform & workload_effort & workload_frustration \\
\hline Dash2 & Part1 & 0.2 & 0 & 0.33 & 0.2 & 0.07 & 0.2 \\
\hline Dash1 & Part1 & 0.27 & 0 & 0.2 & 0.33 & 0.07 & 0.13 \\
\hline Dash3 & Part1 & 0.2 & 0 & 0.33 & 0.27 & 0.13 & 0.07 \\
\hline Dash1 & Part2 & 0.27 & 0 & 0.33 & 0.2 & 0.13 & 0.07 \\
\hline Dash2 & Part2 & 0.27 & 0 & 0.2 & 0.33 & 0.13 & 0 \\
\hline Dash3 & Part2 & 0.33 & 0 & 0.2 & 0.27 & 0.13 & 0 \\
\hline Dash3 & Part3 & 0.33 & 0 & 0.07 & 0.2 & 0.2 & 0.2 \\
\hline Dash1 & Part3 & 0.27 & 0 & 0.13 & 0.33 & 0.2 & 0.07 \\
\hline Dash2 & Part3 & 0.27 & 0 & 0.07 & 0.27 & 0.27 & 0.13 \\
\hline Dash2 & Part4 & 0.27 & 0 & 0.13 & 0.33 & 0.13 & 0 \\
\hline Dash3 & Part4 & 0.2 & 0 & 0.2 & 0.33 & 0.2 & 0 \\
\hline Dash1 & Part4 & 0.27 & 0 & 0.13 & 0.33 & 0.2 & 0.07 \\
\hline Dash1 & Part5 & 0.27 & 0.07 & 0.27 & 0.27 & 0.13 & 0 \\
\hline Dash3 & Part5 & 0.27 & 0.07 & 0.2 & 0.27 & 0.2 & 0 \\
\hline Dash2 & Part5 & 0.2 & 0.07 & 0.27 & 0.33 & 0.13 & 0 \\
\hline Dash3 & Part6 & 0.13 & 0 & 0.33 & 0.2 & 0.27 & 0.07 \\
\hline Dash1 & Part6 & 0.27 & 0 & 0.33 & 0.2 & 0.13 & 0.07 \\
\hline Dash2 & Part6 & 0.2 & 0 & 0.27 & 0.33 & 0.13 & 0 \\
\hline Dash3 & Part7 & 0.27 & 0 & 0.33 & 0.07 & 0.13 & 0.2 \\
\hline Dash2 & Part7 & 0.13 & 0 & 0.33 & 0.13 & 0.13 & 0.27 \\
\hline Dash1 & Part7 & 0.13 & 0 & 0.33 & 0.07 & 0.2 & 0.27 \\
\hline Dash1 & Part8 & 0.27 & 0.07 & 0.2 & 0.33 & 0.13 & 0 \\
\hline Dash2 & Part8 & 0.2 & 0 & 0.33 & 0.27 & 0.13 & 0.07 \\
\hline Dash3 & Part8 & 0.13 & 0 & 0.27 & 0.33 & 0.2 & 0.07 \\
\hline Dash1 & Part9 & 0.27 & 0.07 & 0.13 & 0.33 & 0.2 & 0 \\
\hline Dash3 & Part9 & 0.27 & 0.07 & 0.13 & 0.33 & 0.2 & 0 \\
\hline Dash2 & Part9 & 0.2 & 0.07 & 0.27 & 0.33 & 0.13 & 0 \\
\hline Dash2 & Part10 & 0.27 & 0 & 0.2 & 0.13 & 0.13 & 0.27 \\
\hline Dash1 & Part10 & 0.13 & 0 & 0.27 & 0.27 & 0.07 & 0.27 \\
\hline
\end{tabular}




\begin{tabular}{|c|c|c|c|c|c|c|c|}
\hline Dash3 & Part10 & 0.2 & 0 & 0.07 & 0.33 & 0.13 & 0.27 \\
\hline Dash2 & Part11 & 0.2 & 0.13 & 0.33 & 0.2 & 0.13 & 0 \\
\hline Dash3 & Part11 & 0.14 & 0.14 & 0 & 0.2 & 0.2 & 0.07 \\
\hline Dash1 & Part11 & 0.27 & 0 & 0.2 & 0.07 & 0.13 & 0.33 \\
\hline Dash3 & Part12 & 0.13 & 0 & 0.27 & 0.33 & 0.2 & 0.07 \\
\hline Dash2 & Part12 & 0.13 & 0 & 0.27 & 0.33 & 0.2 & 0.07 \\
\hline Dash1 & Part12 & 0.14 & 0 & 0.27 & 0.33 & 0.2 & 0.07 \\
\hline Dash1 & Part13 & 0.33 & 0.07 & 0.27 & 0.2 & 0.13 & 0 \\
\hline Dash2 & Part13 & 0.2 & 0 & 0.13 & 0.33 & 0.27 & 0.07 \\
\hline Dash3 & Part13 & 0.27 & 0.07 & 0.33 & 0.13 & 0.2 & 0 \\
\hline Dash1 & Part14 & 0.27 & 0.07 & 0.13 & 0.27 & 0.27 & 0 \\
\hline Dash3 & Part14 & 0.27 & 0.07 & 0.13 & 0.2 & 0.33 & 0 \\
\hline Dash2 & Part14 & 0.33 & 0.07 & 0.13 & 0.2 & 0.27 & 0 \\
\hline Dash2 & Part15 & 0.33 & 0 & 0.27 & 0.2 & 0 & 0 \\
\hline Dash1 & Part15 & 0 & 0 & 0.13 & 0.2 & 0.27 & 0 \\
\hline Dash3 & Part15 & 0 & 0 & 0 & 0 & 0 & 0 \\
\hline Dash2 & Part16 & 0.2 & 0.07 & 0.27 & 0.33 & 0.13 & 0 \\
\hline Dash3 & Part16 & 0.13 & 0.07 & 0.27 & 0.33 & 0.2 & 0 \\
\hline Dash1 & Part16 & 0.33 & 0.07 & 0.27 & 0.2 & 0.13 & 0 \\
\hline Dash3 & Part17 & 0.13 & 0 & 0.33 & 0.27 & 0.13 & 0.13 \\
\hline Dash1 & Part17 & 0.07 & 0 & 0.33 & 0.27 & 0.2 & 0.13 \\
\hline Dash2 & Part17 & 0.2 & 0 & 0.33 & 0.13 & 0.13 & 0.2 \\
\hline Dash3 & Part18 & 0.33 & 0.07 & 0.13 & 0.27 & 0 & 0 \\
\hline Dash2 & Part18 & 0.33 & 0.07 & 0.27 & 0.13 & 0.2 & 0 \\
\hline Dash1 & Part18 & 0.33 & 0 & 0.27 & 0.13 & 0.2 & 0 \\
\hline Dash1 & Part19 & 0.27 & 0 & 0.33 & 0.13 & 0.07 & 0.2 \\
\hline Dash2 & Part19 & 0.2 & 0 & 0.27 & 0.07 & 0.13 & 0.33 \\
\hline Dash3 & Part19 & 0.33 & 0 & 0.27 & 0.2 & 0.07 & 0.13 \\
\hline Dash1 & Part20 & 0.33 & 0.07 & 0.27 & 0.2 & 0.13 & 0 \\
\hline Dash3 & Part20 & 0.27 & 0 & 0.27 & 0.2 & 0.2 & 0.07 \\
\hline
\end{tabular}


P a g e | 112

\begin{tabular}{|c|c|c|c|c|c|c|c|}
\hline Dash2 & Part20 & 0.27 & 0 & 0.2 & 0.2 & 0.2 & 0.07 \\
\hline Dash2 & Part21 & 0.27 & 0.07 & 0.33 & 0.2 & 0.13 & 0 \\
\hline Dash1 & Part21 & 0.27 & 0.07 & 0.2 & 0.14 & 0.33 & 0 \\
\hline Dash3 & Part21 & 0.2 & 0 & 0.2 & 0.2 & 0.33 & 0.07 \\
\hline Dash2 & Part22 & 0.2 & 0 & 0.27 & 0.33 & 0.13 & 0 \\
\hline Dash3 & Part22 & 0.2 & 0 & 0.33 & 0.27 & 0.13 & 0 \\
\hline Dash1 & Part22 & 0.2 & 0 & 0.33 & 0.27 & 0.13 & 0.07 \\
\hline Dash3 & Part23 & 0.13 & 0 & 0.27 & 0.33 & 0.13 & 0.13 \\
\hline Dash1 & Part23 & 0.33 & 0 & 0.13 & 0.2 & 0.2 & 0.13 \\
\hline Dash2 & Part23 & 0.2 & 0 & 0.2 & 0.33 & 0.13 & 0.13 \\
\hline Dash3 & Part24 & 0.27 & 0 & 0.33 & 0.07 & 0.13 & 0.2 \\
\hline Dash2 & Part24 & 0.2 & 0 & 0.33 & 0.07 & 0.27 & 0.13 \\
\hline Dash1 & Part24 & 0.13 & 0 & 0.33 & 0.07 & 0.2 & 0.27 \\
\hline Dash1 & Part25 & 0.33 & 0.07 & 0.2 & 0.13 & 0.27 & 0 \\
\hline Dash2 & Part25 & 0.27 & 0 & 0.33 & 0.13 & 0.2 & 0.07 \\
\hline Dash3 & Part25 & 0.27 & 0.07 & 0.2 & 0.13 & 0.33 & 0 \\
\hline
\end{tabular}




\begin{tabular}{|c|c|c|c|c|c|c|c|}
\hline $\begin{array}{l}\text { experime } \\
\text { ntalID }\end{array}$ & $\begin{array}{l}\text { particip } \\
\text { antID }\end{array}$ & $\begin{array}{l}\text { workloadWeight } \\
\text { ed_mental }\end{array}$ & $\begin{array}{l}\text { workloadWeighte } \\
\text { d_physical }\end{array}$ & $\begin{array}{l}\text { workloadWeighte } \\
\text { d_temporal }\end{array}$ & $\begin{array}{l}\text { workloadWeighte } \\
\text { d_perform }\end{array}$ & $\begin{array}{l}\text { workloadWeigh } \\
\text { ted_effort }\end{array}$ & $\begin{array}{l}\text { workloadWeighted } \\
\text { frustration }\end{array}$ \\
\hline Dash2 & Part1 & 2.8 & 0 & 21.33 & 10 & 2.8 & 5.8 \\
\hline Dash1 & Part1 & 2.67 & 0 & 9.8 & 7.33 & 2.67 & 1.2 \\
\hline Dash3 & Part1 & 0.8 & 0 & 4.33 & 3.73 & 2 & 1.33 \\
\hline Dash1 & Part2 & 6.67 & 0 & 16.33 & 10.2 & 5.2 & 0.67 \\
\hline Dash2 & Part2 & 4 & 0 & 2.8 & 8.67 & 2 & 0 \\
\hline Dash3 & Part2 & 3 & 0 & 2 & 8.27 & 2.4 & 0 \\
\hline Dash3 & Part3 & 13 & 0 & 4.33 & 2.2 & 14.8 & 13.2 \\
\hline Dash1 & Part3 & 16 & 0 & 3.73 & 5.67 & 13.2 & 2.73 \\
\hline Dash2 & Part3 & 6.67 & 0 & 2.87 & 2.67 & 17.33 & 6.67 \\
\hline Dash2 & Part4 & 1.33 & 0 & 2 & 1.67 & 6.67 & 0 \\
\hline Dash3 & Part4 & 0.8 & 0 & 0.8 & 0.33 & 0.8 & 0 \\
\hline Dash1 & Part4 & 2.4 & 0 & 1.47 & 3.67 & 2 & 0.27 \\
\hline Dash1 & Part5 & 12.8 & 1.07 & 7.73 & 4.27 & 1.6 & 0 \\
\hline Dash3 & Part5 & 5.07 & 1.33 & 3.8 & 4.27 & 3 & 0 \\
\hline Dash2 & Part5 & 7.6 & 0.73 & 7.2 & 8.33 & 4.53 & 0 \\
\hline Dash3 & Part6 & 9.2 & 0 & 26 & 3.2 & 10.4 & 0.53 \\
\hline Dash1 & Part6 & 19.73 & 0 & 24 & 5.8 & 6.67 & 1.93 \\
\hline Dash2 & Part6 & 6.6 & 0 & 12.27 & 0.33 & 7.07 & 0 \\
\hline Dash3 & Part7 & 13.33 & 0 & 22.33 & 2.6 & 4 & 10 \\
\hline Dash2 & Part7 & 7.87 & 0 & 24.67 & 4.8 & 8 & 18.67 \\
\hline Dash1 & Part7 & 7.73 & 0 & 23.33 & 2.2 & 12 & 17.33 \\
\hline Dash1 & Part8 & 6.4 & 0.07 & 7 & 4 & 1.73 & 0 \\
\hline Dash2 & Part8 & 1 & 0 & 6.67 & 5.07 & 1.33 & 0.2 \\
\hline Dash3 & Part8 & 0.13 & 0 & 3.47 & 2.33 & 2.4 & 0.27 \\
\hline Dash1 & Part9 & 8.53 & 0.07 & 3.07 & 4.33 & 8.2 & 0 \\
\hline Dash3 & Part9 & 9.07 & 0.53 & 2.53 & 3.67 & 8.8 & 0 \\
\hline Dash2 & Part9 & 8.4 & 0.53 & 6.13 & 11.67 & 4.4 & 0 \\
\hline
\end{tabular}




\begin{tabular}{|c|c|c|c|c|c|c|c|}
\hline Dash2 & Part10 & 9.07 & 0 & 10 & 4.13 & 6.67 & 13.07 \\
\hline Dash1 & Part10 & 8 & 0 & 17.33 & 2.93 & 4 & 13.33 \\
\hline Dash3 & Part10 & 3.8 & 0 & 2 & 3.33 & 4 & 3.73 \\
\hline Dash2 & Part11 & 5.8 & 0.67 & 9.67 & 3.2 & 2.53 & 0 \\
\hline Dash3 & Part11 & 0.27 & 0.27 & 0 & 0.2 & 1.2 & 0.07 \\
\hline Dash1 & Part11 & 22.4 & 0 & 17.8 & 3.33 & 9.33 & 20 \\
\hline Dash3 & Part12 & 2.53 & 0 & 2.4 & 3.67 & 4 & 0.47 \\
\hline Dash2 & Part12 & 1.87 & 0 & 3.2 & 2.33 & 5.6 & 0.47 \\
\hline Dash1 & Part12 & 0.27 & 0 & 1.07 & 1 & 1 & 0.13 \\
\hline Dash1 & Part13 & 14.67 & 0.33 & 12 & 0.4 & 5.87 & 0 \\
\hline Dash2 & Part13 & 3.8 & 0 & 6.67 & 1.67 & 13.07 & 0.53 \\
\hline Dash3 & Part13 & 18.67 & 0.67 & 16.67 & 4 & 12.8 & 0 \\
\hline Dash1 & Part14 & 1.87 & 0.53 & 6.67 & 9.33 & 18.67 & 0 \\
\hline Dash3 & Part14 & 3.47 & 0.6 & 8.4 & 6.4 & 25 & 0 \\
\hline Dash2 & Part14 & 10.67 & 0.27 & 4 & 7.4 & 24 & 0 \\
\hline Dash2 & Part15 & 1.67 & 0 & 13.07 & 0.4 & 0 & 0 \\
\hline Dash1 & Part15 & 0 & 0 & 6 & 0.2 & 25.07 & 0 \\
\hline Dash3 & Part15 & 0 & 0 & 0 & 0 & 0 & 0 \\
\hline Dash2 & Part16 & 5.4 & 0.2 & 13.87 & 6.33 & 2.93 & 0 \\
\hline Dash3 & Part16 & 2.27 & 0.07 & 10.93 & 8 & 1.6 & 0 \\
\hline Dash1 & Part16 & 20.33 & 0.07 & 11.2 & 7 & 4.93 & 0 \\
\hline Dash3 & Part17 & 10.53 & 0 & 26.67 & 5.33 & 8 & 6.67 \\
\hline Dash1 & Part17 & 4.4 & 0 & 31 & 16.27 & 14.4 & 7.33 \\
\hline Dash2 & Part17 & 15.8 & 0 & 24.67 & 5.6 & 9.87 & 12.6 \\
\hline Dash3 & Part18 & 5 & 0.07 & 1.2 & 5.87 & 0 & 0 \\
\hline Dash2 & Part18 & 12.67 & 0.47 & 1.33 & 4 & 5.8 & 0 \\
\hline Dash1 & Part18 & 10 & 0 & 2.93 & 2.67 & 8.8 & 0 \\
\hline Dash1 & Part19 & 15.73 & 0 & 28 & 1.47 & 5 & 13 \\
\hline Dash2 & Part19 & 11.8 & 0 & 20 & 0.93 & 10.4 & 21 \\
\hline Dash3 & Part19 & 18.33 & 0 & 21.07 & 1 & 4 & 7.2 \\
\hline
\end{tabular}


P a g e | 115

\begin{tabular}{|c|c|c|c|c|c|c|c|}
\hline Dash1 & Part20 & 12 & 0.2 & 12.8 & 2.8 & 6.53 & 0 \\
\hline Dash3 & Part20 & 11.73 & 0 & 15.47 & 4.6 & 3.6 & 0.6 \\
\hline Dash2 & Part20 & 1.07 & 0 & 2 & 2.2 & 12.8 & 0.67 \\
\hline Dash2 & Part21 & 10.93 & 0.07 & 11.33 & 0.2 & 2.53 & 0 \\
\hline Dash1 & Part21 & 13.33 & 0.2 & 9 & 0.27 & 8 & 0 \\
\hline Dash3 & Part21 & 7.2 & 0 & 8.8 & 0.4 & 4.67 & 0.07 \\
\hline Dash2 & Part22 & 9.8 & 0 & 5.33 & 10 & 6.8 & 0 \\
\hline Dash3 & Part22 & 2.8 & 0 & 21.67 & 7.73 & 2.67 & 0 \\
\hline Dash1 & Part22 & 4.2 & 0 & 16.67 & 9.6 & 2.67 & 0.33 \\
\hline Dash3 & Part23 & 4 & 0 & 4 & 6.67 & 1.33 & 0.67 \\
\hline Dash1 & Part23 & 11.33 & 0 & 7.2 & 4.4 & 9.2 & 4.27 \\
\hline Dash2 & Part23 & 4.4 & 0 & 6 & 5.33 & 2.13 & 1.33 \\
\hline Dash3 & Part24 & 6.67 & 0 & 18 & 2.33 & 4.4 & 9.8 \\
\hline Dash2 & Part24 & 9.8 & 0 & 18 & 3 & 16 & 6.67 \\
\hline Dash1 & Part24 & 4 & 0 & 21.33 & 3.67 & 12.8 & 16.8 \\
\hline Dash1 & Part25 & 14.67 & 0.33 & 13.6 & 2.8 & 18.4 & 0 \\
\hline Dash2 & Part25 & 9.33 & 0 & 21.33 & 4.8 & 15 & 2.67 \\
\hline Dash3 & Part25 & 5.07 & 0.93 & 5.2 & 1.47 & 3.33 & 0 \\
\hline
\end{tabular}




\section{Appendix C: Design Factor ANOVA Testing}




\section{Appendix C-1: Analytical Ratings - Normal Distribution}

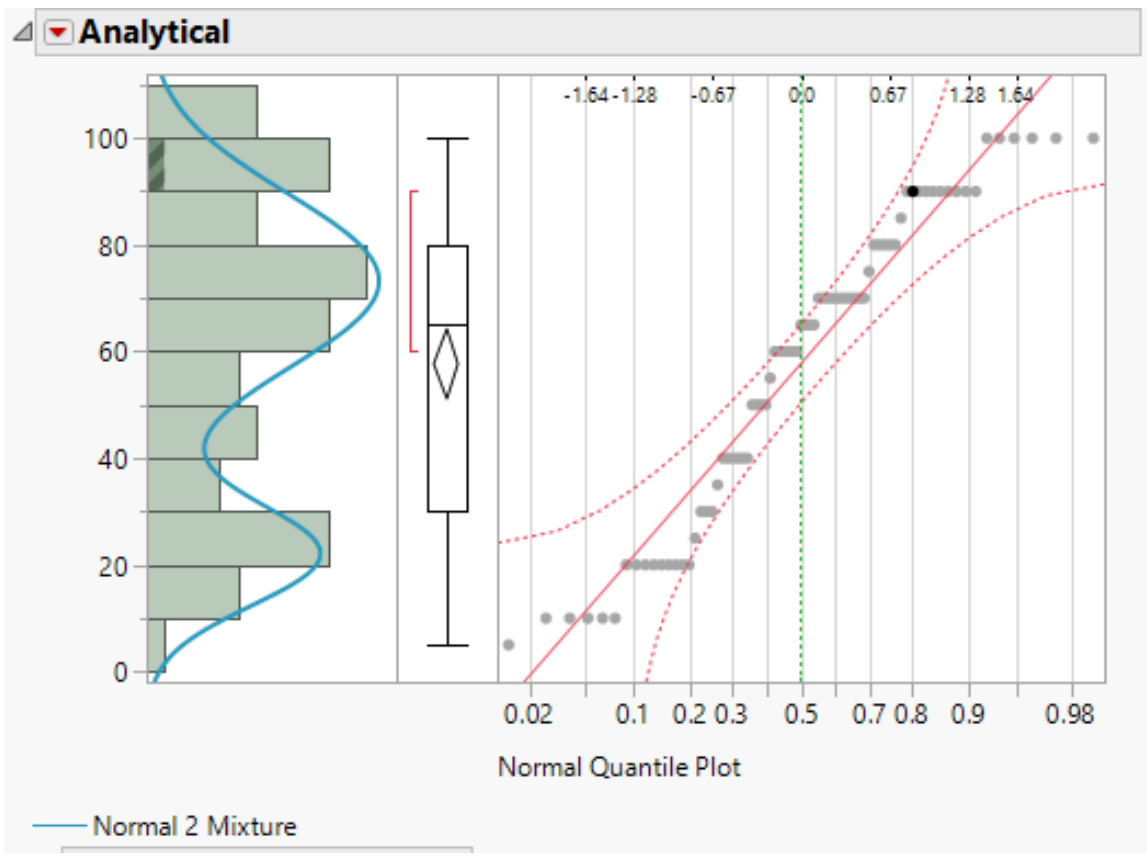


Appendix C-2: Analytical Ratings - Normality of Residuals and Equality of Variances Normality of Residuals

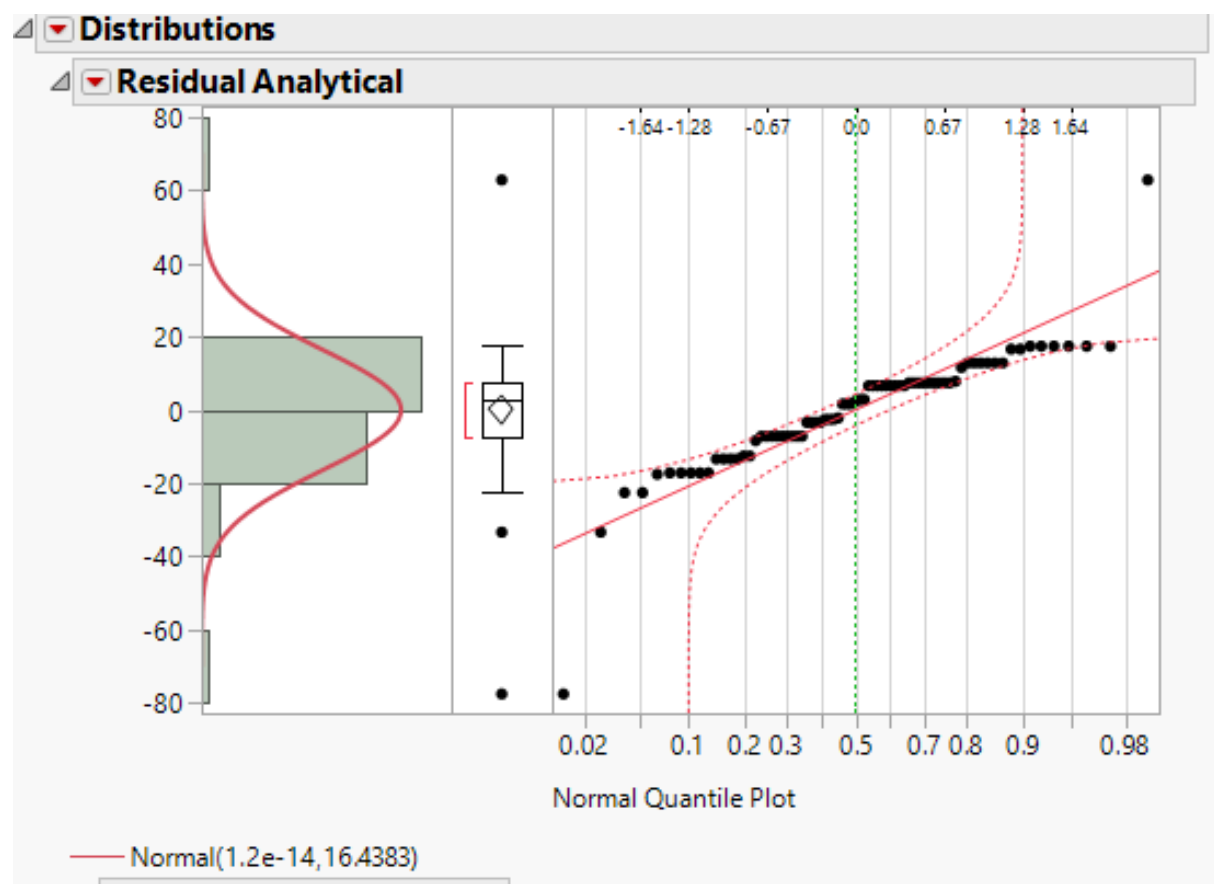

\section{Equality of Variances}

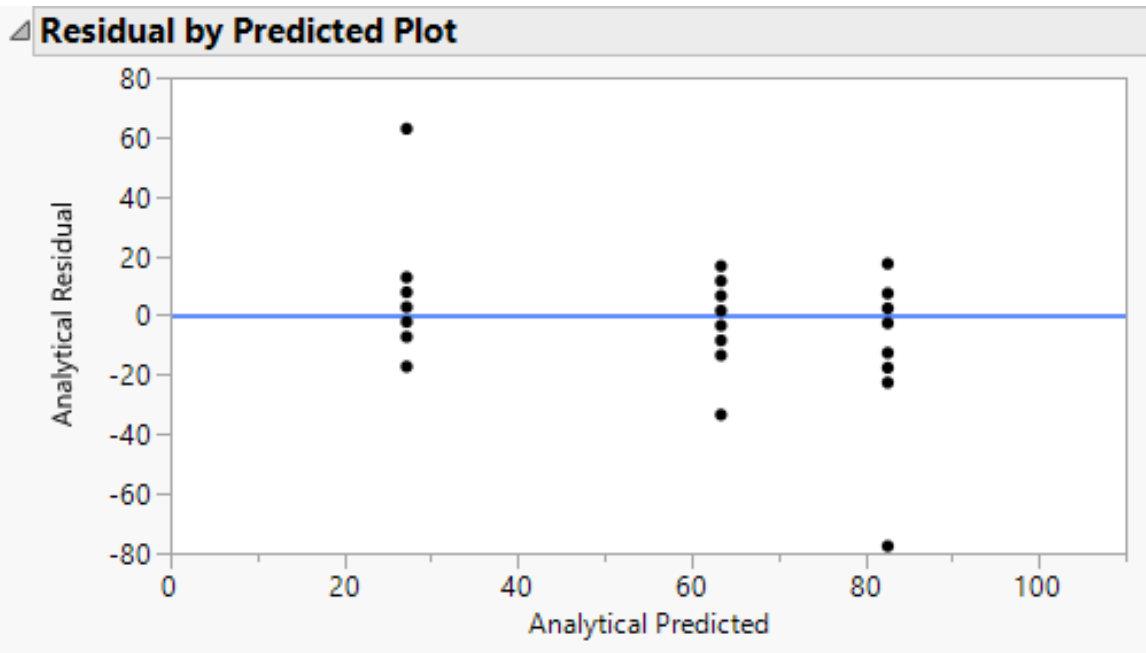


Appendix C-3: Analytical Ratings - ANOVA Testing

\begin{tabular}{|c|c|c|c|c|c|}
\hline \multicolumn{4}{|c|}{$\triangle$ Summary of Fit } & & \\
\hline \multicolumn{3}{|c|}{ RSquare } & \multicolumn{3}{|l|}{0.664298} \\
\hline \multicolumn{3}{|c|}{ RSquare Adj } & \multicolumn{3}{|l|}{0.654973} \\
\hline \multicolumn{3}{|c|}{ Root Mean Square Error } & \multicolumn{3}{|l|}{16.665} \\
\hline \multicolumn{3}{|c|}{ Mean of Response } & \multicolumn{3}{|l|}{57.73333} \\
\hline \multicolumn{3}{|c|}{ Observations (or Sum Wgts) } & \multicolumn{3}{|l|}{75} \\
\hline \multicolumn{6}{|c|}{$\triangle$ Analysis of Variance } \\
\hline Source & DF & $\begin{array}{r}\text { Sum of } \\
\text { Squares }\end{array}$ & \multicolumn{2}{|c|}{ Mean Square } & F Ratio \\
\hline Model & 2 & 39568.667 & & 784.3 & 71.2378 \\
\hline Error & 72 & 19996.000 & & 277.7 Pro & Prob $>F$ \\
\hline C. Total & 745 & 59564.667 & & & $<.0001^{*}$ \\
\hline \multicolumn{6}{|c|}{$\triangleright$ Parameter Estimates } \\
\hline \multicolumn{6}{|c|}{$\triangle$ Effect Tests } \\
\hline Source & Nparm & DF & $\begin{array}{r}\text { Sum of } \\
\text { Squares }\end{array}$ & F Ratio & Prob $>F$ \\
\hline Dashboard & & 2 & 39568.667 & 71.2378 & $<.0001^{*}$ \\
\hline
\end{tabular}


$\underline{\text { Appendix C-4: Analytical Ratings - Pairwise Comparisons }}$

\begin{tabular}{|c|c|c|c|c|c|c|c|c|}
\hline \multicolumn{9}{|c|}{$\triangle$ Multiple Comparisons for Dashboard } \\
\hline \multicolumn{9}{|c|}{$\triangle$ Least Squares Means Estimates } \\
\hline Dashboard & Estimate & Std Error & DF & Lower & r $95 \%$ & Upper $95 \%$ & $\begin{array}{l}\text { Arithme } \\
\text { Mean Estim }\end{array}$ & $\begin{array}{l}\text { etic } \\
\text { late }\end{array}$ \\
\hline 1 & 82.600000 & 3.3330000 & 72 & 75.9 & 55786 & 89.244214 & 82.600 & 000 \\
\hline 2 & 63.400000 & 3.3330000 & 72 & 56.7 & 55786 & 70.044214 & 63.400 & 0000 \\
\hline 3 & 27.200000 & 3.3330000 & 72 & 20.5 & 55786 & 33.844214 & 27.200 & 000 \\
\hline \multicolumn{9}{|c|}{$\Delta \nabla$ Student's t All Pairwise Comparisons } \\
\hline \multicolumn{9}{|c|}{ Quantile $=1.99346, \mathrm{DF}=72.0$} \\
\hline \multicolumn{9}{|c|}{$\triangle$ All Pairwise Differences } \\
\hline Dashboard & -Dashboard & Difference & Std & Error & t Ratio & Prob $>|t|$ & Lower $95 \%$ & Upper $95 \%$ \\
\hline 1 & 2 & 19.20000 & 4.7 & 13574 & 4.07 & $0.0001^{*}$ & 9.80366 & 28.59634 \\
\hline 1 & 3 & 55.40000 & 4.7 & 13574 & 11.75 & $<.0001^{*}$ & 46.00366 & 64.79634 \\
\hline 2 & 3 & 36.20000 & 4.7 & 13574 & 7.68 & $<.0001^{\star}$ & 26.80366 & 45.59634 \\
\hline
\end{tabular}




\section{Appendix C-5: Engaging Ratings - Normal Distribution}

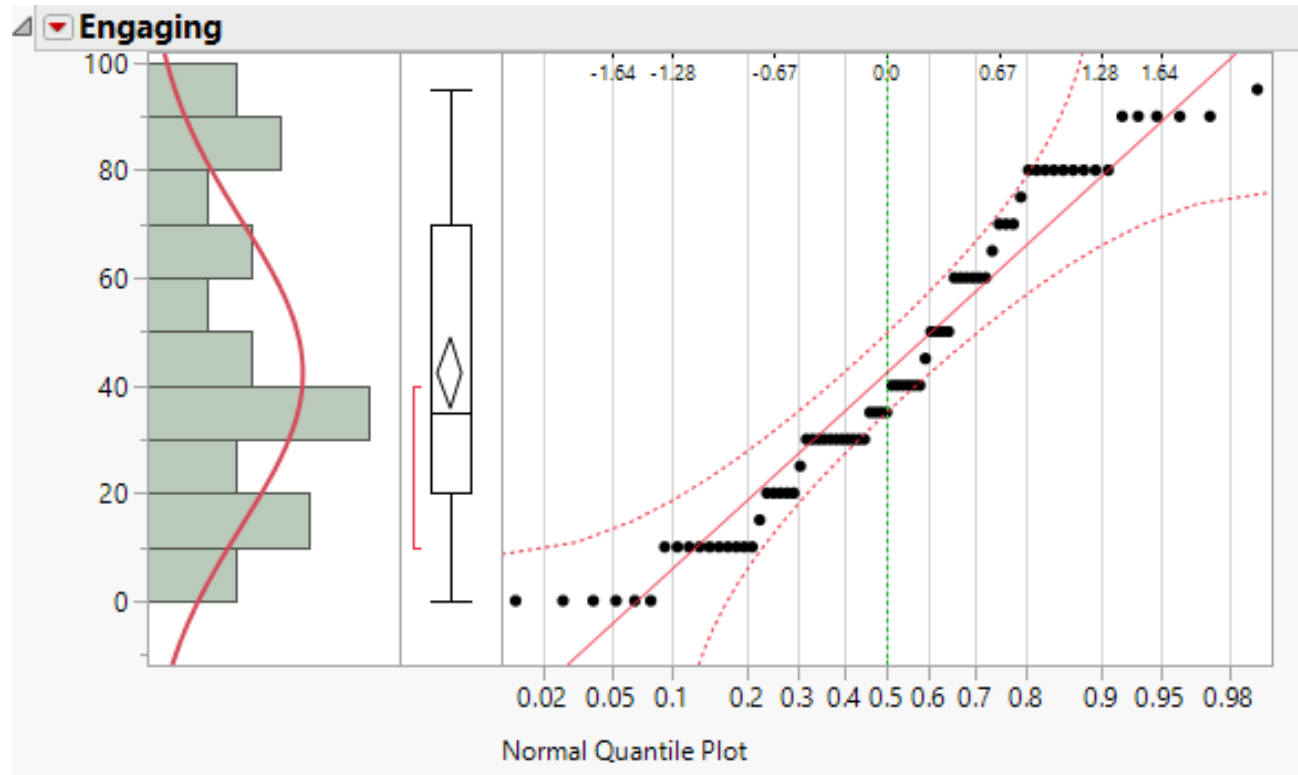

- Normal(42.2667,28.3713) 


\section{Appendix C-6: Engaging Ratings - Normality of Residuals and Equality of Variances}

\section{Normality of Residuals}

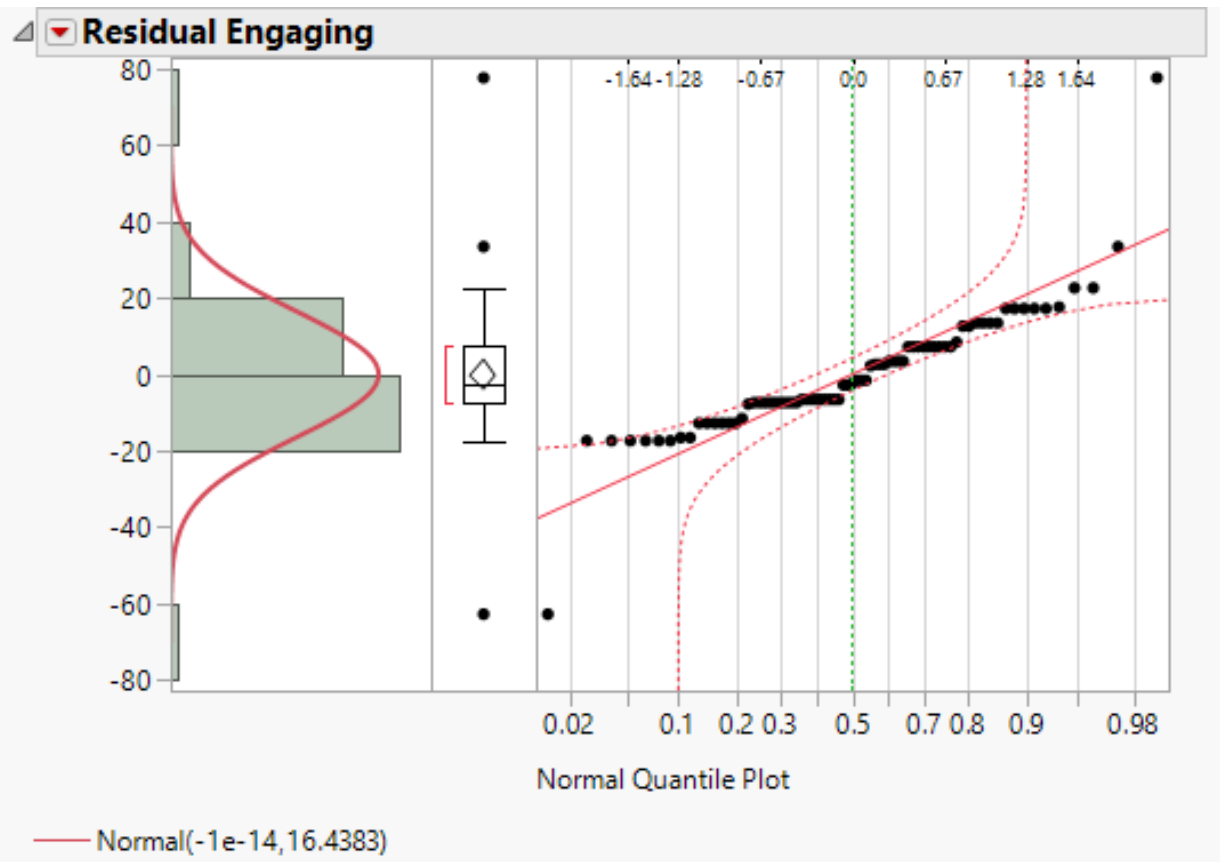

\section{Equality of Variances}

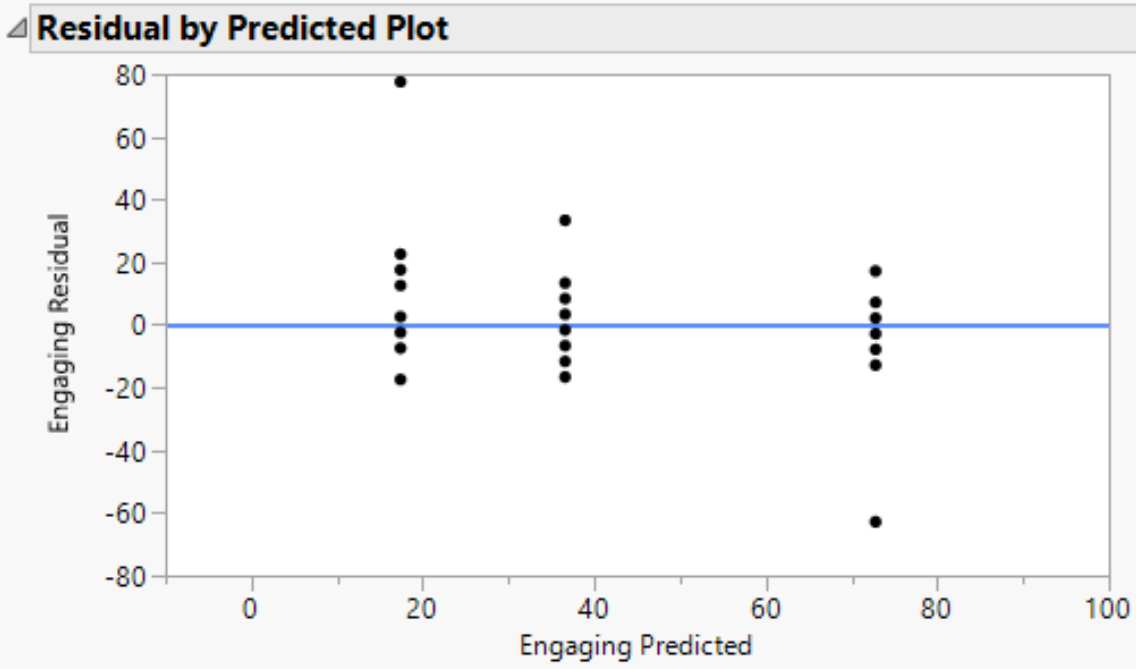




\section{Appendix C-7: Engaging Ratings - ANOVA Testing}

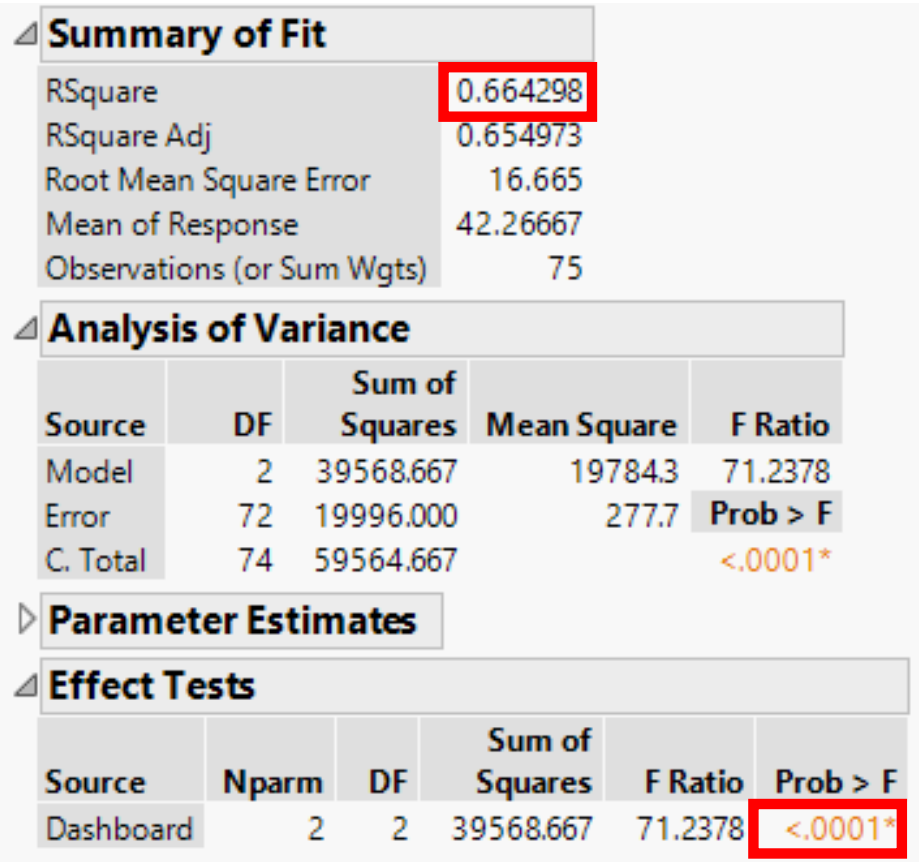




\section{Appendix C-8: Engaging Ratings - Pairwise Comparisons}

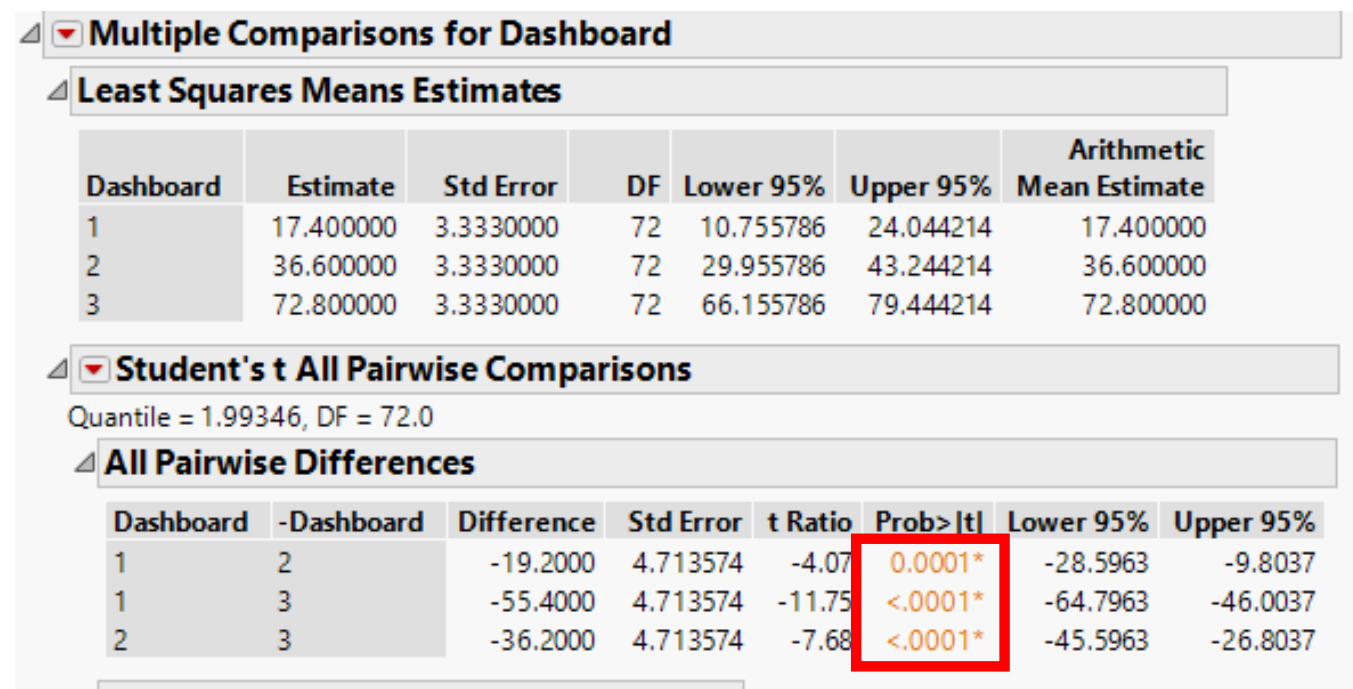




\section{Appendix C-9: Interesting Rating - Distribution Fit and Box-Cox Transformation}
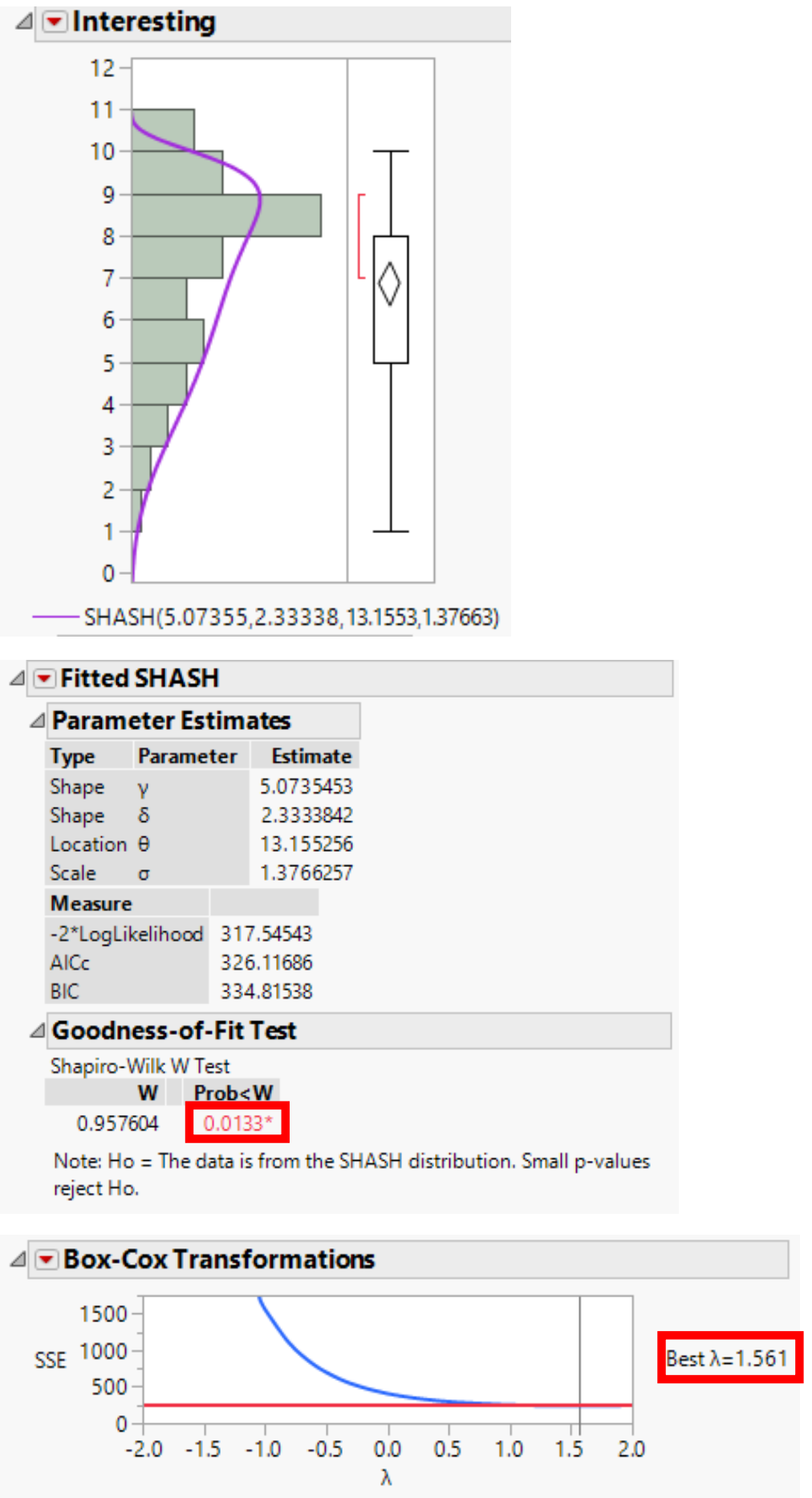
Appendix C-10: Interesting Ratings - Normality of Residuals and Equality of Variances

Normality of Residuals

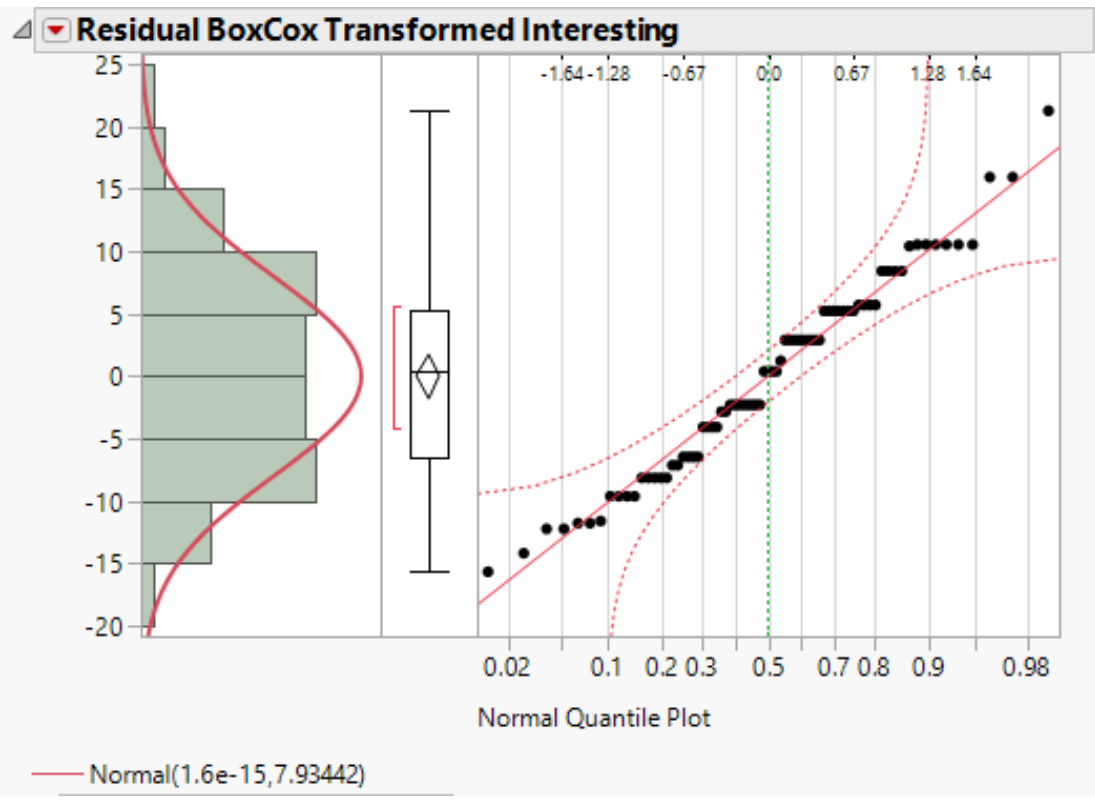

\section{Equality of Variances}

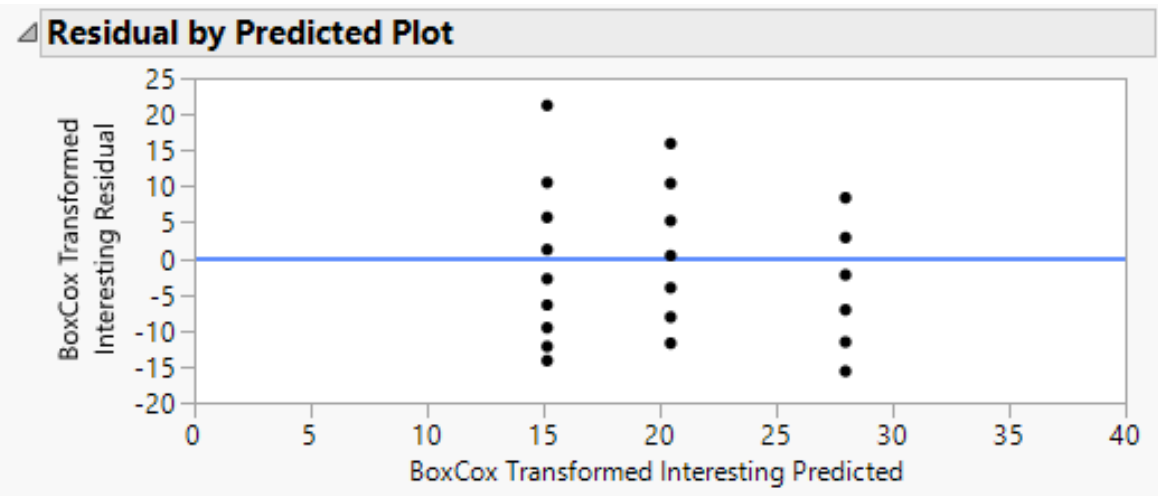


Appendix C-11: Interesting Ratings - ANOVA Testing

\begin{tabular}{|c|c|c|c|c|c|}
\hline \multicolumn{4}{|c|}{$\Delta$ Summary of Fit } & & \\
\hline \multicolumn{3}{|l|}{ RSquare } & \multicolumn{3}{|l|}{0.308006} \\
\hline \multicolumn{3}{|c|}{ RSquare Adj } & \multicolumn{3}{|l|}{0.288784} \\
\hline \multicolumn{3}{|c|}{ Root Mean Square Error } & \multicolumn{3}{|l|}{8.043868} \\
\hline \multicolumn{3}{|c|}{ Mean of Response } & \multicolumn{3}{|l|}{21.19796} \\
\hline \multicolumn{3}{|c|}{ Observations (or Sum Wgts) } & \multicolumn{3}{|l|}{75} \\
\hline \multicolumn{6}{|c|}{$\triangle$ Analysis of Variance } \\
\hline Source & DF & $\begin{array}{r}\text { Sum of } \\
\text { Squares }\end{array}$ & \multicolumn{2}{|c|}{ Mean Square } & F Ratio \\
\hline Model & 2 & 2073.5766 & \multicolumn{2}{|c|}{1036.79} & 16.0236 \\
\hline Error & 72 & 4658.6749 & & $64.70 \operatorname{Prc}$ & Prob $>\mathrm{F}$ \\
\hline C. Total & 74 & 6732.2515 & & & $<.0001^{*}$ \\
\hline \multicolumn{6}{|c|}{$\triangleright$ Parameter Estimates } \\
\hline \multicolumn{6}{|c|}{$\triangle$ Effect Tests } \\
\hline Source & Nparm & DF & $\begin{array}{r}\text { Sum of } \\
\text { Squares }\end{array}$ & F Ratio & Prob $>F$ \\
\hline Dashboard & & 2 & 2073.5766 & 16.0236 & $<, 0001^{*}$ \\
\hline
\end{tabular}


Appendix C-12: Interesting Ratings - Pairwise Comparisons

\begin{tabular}{|c|c|c|c|c|c|c|c|c|}
\hline \multicolumn{9}{|c|}{$\Delta$ Least Squares Means Estimates } \\
\hline Dashboard & Estimate & Std Error & DF & \multicolumn{2}{|c|}{ Lower $95 \%$} & Upper $95 \%$ & \multicolumn{2}{|c|}{$\begin{array}{r}\text { Arithmetic } \\
\text { Mean Estimate }\end{array}$} \\
\hline 1 & 15.157863 & 1.6087737 & 72 & \multicolumn{2}{|c|}{11.950832} & 18.364895 & \multicolumn{2}{|c|}{15.157863} \\
\hline 2 & 20.461760 & 1.6087737 & 72 & \multicolumn{2}{|c|}{17.254728} & 23.668791 & \multicolumn{2}{|c|}{20.461760} \\
\hline 3 & 27.974265 & 1.6087737 & 72 & \multicolumn{2}{|c|}{24.767233} & 31.181296 & \multicolumn{2}{|c|}{27.974265} \\
\hline \multicolumn{9}{|c|}{$\triangle$ Student's t All Pairwise Comparisons } \\
\hline \multicolumn{9}{|c|}{ Quantile $=1.99346$, DF $=72.0$} \\
\hline \multicolumn{9}{|c|}{$\triangle$ All Pairwise Differences } \\
\hline Dashboard & -Dashboard & Difference & Std & Error & t Ratio & Prob $>|t|$ & Lower $95 \%$ & Upper $95 \%$ \\
\hline 1 & 2 & -5.3039 & 2.2 & 75150 & -2.33 & $0.0225^{\star}$ & -9.8393 & -0.76847 \\
\hline 1 & 3 & -12.8164 & 2.2 & 75150 & -5.63 & $<.0001^{*}$ & -17.3518 & -8.28097 \\
\hline 2 & 3 & -7.5125 & 2.2 & 75150 & -3.30 & $0.0015^{\star}$ & -12.0479 & -2.97708 \\
\hline
\end{tabular}


Appendix C-13: Trustworthy Ratings - Distribution Fitting and Box-Cox

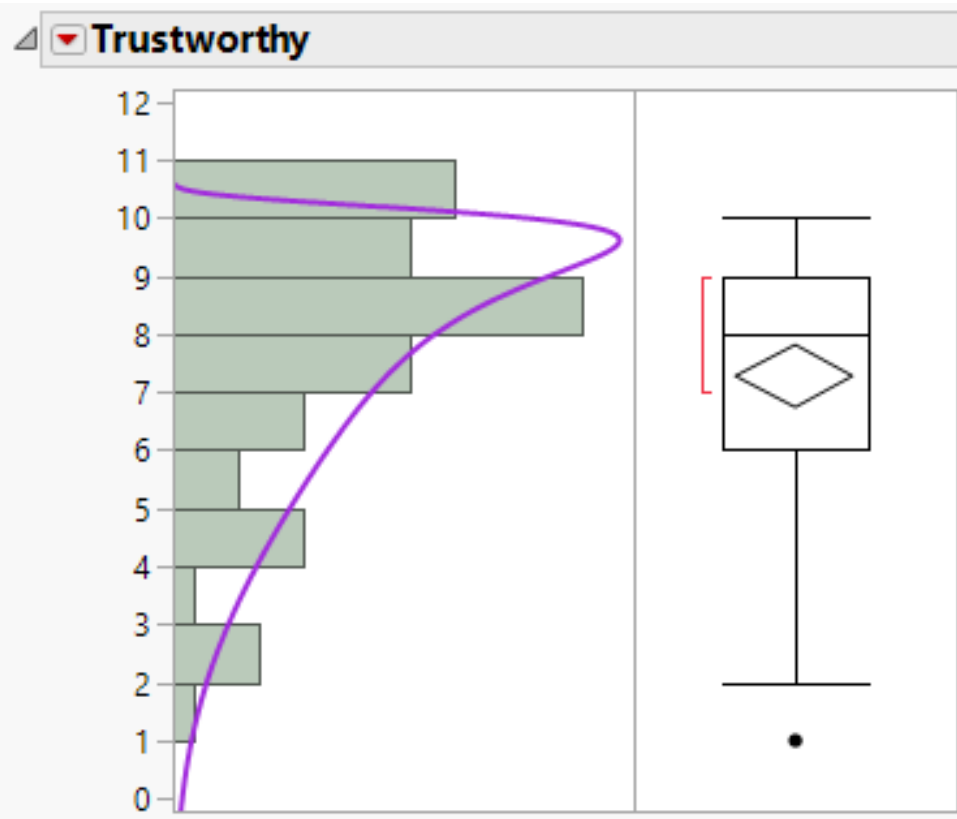

$-\operatorname{SHASH}(5.62662,1.29909,11.1974,0.08342)$

\begin{tabular}{|c|c|c|c|}
\hline \multicolumn{4}{|c|}{$\nabla$ Fitted SHASH } \\
\hline \multicolumn{4}{|c|}{$\triangle$ Parameter Estimates } \\
\hline Type & \multicolumn{2}{|c|}{ Parameter } & Estimate \\
\hline Shape & \multicolumn{2}{|c|}{ y } & 5.6266217 \\
\hline Shape & \multicolumn{2}{|l|}{$\delta$} & 1.2990908 \\
\hline Location & \multicolumn{2}{|l|}{$\theta$} & 11.197358 \\
\hline Scale & \multicolumn{2}{|l|}{$\sigma$} & 0.0834188 \\
\hline \multicolumn{4}{|c|}{ Measure } \\
\hline \multicolumn{2}{|c|}{$-2 *$ LogLikelihood } & \multicolumn{2}{|c|}{312.9594} \\
\hline \multicolumn{2}{|c|}{$\mathrm{AlCc}$} & \multicolumn{2}{|c|}{321.53083} \\
\hline \multicolumn{2}{|l|}{$\mathrm{BIC}$} & \multicolumn{2}{|c|}{330.22935} \\
\hline
\end{tabular}

$\triangle$ Goodness-of-Fit Test

Shapiro-Wilk W Test

\begin{tabular}{r|r|r|}
\hline W & Prahew/ \\
0.931430 & $0.0005^{*}$
\end{tabular}

Note: $\mathrm{Ho}=$ The data is from the SHASH distribution. Small p-values reject $\mathrm{Ho}$.

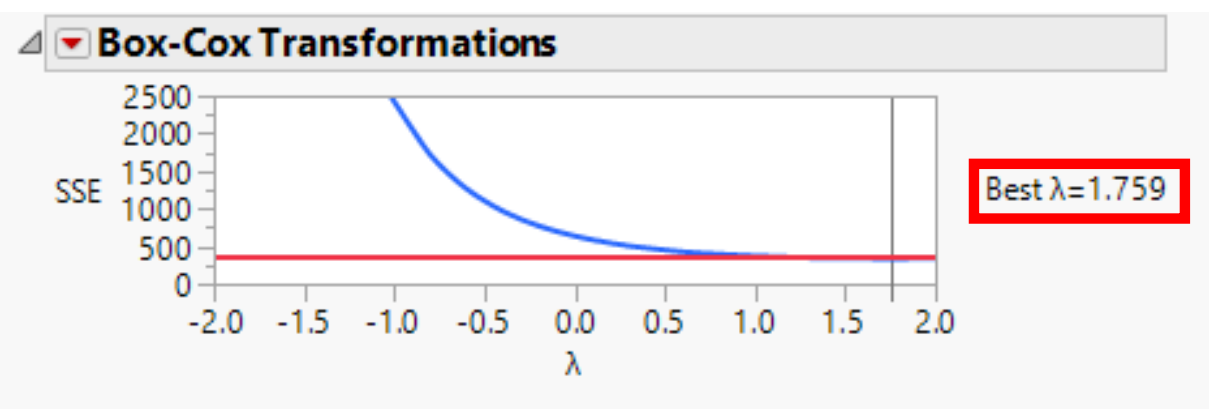


Appendix C-14: Trustworthy Ratings - Normality of Residuals and Equality of Variances Normality of Residuals

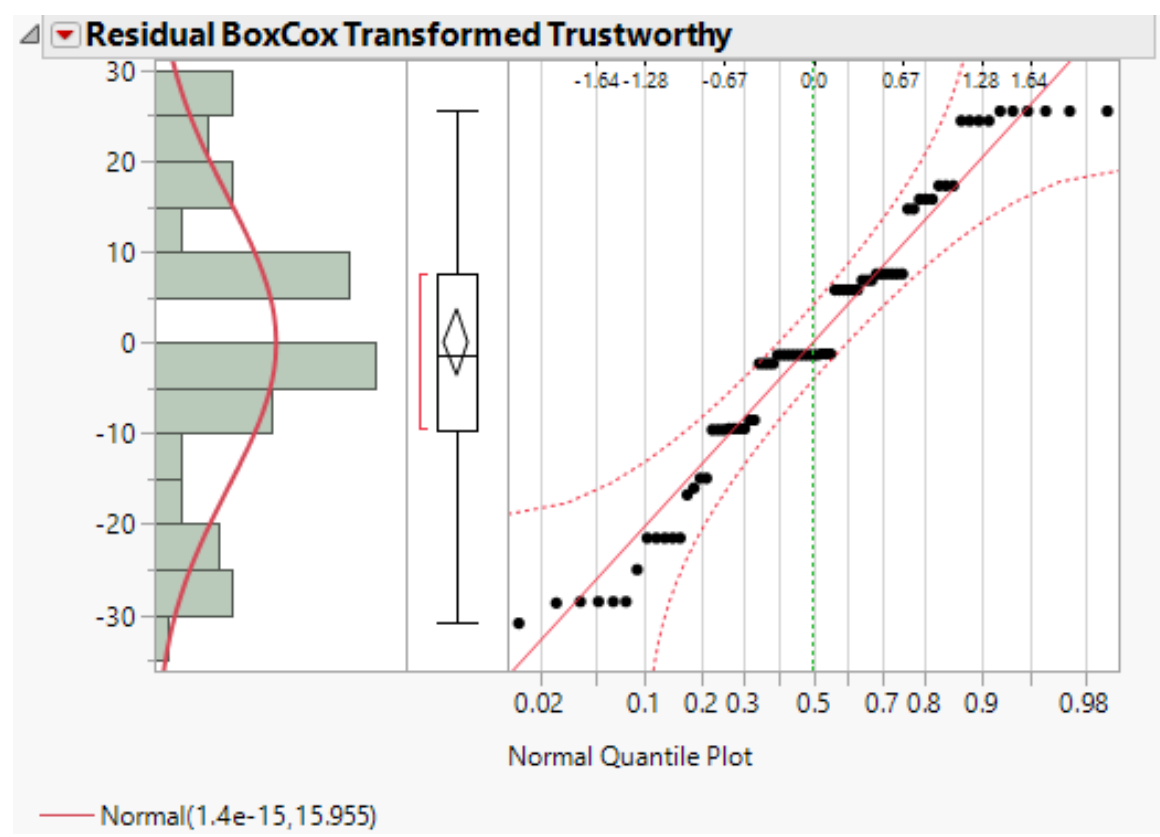

\section{Equality of Variances}

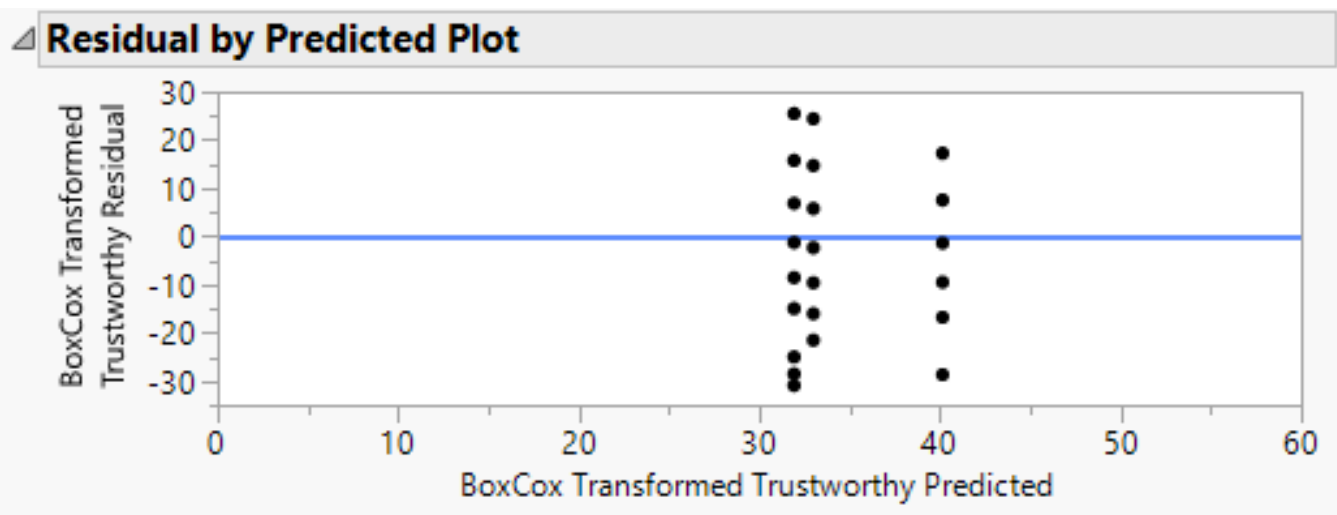


Appendix C-15: Trustworthy Ratings - ANOVA Testing

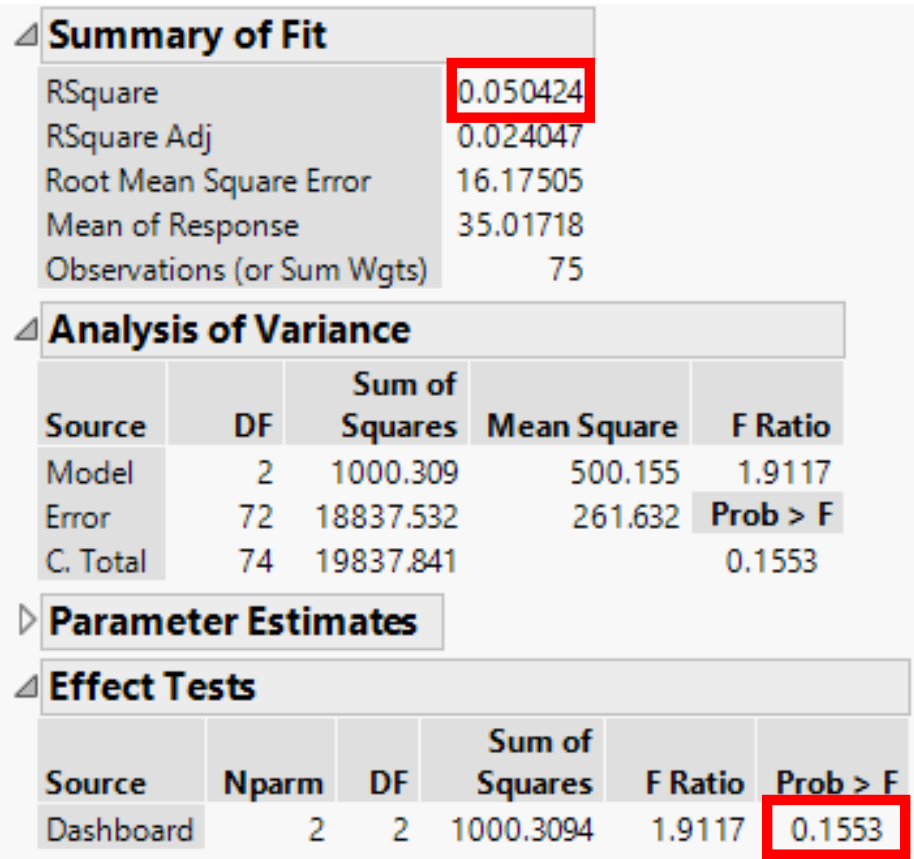


Appendix D: NASA TLX ANOVA Testing 


\section{Appendix D-1: NASA TLX Scores - Distribution Check}

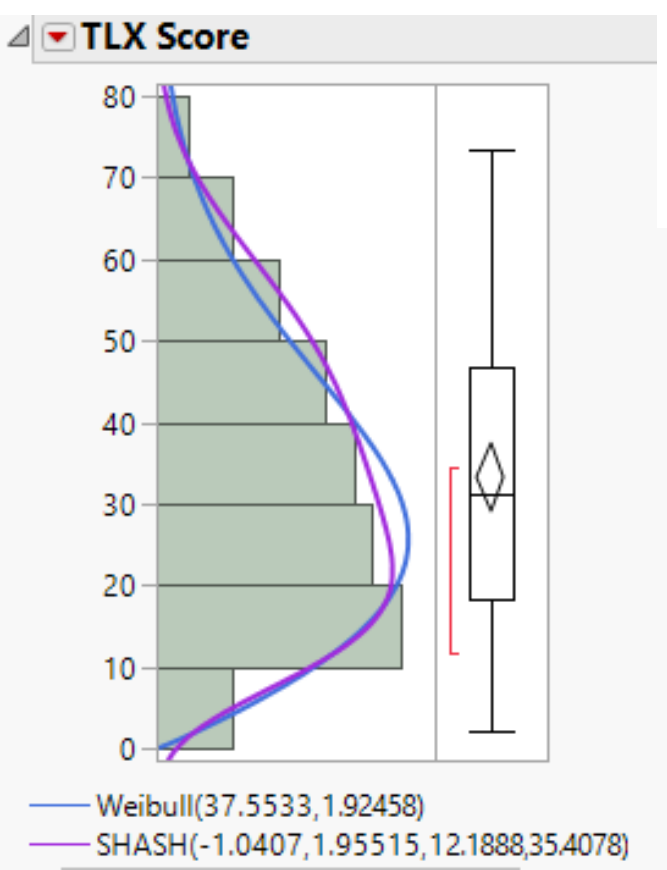

\begin{tabular}{|c|c|c|c|}
\hline \multicolumn{4}{|c|}{$\triangle$ Parameter Estimates } \\
\hline Type Parameter & Estimate & Lower $95 \%$ & Upper $95 \%$ \\
\hline Scale $\alpha$ & 37.553299 & 33.029355 & 42.513317 \\
\hline Shape $\beta$ & 1.9245778 & 1.5897956 & 2.2940297 \\
\hline \multicolumn{4}{|l|}{ Measure } \\
\hline$-2 *$ LogLikelihood & \multicolumn{3}{|l|}{630.38681} \\
\hline $\mathrm{AlCc}$ & \multicolumn{3}{|l|}{634.55583} \\
\hline $\mathrm{BIC}$ & \multicolumn{3}{|l|}{638.99494} \\
\hline \multicolumn{4}{|c|}{$\triangle$ Goodness-of-Fit Test } \\
\hline \multicolumn{4}{|c|}{ Cramer-von Mises W Test } \\
\hline W-Square & \multicolumn{3}{|l|}{ Proh $>W \wedge 2$} \\
\hline $0.029259>$ & 0.2500 & & \\
\hline
\end{tabular}

Note: $\mathrm{Ho}=$ The data is from the Weibull distribution. Small p-values reject Ho.

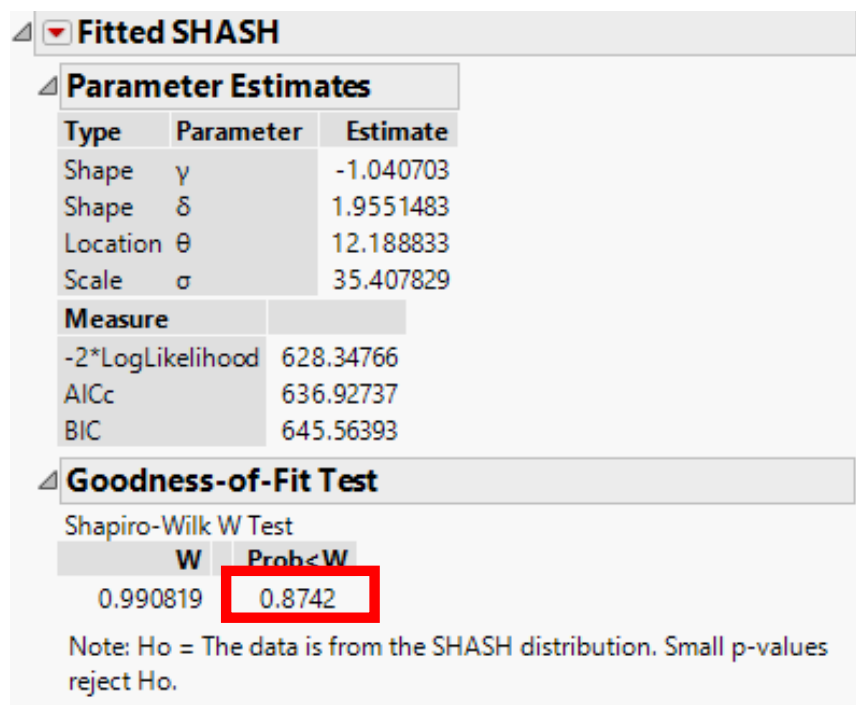


Appendix D-2: Overall NASA TLX Scores - Normality of Residuals and Equality of Variance Check

Normality of Residuals

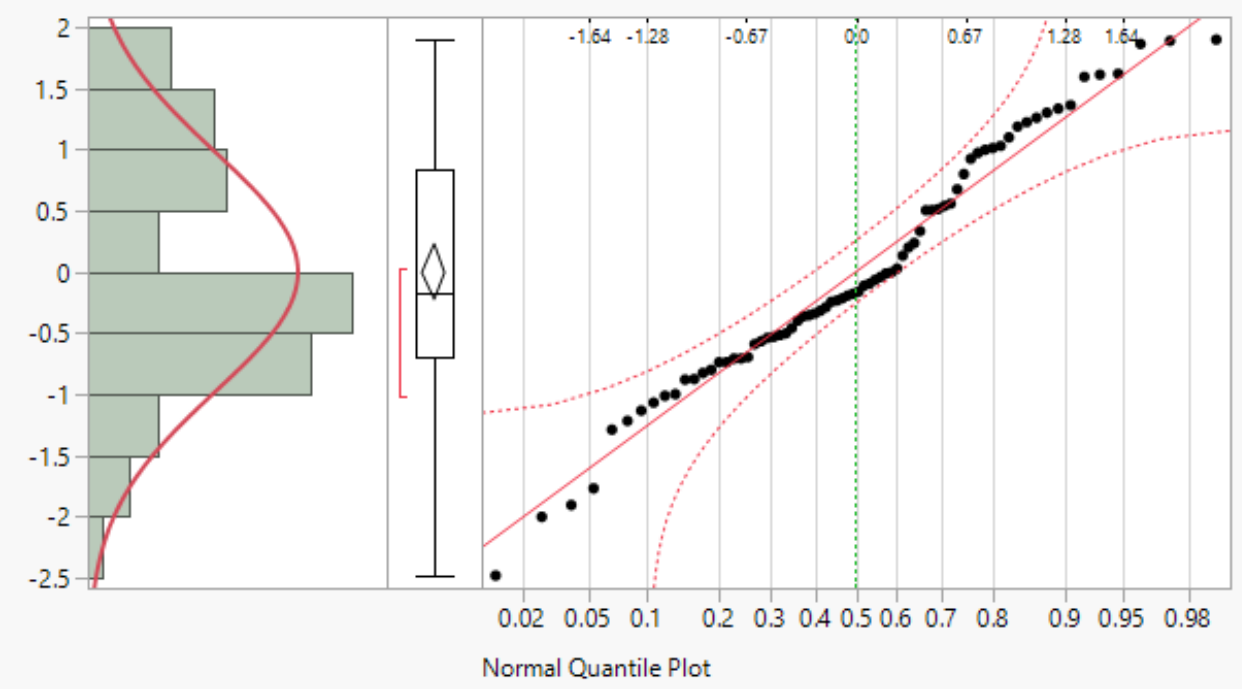

\section{Equality of Variance}

\section{$\triangle$ Residual by Predicted Plot}

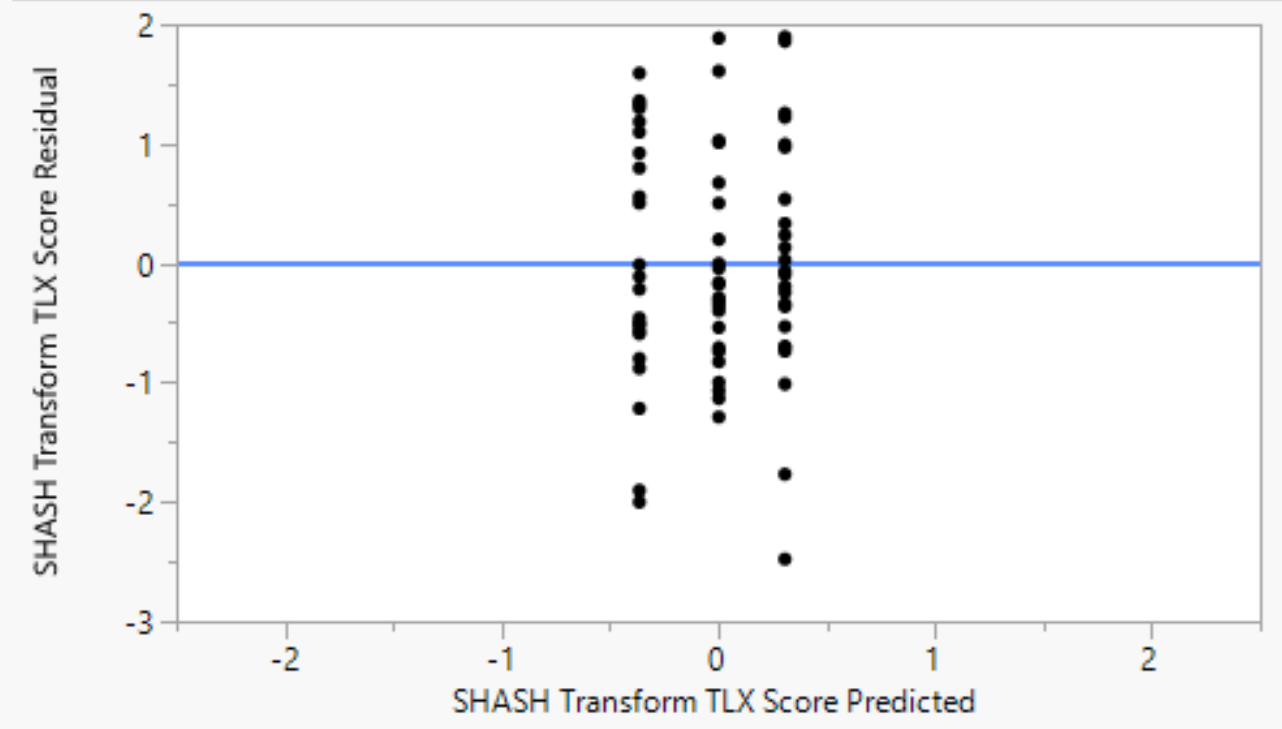


Appendix D-3: Overall NASA TLX Score - ANOVA Testing

\begin{tabular}{|c|c|c|c|c|c|}
\hline \multicolumn{6}{|c|}{$\triangle$ Analysis of Variance } \\
\hline Source & DF & Squares & If Mean Square & \multicolumn{2}{|c|}{ F Ratio } \\
\hline Model & 2 & 5.531829 & 2.76591 & \multicolumn{2}{|c|}{2.8163} \\
\hline Error & 71 & 69.730152 & 0.98211 & \multicolumn{2}{|c|}{ Prob $>F$} \\
\hline C. Total & 73 & 75.261981 & & \multicolumn{2}{|c|}{0.0665} \\
\hline \multicolumn{6}{|c|}{$\triangleright$ Parameter Estimates } \\
\hline \multicolumn{6}{|c|}{$\triangle$ Effect Tests } \\
\hline Source & Nparm & DF & $\begin{array}{r}\text { Sum of } \\
\text { Squares }\end{array}$ & atio & Prob $>F$ \\
\hline Dashboard & & 2 & 5.5318294 & 3163 & 0.0665 \\
\hline
\end{tabular}


Appendix D-4: Temporal Demand - Distribution Fitting

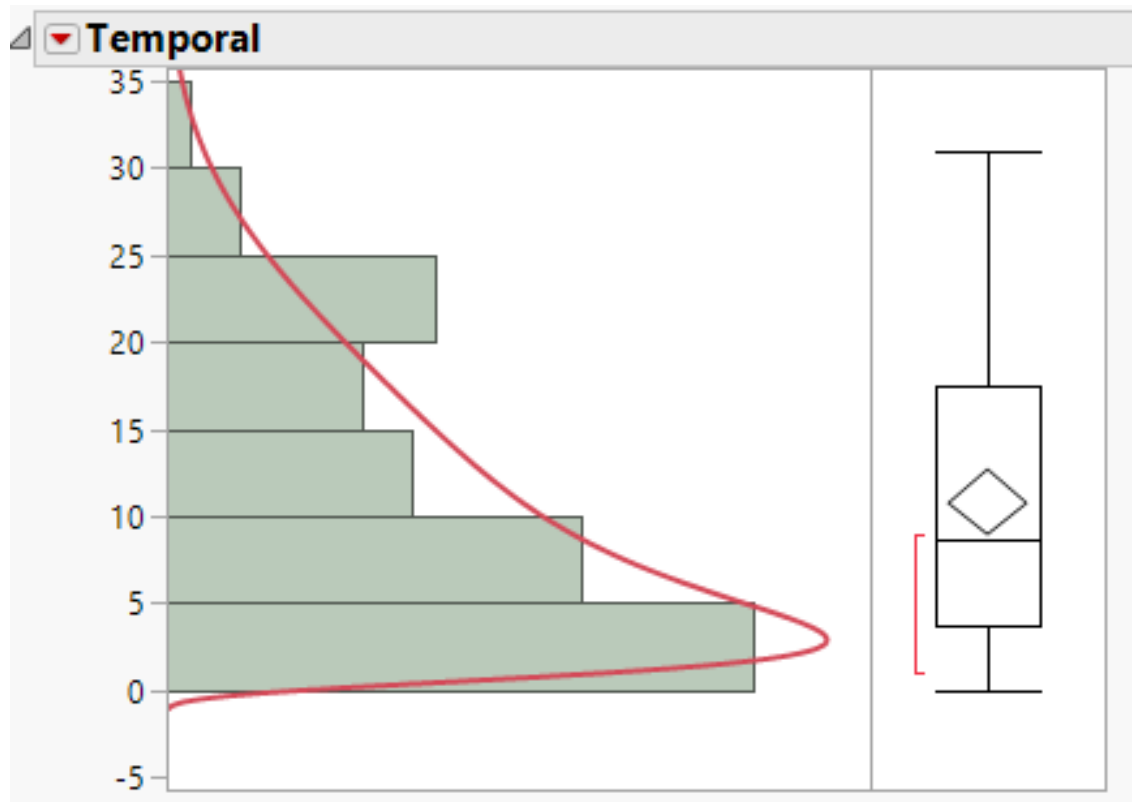

SHASH(-7.2398, 1.45417,-3.9702,0.17202)

\section{Fitted SHASH}

\section{$\triangle$ Parameter Estimates}

\begin{tabular}{l|r|}
\hline Type Parameter & Estimate \\
\hline Shape $\gamma$ & -7.239761 \\
Shape $\delta$ & 1.4541732 \\
Location $\theta$ & -3.970246 \\
\hline Scale $\sigma$ & 0.1720199 \\
\hline Measure & \\
\hline -2*LogLikelihood & 490.61531 \\
AlCe & 499.19502 \\
BIC & 507.83157
\end{tabular}

\section{$\triangle$ Goodness-of-Fit Test}

Shapiro-Wilk W Test

$$
\begin{array}{r|c|}
\text { W } & \text { Prob }<\text { W } \\
\hline 0.985413 & 0.5543 \\
\hline
\end{array}
$$

Note: $\mathrm{Ho}=$ The data is from the SHASH distribution. Small p-values reject Ho. 
Appendix D-5: Temporal Demand - Normality of Residuals and Equality of Variance Check

\section{Normality of Residuals}

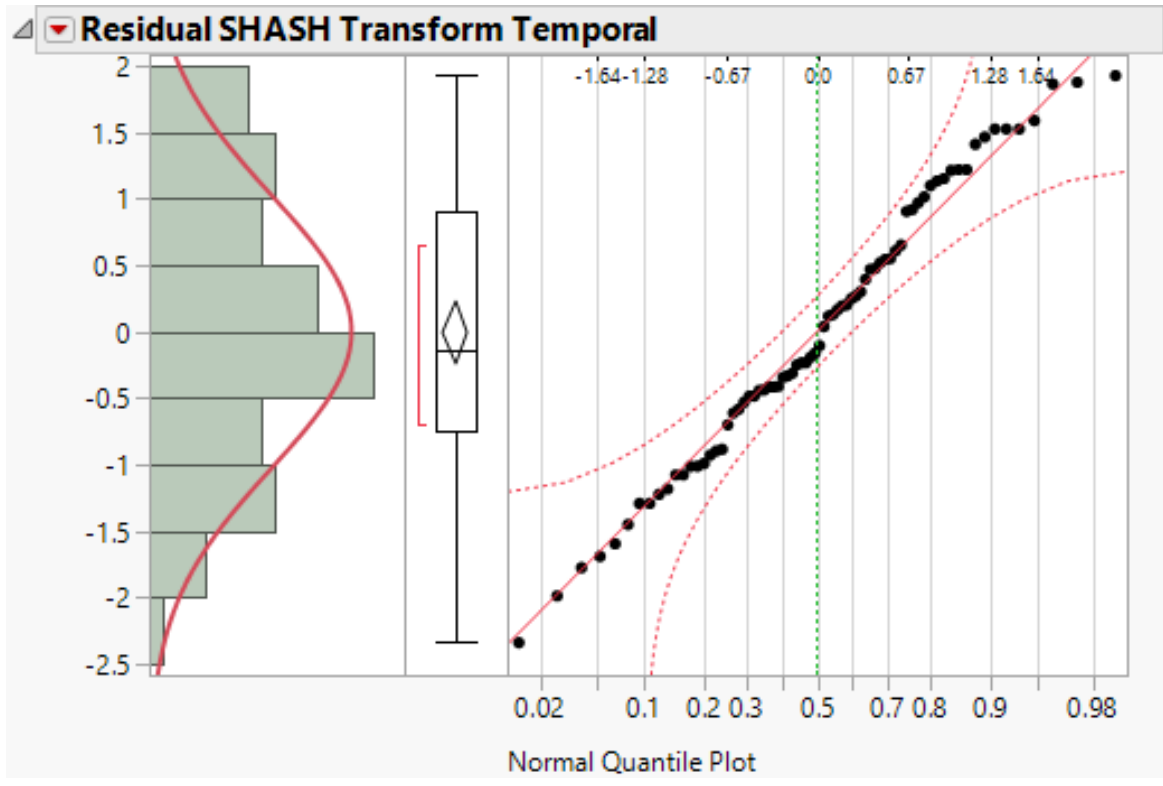

\section{Equality of Variance}

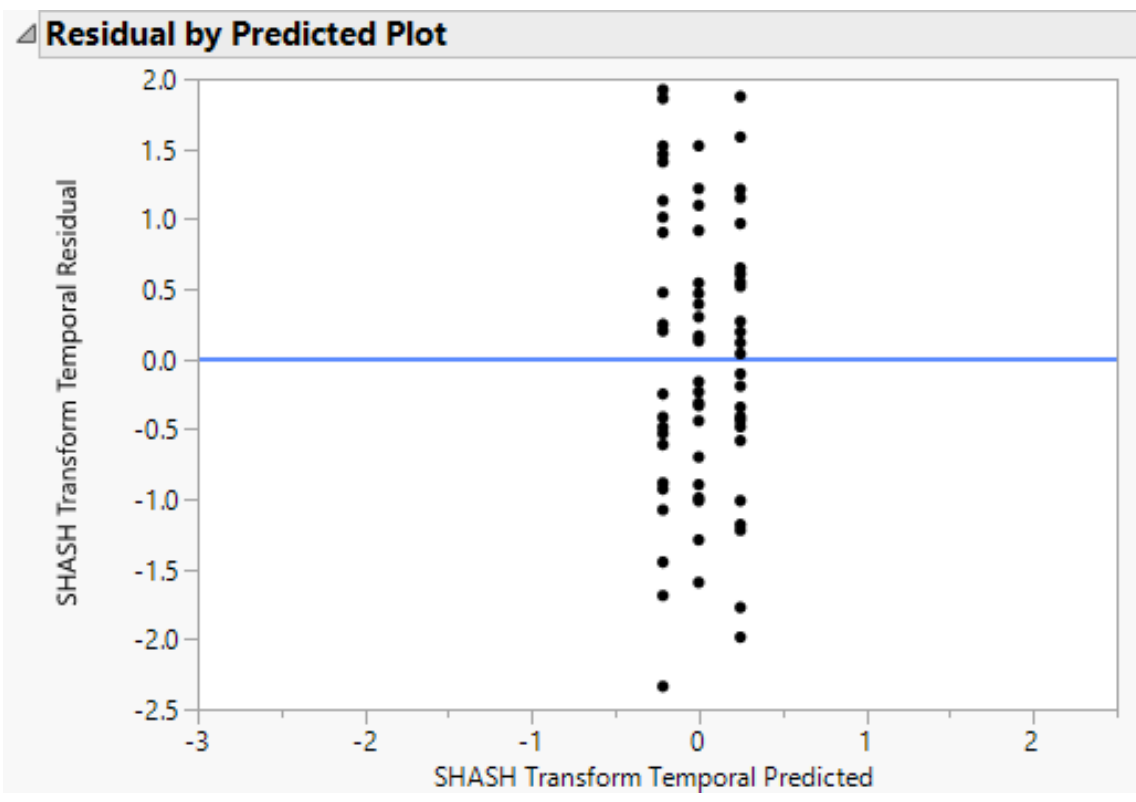


Appendix D-6: Temporal Demand - ANOVA Testing

\begin{tabular}{|c|c|c|c|c|c|c|}
\hline \multicolumn{7}{|c|}{$\triangle$ Analysis of Variance } \\
\hline Source & DF & $\begin{array}{r}\text { Sum of } \\
\text { Squares }\end{array}$ & \multicolumn{2}{|c|}{ Mean Square } & \multicolumn{2}{|c|}{ F Ratio } \\
\hline Model & 2 & 2.637315 & \multicolumn{2}{|c|}{1.31866} & \multicolumn{2}{|c|}{1.2287} \\
\hline Error & 71 & 76.197200 & 1.07 & 7320 & \multicolumn{2}{|c|}{ Prob $>$ F } \\
\hline C. Total & 73 & 78.834515 & & & \multicolumn{2}{|c|}{0.2988} \\
\hline \multicolumn{7}{|c|}{ Parameter Estimates } \\
\hline \multicolumn{7}{|c|}{$\triangle$ Effect Tests } \\
\hline Source & Nparm & DF & $\begin{array}{r}\text { Sum of } \\
\text { Squares }\end{array}$ & $\mathbf{F R}$ & atio & Prob $>\mathrm{F}$ \\
\hline Dashboard & 2 & 2 & 2.6373146 & & 287 & 0.2988 \\
\hline
\end{tabular}


Appendix D-7: Performance - Distribution Fitting and Box-Cox Transformation

\section{Distribution Fitting}

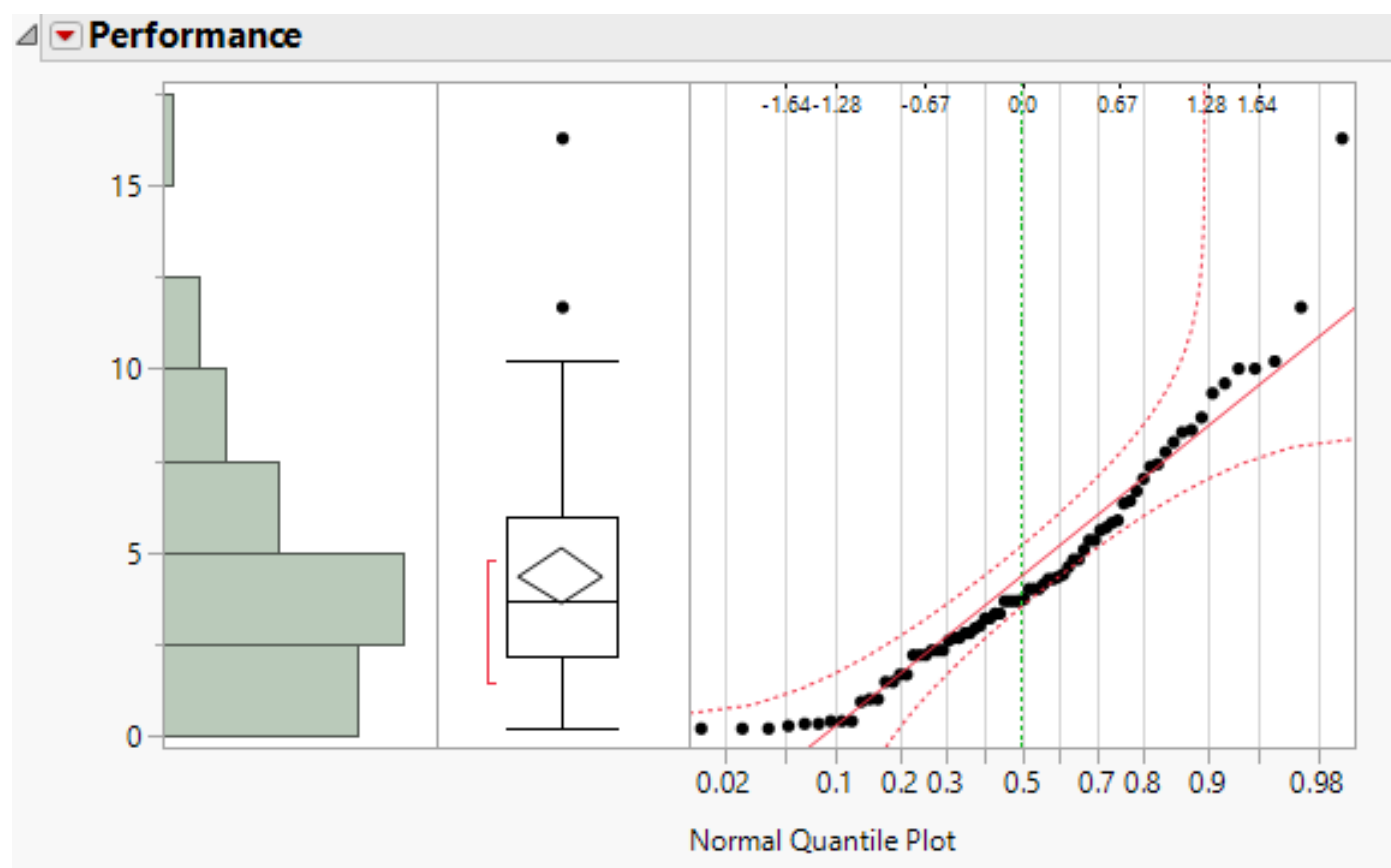

\section{Box-Cox Transformation}

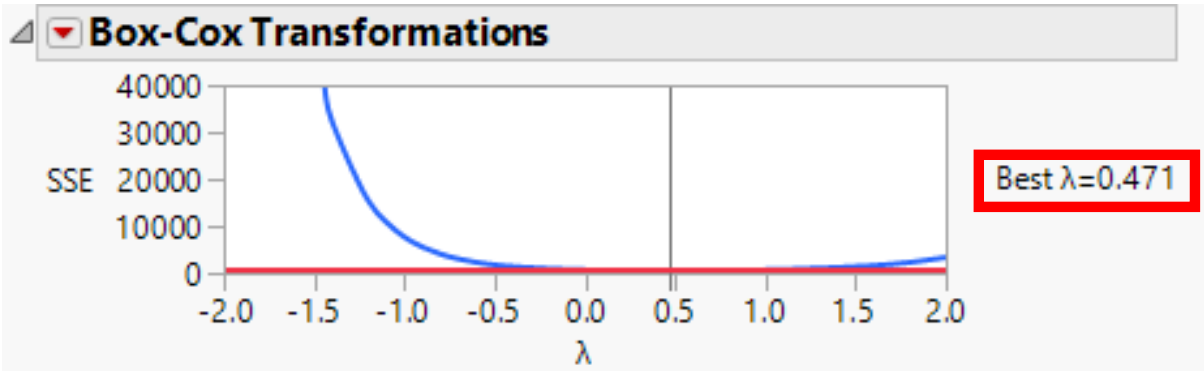


Appendix D-8: Performance - Normality of Residuals and Equality of Variances

Normality of Residuals

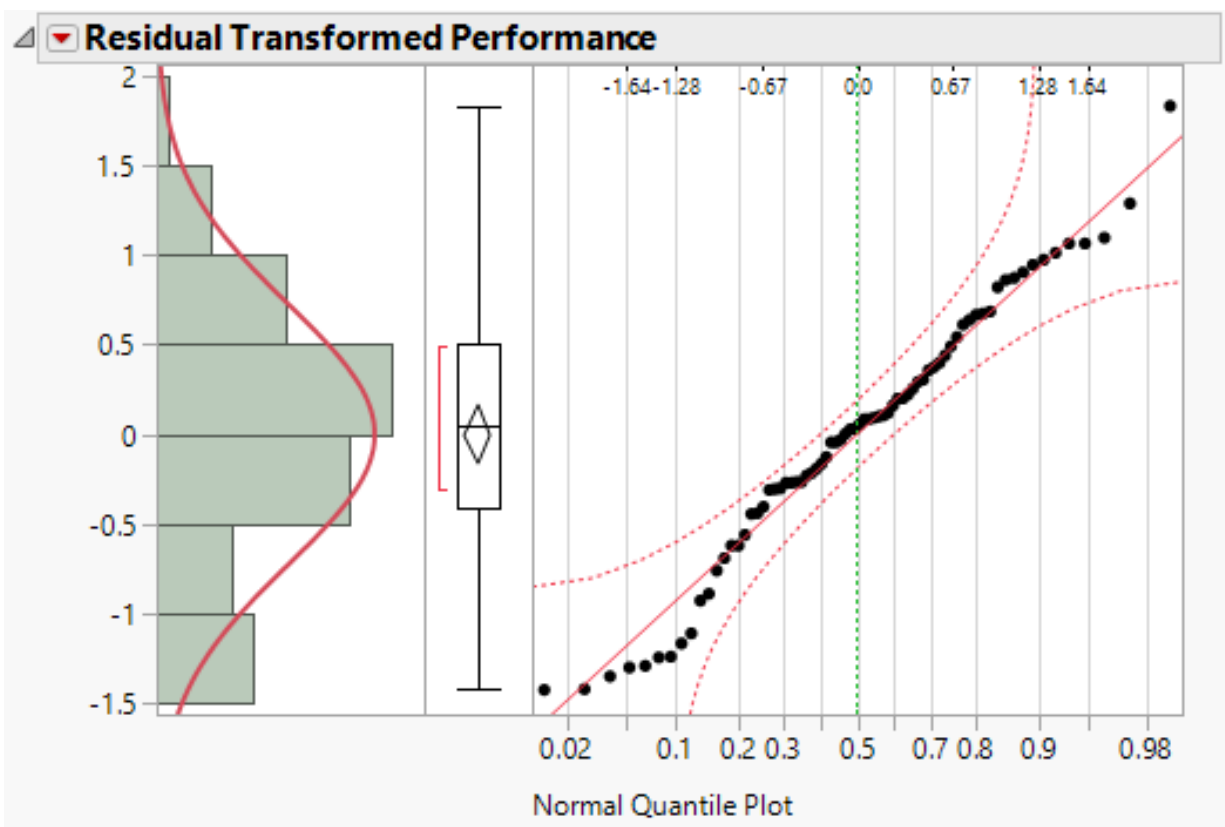

Equality of Variances

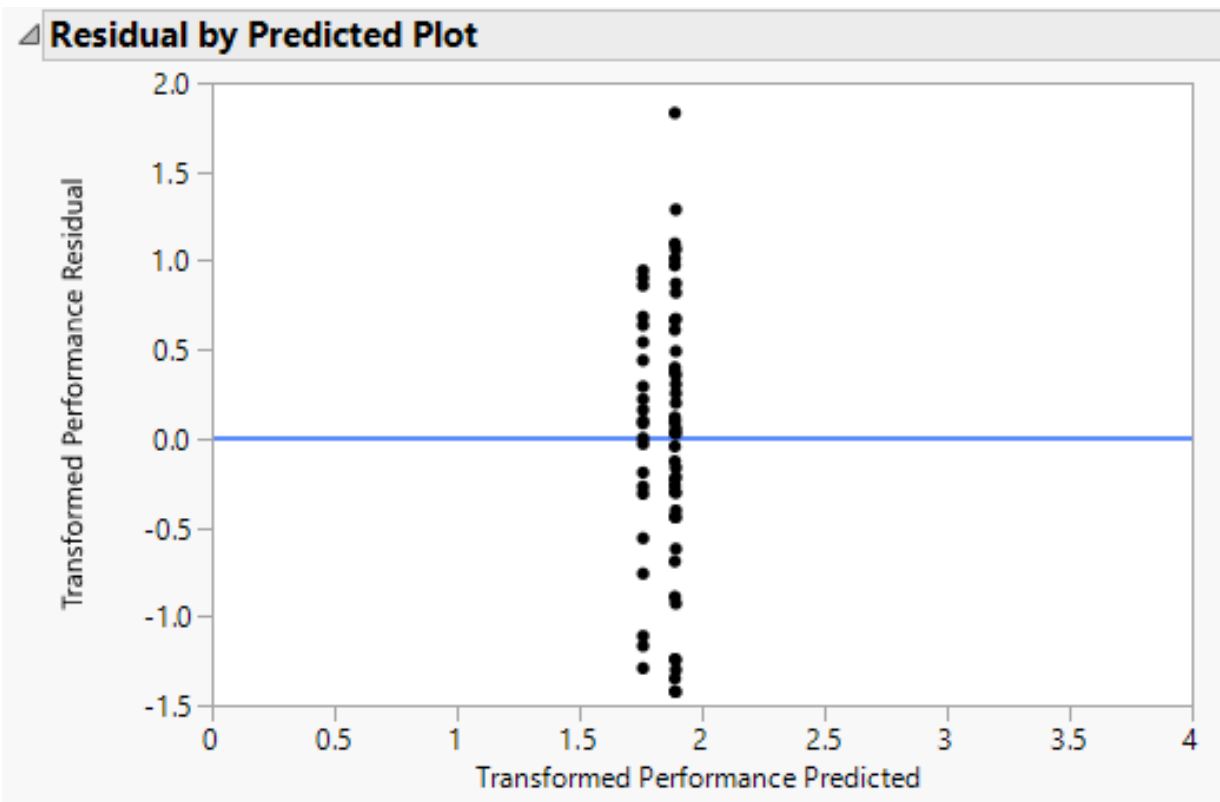




\section{Appendix D-9: Performance - ANOVA Testing}

\begin{tabular}{|c|c|c|c|c|c|c|}
\hline \multicolumn{7}{|c|}{$\triangle$ Analysis of Variance } \\
\hline Source & DF & $\begin{array}{l}\text { Sum of } \\
\text { Squares }\end{array}$ & \multicolumn{2}{|c|}{ Mean Square } & \multicolumn{2}{|c|}{ F Ratio } \\
\hline Model & 2 & 0.282741 & \multicolumn{2}{|c|}{0.141371} & \multicolumn{2}{|c|}{0.2635} \\
\hline Error & 71 & 38.097982 & 0.53 & 6591 & \multicolumn{2}{|c|}{ Prob $>$ F } \\
\hline C. Total & 73 & 38.380723 & & & \multicolumn{2}{|c|}{0.7691} \\
\hline \multicolumn{7}{|c|}{$\triangleright$ Parameter Estimates } \\
\hline \multicolumn{7}{|c|}{$\triangle$ Effect Tests } \\
\hline Source & Nparr & DF & $\begin{array}{r}\text { Sum of } \\
\text { Squares }\end{array}$ & & atio & Prob $>F$ \\
\hline Dashboard & & 20 & 0.28274138 & & & 0.7691 \\
\hline
\end{tabular}




\section{Appendix E: Time ANOVA Testing}




\section{Appendix E-1: Group 1 - Distribution Check and Box-Cox Transformation}

\section{Distribution Check}

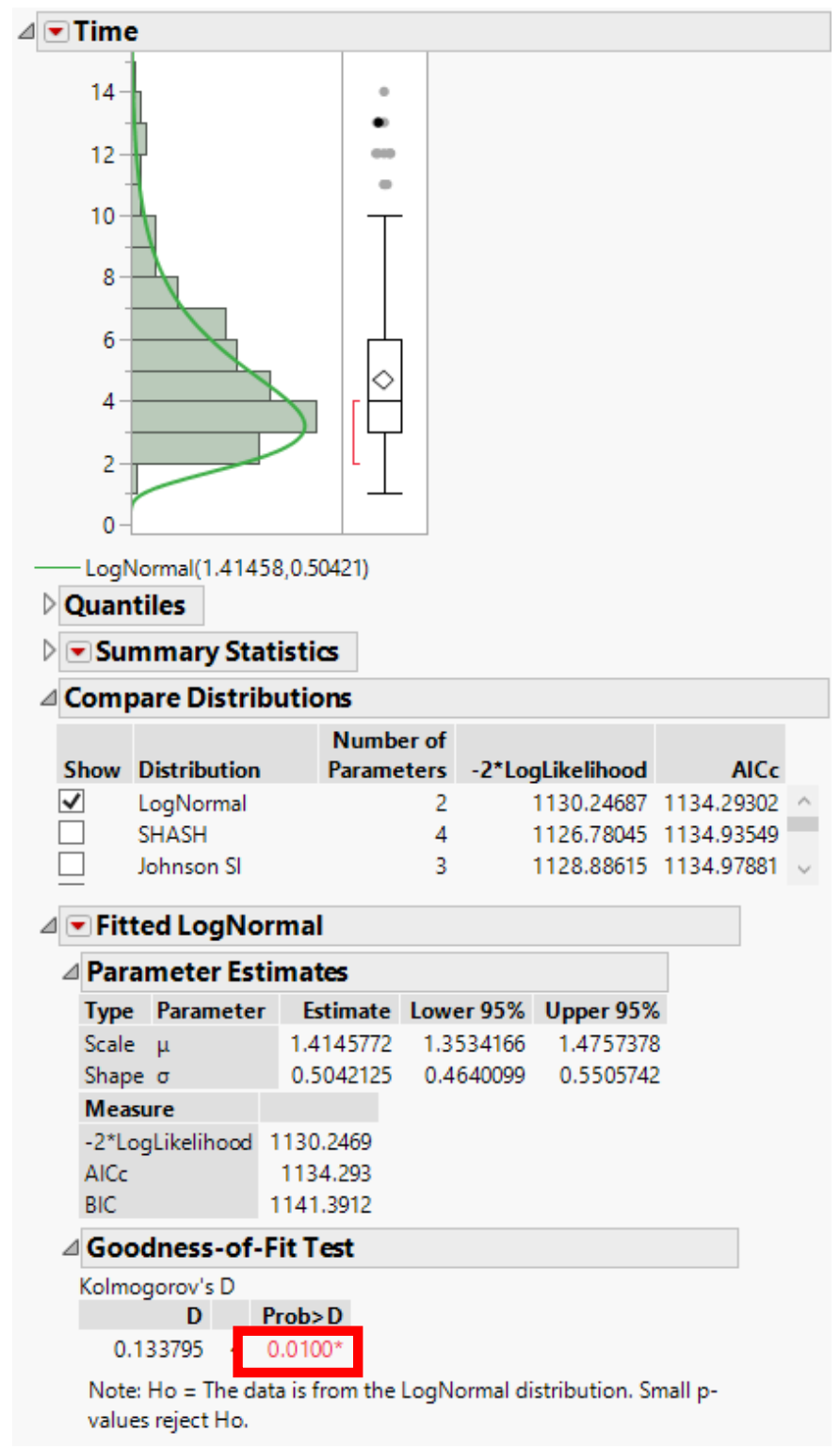

\section{Box-Cox Transformation}

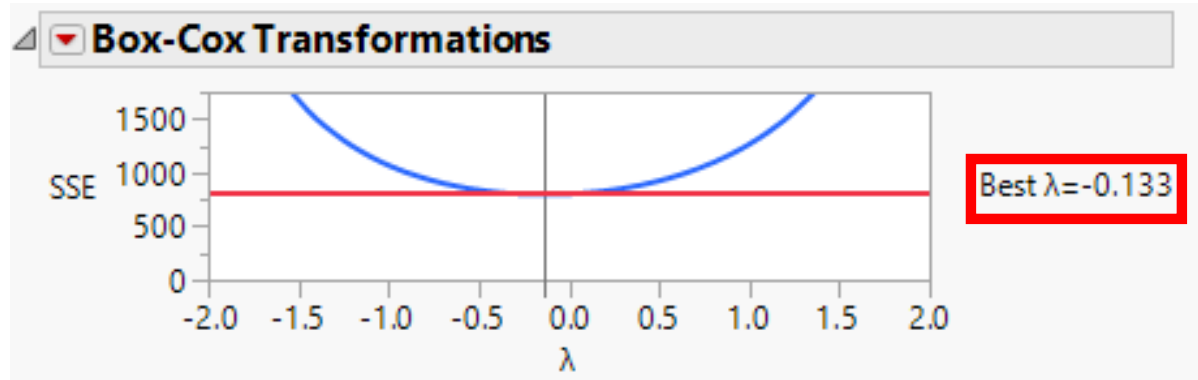


Appendix E-2: Group 1 - Check for Normality of Residuals and Equality of Variances Normality of Residuals

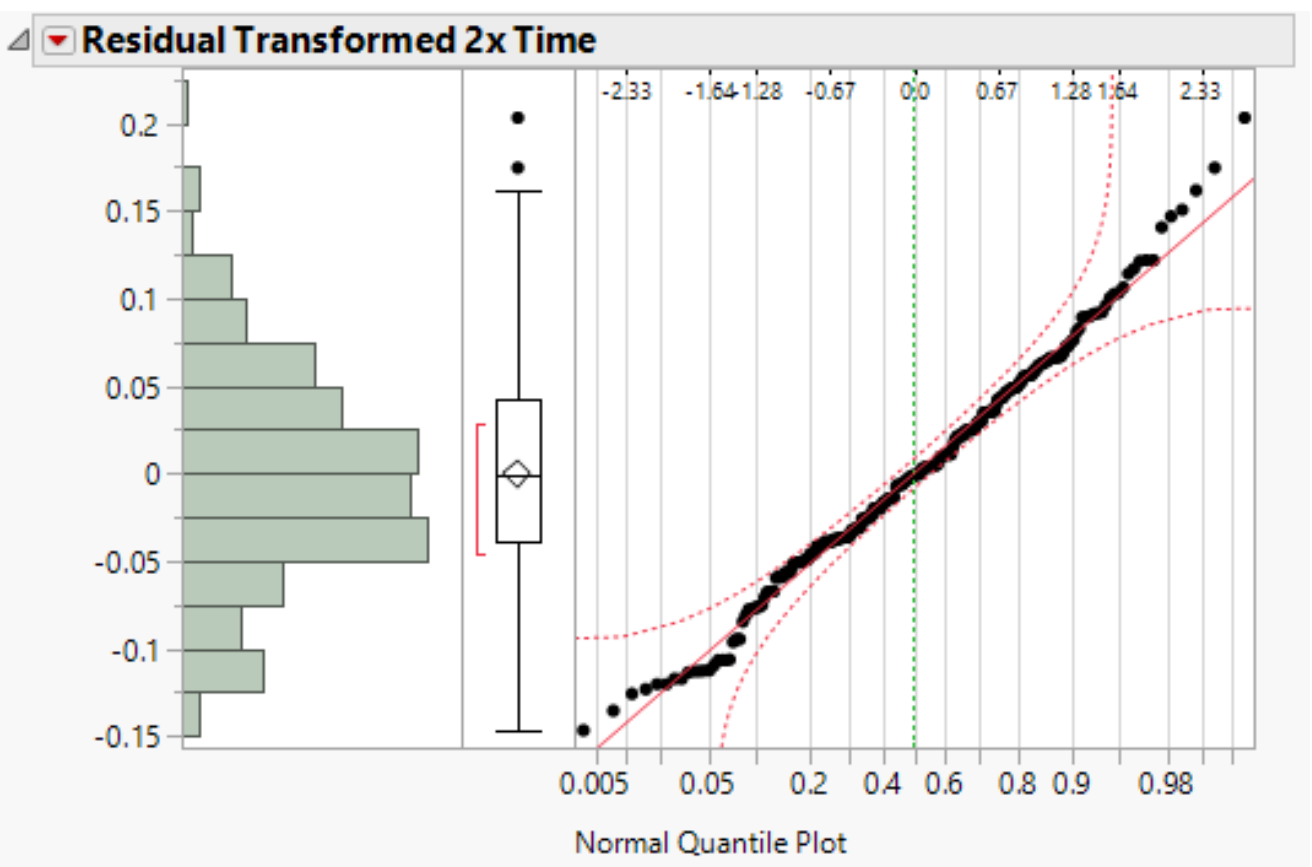

Equality of Variances

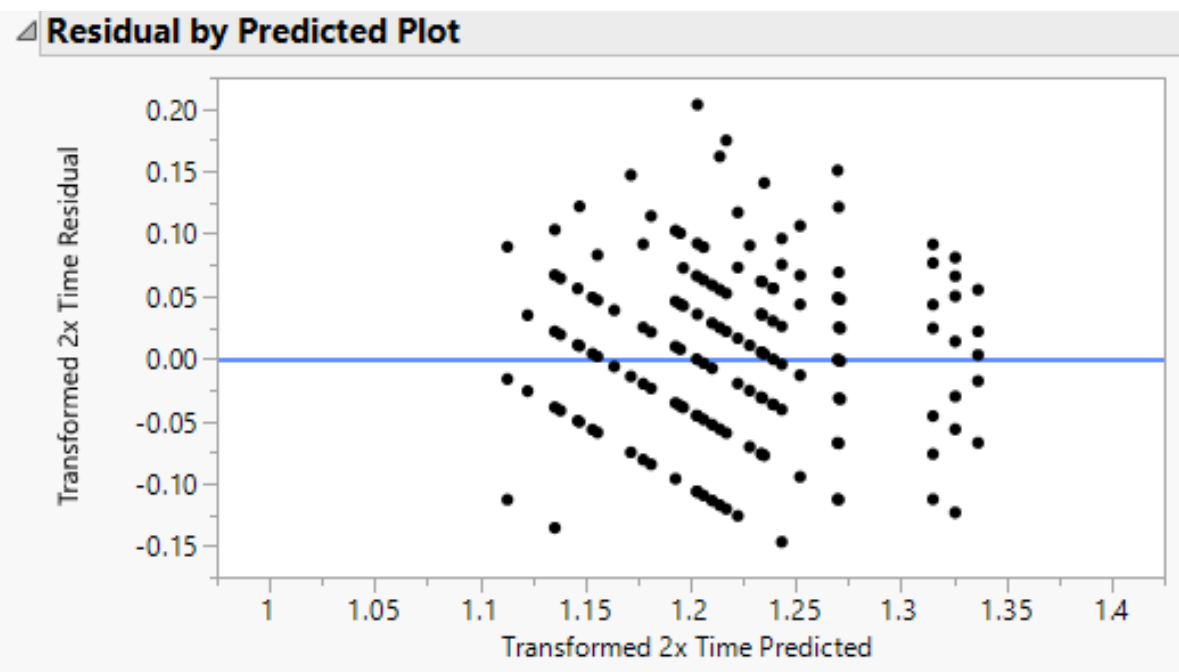


Appendix E-3: Group 1 - Full Factorial ANOVA

\begin{tabular}{|c|c|c|c|c|c|c|c|c|}
\hline \multicolumn{5}{|c|}{$\triangle$ Summary of Fit } & & & & \\
\hline \multirow{2}{*}{\multicolumn{3}{|c|}{$\begin{array}{l}\text { RSquare } \\
\text { RSquare Adj }\end{array}$}} & \multicolumn{6}{|c|}{0.436347} \\
\hline & & & \multicolumn{6}{|c|}{0.34944} \\
\hline \multicolumn{3}{|c|}{ Root Mean Square Error } & \multicolumn{6}{|c|}{0.065893} \\
\hline \multicolumn{3}{|c|}{ Mean of Response } & \multicolumn{6}{|c|}{1.209726} \\
\hline \multicolumn{3}{|c|}{ Observations (or Sum Wgts) } & \multicolumn{4}{|c|}{263} & & \\
\hline \multicolumn{9}{|c|}{$\triangle$ Analysis of Variance } \\
\hline Source & DF & $\begin{array}{r}\text { Sum of } \\
\text { Squares }\end{array}$ & \multicolumn{3}{|c|}{ Mean Square } & \multicolumn{3}{|l|}{ F Ratio } \\
\hline Model & 35 & 0.7630019 & \multicolumn{3}{|c|}{0.021800} & 5.0209 & & \\
\hline Error & 227 & 0.9856123 & \multicolumn{3}{|c|}{0.004342} & Prob $>F$ & & \\
\hline C. Total & 262 & 1.7486142 & & & & $<.0001^{*}$ & & \\
\hline \multicolumn{9}{|c|}{$D$ Parameter Estimates } \\
\hline \multicolumn{9}{|c|}{$\triangle$ Effect Tests } \\
\hline \multicolumn{4}{|c|}{ Source } & Nparm & DF & $\begin{array}{r}\text { Sum of } \\
\text { Squares }\end{array}$ & F Ratio & Prob $>F$ \\
\hline \multicolumn{4}{|c|}{ Dashboard } & 2 & 2 & 0.02315423 & 2.6664 & 0.0717 \\
\hline \multicolumn{4}{|c|}{ Questions } & 3 & 3 & 0.40005078 & 30.7124 & $<.0001^{*}$ \\
\hline \multicolumn{4}{|c|}{ Dashboard ${ }^{\star}$ Questions } & 6 & 6 & 0.04978908 & 1.9112 & 0.0800 \\
\hline \multicolumn{4}{|c|}{ First Dash } & 2 & 2 & 0.08681182 & 9.9970 & $<.0001^{*}$ \\
\hline \multicolumn{4}{|c|}{ DashboardFirst Dash } & 4 & 4 & 0.13947878 & 8.0310 & $<.0001^{*}$ \\
\hline \multicolumn{4}{|c|}{ Questions*First Dash } & 6 & 6 & 0.02229418 & 0.8558 & 0.5283 \\
\hline \multicolumn{4}{|c|}{ Dashboard ${ }^{\star}$ Questions ${ }^{\star}$ First Dash } & 12 & 12 & 0.04695567 & 0.9012 & 0.5465 \\
\hline
\end{tabular}




\section{Appendix E-4: Group 1 - Post-Hoc Analysis}

\section{Questions}

\begin{tabular}{|c|c|c|c|c|c|c|}
\hline \multicolumn{7}{|c|}{$\Delta$ Least Squares Means Estimates } \\
\hline Questions & Estimate & Std Error & DF & Lower 95\% & Upper 95\% & $\begin{array}{l}\text { Arithmetic } \\
\text { Mean Estimate }\end{array}$ \\
\hline 2 & 1.2635409 & 0.00818564 & 227 & 1.2474114 & 1.2796705 & 1.2632698 \\
\hline 6 & 1.1940331 & 0.00812696 & 227 & 1.1780192 & 1.2100470 & 1.1937373 \\
\hline 7 & 1.2251970 & 0.00812696 & 227 & 1.2091831 & 1.2412110 & 1.2251207 \\
\hline 11 & 1.1573315 & 0.00812696 & 227 & 1.1413176 & 1.1733455 & 1.1575866 \\
\hline
\end{tabular}

$\checkmark$ Student's t All Pairwise Comparisons

Quantile $=1.97047$, DF $=227.0$

$\triangle$ All Pairwise Differences

\begin{tabular}{ll|r|r|r|r|r|r} 
Questions & -Questions & Difference & Std Error & t Ratio & Prob $>$ |t| & Lower 95\% & Upper 95\% \\
\hline 2 & 6 & 0.069508 & 0.0115348 & 6.03 & $<.0001^{*}$ & 0.046779 & 0.092237 \\
2 & 7 & 0.038344 & 0.0115348 & 3.32 & $0.0010^{*}$ & 0.015615 & 0.061073 \\
2 & 11 & 0.106209 & 0.0115348 & 9.21 & $<.0001^{*}$ & 0.083480 & 0.128938 \\
6 & 7 & -0.031164 & 0.0114933 & -2.71 & $0.0072^{*}$ & -0.053811 & -0.008517 \\
6 & 11 & 0.036702 & 0.0114933 & 3.19 & $0.0016^{*}$ & 0.014054 & 0.059349 \\
7 & 11 & 0.067865 & 0.0114933 & 5.90 & $<.0001^{*}$ & 0.045218 & 0.090513
\end{tabular}

\section{FirstDash}

\begin{tabular}{|c|c|c|c|c|c|c|}
\hline First Dash & Estimate & Std Error & DF & Lower $95 \%$ & Upper 95\% & $\begin{array}{l}\text { Arithmetic } \\
\text { Mean Estimate }\end{array}$ \\
\hline 1 & 1.1899019 & 0.00718953 & 227 & 1.1757352 & 1.2040687 & 1.1899019 \\
\hline 2 & 1.2346396 & 0.00718953 & 227 & 1.2204728 & 1.2488063 & 1.2346396 \\
\hline 3 & 1.2055355 & 0.00676510 & 227 & 1.1922050 & 1.2188659 & 1.2052252 \\
\hline
\end{tabular}

\section{Student's t All Pairwise Comparisons}

Quantile $=1.97047, \mathrm{DF}=227.0$

\section{$\triangle$ All Pairwise Differences}

\begin{tabular}{|l|l|r|r|r|r|r|r|}
\hline First Dash & -First Dash & Difference & Std Error & t Ratio & Prob $>|\mathbf{t}|$ & Lower 95\% & Upper 95\% \\
\hline 1 & 2 & -0.044738 & 0.0101675 & -4.40 & $<.0001^{*}$ & -0.064772 & -0.024703 \\
1 & 3 & -0.015634 & 0.0098720 & -1.58 & 0.1147 & -0.035086 & 0.003819 \\
2 & 3 & 0.029104 & 0.0098720 & 2.95 & $0.0035^{*}$ & 0.009652 & 0.048557
\end{tabular}


Appendix E-5: Group 2 - Distribution Check and Box-Cox Transformation

Distribution Check

\section{$\triangle$ Compare Distributions}

\begin{tabular}{|c|c|c|c|c|}
\hline Show & Distribution & $\begin{array}{l}\text { Number of } \\
\text { Parameters }\end{array}$ & $-2^{*}$ LogLikelihood & AICc \\
\hline$\checkmark$ & SHASH & 4 & -19752.941 & -19744.865 \\
\hline$\square$ & Johnson Su & 4 & -14782.261 & -14774.184 \\
\hline ח & 1 & , & บมธวากา & tAencon \\
\hline
\end{tabular}

$\triangle$ Fitted SHASH

$\triangle$ Parameter Estimates

Type Parameter Estimate

Shape $\gamma \quad-1.231681$

Shape $\delta \quad 0.0525468$

Location $\theta \quad 1$

Scale $\begin{array}{ll}\sigma & 6.259 \mathrm{e}-20\end{array}$

Measure

-2*LogLikelihood -19752.94

AlCc $\quad-19744.86$

BIC $\quad-19727.88$

$\triangle$ Goodness-of-Fit Test

Shapiro-Wilk W Test

\begin{tabular}{r|r|}
$\mathbf{W}$ & Prob $<\mathbf{W}$ \\
\hline 0.654668 & $<.0001^{*}$ \\
\hline
\end{tabular}

Note: Ho = The data is from the SHASH distribution. Small p-values reject Ho.

\section{Box-Cox Transformation}

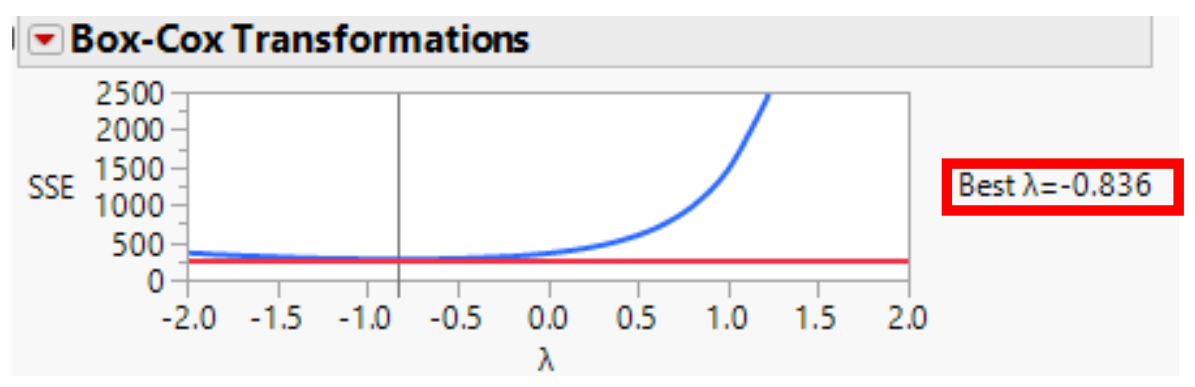


Appendix E-6: Group 2 - Normality of Residual and Equality of Variances Check Normality of Residuals

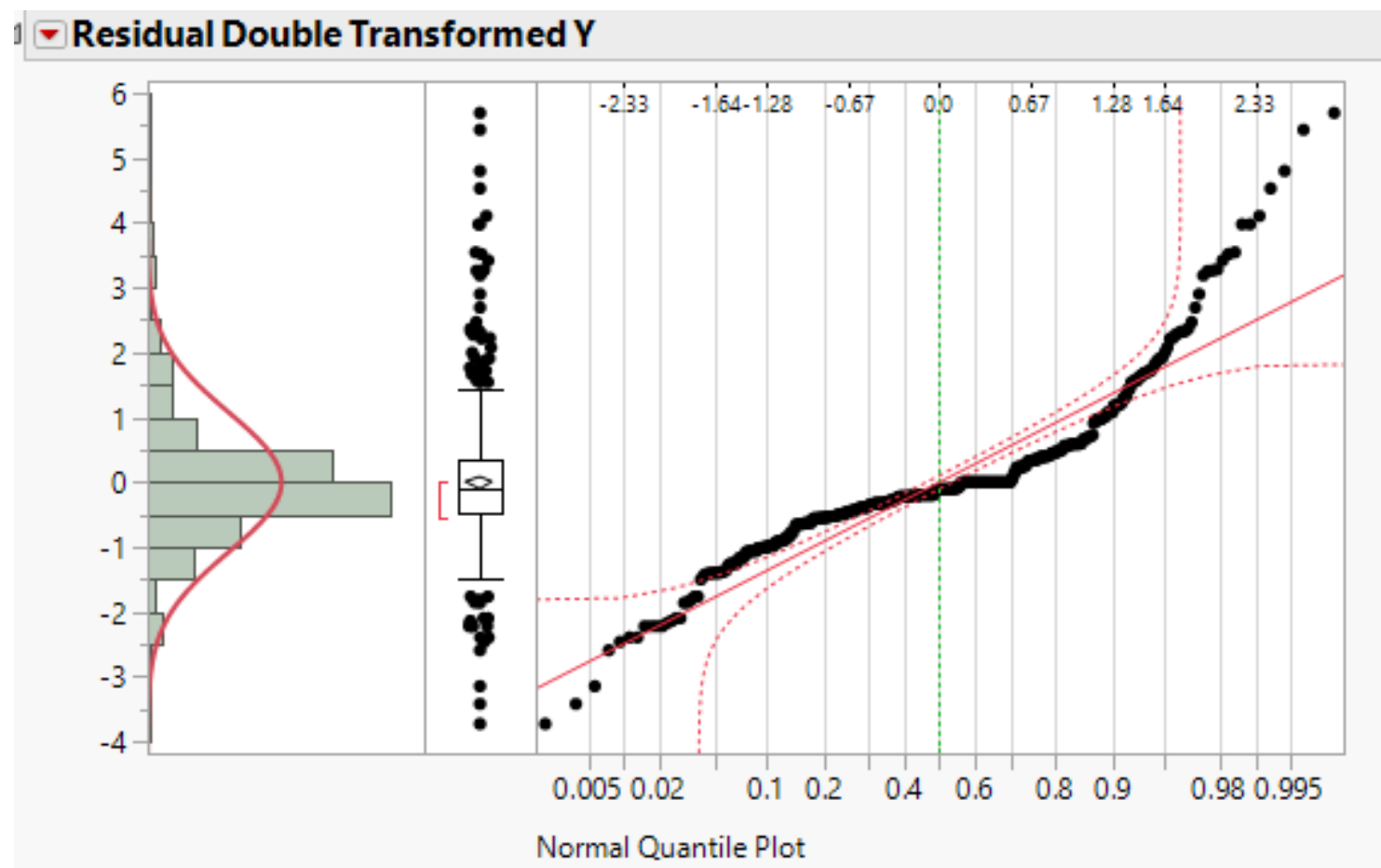

\section{Equality of Variances}

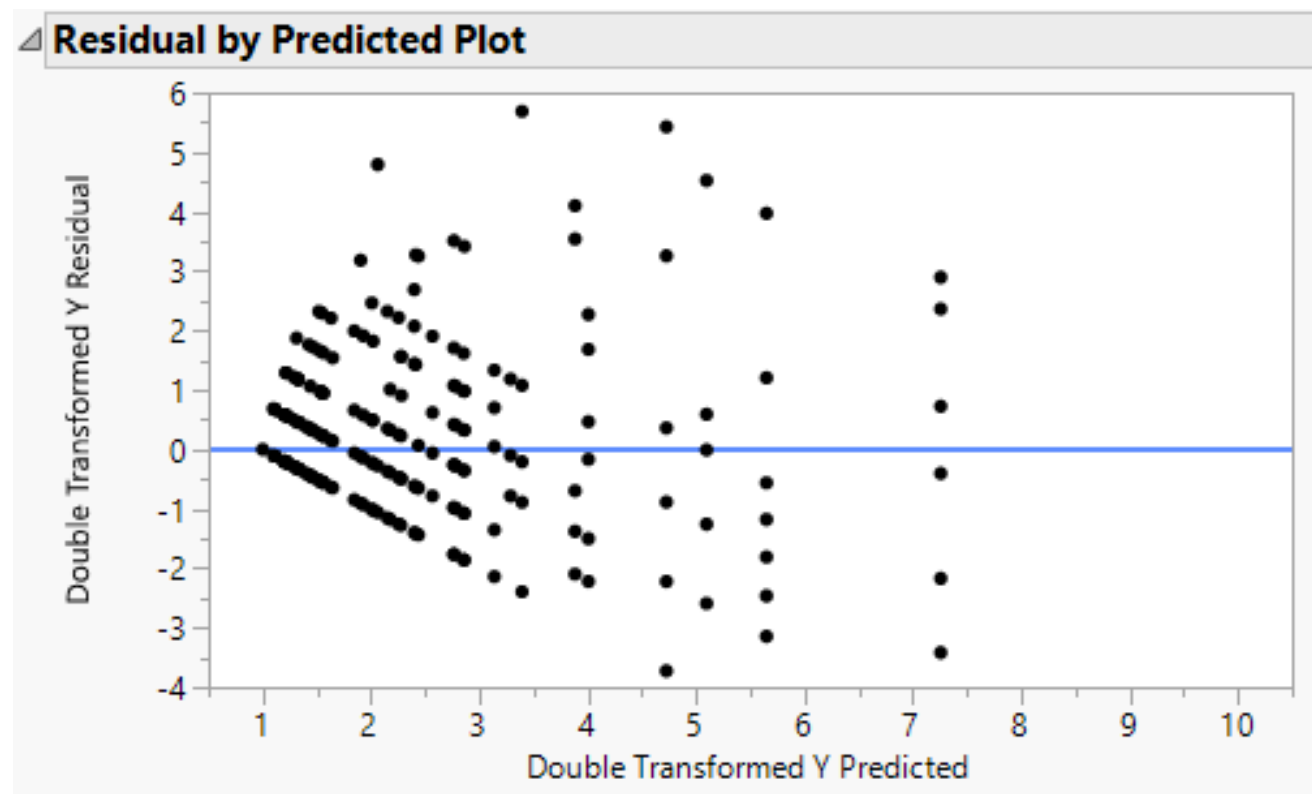


Appendix E-7: Group 2 - ANOVA Testing and Comparing Means

ANOVA Testing

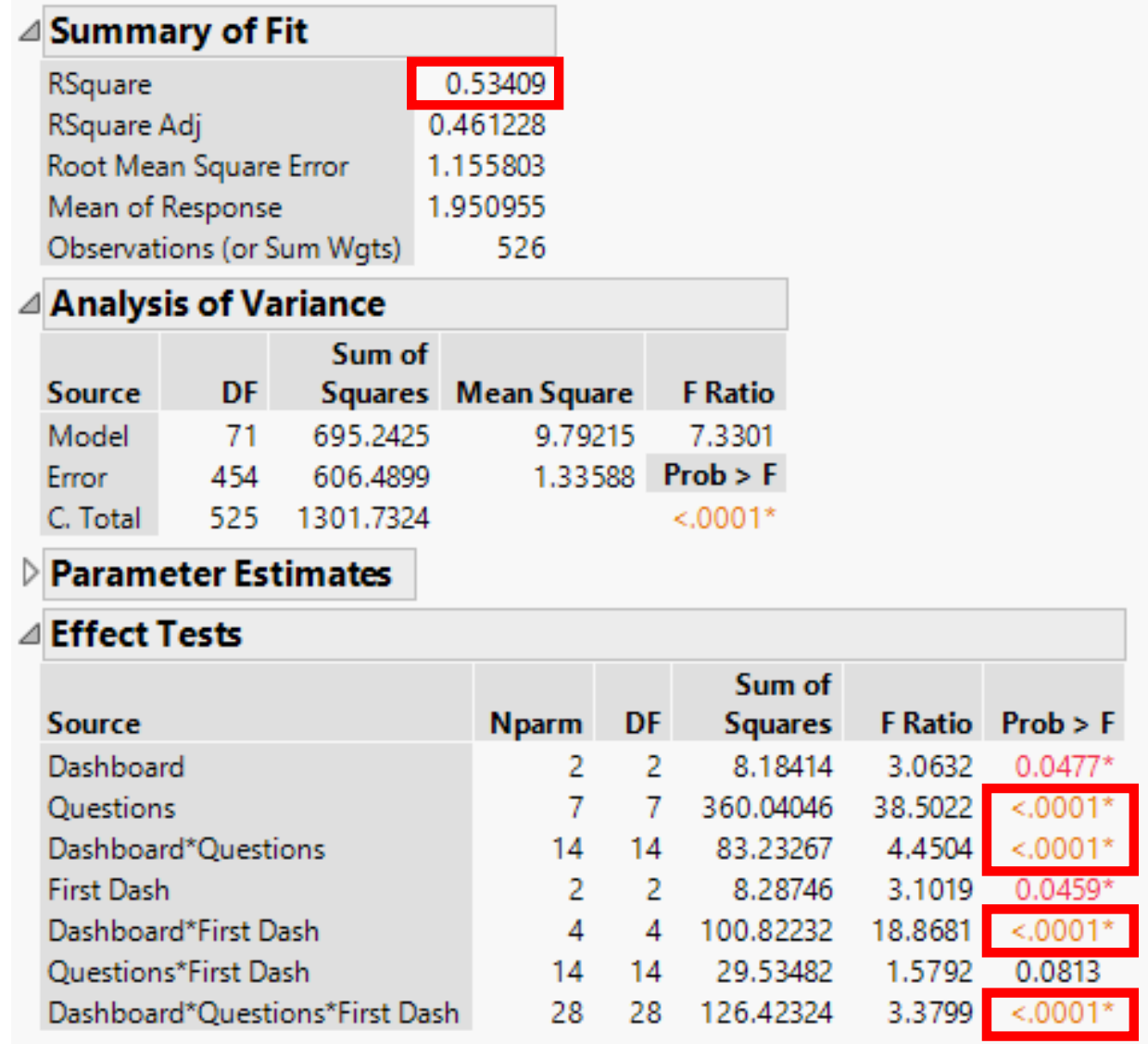




\section{Appendix E-8: Group 2 - Comparing Means}

\section{Dashboards}

\begin{tabular}{|c|c|c|c|c|c|c|c|c|}
\hline \multicolumn{9}{|c|}{$\Delta$ Least Squares Means Estimates } \\
\hline \multirow{4}{*}{$\begin{array}{l}\text { Dashboard } \\
1 \\
2 \\
3\end{array}$} & \multirow{4}{*}{$\begin{array}{r}\text { Estimate } \\
2.1013703 \\
1.9946908 \\
1.7996302\end{array}$} & Std Error & DF & \multicolumn{2}{|c|}{ Lower $95 \%$} & Upper 95\% & \multicolumn{2}{|c|}{$\begin{array}{r}\text { Arithmetic } \\
\text { Mean Estimate }\end{array}$} \\
\hline & & 0.08761034 & 454 & \multicolumn{2}{|c|}{1.9291982} & 2.2735424 & \multicolumn{2}{|c|}{2.0808271} \\
\hline & & 0.08761034 & 454 & \multicolumn{2}{|c|}{1.8225186} & 2.1668629 & \multicolumn{2}{|c|}{1.9457923} \\
\hline & & 0.08729463 & 454 & \multicolumn{2}{|c|}{1.6280785} & 1.9711819 & \multicolumn{2}{|c|}{1.8269542} \\
\hline \multicolumn{9}{|c|}{$\triangle \nabla$ Student's t All Pairwise Comparisons } \\
\hline \multicolumn{9}{|c|}{ Quantile $=1.9652, \mathrm{DF}=454.0$} \\
\hline \multicolumn{9}{|c|}{$\triangle$ All Pairwise Differences } \\
\hline Dashboard & -Dashboard & Difference & Std & Error & t Ratio & o Prob $>|t|$ & Lower $95 \%$ & Upper $95 \%$ \\
\hline 1 & 2 & 0.1066795 & 0.12 & 38997 & 0.86 & $6 \quad 0.3897$ & -0.136809 & 0.3501676 \\
\hline 1 & 3 & 0.3017401 & 0.12 & 36767 & 2.44 & $0.0151^{*}$ & 0.058690 & 0.5447899 \\
\hline 2 & 3 & 0.1950605 & 0.12 & 36767 & 1.58 & 80.1155 & -0.047989 & 0.4381103 \\
\hline
\end{tabular}




\section{Questions}

\begin{tabular}{|c|c|c|c|c|c|c|}
\hline \multicolumn{7}{|c|}{$\Delta$ Least Squares Means Estimates } \\
\hline Questions & Estimate & Std Error & DF & Lower $95 \%$ & Upper $95 \%$ & $\begin{array}{l}\text { Arithmetic } \\
\text { Mean Estimate }\end{array}$ \\
\hline 1 & 2.9277296 & 0.14255153 & 454 & 2.6475870 & 3.2078723 & 2.9247895 \\
\hline 3 & 1.4705685 & 0.14255153 & 454 & 1.1904258 & 1.7507112 & 1.4733365 \\
\hline 4 & 3.7396962 & 0.14528004 & 454 & 3.4541914 & 4.0252009 & 3.6926597 \\
\hline 5 & 1.9058707 & 0.14255153 & 454 & 1.6257280 & 2.1860134 & 1.9022082 \\
\hline 9 & 1.6264649 & 0.14255153 & 454 & 1.3463223 & 1.9066076 & 1.6095651 \\
\hline 10 & 1.3661031 & 0.14255153 & 454 & 1.0859604 & 1.6462458 & 1.3695875 \\
\hline 12 & 1.2369296 & 0.14255153 & 454 & 0.9567869 & 1.5170723 & 1.2376132 \\
\hline 13 & 1.4484806 & 0.14255153 & 454 & 1.1683379 & 1.7286233 & 1.4506594 \\
\hline
\end{tabular}

\section{$\triangle$ - Student's t All Pairwise Comparisons}

Quantile $=1.9652$, DF $=454.0$

\begin{tabular}{|c|c|c|c|c|c|c|c|}
\hline \multicolumn{8}{|c|}{$\triangle$ All Pairwise Differences } \\
\hline Questions & -Questions & Difference & Std Error & t Ratio & Prob $>|t|$ & Lower $95 \%$ & Upper $95 \%$ \\
\hline 1 & 3 & 1.45716 & 0.2015983 & 7.23 & $<.0001^{*}$ & 1.06098 & 1.85334 \\
\hline 1 & 4 & -0.81197 & 0.2035368 & -3.99 & $<.0001^{*}$ & -1.21196 & -0.41198 \\
\hline 1 & 5 & 1.02186 & 0.2015983 & 5.07 & $<.0001^{*}$ & 0.62568 & 1.41804 \\
\hline 1 & 9 & 1.30126 & 0.2015983 & 6.45 & $<.0001^{*}$ & 0.90508 & 1.69745 \\
\hline 1 & 10 & 1.56163 & 0.2015983 & 7.75 & $<.0001^{*}$ & 1.16544 & 1.95781 \\
\hline 1 & 12 & 1.69080 & 0.2015983 & 8.39 & $<.0001^{*}$ & 1.29462 & 2.08698 \\
\hline 1 & 13 & 1.47925 & 0.2015983 & 7.34 & $<.0001^{*}$ & 1.08307 & 1.87543 \\
\hline 3 & 4 & -2.26913 & 0.2035368 & -11.15 & $<.0001^{*}$ & -2.66912 & -1.86914 \\
\hline 3 & 5 & -0.43530 & 0.2015983 & -2.16 & $0.0314^{*}$ & -0.83148 & -0.03912 \\
\hline 3 & 9 & -0.15590 & 0.2015983 & -0.77 & 0.4397 & -0.55208 & 0.24029 \\
\hline 3 & 10 & 0.10447 & 0.2015983 & 0.52 & 0.6046 & -0.29172 & 0.50065 \\
\hline 3 & 12 & 0.23364 & 0.2015983 & 1.16 & 0.2471 & -0.16254 & 0.62982 \\
\hline 3 & 13 & 0.02209 & 0.2015983 & 0.11 & 0.9128 & -0.37409 & 0.41827 \\
\hline 4 & 5 & 1.83383 & 0.2035368 & 9.01 & $<.0001^{*}$ & 1.43383 & 2.23382 \\
\hline 4 & 9 & 2.11323 & 0.2035368 & 10.38 & $<.0001^{*}$ & 1.71324 & 2.51322 \\
\hline 4 & 10 & 2.37359 & 0.2035368 & 11.66 & $<.0001^{*}$ & 1.97360 & 2.77358 \\
\hline 4 & 12 & 2.50277 & 0.2035368 & 12.30 & $<.0001^{*}$ & 2.10278 & 2.90276 \\
\hline 4 & 13 & 2.29122 & 0.2035368 & 11.26 & $<.0001^{*}$ & 1.89122 & 2.69121 \\
\hline 5 & 9 & 0.27941 & 0.2015983 & 1.39 & 0.1664 & -0.11678 & 0.67559 \\
\hline 5 & 10 & 0.53977 & 0.2015983 & 2.68 & $0.0077^{*}$ & 0.14359 & 0.93595 \\
\hline 5 & 12 & 0.66894 & 0.2015983 & 3.32 & $0.0010^{*}$ & 0.27276 & 1.06512 \\
\hline 5 & 13 & 0.45739 & 0.2015983 & 2.27 & $0.0237^{*}$ & 0.06121 & 0.85357 \\
\hline 9 & 10 & 0.26036 & 0.2015983 & 1.29 & 0.1972 & -0.13582 & 0.65654 \\
\hline 9 & 12 & 0.38954 & 0.2015983 & 1.93 & 0.0540 & -0.00665 & 0.78572 \\
\hline 9 & 13 & 0.17798 & 0.2015983 & 0.88 & 0.3778 & -0.21820 & 0.57417 \\
\hline 10 & 12 & 0.12917 & 0.2015983 & 0.64 & 0.5220 & -0.26701 & 0.52536 \\
\hline 10 & 13 & -0.08238 & 0.2015983 & -0.41 & 0.6830 & -0.47856 & 0.31380 \\
\hline 12 & 13 & -0.21155 & 0.2015983 & -1.05 & 0.2946 & -0.60773 & 0.18463 \\
\hline
\end{tabular}




\section{FirstDash}

- Multiple Comparisons for First Dash

$\triangle$ Least Squares Means Estimates

\begin{tabular}{|c|c|c|c|c|c|c|}
\hline First Dash & Estimate & Std Error & DF & Lower $95 \%$ & Upper $95 \%$ & $\begin{array}{r}\text { Arithmetic } \\
\text { Mean Estimate }\end{array}$ \\
\hline 1 & 1.8299542 & 0.08948124 & 454 & 1.6541054 & 2.0058030 & 1.8212275 \\
\hline 2 & 2.1378053 & 0.08948124 & 454 & 1.9619565 & 2.3136541 & 2.1071525 \\
\hline 3 & 1.9279317 & 0.08341291 & 454 & 1.7640084 & 2.0918550 & 1.9279317 \\
\hline
\end{tabular}

\section{$\triangle$ Student's t All Pairwise Comparisons}

Quantile $=1.9652, \mathrm{DF}=454.0$

\section{$\triangle$ All Pairwise Differences}

\begin{tabular}{|c|c|c|c|c|c|c|c|}
\hline First Dash & -First Dash & Difference & Std Error & t Ratio & Prob $>|t|$ & Lower $95 \%$ & Upper $95 \%$ \\
\hline 1 & 2 & -0.307851 & 0.1265456 & -2.43 & $0.0154^{*}$ & -0.556539 & -0.059163 \\
\hline 1 & 3 & -0.097977 & 0.1223299 & -0.80 & 0.4236 & -0.338381 & 0.142426 \\
\hline 2 & 3 & 0.209874 & 0.1223299 & 1.72 & 0.0869 & -0.030529 & 0.450277 \\
\hline
\end{tabular}


Appendix F: General Comments

\begin{tabular}{|c|c|c|c|c|c|}
\hline & \multicolumn{5}{|c|}{ Question } \\
\hline Participant & 1 & 2 & 3 & 4 & 5 \\
\hline 1 & $\begin{array}{l}\text { Gauges. Engaging was } \\
\text { better }\end{array}$ & $\begin{array}{l}\text { Very realistic. I would see } \\
\text { how and why people use this } \\
\text { to reduce energy } \\
\text { consumption. The monthly } \\
\text { would be very helpful }\end{array}$ & $\begin{array}{l}\text { Knowing lights were } \\
\text { on vs off was easy } \\
\text { because green= on } \\
\text { and red=off. Gauges } \\
\text { were easier to read } \\
\text { because of the little } \\
\text { lines between the } \\
\text { numbers }\end{array}$ & $\begin{array}{l}\text { Learning about } \\
\text { water pulses and } \\
\text { how they are } \\
\text { measured and } \\
\text { read off of a } \\
\text { graph }\end{array}$ & $\begin{array}{l}\text { I did not like to bar } \\
\text { graphs. They were too } \\
\text { difficult to read } \\
\text { continuously. Maybe the } \\
\text { line graph next to a } \\
\text { number that shows } \\
\text { instantaneous \% would be } \\
\text { better }\end{array}$ \\
\hline 2 & $\begin{array}{l}\text { Natural Gas spelled } \\
\text { out rather than NG. } \\
\text { Light button } \\
\text { (red/green), water } \\
\text { meter (red/green), } \\
\text { energy table instead } \\
\text { of pie chart. } \\
\text { Electric/gas and } \\
\text { chart/dials - no } \\
\text { preference. }\end{array}$ & Very realistic & $\begin{array}{l}\text { Light and water } \\
\text { (red/green) was much } \\
\text { better. Table for } \\
\text { usage to date instead } \\
\text { of pie chart }\end{array}$ & $\begin{array}{l}\text { Could find info } \\
\text { quickly }\end{array}$ & $\begin{array}{l}\text { Color difference between } \\
\text { electric and gas }\end{array}$ \\
\hline 3 & Gauges & It seems to be realistic & Engaging visuals & $\begin{array}{l}\text { Can actually see } \\
\text { how it changes } \\
\text { on the electrical } \\
\text { instrument }\end{array}$ & $\begin{array}{l}\text { Add more colors to } \\
\text { design. For example, if } \\
\text { load crosses a certain } \\
\text { limit, then it shows red. If } \\
\text { it is ideal for both } \\
\text { historical and current, } \\
\text { show as green }\end{array}$ \\
\hline
\end{tabular}




\begin{tabular}{|c|c|c|c|c|c|}
\hline 4 & Dash 3 & $\begin{array}{l}\text { Will help to monitor and } \\
\text { keep track of things }\end{array}$ & Engaging visuals & $\begin{array}{l}\text { Visuals and } \\
\text { changes it made }\end{array}$ & $\begin{array}{l}\text { More specific/highlighted } \\
\text { titles for energy usage to } \\
\text { date }\end{array}$ \\
\hline 5 & Dashboard 3 & $\begin{array}{l}\text { I definitely did not see them } \\
\text { being used. But it would be } \\
\text { very helpful for light } \\
\text { commercial businesses to } \\
\text { reduce their energy usage } \\
\text { and energy peak }\end{array}$ & $\begin{array}{l}\text { I prefer engaging } \\
\text { visuals like lights on or } \\
\text { off and water pulse } \\
\text { on/off }\end{array}$ & $\begin{array}{l}\text { Having the } \\
\text { hands-on } \\
\text { experience so I } \\
\text { know how it } \\
\text { works }\end{array}$ & $\begin{array}{l}\text { In dashboard } 3, \text { I would } \\
\text { prefer direct numbers } \\
\text { instead of gauges }\end{array}$ \\
\hline 6 & Dashboard 2 & $\begin{array}{l}\text { I could see any of them being } \\
\text { used }\end{array}$ & $\begin{array}{l}\text { I think the analytical } \\
\text { visuals provide an } \\
\text { easier way of } \\
\text { recording data more } \\
\text { efficiently }\end{array}$ & $\begin{array}{l}\text { I liked that the } \\
\text { pace of the } \\
\text { activity made } \\
\text { you feel under a } \\
\text { crunch to } \\
\text { perform even } \\
\text { though the task } \\
\text { wasn't too hard }\end{array}$ & $\begin{array}{l}\text { I think the designs were all } \\
\text { effective. Maybe a little } \\
\text { differentiation between } \\
\text { the line graphs in Dash } 1 \\
\text { and Dash } 2\end{array}$ \\
\hline 7 & Graphs, Dashboard 1 & Very realistic & $\begin{array}{l}\text { I prefer analytical } \\
\text { visuals such as line } \\
\text { graphs }\end{array}$ & $\begin{array}{l}\text { It was cool to see } \\
\text { the information } \\
\text { as it changed }\end{array}$ & $\begin{array}{l}\text { I think they were fine as } \\
\text { they were }\end{array}$ \\
\hline 8 & $\begin{array}{l}\text { The gauges from Dash } \\
3 \text {, the water pulse } \\
\text { meter from } 1 \text { and } 2 \text {, } \\
\text { the pie charts, and } \\
\text { red/green light } \\
\text { indicators }\end{array}$ & Very realistic & $\begin{array}{l}\text { I liked the gauges for } \\
\text { electricity and NG, but } \\
\text { prefered analytical } \\
\text { visuals for everything } \\
\text { else }\end{array}$ & $\begin{array}{l}\text { Reading the } \\
\text { gauges, figuring } \\
\text { out monthly } \\
\text { usages between } \\
2 \text { meters or } \\
\text { equipment }\end{array}$ & $\begin{array}{l}\text { The gauges are easier to } \\
\text { read and the line graph } \\
\text { water pulse should be } \\
\text { used instead of red/green } \\
\text { light }\end{array}$ \\
\hline 9 & $\begin{array}{l}\text { Dashboard } 3 \text { was my } \\
\text { favorite but I found } \\
\text { that the table on } 1 \\
\text { was easier to read } \\
\text { than the pie charts }\end{array}$ & Very realistic & $\begin{array}{l}\text { The gauges were } \\
\text { easier to read. I found } \\
\text { the lighting in } 2 \& 3 \\
\text { were easier than the } \\
\text { graph in } 1 .\end{array}$ & $\begin{array}{l}\text { Interactivity. All } \\
\text { information you } \\
\text { would need in } \\
\text { one place }\end{array}$ & $\begin{array}{l}\text { For the ideal dashboard, I } \\
\text { would use the gauges } \\
\text { from DB3, the lighting in } 2 \\
\text { and } 3 \text {, and the table in } 1 .\end{array}$ \\
\hline
\end{tabular}




\begin{tabular}{|c|c|c|c|c|c|}
\hline 10 & $\begin{array}{l}\text { Dashboard } 2 \text {. It was } \\
\text { well organized and } \\
\text { not too busy with the } \\
\text { graphs }\end{array}$ & $\begin{array}{l}\text { I could see the dashboard } \\
\text { being used because it allows } \\
\text { for a quick breakdown of } \\
\text { energy usages }\end{array}$ & $\begin{array}{l}\text { I liked the analytical } \\
\text { visuals to show exact } \\
\text { data, but engaging } \\
\text { visuals show a "quick } \\
\text { overview" of what is } \\
\text { going on }\end{array}$ & $\begin{array}{l}\text { I liked that the } \\
\text { data was right in } \\
\text { front of you }\end{array}$ & $\begin{array}{l}\text { I wouldn't use the gauges } \\
\text { (like on Dashboard 3) } \\
\text { because I'd be afraid of } \\
\text { unreliable readings }\end{array}$ \\
\hline 11 & Gauges & It is realistic & $\begin{array}{l}\text { Combination of } \\
\text { Engaging and } \\
\text { Analytical }\end{array}$ & $\begin{array}{l}\text { It is a fun and } \\
\text { interactive way } \\
\text { to learn how } \\
\text { energy is } \\
\text { monitored in a } \\
\text { real setting }\end{array}$ & $\begin{array}{l}\text { Keep water meter of } \\
\text { dashboard } 2 \text { in Dash } 3\end{array}$ \\
\hline 12 & Dashboard 3 & $\begin{array}{l}\text { It can be readily used in } \\
\text { commercial businesses }\end{array}$ & $\begin{array}{l}\text { I prefer engaging } \\
\text { visuals. But, analytical } \\
\text { visuals help to know } \\
\text { fluctuations }\end{array}$ & $\begin{array}{l}\text { I know my } \\
\text { consumption } \\
\text { over a period } \\
\text { over a year and } \\
\text { at the current } \\
\text { time using the } \\
\text { visualization tool }\end{array}$ & $\begin{array}{l}\text { Not much to add. It gives } \\
\text { all data I need to know } \\
\text { about my energy } \\
\text { consumption }\end{array}$ \\
\hline 13 & Dashboard 2 & Moderately realistic & $\begin{array}{l}\text { Analytical visuals (bar } \\
\text { charts) }\end{array}$ & Easy to read & $\begin{array}{l}\text { I liked the "Energy Used to } \\
\text { Date" on Dash } 1 . \text { I think } \\
\text { having that accompanying } \\
\text { the pie chart would be } \\
\text { great }\end{array}$ \\
\hline 14 & Dashboard 3 & Very realistic. Easy to read & Engaging visuals & $\begin{array}{l}\text { Learning } \\
\text { something new }\end{array}$ & $\begin{array}{l}\text { Make graphics easier to } \\
\text { read (larger images) }\end{array}$ \\
\hline 15 & Dashboard 3 & Yes it could be used there & $\begin{array}{l}\text { I go with Engaging } \\
\text { Visuals }\end{array}$ & $\begin{array}{l}\text { To understand } \\
\text { my bill }\end{array}$ & Nothing \\
\hline
\end{tabular}




\begin{tabular}{|c|c|c|c|c|c|}
\hline 16 & $\begin{array}{l}\text { Dashboard 3. Because } \\
\text { of the gauges (In } \\
\text { general \#3 was more } \\
\text { visually appealing) }\end{array}$ & It is realistic & Engaging visuals & $\begin{array}{l}\text { The tasks got } \\
\text { easier and were } \\
\text { performed faster } \\
\text { after completing } \\
\text { each dashboard } \\
\text { a couple of times }\end{array}$ & $\begin{array}{l}\text { A summary table below } \\
\text { each energy source } \\
\text { instead of one table }\end{array}$ \\
\hline 17 & $\begin{array}{l}\text { Dash 3. Would have } \\
\text { liked numbers } \\
\text { displayed vs. gauge }\end{array}$ & $\begin{array}{l}\text { Not sure of benefit for non- } \\
\text { energy intensive businesses }\end{array}$ & $\begin{array}{l}\text { Engaging for lights } \\
\text { and water. Analytical } \\
\text { for monthly data }\end{array}$ & $\begin{array}{l}\text { It only took a } \\
\text { moment to know } \\
\text { the consumption }\end{array}$ & $\begin{array}{l}\text { The gauges were } \\
\text { confusing but better than } \\
\text { charts }\end{array}$ \\
\hline 18 & Dashboard 3 & $\begin{array}{l}\text { It's very realistic to use Dash } \\
3\end{array}$ & $\begin{array}{l}\text { Engaging visuals were } \\
\text { much better } \\
\text { especially the gauges }\end{array}$ & $\begin{array}{l}\text { It was easier to } \\
\text { read }\end{array}$ & $\begin{array}{l}\text { I would make the readings } \\
\text { more distinct on gauges }\end{array}$ \\
\hline 19 & Dashboard 3 & $\begin{array}{l}\text { I think it is realistic enough to } \\
\text { be implemented in a light } \\
\text { commercial business }\end{array}$ & $\begin{array}{l}\text { I prefer engaging } \\
\text { visuals }\end{array}$ & $\begin{array}{l}\text { It gives real-time } \\
\text { energy } \\
\text { consumption } \\
\text { information. And } \\
\text { it will help to } \\
\text { reduce energy } \\
\text { consumption }\end{array}$ & $\begin{array}{l}\text { There should be a few } \\
\text { warning lights on } \\
\text { dashboard when unusual } \\
\text { energy consumption takes } \\
\text { places. For example, } \\
\text { water consumption in an } \\
\text { empty hotel room }\end{array}$ \\
\hline 20 & Dashboard 3 & Very realistic & $\begin{array}{l}\text { I think engaging } \\
\text { visuals is better }\end{array}$ & $\begin{array}{l}\text { How changing } \\
\text { the display made } \\
\text { it easy to read } \\
\text { from graph to } \\
\text { graph }\end{array}$ & $\begin{array}{l}\text { I would work on different } \\
\text { colors as it was hard to } \\
\text { read sometimes }\end{array}$ \\
\hline 21 & Dashboard 2 & Very realistic & $\begin{array}{l}\text { Analytical visuals. It } \\
\text { was easier to read } \\
\text { numbers and see the } \\
\text { overall flow }\end{array}$ & $\begin{array}{l}\text { I enjoyed the } \\
\text { easiness of the } \\
\text { data and how } \\
\text { you were able to } \\
\text { watch the flows }\end{array}$ & $\begin{array}{l}\text { I wouldn't change } \\
\text { anything }\end{array}$ \\
\hline
\end{tabular}




\begin{tabular}{|c|c|c|c|c|c|}
\hline 22 & $\begin{array}{l}\text { Gauges and Usage } \\
\text { graph }\end{array}$ & Very realistic & Engaging & $\begin{array}{l}\text { Visuals were } \\
\text { easy to } \\
\text { understand }\end{array}$ & $\begin{array}{l}\text { Speed of change in line } \\
\text { graphs and size of axis } \\
\text { made hard to read quickly }\end{array}$ \\
\hline 23 & Dashboard 3 & $\begin{array}{l}\text { I don't know whats currently } \\
\text { in place, but this certainly } \\
\text { seems like a good option to } \\
\text { give an owner more } \\
\text { awareness of his energy } \\
\text { consumption }\end{array}$ & $\begin{array}{l}\text { Gauges, lights, } \\
\text { alternating light water } \\
\text { meter, bar graph }\end{array}$ & $\begin{array}{l}\text { How easy it was } \\
\text { to see monthly } \\
\text { and up to date } \\
\text { consumption }\end{array}$ & $\begin{array}{l}\text { Over time, it would be } \\
\text { nice to see yearly } \\
\text { consumption or have two } \\
\text { years in same graph to } \\
\text { compare previous year to } \\
\text { current year }\end{array}$ \\
\hline 24 & $\begin{array}{l}\text { Lights were best for if } \\
\text { something is on/off or } \\
\text { running. Pie charts } \\
\text { and gauges from } 3\end{array}$ & Very realistic & $\begin{array}{l}\text { Engaging was much } \\
\text { better. Running water } \\
\text { pulse light is better } \\
\text { than the graph }\end{array}$ & $\begin{array}{l}\text { Dashboard } 3 \text { was } \\
\text { most } \\
\text { enjoyable/easy } \\
\text { to read }\end{array}$ & $\begin{array}{l}\text { On the analytical } \\
\text { layouts/charts, the \% } \\
\text { indicators should be on } \\
\text { the right side of the } \\
\text { graphs to read easily. And } \\
\text { use whole numbers (10s) }\end{array}$ \\
\hline 25 & $\begin{array}{l}\text { Gauges, lights for } \\
\text { on/off, pie chart. } \\
\text { Overall, number } 3 \text { was } \\
\text { best }\end{array}$ & Fairly practical & Engaging visuals & $\begin{array}{l}\text { It was cool to see } \\
\text { real-time data } \\
\text { flowing in graphs } \\
\text { and charts }\end{array}$ & $\begin{array}{l}\text { On graphs, make } \\
\text { increments easy to read } \\
\text { instead of awkward } \\
\text { increments }\end{array}$ \\
\hline
\end{tabular}

